\title{
Advanced methods and models in uncertainty for the order promising process in supply chain characterized by the lack of homogeneity in product.
}

\author{
Hanzel Grillo Espinoza
}

Supervisors:

Dr. María del Mar Eva Alemany Diaz

Dr. Angel Ortiz Bas 

A mis padres, que siempre han estado conmigo apoyándome en todo cuanto les es posible y me han enseñado que con esfuerzo y dedicación, cosas grandes se pueden lograr. A mis hermanas y a mi hermano, que de una u otra forma siempre han contribuido a mi crecimiento como persona. En especial a mi hermana Marianela, que aún no estando ya con nosotros, estará siempre en nuestros recuerdos $y$ pensamientos. 



\section{Agradecimientos}

Mi más profundo agradecimiento a todas las personas que han contribuido al desarrollo de este importante objetivo en mi vida. A mi tutora, Dra. María del Mar Eva Alemany Diaz, quiero agradecer por estos ya 6 años (1 del máster y 5 del doctorado) de tiempo y dedicación que ha invertido en este proyecto y en mí; desde un principio depositó confianza en mi trabajo al incluirme en su proyecto de investigación para desarrollar mi tesis. Hoy vemos los frutos del esfuerzo realizado. A mi co-director, Dr. Ángel Ortiz Bas, que ha sido de gran apoyo en todo cuanto le hemos necesitado. Para ambos, muchas gracias.

Quiero agradecer además, a todos los miembro del Centro de Investigación y Gestión en Ingeniería de Producción (CIGIP) de la Universidad Politécnica de Valencia donde desarrollé mi tesis. Muchas gracias a todos en especial a los que contribuyeron directamente en este trabajo; a la Dra. Josefa Mula Bru quién además de participar como autora en uno de los capítulos, también me brindó la oportunidad de trabajar con ella y continuar con mi estancia en Valencia; a Francisco Gómez que trabajó conmigo en la implementación y experimentación de varias de las herramientas que aquí se proponen. A los miembros del centro de investigación KERMIT, del departamento de modelado matemático, estadística y bioinformática de la Universidad de Gante, Bélgica, que me recibieron durante 3 meses para realizar mi estancia de investigación complementaria, con el objetivo de obtener la mención internacional para esta tesis. En especial al Dr. Bernard De Baets quien fue mi profesor colaborador en dicho centro y con quien pudimos desarrollar el último capítulo.

A todos mis amigos y personas allegadas que he conocido en Valencia, y han estado conmigo durante estos 6 años. Mi experiencia de vivir aquí ha sido única, no la cambiaría.

Finalmente mi agradecimiento más especial para las personas que fueron mi familia durante 4 años en Valencia, que hicieron esto posible en gran parte y que me ayudaron de todas las formas que uno pueda imaginar. 



\section{Abstract}

The Lack of Homogeneity in the Product (LHP) appears in productive processes with raw materials, which directly stem from nature and/or production processes with operations that confer heterogeneity to the characteristics of the outputs obtained, even when the inputs used are homogeneous. LHP appears in different sectors such as ceramic tile, horticulture, marble, snacks, among others. LHP becomes a managerial problem when customers require to be served with homogeneous product. Supply chains responsible to provide homogeneous product face the need to include classification activities in their productive processes to obtain sub-lots of homogeneous product. Due to the inherent LHP uncertainty, these homogeneous sub-lots will not be known until the product have been produced and classified. An improper management of the LHP can have a very negative impact on the customers' satisfaction due to inconsistencies in the answer to their requirements and also on the Supply Chain's efficiency.

The Order Promising Process (OPP) appears as a key element for properly managing the LHP in order to ensure the matching of uncertain homogeneous supply with customer order proposals. The OPP refers to the set of business activities that are triggered to provide a response to the orders from customers. These activities are related to the acceptance/rejection decision, and to set delivery dates. For supply chains affected by the LHP, the OPP must consider the homogeneity as another requirement in the answer to the orders. Besides, due to the LHP inherent uncertainty, discrepancies between the real and planned homogeneous quantities might provoke that previously committed orders cannot be served. The Shortage Planning (SP) process intends to find alternatives in order to minimise the negative impact on customers and the supply chain.

Considering LHP in the OPP brings a set of new challenging features to be addressed. The conventional approach of assuming homogeneity in the product for the master production schedule (MPS) and the quantities Available-To-Promise (ATP) derived from it is no longer adequate. Instead, both the MPS and ATP should be handled in terms of homogeneous sub-lots. Since the exact quantity of homogeneous product from the planned lots in the MPS is not exactly known until the classification activities have been performed, the ATP also inherits this uncertainty, bringing a new level of complexity. Non-homogeneous product cannot 
be accumulated in order to fulfil future incoming orders. Even more, if the product handled is perishable, the homogeneity management becomes considerably more complex. This is because the state of the product is dynamic with time and related variables to it, like quality, price, etc., could change with time. This situation could bring unexpected wasting costs apart from the shortages already mentioned. The perishability factor is itself another source of uncertainty associated to the LHP.

This dissertation proposes a conceptual framework and different mathematical programming models and tools, in both deterministic and uncertainty environments, in order to support the OPP and SP under LHP's effect. The aim is to provide a reliable commitment with customer orders looking for a high service level not just in the due date and quantity but also in the homogeneity requirements. The modelling of the characteristics inherent to LHP under deterministic context constitutes itself one of the main contribution of this dissertation. Another novelty consists in the inclusion of uncertainty in the definition of homogeneous sub-lots, their quantities and their dynamic state and value. The uncertainty modelling approach proposed is mainly based on the application of fuzzy set theory and possibility theory.

The proposed mathematical models and tools have been validated in real cases of SC, specifically in the ceramic tile sector for non perishables, and in the fruit sector for perishables. The results show a very good performance in terms of the interpretation and adaptability to the LHP's effect in both deterministic and uncertainty environments. The uncertainty models outperform the results of the deterministic ones in terms of objectives and robustness for both, planned and simulations of reality, showing more sensitive conditions to better interpret the real behaviour of the LHP problem, which is also an important objective of this work. 


\section{Resumen}

La Falta de Homogeneidad en el Producto (LHP, por sus siglas del inglés "Lack of Homogeneity in the Product") aparece en procesos productivos con materias primas que derivan directamente de la naturaleza y/o procesos de producción con operaciones que confieren heterogeneidad a las características de los productos obtenidos, incluso cuando los insumos utilizados son homogéneos. La LHP aparece en diferentes sectores como la cerámica, horticultura, mármol, snacks, entre otros. Se convierte en un problema gerencial cuando los clientes requieren homogeneidad en el producto y las cadenas de suministro enfrentan la necesidad de incluir actividades de clasificación en sus procesos productivos para obtener sub-lotes de producto homogéneo. Debido a la incertidumbre inherente a la LHP, los sub-lotes homogéneos y su cantidad no serán conocidos hasta que el producto haya sido producido y clasificado. Una gestión inadecuada de la LHP puede tener un impacto muy negativo en la satisfacción de los clientes debido a inconsistencias en la respuesta a sus requerimientos y también en la eficacia de la Cadena de Suministro.

El Proceso de Comprometer de Pedido (OPP, por sus siglas del inglés "Order Promising Process") aparece como un elemento clave para gestionar adecuadamente la LHP, con el fin de asegurar la coincidencia entre el suministro incierto de producto homogéneo y las propuestas de pedido del cliente. El OPP se refiere al conjunto de actividades empresariales realizadas para proporcionar una respuesta a las órdenes de los clientes. Estas actividades están relacionadas con las decisiones de aceptación/rechazo, y establecimiento de fechas de entrega para las órdenes del cliente. En las cadenas de suministro afectadas por la LHP, el OPP debe considerar la homogeneidad como otro requisito adicional en la respuesta a los pedidos. Además, debido a la incertidumbre intrínseca de la LHP, las discrepancias entre las cantidades homogéneas reales y planificadas podrían provocar que las órdenes comprometidas anteriormente no puedan ser completadas debido a la escasez de producto. El proceso de planificación de la escasez (SP, por sus siglas del inglés "Shortage Planning") se encarga de encontrar alternativas para minimizar este impacto negativo en los clientes y la cadena de suministro.

Considerar la LHP dentro del OPP implica un conjunto nuevo de características desafiantes que deben ser abordadas. El enfoque convencional de asumir la ho- 
mogeneidad en el producto para el programa maestro de producción (MPS, por sus siglas del inglés "Master Production Schedule") y las cantidades disponibles a comprometer (ATP, por sus siglas del inglés "Available-To-Promise") derivadas de él, no es adecuado. En cambio, tanto el MPS como el ATP deben manejarse en términos de sub-lotes homogéneos. Dado que la cantidad exacta de producto homogéneo de los lotes previstos en el MPS no se sabe exactamente hasta que se han realizado las actividades de clasificación, el ATP también hereda esta incertidumbre, trayendo un nuevo nivel de complejidad. El producto no homogéneo no se puede acumular para satisfacer futuras órdenes entrantes. Más aún, si el producto manipulado es perecedero, el manejo de la homogeneidad se vuelve mucho más complejo. Esto se debe a que el estado del producto es dinámico en el tiempo, y variables relacionadas como calidad, precio, etc., podrían también cambiar con el tiempo. Esta situación puede provocar costos inesperados de desperdicio aparte de la escasez ya mencionada. El factor de perecedero es en sí mismo otra fuente de incertidumbre asociada a la LHP.

Esta disertación propone un marco conceptual y diferentes modelos y herramientas de programación matemática, tanto en entornos deterministas como de incertidumbre, para apoyar al OPP y SP considerando el efecto de LHP. El objetivo es proporcionar un compromiso fiable con los pedidos de los clientes en busca de un alto nivel de servicio no sólo en la fecha y la cantidad esperadas, sino también en los requisitos de homogeneidad. El modelado de las características inherentes al LHP en contexto determinista constituye en sí mismo uno de los principales aportes de esta tesis. Otra novedad consiste en la inclusión de la incertidumbre en la definición de sub-lotes homogéneos, sus cantidades y su estado y valor dinámicos. El enfoque de modelado de incertidumbre propuesto se basa principalmente en la aplicación de la teoría de conjuntos difusos y la teoría de la posibilidad.

Las herramientas y modelos matemáticas propuestos han sido validados en casos reales de cadena de suministro, específicamente en el sector cerámico para no perecederos, y en el sector de la fruta para productos perecederos. Los resultados muestran un buen desempeño en términos de interpretación y adaptabilidad al efecto de la LHP tanto en entornos deterministas como de incertidumbre. Los modelos de incertidumbre superan los resultados de los modelos deterministas en términos del rendimiento de los objetivos y robustez, tanto con datos planificados como para las simulaciones de la realidad, mostrando condiciones más sensibles para interpretar el comportamiento real del problema de la LHP, lo cual es un objetivo importante de este trabajo. 


\section{Resum}

La Falta d'Homogeneïtat en el Producte (LHP, per les seues sigles de l'anglés 'Lack of Homogeneity in the Product") apareix en processos productius amb matèries primes que deriven directament de la natura i/o processos de producció amb operacions que conferixen heterogeneïtat a les característiques dels productes obtinguts, fins i tot quan les entrades utilitzades són homogènies . La LHP apareix en diferents sectors com la ceràmica, horticultura, marbre, snacks, entre altres. Es convertix en un problema gerencial quan els clients requereixen homogeneïtat en el producte i les cadenes de subministrament enfronten la necessitat d'incloure activitats de classificació en els seus processos productius per a obtindre sublots de producte homogeni. A causa de la incertesa inherent a la LHP, els sublots homogenis i la seua quantitat no seran coneguts fins que el producte haja sigut produït i classificat. Una gestió inadequada de la LHP pot tindre un impacte molt negatiu en la satisfacció dels clients degut a inconsistències en la resposta als seus requeriments i també en l'eficàcia de la Cadena de Subministrament.

El Procés de Comprometre Comandes (OPP, per les seues sigles de l'anglés "Order Promising Process") apareix com un element clau per a gestionar adequadament la LHP, a fi d'assegurar la coincidència entre el subministrament incert de producte homogeni i les propostes de comanda del client. L'OPP es refereix al conjunt d'activitats empresarials realitzades per a proporcionar una resposta a les ordres dels clients. Aquestes activitats estan relacionades amb les decisions d'acceptació/rebuig, i establiment de dates de lliurament per a les ordres del client. En les cadenes de subministrament afectades per la LHP, l'OPP ha de considerar l'homogeneïtat com un altre requisit addicional en la resposta a les comandes. A més, a causa de la incertesa intrínseca de la LHP, les discrepàncies entre les quantitats homogènies reals i planificades podrien provocar que les ordres compromeses anteriorment no puguen ser completades a causa de l'escassetat de producte. El procés de planificació de l'escassetat (SP, per les seues sigles de l'anglés "Shortage Planning") s'encarrega de trobar alternatives per a minimitzar aquest impacte negatiu en els clients i en la cadena de subministrament.

Considerar la LHP dins de l'OPP implica un conjunt nou de característiques desafiants que han de ser abordades. L'enfocament convencional d'assumir l'homogeneïtat en el producte per al programa mestre de producció (MPS, per les seues sigles de 
l'anglés "Master Production Schedule") i les quantitats disponibles a comprometre (ATP, per les seues sigles de l'anglés "Available-To-Promise") derivades d'ell, no és adequat. En canvi, tant el MPS com l'ATP han de manejar-se en termes de sublots homogenis. Atés que la quantitat exacta de producte homogeni dels lots previstos en el MPS no se sap exactament fins que s'han realitzat les activitats de classificació, l'ATP també hereta aquesta incertesa, portant un nou nivell de complexitat. El producte no homogeni no es pot acumular per a satisfer futures ordees entrants. Més encara, si el producte manipulat és perible, el maneig de l'homogeneïtat es torna molt més complex. Açò es deu al fet que l'estat del producte és dinàmic en el temps, i variables relacionades com qualitat, preu, etc., podrien també canviar amb el temps. Aquesta situació pot provocar costos inesperats de rebuig a banda de l'escassetat ja esmentada. El factor de perible és en si mateix un altra font d'incertesa associada a la LHP.

Aquesta dissertació proposa un marc conceptual i diferents models i eines de programació matemàtica, tant en entorns deterministes com d'incertesa, per a recolzar a l'OPP i SP considerant l'efecte de LHP. L'objectiu és proporcionar un compromís fiable amb les comandes dels clients a la recerca d'un alt nivell de servei no sols en la data i la quantitat esperades, sinó també en els requisits d'homogeneïtat. El modelatge de les característiques inherents al LHP en context determinista constituïx en si mateix una de les principals aportacions d'aquesta tesi. Una altra novetat consisteix en la inclusió de la incertesa en la definició de sublots homogenis, les seues quantitats i el seu estat i valor dinàmics. L'enfocament de modelatge d'incertesa proposat es basa principalment en l'aplicació de la teoria de conjunts difusos i la teoria de la possibilitat.

Les eines i models matemàtics proposats han sigut validats en casos reals de cadena de subministrament, específicament en el sector ceràmic per a no peribles, i en el sector de la fruita per a productes peribles. Els resultats mostren un bon acompliment en termes d'interpretació i adaptabilitat a l'efecte de la LHP tant en entorns deterministes com d'incertesa. Els models d'incertesa superen els resultats dels deterministes en termes del rendiment dels objectius i robustesa, tant amb dades planificades com per a les simulacions de la realitat, mostrant condicions més sensibles per a interpretar el comportament real del problema de la LHP, la qual cosa és un objectiu important d'aquest treball. 


\section{Contents}

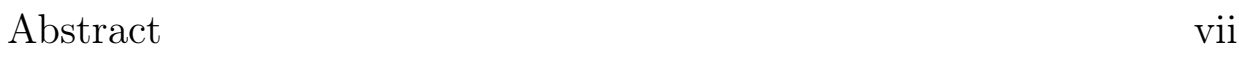

Resumen ix

Resum xi

Contents xiii

Chapter I: Introduction 1

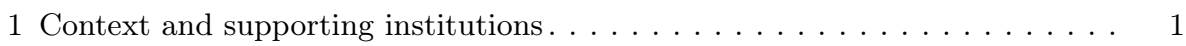

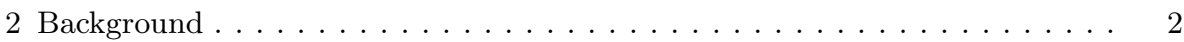

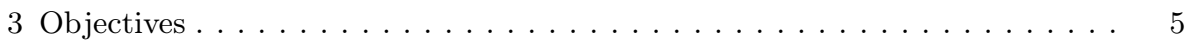

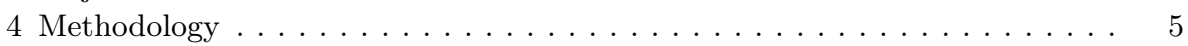

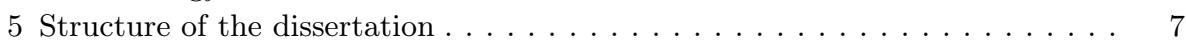

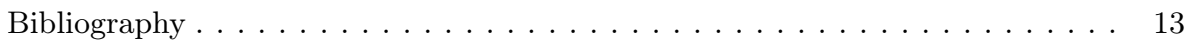

Chapter II: A review of mathematical models for supporting the order promising process under Lack of Homogeneity in Product \begin{tabular}{lr}
\hline and other sources of uncertainty & 15
\end{tabular}

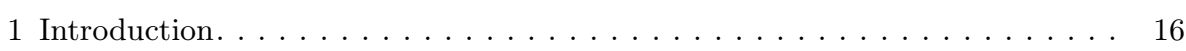

2 LHP inherent characteristics. . . . . . . . . . . . . . . . . . . . . . . . 19

3 Literature review methodology . . . . . . . . . . . . . . . . . . . . . . 20

4 Structural dimensions for the review . . . . . . . . . . . . . . . . . . 22

4.1 Environment . . . . . . . . . . . . . . . . . . . . . . . 24

4.2 LHP/uncertainty modelling . . . . . . . . . . . . . . . . . . . 25

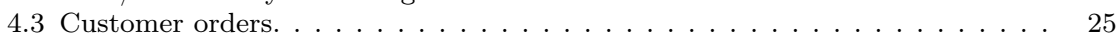

4.4 Order promising. . . . . . . . . . . . . . . . . . . . . 25

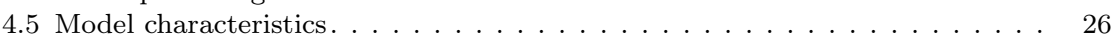

5 Material evaluation . . . . . . . . . . . . . . . . . . . . . . . 27

5.1 Environment . . . . . . . . . . . . . . . . . . . . . . . 27

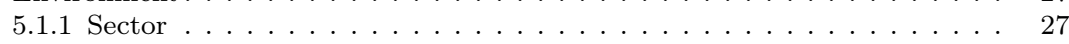


5.1 .2 Supply chain physical scope . . . . . . . . . . . . . . . . . . . . 29

5.1 .3 Manufacturing strategy $\ldots \ldots \ldots \ldots$. . . . . . . . . . . . . . 30

5.1 .4 Findings . . . . . . . . . . . . . . . . . . . . . . . . . . . . 30

5.2 LHP uncertainty modelling . . . . . . . . . . . . . . . . . . . . . 32

5.2 .1 Modelling inherent LHP characteristics . . . . . . . . . . . . . 32

5.2 .2 Uncertainty modelling $\ldots \ldots \ldots \ldots \ldots \ldots \ldots$

5.2 .3 Findings . . . . . . . . . . . . . . . . . . . . . . . . . . . . . . 38

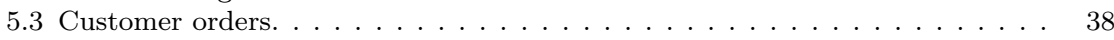

5.3 .1 Order lines . . . . . . . . . . . . . . . . . . . . . . . . 38

5.3 .2 Homogeneity requirements . . . . . . . . . . . . . . . . . . . . . . . . . 39

5.3 .3 Flexibility in requirements . . . . . . . . . . . . . . . . . . . . . 40

5.3 .4 Findings . . . . . . . . . . . . . . . . . . . . . . . . . . 42

5.4 Order promising . . . . . . . . . . . . . . . . . . . . . . . . 42

5.4 .1 Allocation rules . . . . . . . . . . . . . . . . . . . . 42

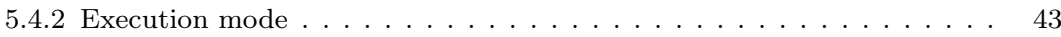

5.4 .3 Availability levels . . . . . . . . . . . . . . . . . . . . . . . 43

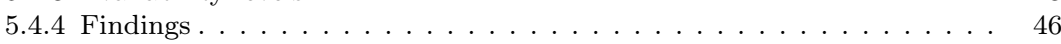

5.5 Model characteristics . . . . . . . . . . . . . . . . . . . . . 46

5.5 .1 Purpose . . . . . . . . . . . . . . . . . . . . . . 47

5.5 .2 Validation method . . . . . . . . . . . . . . . . . . . . . 47

5.5 .3 Modelling approach $\ldots \ldots \ldots \ldots$

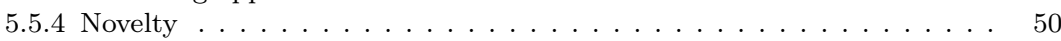

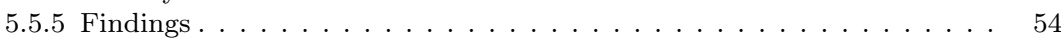

6 Conclusions. Identifying areas for further research . . . . . . . . . . . . . . . . . . . . . . . . . . . . . . 66

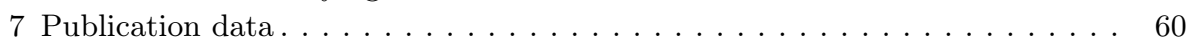

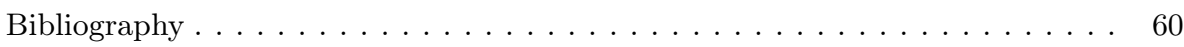

\section{Chapter III: A Fuzzy Order Promising Model With Non Uniform}

Finished Goods 65

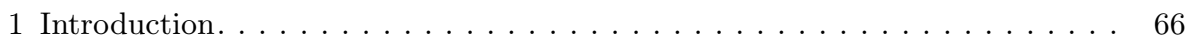

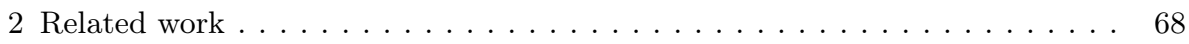

3 The FMILP-ATP-LHP Model. . . . . . . . . . . . . . . . . . . . . . . . . 70

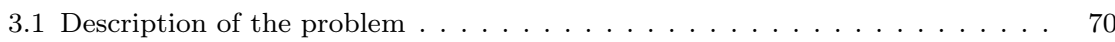

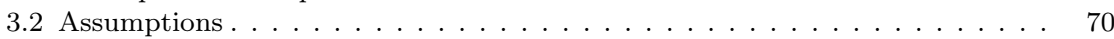

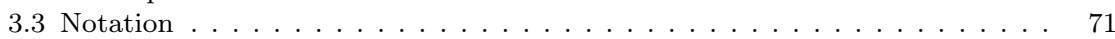

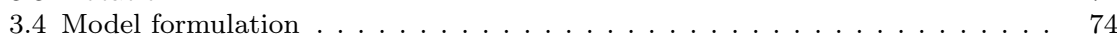

4 Solution methodology . . . . . . . . . . . . . . . . . 76 4.1 Transforming the FMILP-ATP-LHP model into an equivalent $\alpha$-parametric ${ }_{76}$ 4.2 Methodology for alpha level evaluation based on fuzzy TOPSIS . . . . . . . 78

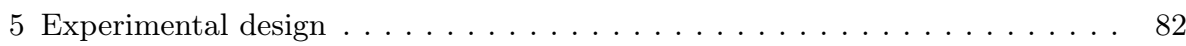

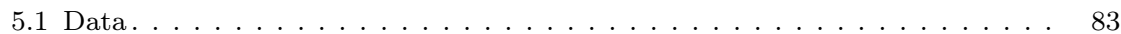

5.2 Evaluation of Deterministic and Fuzzy Decisions: Experimental Methodol-

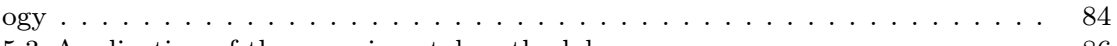

5.3 Application of the experimental methodology . . . . . . . . . . . . . . 86

5.3 .1 Alpha evaluation for the FMILP-ATP-LHP model . . . . . . . . . . 86

5.3 .2 Evaluating the Deterministic and Fuzzy Solutions . . . . . . . . . . . . . . . . . . . . . . . . . . . . . . . . . . .

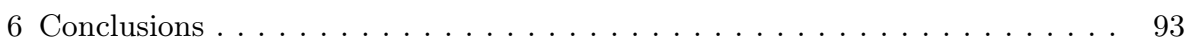

7 Publication data. . . . . . . . . . . . . . . . . . . . . 94

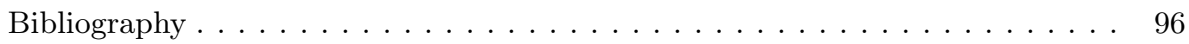


Chapter IV: A fuzzy model for shortage planning under uncertainty due to lack of homogeneity in planned production lots $\quad 99$

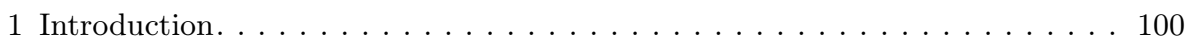

2 Shortage planning problem characteristics. . . . . . . . . . . . . . . . 104

3 Fuzzy shortage planning LHP model formulation . . . . . . . . . . . . 107

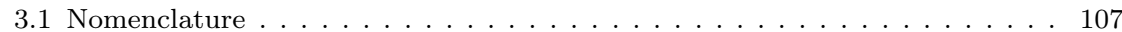

3.2 Objective . . . . . . . . . . . . . . . . . . . . . . . . 107

3.3 Constraints. . . . . . . . . . . . . . . . . . . . . . . . 110

4 Solution methodology for the LHP fuzzy shortage planning model . . . . . . 113 4.1 Transforming the fuzzy mixed-integer linear programming model into an equivalent crisp model $\ldots \ldots \ldots \ldots \ldots \ldots \ldots$

4.2 The equivalent auxiliary crisp LHP-FSP model . . . . . . . . . . . . . . . . . 117

4.3 Methodology for final solution selection $\ldots \ldots \ldots \ldots$. . . . . . . . 117

5 Computational experiments: application to a ceramic tile company. . . . . . . 119

5.1 Problem data description $\ldots \ldots \ldots \ldots \ldots \ldots \ldots \ldots$

5.2 Generation of scenarios . . . . . . . . . . . . . . . . . . . . . . . . . . . . . . . . . . . . . . . . . . . . . . . . . . .

5.3 Experimental results . . . . . . . . . . . . . . . . . . . . . . . . 123

5.4 Selecting the final solution to be implemented . . . . . . . . . . . . . . . . 125

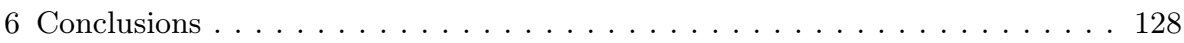

7 Publication data. . . . . . . . . . . . . . . . . . . . . . . . . 129

Bibliography . . . . . . . . . . . . . . . . . . . . . . 129

Chapter V: Modelling pricing policy based on shelf-life of non homogeneous Available-To-Promise in fruit supply chains 135

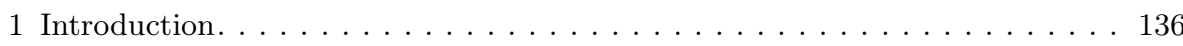

2 Related work . . . . . . . . . . . . . . . . . . . . . . . . . 137

3 Modelling the homogeneous Available-To-Promise for fruit supply chains . . . 138

4 Modelling the shelf-life $\ldots \ldots \ldots \ldots \ldots \ldots \ldots \ldots \ldots \ldots \ldots \ldots \ldots \ldots \ldots$

5 Shelf life-based pricing policy . . . . . . . . . . . . . . . . . . . . 140

6 Numerical example . . . . . . . . . . . . . . . . . . . . . . . . . . . . . . 142

7 Conclusion . . . . . . . . . . . . . . . . . . . . . . . . . . . . . . . . 145

8 Publication data. . . . . . . . . . . . . . . . . . . . . . . 145

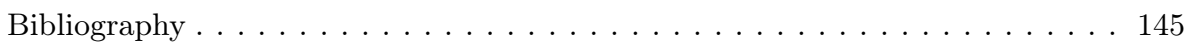

Chapter VI: Mathematical modelling of the order-promising process for fruit supply chains considering the perishability and sub\begin{tabular}{ll}
\hline types of products & 147 \\
\hline
\end{tabular}

1 Introduction . . . . . . . . . . . . . . . . . . . . . . . . . . . . . . 148

2 Related work and contributions. . . . . . . . . . . . . . . . . . . . . 150

2.1 OPP-related models $\ldots \ldots \ldots \ldots \ldots \ldots \ldots \ldots \ldots \ldots \ldots \ldots \ldots$

2.2 Operations research models in agri-food supply chains $\ldots \ldots \ldots \ldots \ldots .151$

2.3 Contributions of our work $\ldots \ldots \ldots \ldots \ldots \ldots \ldots \ldots \ldots \ldots \ldots$

3 Problem description . . . . . . . . . . . . . . . . . . . . . . 154

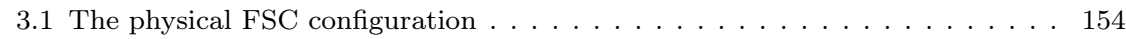

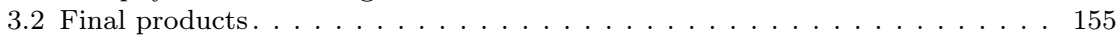

3.3 Customer order proposals. $\ldots \ldots \ldots \ldots \ldots \ldots \ldots \ldots \ldots \ldots \ldots \ldots \ldots$ 
$3 . 4 \longdiv { \text { Order promising process (OPP) } \ldots \ldots \ldots \ldots \ldots . \ldots \ldots } 1 5 7$

$4 \longdiv { \text { FSC-OPP model description } \ldots \ldots \ldots \ldots \ldots }$

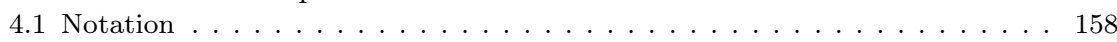

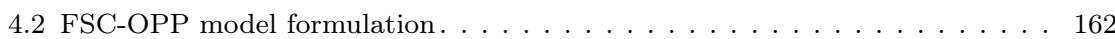

4.2 .1 Objective Function $\ldots \ldots \ldots$. . . . . . . . . . . . . . . . . . 162

4.2 .2 Constraints . . . . . . . . . . . . . . . . . . . . . . . . . . . . . . 164

4.3 Implementing the FSC-OPP model into a dynamic batching mode . . . . . . 167

5 Experimental design: application to an orange and tangerine supply chain. . 168

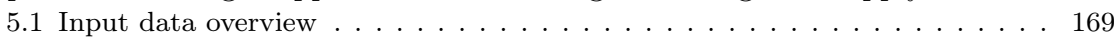

5.2 Experimental design . . . . . . . . . . . . . . . . . . . . . . . . . . . 169

5.3 Experimental results . . . . . . . . . . . . . . . . . . . . . . . . . 170

5.3 .1 Interaction between the objectives . . . . . . . . . . . . . . . . 170

5.3 .2 Impact of price variation on the objectives. . . . . . . . . . . . . . . 172

5.3 .3 Impact of SL on the objectives . . . . . . . . . . . . . . . . . . . 172

5.3 .4 Computational efficiency . . . . . . . . . . . . . . . . . . . . . . . 172

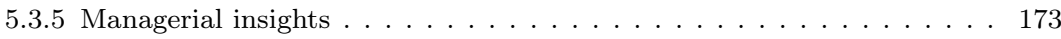

6 Conclusions and future research lines . . . . . . . . . . . . . . . . . . . . . . . . . . . . . . . . . . . . . . . . . . .

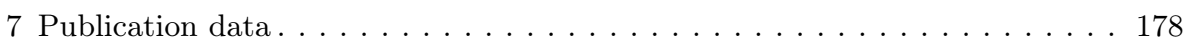

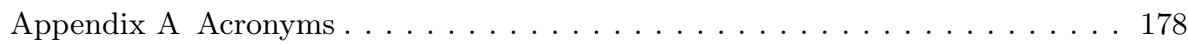

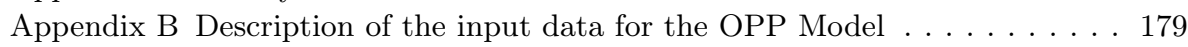

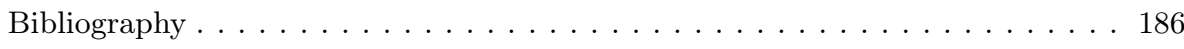

Chapter VII: Compositions of possibilistic variables and state functions:

application to an order promising model for perishables 189

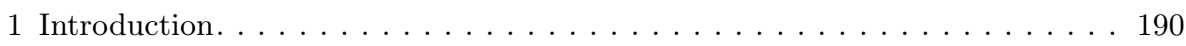

2 Modelling compositions with possibilistic variables . . . . . . . . . . . . . . 193

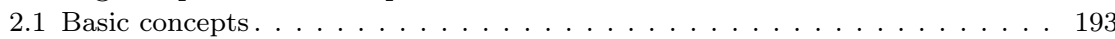

2.2 Compositions . . . . . . . . . . . . . . . . . . . . . . 195

2.3 Using compositions in practice. . . . . . . . . . . . . . . . . . . . . 199

3 Modelling State functions . . . . . . . . . . . . . . . . . . . . . . 199

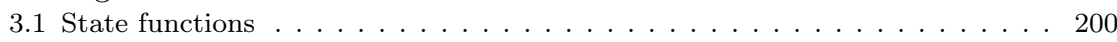

4 Application to the order promising process for perishables . . . . . . . . . . 201

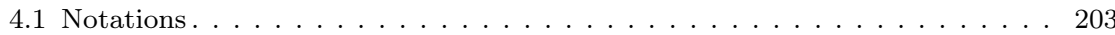

4.2 Mathematical modelling. . . . . . . . . . . . . . . . . . . . . . . . . 204

4.3 Equivalent MILP modell. . . . . . . . . . . . . . . . . . . . . . . . . . . 206

4.3 .1 Computations on the price for the objective function . . . . . . . . . 206

4.3 .2 Computations on the possibilistic constraints . . . . . . . . . . . . . 208

4.3 .3 Equivalent MILP model . . . . . . . . . . . . . . . . . . . . . . . . . 208

4.3 .4 Implementing dynamic batching mode . . . . . . . . . . . . . . . . . . . 209

5 Experimental design: application to an orange an tangerine supply chain. . . 209

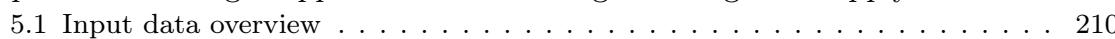

5.2 Definition of evaluation instances . . . . . . . . . . . . . . . . . 210

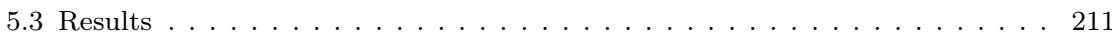

5.3 .1 Committed orders and generated profits . . . . . . . . . . . . 211

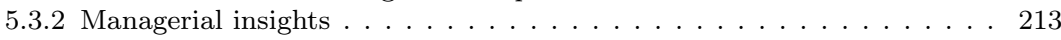

5.3 .3 Computational efficiency. . . . . . . . . . . . . . . . . . . . . . . . . 214

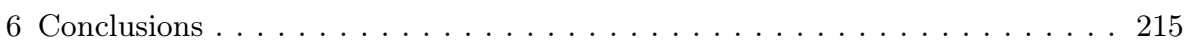

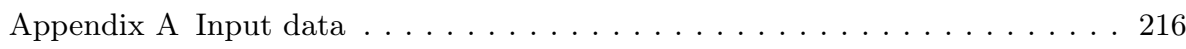


Bibliography. . . . . . . . . . . . . . . . . . . . . 221

Chapter VIII: Conclusions and future research lines 225

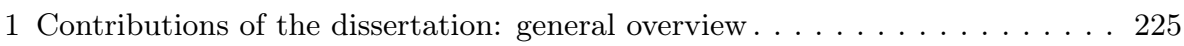

1.1 Inherent LHP characteristics addressed $\ldots \ldots \ldots \ldots \ldots \ldots \ldots \ldots$

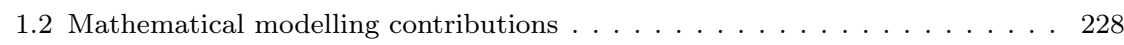

1.3 Final remarks on LHP inherent uncertainty. . . . . . . . . . . . . . . 231

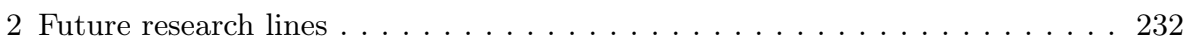

2.1 Inherent LHP characteristics. . . . . . . . . . . . . . . . . . . . 232

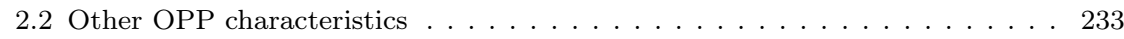

2.3 Mathematical modelling and resolutions tools $\ldots \ldots \ldots \ldots \ldots \ldots .233$

Appendix A: Mathematical modelling of uncertainty in non-homogenepus

lots. 235

1 Introduction . . . . . . . . . . . . . . . . . . . . . . . 236

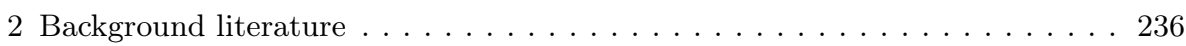

3 Modelling Context . . . . . . . . . . . . . . . . . . . . . . . . . . . 237

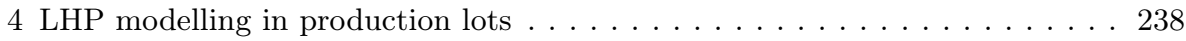

4.1 Deterministic LHP modelling in production lots . . . . . . . . . . . . . 239

4.2 Modelling the LHP uncertainty in production lots. . . . . . . . . . . . . 239

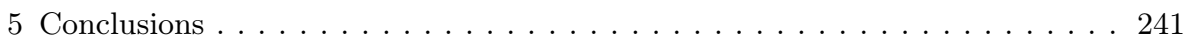

6 Publication data . . . . . . . . . . . . . . . . . . . . . . . . . 242

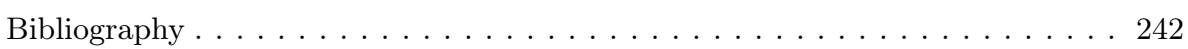

Appendix B: Journal authorizations 245 



\section{Chapter I}

\section{Introduction}

In this chapter, a general overview of the structure of the dissertation and the relationship among the research work that compose it, is introduced. To do this, the context in which this dissertation has been developed concerning the funding institutions and research centre is presented in Section [1. In Section 2 the background of the research area in what the dissertation fits is briefly described. In Section 3 the main objectives are established, meanwhile, the Section 4 describes the research methodology applied. Finally, since this dissertation has been developed as a compendium of research articles, Section 5 introduces the structure and the argument of the group of articles presented.

\section{Context and supporting institutions}

This dissertation has been developed as part of the Spanish Ministry of Economy and Competitiveness Project 'Methods and models for operations planning and order management in supply chains characterised by uncertainty in production due to the lack of product uniformity' (PLANGES-FHP)(Ref. DPI2011-23597). This project has been lead by the director of this dissertation Dr. María del Mar Eva Alemany Díaz, who is an associate professor in the Research Centre of Management and Production Engineering (CIGIP, for its acronym in Spanish "Centro de Investigación y Gestión en Ingeniería de Producción") of the Polytechnic University of Valence (Universitat Politècnica de València). Furthermore, this dissertation has received the support of the Costa Rican Ministry of Science, Technology and Telecommunications (MICITT, for its acronym in Spanish "Ministerio de Ciencia, Tecnología y Telecomunicaciones"), through the programme of innovation and human capital for competitiveness (PINN, for its acronym in Spanish "Programa de Innovación y Capital Humano para la Competitividad"), contract number PED019-2015-1. Finally, in light of the international mention of this dissertation, it 
was developed with the collaboration of Ghent University (Universiteit Gent, Belgium) through the KERMIT research centre of the department of mathematical modelling, statistics and bioinformatics, lead by the professor Dr. Bernard De Baets. A research stance of three months in Ghent University was done in order to collaborate with the development of some of the mathematical tools presented in this dissertation.

\section{Background}

The order promising process (OPP) has made significant advances in processes of supply, production, storage and delivery, since it has improved the efficiency in the attention of demand requirements with high standards of service level and customer satisfaction [1]. According to Alemany et al. [2], the OPP refers to the set of business activities that are triggered to provide a response to customer order requests. Much research on OPP has been done. However, there are sectors that are not yet sufficiently investigated. Such sectors present particular common characteristics with a great impact on the OPP. Examples of these sectors are relevant ones, like agri-food, ceramic, wood and reverse logistics, among others. They are all characterised by the presence of the so-called lack of homogeneity in product (LHP), defined as the lack of uniformity in products required by customers 3. LHP appears in production processes with raw materials that directly originate from nature and/or production processes with operations that confer heterogeneity to the characteristics of the outputs obtained, even when the inputs used are homogeneous 2. The results are units of the same finished good (FG) in a lot with some different characteristics that are relevant for customers.

LHP may become a considerable problem when customers acquire several units of a given product and require homogeneity to use, present, arrange or consume them [1. A slight difference in a unit is easily seen in products such as parquet strips, leather wear, floor tiles or pearl necklaces [3. Figure 1 shows a general schema of the appearance and the effect of LHP on production processes.

As it can be noticed in the Figure 11 supply chains affected by the LHP are forced to classify items into different homogeneous sub-lots, known as subtypes. The subtypes are defined based on certain criteria, for the purpose of satisfying the customer homogeneity requirement. However, the homogeneous quantity of each subtype that will be available to customers is not known until the product has been manufactured and classified [4]. This becomes a problem because the OPP is based on the concept of Available-To-Promise (ATP) [5] what is known as the uncommitted quantity of supply, obtained as the subtraction of the already promised orders to the master production schedule (MPS) and the product in stock. Traditional models of OPP assume the homogeneity in units of the same product for both the MPS and the ATP, but this assumption is not adequate in supply chains affected by the LHP because customers require homogeneity; consequently, the MPS and ATP must be handled in terms of subtypes. 


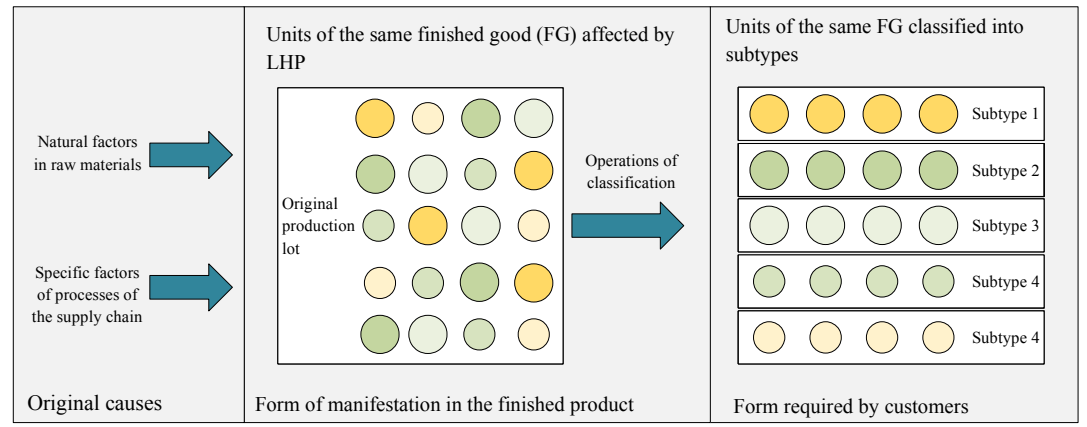

Figure 1: General schema of the appearance and effect of LHP on production process (Source Grillo et al. [1])

As mentioned before, the homogeneous ATP is uncertain until the moment the classification activities have been performed to the already produced quantities. Furthermore, different subtypes of the same finished good cannot be mixed to promise a specific order, and even more, different subtypes cannot be accumulated in order to serve bigger orders if the product has the property to change some of its conditions over the time. Due to this, the typical way of calculating the accumulated ATP from the MPS will not be valid in LHP contexts.

The possibility of obtaining subtypes as an effect of LHP introduces to the ATP different sources of uncertainty (see Figure 2): the number of resulting subtypes, the quantity of each subtype, the value of the subtype and the state of the subtype (this is only if the product can change its characteristics over the time, for example perishables). All of these LHP inherent characteristics can appear in different stages of the supply chain; supply, process and demand, as it is shown in Figure 2

\begin{tabular}{|c|c|c|c|}
\hline & Supply (Sp) & Process (Pr) & Demand $(\mathrm{Dm})$ \\
\hline Subtypes (ST) & $\begin{array}{l}\text { Existence of subtypes in supplied } \\
\text { raw materials or components } \\
\text { (LHRM) in a specific lot or } \\
\text { among lots }\end{array}$ & $\begin{array}{l}\text { Existence of subtypes in } \\
\text { intermediate (LHIP) or finished } \\
\text { goods(LHFG) }\end{array}$ & $\begin{array}{l}\text { Customers/markets request their } \\
\text { products by specifying the sub- } \\
\text { type required (LHFG) in their } \\
\text { orders }\end{array}$ \\
\hline $\begin{array}{l}\text { Subtype } \\
\text { quantity (SQ) }\end{array}$ & $\begin{array}{l}\text { Variable quantities per subtype } \\
\text { of LHRM (in the same lot or } \\
\text { among lots) }\end{array}$ & $\begin{array}{l}\text { Variable quantities per subtype } \\
\text { of LHIP or LHFG (in the same lot } \\
\text { or among lots) are variable }\end{array}$ & $\begin{array}{l}\text { Variable quantities required for } \\
\text { each subtype (LHFG) and } \\
\text { customer/market }\end{array}$ \\
\hline $\begin{array}{l}\text { Subtype value } \\
\text { (SV) }\end{array}$ & $\begin{array}{l}\text { The value (cost) of supplied } \\
\text { subtypes can vary according to } \\
\text { the availability and demand of } \\
\text { LHRM subtypes }\end{array}$ & $\begin{array}{l}\text { The value (cost) of produced } \\
\text { LHIP subtypes can be vary } \\
\text { according to the finished good } \\
\text { demand, process (storage } \\
\text { conditions) or the final } \\
\text { availability of subtypes }\end{array}$ & $\begin{array}{l}\text { The value (price) of produced } \\
\text { finished good (LHFG) in the } \\
\text { market can vary according to the } \\
\text { sub type }\end{array}$ \\
\hline $\begin{array}{l}\text { Subtype state } \\
\text { (SS) }\end{array}$ & $\begin{array}{l}\text { The state of the subtype (LHRM) } \\
\text { is dynamic (perishability, } \\
\text { obsolescence) }\end{array}$ & $\begin{array}{l}\text { The state of the subtype (LHIP or } \\
\text { LHFG) is dynamic (perishability, } \\
\text { obsolescense) }\end{array}$ & $\begin{array}{l}\text { The state of the subtype (LHFG) } \\
\text { is dynamic (perishability, } \\
\text { obsolescence) }\end{array}$ \\
\hline
\end{tabular}

Figure 2: LHP inherent characteristics (Source Grillo et al. [1]). 
In this dissertation, the effect of the LHP on the OPP will be studied. The main focus is on the supply chain's process and demand stages, more specifically, on the analysis of the uncertainty the LHP brings to the process, in all possible aspects, such as the subtypes definition, the quantity per subtype, the subtype value and the subtype state. Due to this inherent LHP uncertainty, it is possible that an order already promised, based on an estimation of these features, cannot be finally served. This can occur in the case when the real characteristics of the processed quantities after the classification activities might not match with the planned ones. Consequently the previously promised orders based on planned ATP cannot be served. In this case, a shortage situation can occur, endangering the accomplishment of previous commitments with customers. The shortage planning (SP) 6] intends to find alternative solutions to accomplish with previous commitments in order to minimize the negative impact on both, the customer satisfaction and the supply chain effectiveness.

In terms of mathematical modelling of the OPP, the literature shows that the LHP's inherent characteristics have been shortly considered in the majority of studies. Furthermore, in those dealing some LHP characteristic, they consider it in a sporadic way, that is, without conceptualising the LHP in an integral manner. Another identified under researched area is the inclusion of uncertainty in the OPP modelling, not only in usual parameters such as the ATP quantities, but also in the resulting uncertainty as a consequence of the LHP.

The improper management of LHP during the OPP can originate very negative effects for these type of supply chains such as poor customer service level, even with high stocks of not mixable subtypes, remains of subtypes along the supply chain that cannot be allocated to any order, and high waste for perishable products, among others. Therefore, in order to achieve a competitive advantage, supply chains with LHP should combine technological advances with the development of new solutions in the management field to handle the non-uniformity of products and the LHP inherent sources of uncertainty. This dissertation intends to increase the competitiveness of these types of supply chains by developing managerial solutions in the field of OPP and SP taking into account: the inherent characteristics and uncertainty of the LHP, and the previous research work made until now on this topic, in order to provide a general framework for the LHP analysis and management. Mathematical programming models have been developed to describe, analyse and characterise the OPP and SP under the inherent LHP uncertainty.

These models have been validated by their application in ceramic tile and horticulture supply chains. The reason is that the LHP's effect is very relevant for these type of supply chains. For ceramic tile, the same product can present noticeable differences in quality (defects), tone (colour), and gage (thickness), due to characteristics of the raw materials and uncontrollable conditions of the production process. For horticulture, natural factors like weather, temperature, fertilisers, etc., or even the own perishability, might cause perceptible differences among units of the same product once harvested and sold. Given the highlighted importance 
of homogeneity in these two types of supply chains, in this dissertation the focus on the analysis will be the effect of the LHP in the OPP and SP for both cases.

\section{Objectives}

The main objective of this dissertation is to propose new and suitable solutions based on methods and mathematical models, to analyse and support the OPP and SP, under the effect of the LHP for both, deterministic and uncertainty conditions. The resulting models are validated in two industrial sectors highly affected by the LHP's inherent characteristics: ceramic sector and perishables (specifically the fruit sector). In order to achieve this general objective, the following specific objectives have been defined:

1. To develop a conceptual framework aimed to analyse the existing research on the OPP and SP that considers some characteristics of the LHP in both deterministic and uncertainty conditions.

2. To characterise the LHP and its impact on the OPP and SP based on the proposed framework.

3. To elaborate methods and mathematical models to support the OPP and SP for supply chains affected by the LHP.

4. To propose mechanisms and procedures to validate and compare the developed models under deterministic and uncertainty conditions.

5. To design optimization tools for the OPP and SP, by means of the implementation of the mathematical models in a readable computer language, linked with optimization software.

6. To validate the optimization tools in real cases of supply chains, specifically, in the ceramic tile and fruit sectors.

In the next section, the methodology proposed to achieve these objectives is presented.

\section{Methodology}

Hereunder the methodology that was used in this work is described, in order to explain how the objectives described before were achieved.

Phase I: Literature review: Conceptual Framework for the OPP and SP under LHP conditions.

This phase includes the development of a conceptual framework that serves as a basis for the analysis and characterisation of the OPP and SP under the LHP characteristics in both deterministic and uncertainty contexts. An extensive literature review has been conducted based on this framework, in order to contextualise, characterise and identify the existing work on mathematical models, as well as the 
critical lacking areas of research. The abstraction of the common characteristics of different sectors by means of the framework can be used to transfer existing knowledge among them. Hence, the decision support tools, methods and mathematical models required to integrally analyse the OPP under the exposed characteristics of LHP can be developed through that transference of knowledge and extension to the areas that lack research. This phase is linked with specific objectives 1 and 2 of the previous section.

Phase II: Methods and models to support the decision making in OPP and SP under deterministic and uncertainty contexts.

In order to cover some of the gaps identified in Phase I, during this phase, the proposal of methods and mathematical programming models required to support the decision making in the OPP and SP under the LHP conditions are developed. As a first step, deterministic models are presented including specific LHP characteristics such as the definition of subtypes and the quantity of product per subtype, with the aim of serving customers with homogeneous units. This is done specifically for the OPP and SP and it is more oriented for the ceramic tile sector. As a second step, deterministic models for the OPP are developed, but including an additional LHP feature: the subtype state (through the consideration of the shelf life), being more oriented for the sector of perishables. As a third step, the extension from the deterministic to uncertainty context of some of the previous models for OPP and SP is performed by considering the LHP inherent uncertainty. The applied approach to deal with uncertainty is mainly based on fuzzy set theory and possibility theory over the subtypes, the quantity, the state and the value per subtype. The mathematical models are validated in ceramic tile and perishables sectors. This phase is linked with the specific objective 3 of the previous section.

Phase III: Development of optimization tools.

This phase includes the development of solution mechanisms based on optimization software and solvers. The mathematical programming models have been translated into a readable machine language and then solved with an optimization solver. This phase is linked with specific objectives 4 and 5 of the previous section.

Phase IV: Validation and conclusions.

During this last phase, experimental procedures have been designed in order to: validate the suitability of the developed models and tools, compare the performance of deterministic and uncertainty models in planned and real situations, and provide managerial insights for the proper dealing of LHP. The validation of the proposed methods and models, already represented as computational tools, is carried out considering realistic data of supply chains of the ceramic tile and perishables (specifically fruit) sectors. The results are analysed and the main managerial insights and conclusions are presented. Finally, possible future research lines are identified. This phase corresponds with the sixth objective of the previous section. 
As a result of the implementation of this methodology, a compendium of research articles have been presented and published in high quality scientific international journals and international conferences. In each article, at least one of the phases of the methodology has been developed. The compendium of articles proves that not only all the above phases have been covered, but also the objectives of this dissertation. In total, 7 articles have been written. These articles compose the different chapters of the dissertation (see Table 1).

In the next section it is described in a detailed manner, the structure and argument of the dissertation based on the topics included in each article and the relationship among them.

\section{Structure of the dissertation}

Since this dissertation is structured as a compendium of articles, each of them is presented as a chapter, except the Chapter VIII that reports the conclusions of the whole dissertation. Even though each article has been written in order to be read and understood independently, they have been presented following an argumentative line in which the phases of research and objectives described in previous sections are addressed. The following chapters are included:

- Chapter I: Introduction.

- Chapter II: A review of mathematical models for supporting the order promising process under Lack of Homogeneity in Product and other sources of uncertainty.

- Chapter III: A fuzzy order promising model with non uniform finished goods.

- Chapter IV: A fuzzy model for shortage planning under uncertainty due to lack of homogeneity in planned production lots.

- Chapter V Modelling pricing policy based on shelf-life of non homogeneous Available-To-Promise in fruit supply chains.

- Chapter VI: Mathematical modelling of the order-promising process for fruit supply chains considering the perishability and subtypes of products.

- Chapter VII: Compositions of possibilistic variables and state functions: application to an order promising model for perishables.

- Chapter VIII: Conclusions.

- Appendix A: Mathematical modelling of uncertainty in non-homogeneous lot.

Table 1 presents the main publishing data of each chapter, the authors, the scientific journal or congress where it has been published, the basic information of quality indicators of the publisher; Journal Citation Report (JCR) and SCImago 
Journal \& Country Rank (SJR) and the respective categories in which the publisher is ranked for each quality measure. Table 1 also shows the basis of the structure of the dissertation, regarding to the specific objectives and phases of the methodology that are covered by each chapter. Based on that structure, the connection among chapters is described in the next paragraphs.

In Chapter II, a review of mathematical programming models for supporting the OPP under LHP conditions and uncertainty in the modelling approach is presented. This research aims to determine the way that LHP and uncertainties either related to it or related to different variables that confer more realistic conditions to OPP, have been modelled. In order to do this, both types of mathematical models for the OPP and SP are considered: those that consider some LHP characteristic and those that consider any type of uncertainty in the modelling approach.The results provide the opportunity to transfer knowledge among different sectors, and to identify the main gaps in this context that have not been already covered. For the development of this review, a conceptual framework with a set of structural dimensions is proposed. This framework is used to analyse and classify the references consulted. The structural dimensions intend to describe, for each paper, aspects related to the supply chain environment, the LHP/uncertainty characteristics addressed, the features of the order promising process, characteristics of the customer's orders, and the modelling approach applied. Each of these categories is evaluated for all the consulted literature. The result is an integral review of the characteristic of the mathematical models for OPP and SP, their modelling approach, what type of uncertain variables they consider and what characteristics of the LHP are present. Additionally, the industrial sector of the supply chain, the scope of the study regarding the nodes of the supply chain considered, and the characteristics and configuration of the order from customers and their requirements of homogeneity are described. It is also specified which models validate their approach through real applications or study cases. The main finding of this work is that research on the OPP modelling, combined with LHP characteristics and uncertainty, is very scarce.

Since the main conclusion derived from the literature review of Chapter II is that the OPP modelling including LHP characteristics for both, deterministic and uncertainty contexts is an under-studied research area, in order to cover this gap, a mathematical model for supporting the OPP in an uncertainty context is proposed in Chapter III. This model is based on a previous work of modelling the OPP with the presence of the LHP, but in a deterministic way 2]. In this research, the ATP is expressed in terms of homogeneous subtypes (ATP-LHP) from which the order proposals must be promised. The uncertainty is considered in the number of subtypes appearing in each lot jointly with the uncertainty in the quantity per subtype. Homogeneity constraints are introduced including fuzzy sets; specifically, the interaction among fuzzy homogeneity coefficients that represent the fraction 


\begin{tabular}{|c|c|c|c|c|c|c|c|}
\hline 跑 & & $x$ & $\star x$ & $x$ & $x$ & $x$ & $x$ \\
\hline 觫 & $\not$ & $\star x$ & $x$ & & $x$ & $\star x$ & \\
\hline $\begin{array}{l}0 \\
0 \\
0\end{array}$ & & $x$ & $x$ & $x$ & $x$ & $\star x$ & $x$ \\
\hline - & $x$ & & & & & & \\
\hline 10 & & $\star *$ & $\star x$ & & $\star x$ & $\not$ & \\
\hline$\infty$ & & $x$ & $x$ & & $x$ & $x$ & \\
\hline 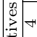 & & $*$ & $x$ & & $x$ & $x$ & \\
\hline$\infty$ & & $x$ & $x$ & 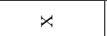 & $x$ & $\not$ & $x$ \\
\hline$\pi$ & $\not$ & & & & & & \\
\hline- & $\not$ & & & & & & \\
\hline 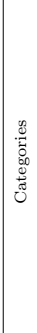 & 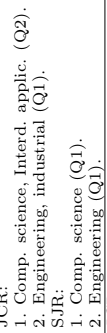 & 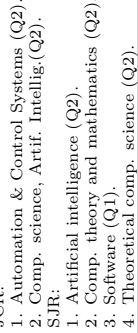 & 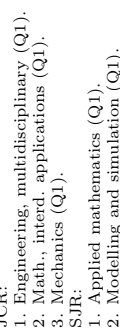 & 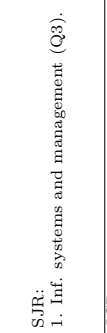 & 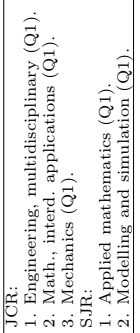 & 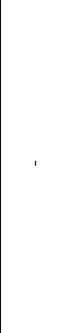 & . \\
\hline 卧 & 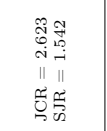 & 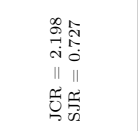 & 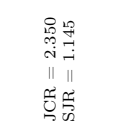 & 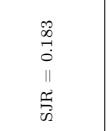 & 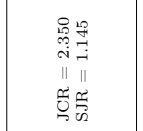 & . & . \\
\hline 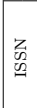 & 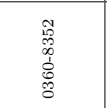 & 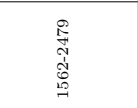 & 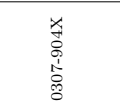 & 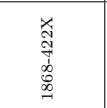 & 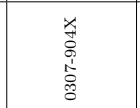 & . & . \\
\hline 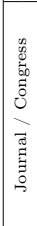 & 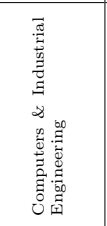 & 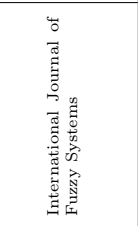 & 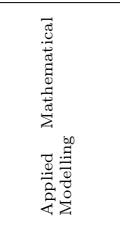 & 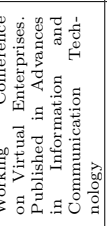 & 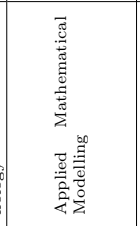 & 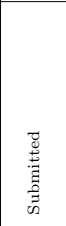 & 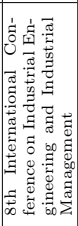 \\
\hline$\vec{\circ}$ & 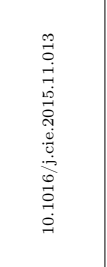 & 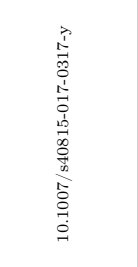 & 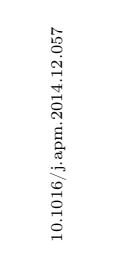 & 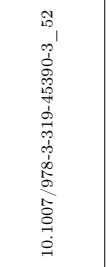 & 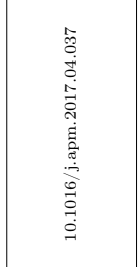 & & ' \\
\hline 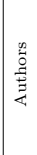 & 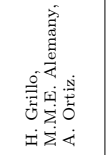 & 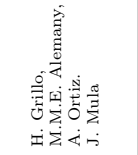 & 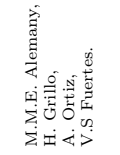 & 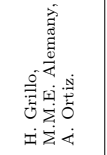 & 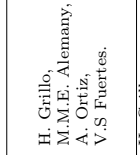 & 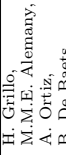 & 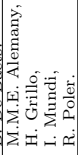 \\
\hline हैं & $\exists$ & $\exists$ & $\geq$ & $>$ & 5 & $\exists$ & 宏 \\
\hline
\end{tabular}


of each homogeneous sublot. Therefore, modelling uncertainty in interdependent technological fuzzy coefficients is one of the main novelties of this research. Hence, in order to reliably meet the homogeneity required by customers, this fuzzy model is proposed to support the OPP in LHP contexts after taking into account uncertainty in planned homogeneous sublots. The fuzzy model is translated into an alpha-parametric equivalent crisp model. Another important novelty of this work is related to the proposed methodology to analyse the suitability of the minimum degree of possibility (the alpha-cut), by means of an adapted TOPSIS-based fuzzy procedure in order to rank the different instances of alpha-cut tested. The experiments are conducted with real data of a ceramic tile supply chain. The proposed validation methodology includes the comparison between the deterministic and fuzzy models for several instances of data scenarios. The performance of both models is also measured and contrasted by simulating different real projections of the real size of homogeneous sublots once produced and classified and the real number of committed orders. The experimental design proves both, the validity of the models and the better performance of the fuzzy approach as compared to the deterministic one.

Until this point, all the work presented has dealt with the OPP itself, without considering the SP that is another of the objectives of the dissertation. For this reason, Chapter IV presents a SP study as an extension of the study presented in Chapter III. Due to inherent LHP uncertainty, the size of each homogeneous sublot is not known until it is produced and classified. Discrepancies between planned homogeneous quantities and the real ones are usual, and can lead to a shortage situation, where the accomplishment of the commitments previously made with customers can be endangered. For this reason, it can occur that not enough homogeneous quantities are available to completely serve all orders as required, although all the lots being produced. In this case, it is necessary to find alternative solutions to minimize the negative impact for the customer and the supply chain. For this purpose, a fuzzy mixed integer linear programming model is proposed in this chapter, in order to support the SP in environments characterized by LHP. The proposed approach consists in the reallocation of stocks and the planned MPS quantities to the already committed orders with the aim of effectively fulfil as much orders as possible while maximising the profits generated by them. This modelling approach also applies the fuzzy interdependent coefficients that represent the fraction of each homogeneous sublot as done in Chapter III. The model is validated with the same set of realistic data of Chapter III from the ceramic tile sector. The experimental design includes the execution of the SP model under different scenarios based on allowing or denying a delay in served orders, the degree of possibility (alpha-cuts) and the value of beta parameters (LHP scenarios). Unlike the case of Chapter III, in this work the ranking of different alpha-cuts is based on the premise that the decision maker (DM) must add his/her expectations for the model objective(s), but by evaluating at the same time the feasibility level of the solutions that better achieve the DM's requirements. 
The obtained results confirm the validity of the model and provide interesting information about its behaviour regarding to the fulfilment of the orders and the effect of the LHP over the shortage.

From the literature review of Chapter II, the sector of perishables is identified as greatly affected by the LHP. Despite this fact, only one work was found for the OPP modelling in perishables. For this reason, in Chapters V and VI we seek to extend the methods and knowledge captured in Chapters III and IV from the ceramic tile sector to the perishables one, more specifically to the fruit sector.

In this context, in Chapter $\mathbf{V}$ a simplified approach to model product's freshness committed to customers, based on a fixed shelf-life of the subtypes is proposed. Perishability leads to the deterioration of the original characteristics of product's subtypes over time, which can generate a shelf life-based pricing policy. Therefore, as another novelty, it is considered that the price (value) of the subtype is dependent on its freshness at the moment of delivery to the customer. This aspect is modelled by linking the consumption of the shelf life (Remaining Shelf Life, RSL) to deterministic ranges of price. The selling price is considered a step function (constant in intervals) with as many intervals as price ranges, which are defined based on product's RSL at the delivery time. The value of the price among the intervals lowers in the way the RSL decreases.

Chapter VI extends the modelling approach for the freshness and price of products committed to customers, by means of a mathematical model of the OPP for fruit supply chains based on homogeneous ATP per subtype. The developed model should ensure that customers are served not only with the required quantities on certain dates, but also with the homogeneity and freshness requested. For this purpose, the model aims to maximise two conflictive objectives: the total profit and the mean product's freshness delivered for the committed orders. The originality of the model derives from considering that the customers specify the subtype required in their orders. Furthermore, the customer satisfaction and the profits are linked to the freshness of the subtypes delivered, making it necessary to consider the traceability of the product's ageing process. This allows to compute shelf life-based pricing policies for the product and to compute and minimize the effect of the LHP over the waste of the subtypes that expire without being assigned to any order. Different scenarios are defined according to the weight of each objective, shelf-life length and the pricing policy in a rolling horizon scheme with data derived from a Spanish supply chain of the orange and tangerine sector. The numerical experiments show the validity of the model to support this complex type of OPP in a reasonable solution time. They also prove the conflicting behaviour of the objectives of the model: the highest profit made at the expense of the lowest mean freshness delivered, and vice versa. Moreover, the narrower the price variation with freshness, the more pronounced the level of conflict between these objectives. Finally, the positive impact of prolonging the product's shelf life on both objectives is shown. 
From the work developed in Chapter VI, the need of developing a more abstract and generic modelling approach for the OPP in these types of supply chains (perishables) considering the LHP inherent uncertainty arises. For this reason, in Chapter VII an interesting study, in collaboration with professor Bernard De Baets of Ghent University is developed. In this study, the concepts of fuzzy interdependent coefficients are generalized into the concept of compositions of possibilistic variables with the aim of developing a theory body of research. Such compositions can be used to model any situation where a vector of possibilistic variables must add up to another possibilistic variable. Since possibilistic variables can include conventional intervals and fuzzy intervals, both possibilities are properly covered. Hence, through the application of compositions to the ATP, it is possible to model the same methodology of the fractions of each subtype, but is is also possible to model directly the total quantity of the subtype as a possibilistic variable. It can be considered that the total amount of the lot is either a constant possibilistic variable (if the total amount is fixed) or an interval possibilistic variable (if the total amount is also uncertain). Since another need is to consider the perishability factor, it is also introduced the concept of state functions. State functions represents the status of a determined characteristic over the time, for example the price. State functions could also be used to model any situation where a determined variable depends on time and where its maximum expected time is uncertain and could be modelled as a possibilistic variable. Procedures to obtain equivalent representations of the possibilistic variables as conventional intervals, based on alpha-cuts, have been developed for the compositions and for the possibilistic variables involved in the state functions. This representation allows to implement linear programming with the aim to increase the computational efficiency. A practical implementation is developed by means of an OPP model for perishables linking the product' shelf life (for each subtype modelled with compositions of possibilistic variables) at the delivery time, with the selling price given by an state function. Numerical experiments, based on the same data of Chapter VI were executed. The experiments showed good results in terms of the interpretations of reality. Both tools could also be extended to other fields of applied mathematics, hence, it can be considered a very significant contribution.

As it can be seen in Table 1, Chapters III-IV and VI-VII jointly include the phases II, III and IV of the methodology, since they all develop mathematical models and design their specific methodology of experimentation, and validation trough data of real supply chains. Meanwhile, all the articles include the phase IV of the methodology, because they all provide conclusions and the highlight of future research lines.

Finally, Chapter VIII presents the general conclusions of this dissertation providing a general overview of how the different chapters cover identified gaps in the literature. Furthermore, future research lines are highlighted.

Additionally, a publication presented at the the "International Conference on Industrial Engineering and Industrial Management" is included in the Appendix 
A. In the latter work, a reduced version of the approach used to model the beta interdependent coefficients by fuzzy sets applied in the studies of Chapters III and IV is described.

\section{Bibliography}

[1] H. Grillo, M. M. E. Alemany, and A. Ortiz. "A review of mathematical models for supporting the order promising process under Lack of Homogeneity in Product and other sources of uncertainty". In: Computers \& Industrial Engineering 91 (2016), pp. 239-261. DOI: $10.1016 /$ j.cie.2015.11.013

[2] M. M. E. Alemany, F. C. Lario, A. Ortiz, and F. Gomez. "Available-To-Promise modeling for multi-plant manufacturing characterized by lack of homogeneity in the product: An illustration of a ceramic case". In: Applied Mathematical Modelling 37.5 (2013), pp. 33803398. DOI: $10.1016 / \mathrm{j} . \mathrm{apm} .2012 .07 .022$

[3] F. Alarcón, M. M. E. Alemany, F. C. Lario, and R. F. Oltra. "The lack of homogeneity in the product (LHP) in the ceramic tile industry and its impact on the reallocation of inventories". In: Boletin De La Sociedad Espanola De Ceramica Y Vidrio 50.1 (2011), pp. 49-57. DOI: 10.3989/cyv.072011

[4] A. Boza, M. M. E. Alemany, F. Alarcón, and L. Cuenca. "A model-driven DSS architecture for delivery management in collaborative supply chains with lack of homogeneity in products". In: Production Planning \& Control 25.8 (2013), pp. 650-661. Dor: 10.1080/ 09537287.2013 .798085

[5] M. O. Ball, C.-Y. Chen, and Z.-Y. Zhao. "Available to Promise". In: Handbook of Quantitative Supply Chain Analysis: Modeling in the E-Business Era. Ed. by D. Simchi-Levi, S. D. Wu, and Z.-J. Shen. Boston, MA: Springer US, 2004, pp. 447-483. DOI: 10.1007/9781-4020-7953-5_11

[6] M. M. E. Alemany, H. Grillo, A. Ortiz, and V. S. Fuertes-Miquel. "A fuzzy model for shortage planning under uncertainty due to lack of homogeneity in planned production lots". In: Applied Mathematical Modelling 39.15 (2015), pp. 4463-4481. Dor: 10.1016/j . apm.2014.12.057 



\title{
Chapter II
}

\section{A review of mathematical models for supporting the order promising process under Lack of Homogeneity in Product and other sources of uncertainty}

\begin{abstract}
This paper presents a review of mathematical programming models for supporting the order promising process (OPP) under Lack of Homogeneity in Product (LHP) conditions and uncertainty in a modelling approach. LHP appears in productive processes with raw materials, which directly stem from nature and/or production processes with operations that confer heterogeneity to the characteristics of the outputs obtained, even when the inputs used are homogenous. LHP has a direct impact on the company's service level, mainly when the customer needs to be served with homogeneous units of the same product. LHP leads to inherent sources of uncertainty due to the natural physical characteristics of the supply chain. This research aims to determine the way that LHP, and uncertainties related either to LHP or different variables that confer more realistic conditions to OPP, have been modelled in different LHP sectors, or others affected by uncertainty. This result may provide the opportunity to transfer knowledge among them and to identify gaps for further research. Accordingly, and in order to set the basis for future research into the OPP topic, for cases affected by LHP and for uncertainties inherent to LHP conditions, or due to
\end{abstract}


other possible uncertain variables, this research needs to consider both mathematical model types: (i) mathematical programming models of the OPP that consider some LHP characteristic and (ii) mathematical programming models of the OPP that consider any type of uncertainty in the modelling approach. We propose a taxonomy approach to classify and analyse the literature based on the main characteristics of its environment, order promising approach, customer order characteristics, modelling characteristics, and LHP and uncertainty modelling. The main finding of this research was that research into OPP modelling, combined with LHP characteristics and uncertainty, are lacking. We provide some starting points for further research in this field.

Keywords: Mathematical programming; Uncertainty; Lack of Homogeneity in Product (LHP); Order promising process.

\section{Introduction}

Customer satisfaction can lead to customer loyalty, which is one of the factors needed to guarantee the sustainability of any business [1]. The order promising process (OPP) has made significant advances in making processes of supply, production, storage and delivery more efficient in order to better attend demand requirements with high standards of service level and customer satisfaction. According to Alemany et al. 2], the OPP refers to a set of business activities triggered to provide a response to customer order requests. Although much research on OPP has been done, there are sectors that present particular common characteristics that have a great impact on the OPP and have not yet been sufficiently investigated. Some examples of these sectors are agri-food, ceramic, wood and reverse logistics, among others. They are all characterised to present the so-called Lack of Homogeneity in Product (LHP), defined as lack of uniformity in the products required by customers [3]. LHP appears in production processes with raw materials that directly derive from nature and/or production processes with operations that confer heterogeneity to the characteristics of the outputs obtained, even when the inputs used are homogeneous [2],. The results are units of the same finished good $(\mathrm{FG})$ in a lot with some attributes that are relevant for customers which can differ.

LHP may become a considerable problem when customers acquire several units of a given product and require product homogeneity to use, present, arrange or consume them together to avoid functional or esthetical problems. One slight difference in a part is easily seen in certain products like parquet strips, leatherwear, floor tiles or pearl necklaces [3. LHP supply chains are forced to classify items into different homogeneous subsets (subtypes) based on certain criteria for the purpose of meeting the customer homogeneity requirement. However, the homogeneous quantities (subtypes) that will be available to customers are not known until they have been manufactured and classified [4]. For instance, in the ceramics sector, 
units in a production lot of the same tile model (FG) can differ in quality (aspect), tone (degree of colour) and calibre (thickness). As customers require uniformity as regards these attributes in their orders to ensure uniform esthetical appearance, ceramic companies inspect each production lot and classify it into homogeneous sublots (subtypes) based on the different combinations of attributes to comply with customer requirements. Fig. 1 shows a general schema of the appearance and effect of LHP on production processes.

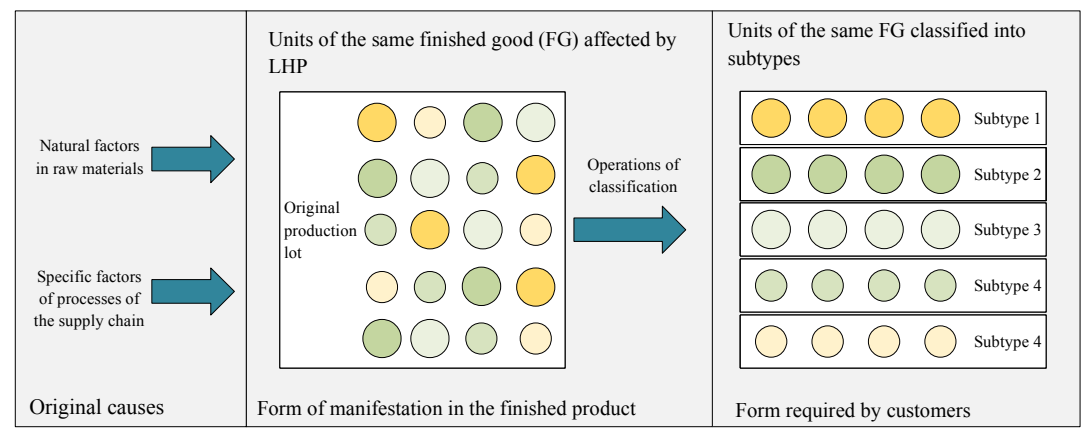

Figure 1: General schema of the appearance and effect of LHP on production process.

According to Mundi and Alemany [5], LHP leads to inherent sources of uncertainty due to the natural physical characteristics of the supply chain. Three possible causes are identified: (1) intrinsic product characteristics caused by lack of homogeneity in raw materials and the dynamic state of some LHP items (subtypes); for example, the perishability factor; (2) the technological characteristics of the process caused by the existence of LHP activities and LHP factors (e.g. humidity, temperature, etc.) and (3) logistic actors' characteristics due to, for instance, consumer eating habits (customers' preferences in required subtypes). The above inherent sources of uncertainty can be associated with supply chain uncertainty stages according to Peidro et al. [6]: (1) supply uncertainty, (2) process uncertainty and (3) demand uncertainty.

LHP inherent uncertainty has a huge impact on the OPP when customer orders that require homogeneity are promised according to uncommitted planned production lots (Master Plan) for which real homogeneous quantities are not known until produced. Due to LHP, inherent uncertainty discrepancies between planned and real homogeneous quantities are usual. This can lead to previously committed orders not being served on time. Therefore, not accomplishing this homogeneity requirement can lead to returns, product and company image deterioration, diminished customer satisfaction, and even loss of customers [4]. Mundi and Alemany [5] stress the importance of studying LHP in supply chain modelling problems according to its potential negative effects on the competitiveness of supply chains: (1) LHP leads to fragmented stocks, which can rapidly become obsolete for products with a short life cycle as they cannot be accumulated to be used in the same order 
given their heterogeneity; (2) uncertainty in the available homogeneous quantities of finished goods (FGs) entails having to produce more than is necessary, which means increasing stocks and (3) the customer service level may prove deficient, even with high stock volumes.

Furthermore, LHP complicates order promising because it increases the volume of information to be managed (different references (subtypes) for the same FG), and other homogeneity requirements-related constraints should be taken into account. In this context, mathematical modelling has proven a powerful tool for the OPP. Thus correct handling of LHP and its inherent uncertainty in order promising modelling is important to reduce and avoid inefficiencies in both order promising itself and previous supply chain processes, like raw materials supply, production, and storage and distribution. Inefficiencies are usually manifested as worse customer service, product waste, delivery time, use of installed production capacity, etc.

Although LHP is present in the supply chains of several sectors (ceramic, marble, tanned hides, leather goods, and horticulture, among others) which suffer the negative effects that derive from inappropriate LHP management, very few models that include LHP or uncertainty aspects have been proposed for the OPP. Even though all these LHP sectors deal with their characteristics as if unique, abstraction can show that some aspects are common to them all. Therefore, a unified study can help to transfer valid solutions from one sector to others and, at the same time, can detect aspects for further research.

According to Meredith [7, a literature review aims to: first summarise existing research by identifying patterns, themes and issues; second, constitute an initial step in the theory development process. To achieve these objectives, a literature review by sectors was made to analyse to what extent LHP has been considered in mathematical models for the OPP in a deterministic or uncertain context. Given the small number of papers in this field, and as we are aware of the importance of modelling LHP-inherent uncertainty in the OPP, this review was extended to uncertain OPP models. Since the OPP is considered a short-term process, very few models have dealt with uncertainty for the OPP. Yet as explained before, when promising orders do not consider LHP inherent uncertainty can lead to very negative consequences. So this literature review shows that LHP modelling in the $\mathrm{OPP}$ is a potential research field that can improve the competitiveness of these supply chains.

The results of this review are:

- LHP inherent characteristics derive from the abstraction of common LHP aspects in different sectors which affect the OPP.

- Definition of a structured framework for reviewing the existing literature on LHP and the uncertainty OPP research area. 
- An analysis of the existing works of OPP mathematical programming models into LHP and/or the uncertainty context based on the above framework.

The utility of the above results can differ depending on the user profile:

- Practitioners: the structural elements that integrate the research framework can be used by practitioners for characterising supply chains of multiple sectors where LHP is an unavoidable factor, and where uncertainty is inherent to either LHP or the variables related to it; the identification of existing works that deal with these structural elements can provide solutions to the problem under study.

- Researchers: the conclusions drawn from this research can comprehensively provide guidelines for the gaps in modelling either LHP or uncertainty. These results can guide future research works to achieve the best possible benefits by minimising the negative impact of LHP and uncertainty on both the OPP and supply chain effectiveness.

The rest of the paper is structured as follows. Section 2 introduces the LHP inherent characteristic. Section 3 describes the literature review methodology applied. Section 4 presents and describes the structural dimensions designed to analyse the reviewed literature. Section 5 carries out the analysis of the research results by classifying, describing and identifying any lacking research areas for all the structural dimensions presented in Section 4. Finally, Section 6 presents the main conclusions drawn from the research.

\section{LHP inherent characteristics}

When a new customer order request arrives during the OPP, it is necessary to compute whether there are enough uncommitted real or planned FGs, materials and/or resources available to fulfil the new order on time. Traditionally, the homogeneity of the different available units of the same FG to be promised to customers has been assumed. This homogeneity characteristic has allowed uncommitted FG availabilities to accumulate from different resources and time periods to meet the same customer order 2 .

However, as previously described, this homogeneity assumption is not valid for manufacturing contexts with LHP where different subtypes of the same FG exist. Due to LHP inherent uncertainty, the real homogeneous quantities available of the same FG to be promised to customers are not known until they have been produced. This aspect is a problem when customer orders have to be promised, reserved and served from the homogeneous units available, which derive from planned production. Therefore, it is necessary to anticipate the future availability of homogeneous quantities (subtypes) when developing mathematical programming models as much as possible to serve customers with the required quantities 
and homogeneity level on time. In order to evaluate LHP characteristics, we based our work on Mundi and Alemany [5] description, where LHP can be divided into four categories according to its aspects: subtypes (ST), subtype quantity (SQ), subtype value (SV) and subtype state (SS).

- Subtypes (ST): refer to the total number of subtypes into which an FG can be classified. Existing subtypes depend on the attributes used in the classification stages and their possible values. For instance, in the ceramics sector, each piece has to be inspected and classified, and individual models (products) are usually stored in homogeneous subgroups (subtypes) according to quality (aspect), tone (degree of colour) and gage (thickness) [3, 8]. The usual consideration of three qualities, two tones and three gages can mean that the number of subtypes for the same model (FG) increases to 13 .

- Subtype quantity (SQ): refers to the quantity of each subtype obtained between lots or in the same lot. Although the final quantity obtained of each subtype may depend on lot size, its proportion can be fixed or variable.

- Subtype value (SV): refers to the economic value or utility given by the customer to the different subtypes of an LHP item. Each subtype value can be the same or may differ. For instance, different qualities of the same item present distinct selling prices.

- Subtype state (SS): The value of the attributes used to classify items into subtypes can be dynamic or static; i.e. can or cannot change over time, respectively. For instance in the food sector, products can be perishable; i.e. their quality (freshness) diminishes with time (decay or perishability).

The above categories can be located mainly in three different supply chain steps: supply $(\mathrm{Sp})$, process $(\mathrm{Pr})$ and demand (Dm). However, since this survey included deterministic and uncertain models with LHP, we generalised the definitions of Mundi and Alemany [5], which they formulated only for uncertainty environments, in order to include deterministic ones. Therefore, LHP inherent characteristics can be summarised as shown in Fig. 2 .

\section{Literature review methodology}

From a methodological point of view, literature reviews can be comprehended as a content analysis. During this literature review, the process model for a content analysis described by Seuring and Müller 9 was adopted:

1. Material collection: the material to be collected was defined and delimited.

2. Descriptive analysis: formal aspects of the material were assessed.

3. Category selection: the structural dimensions and related analytic categories to be applied to the collected material were selected. 


\begin{tabular}{|c|c|c|c|}
\hline & Supply (Sp) & Process (Pr) & Demand (Dm) \\
\hline Subtypes (ST) & $\begin{array}{l}\text { Existence of subtypes in supplied } \\
\text { raw materials or components } \\
\text { (LHRM) in a specific lot or } \\
\text { among lots }\end{array}$ & $\begin{array}{l}\text { Existence of subtypes in } \\
\text { intermediate (LHIP) or finished } \\
\text { goods(LHFG) }\end{array}$ & $\begin{array}{l}\text { Customers/markets request their } \\
\text { products by specifying the sub- } \\
\text { type required (LHFG) in their } \\
\text { orders }\end{array}$ \\
\hline $\begin{array}{l}\text { Subtype } \\
\text { quantity (SQ) }\end{array}$ & $\begin{array}{l}\text { Variable quantities per subtype } \\
\text { of LHRM (in the same lot or } \\
\text { among lots) }\end{array}$ & $\begin{array}{l}\text { Variable quantities per subtype } \\
\text { of LHIP or LHFG (in the same lot } \\
\text { or among lots) are variable }\end{array}$ & $\begin{array}{l}\text { Variable quantities required for } \\
\text { each subtype (LHFG) and } \\
\text { customer/market }\end{array}$ \\
\hline $\begin{array}{l}\text { Subtype value } \\
\text { (SV) }\end{array}$ & $\begin{array}{l}\text { The value (cost) of supplied } \\
\text { subtypes can vary according to } \\
\text { the availability and demand of } \\
\text { LHRM subtypes }\end{array}$ & $\begin{array}{l}\text { The value (cost) of produced } \\
\text { LHIP subtypes can be vary } \\
\text { according to the finished good } \\
\text { demand, process (storage } \\
\text { conditions) or the final } \\
\text { availability of subtypes }\end{array}$ & $\begin{array}{l}\text { The value (price) of produced } \\
\text { finished good (LHFG) in the } \\
\text { market can vary according to the } \\
\text { sub type }\end{array}$ \\
\hline $\begin{array}{l}\text { Subtype state } \\
\text { (SS) }\end{array}$ & $\begin{array}{l}\text { The state of the subtype (LHRM) } \\
\text { is dynamic (perishability, } \\
\text { obsolescence) }\end{array}$ & $\begin{array}{l}\text { The state of the subtype (LHIP or } \\
\text { LHFG) is dynamic (perishability, } \\
\text { obsolescense) }\end{array}$ & $\begin{array}{l}\text { The state of the subtype (LHFG) } \\
\text { is dynamic (perishability, } \\
\text { obsolescence) }\end{array}$ \\
\hline
\end{tabular}

Figure 2: LHP inherent characteristics (adapted from Mundi and Alemany 5|).

4. Material evaluation: the material was analysed according to the structural dimensions. This should allow the identification of relevant issues and the interpretation of the results.

As stated before, the material to be collected referred to the OPP mathematical models that deal with either LHP (deterministic or uncertain) or uncertainties. The search process was carried out by using the search engine referrals web of knowledge, which is able to handle several scientific-technical bibliographic databases, including the most well-known portals, such as Elsevier, Taylor and Francis, Emerald, and many others. In order to extend the search area, different criteria were defined and applied. The key words below were used:

- Order promising process

- Quantity quotation

- Due date quotation

- Order acceptance

- Available to promise

- Capable to promise

- Delivery to promise
- Profitable to promise

- Lack of homogeneity

- Heterogeneity

- Mathematical programming

- Quality levels

- Segmentation

- Uncertainty

This term's definition aimed to include the OPP models for LHP contexts as the backbone of the research, with variations due to uncertainty. The technique of reviewing the references in the citations of papers was also applied for those references that matched the ideal profile for this research. After refining the databases that did not match the research scope, and after focusing on engineering, order promising and mathematical and scientific modelling, 239 references were obtained in the first group. To differentiate among the references found, various criteria were adopted. 
The first refining method involved ruling out those references that did not purely pertain to the OPP. To that end, we based our criteria on the concepts presented by Alarcón et al. [10, 11], who stated the main OPP characterisation concepts. The references that did not explicitly include a mathematical model of any of those concepts had to be eliminated.

The next step was to exclude all the references that did not match uncertainty in the modelling approach or some characteristic lack of homogeneity in the main model definitions $[2,3,12$. After this refining process, 42 articles were selected, and 26 sources were identified of which $97.6 \%$ were scientific journals and $2.4 \%$ were congresses. Of all the references, $60 \%$ belonged to a group of nine journals, which included highly relevant journals, such as the International Journal of Production Research, the European Journal of Operational Research, Computers and Industrial Engineering, Applied Mathematical Modelling and OR Spectrum (Table 1).

References spanned 13 years (see Table 2, 2001-2014), except 2003, when no publications were found. It is stressed that about $73.8 \%$ of the publications were dated after 2009, which proves that the research topic is a relatively new research area. Of this $73.8 \%, 40 \%$ corresponded only to two years with $21 \%$ and $19 \%$ for 2011 and 2010, respectively, and 2011 was the year with the most publications.

Another characteristic was the validation method applied to prove the results of the presented model; in this category, the case study and real application can be mentioned as options. A case study consists in those references that used simulated data to solve the model, while real applications consist in those papers that based their experimental results on data from real supply chain cases. Table 3 presents the results and reveals that $73.8 \%$ were papers that applied a case study, while $26.2 \%$ corresponded to real applications, which means that real applications are lacking in this research field.

\section{Structural dimensions for the review}

The structural dimensions for analysing the selected literature were defined to find out patterns when modelling LHP characteristics and/or uncertainty during the OPP, which can allow knowledge transfer among different LHP sectors. The covering degree of each structural dimension allows the identification of future research lines. These objectives are in agreement with those proposed by Meredith 7 .

The structural dimensions for the review were partially defined according to those proposed by Mula et al. 13] for characterising production and transportation planning models by properly modifying to match our objective. Mula et al. [13 proposed two main classification categories, the model category and the environment, both of which are related with the shared information, limitations and novelty of the reference. Like Mula et al. [13], we defined the environment categories and 
Table 1: Number of publications per source.

\begin{tabular}{lcc}
\hline Source & References & \% Total \\
\hline European Journal of Operational Research & 4 & 9.5 \\
International Journal of Production Research & 4 & 9.5 \\
Applied Mathematical Modelling & 3 & 7.1 \\
Computers \& Industrial Engineering & 3 & 7.1 \\
OR Spectrum & 3 & 7.1 \\
Computers \& Operations Research & 2 & 4.8 \\
Expert Systems with Applications & 2 & 4.8 \\
Journal of Heuristics & 2 & 4.8 \\
The International Journal of Advanced Manufacturing Technology & 2 & 4.8 \\
Annals of Operations Research & 1 & 2.4 \\
Boletín de la Sociedad Española de Cerámica y Vidrio & 1 & 2.4 \\
Computer Aided Chemical Engineering & 1 & 2.4 \\
Computers \& Mathematics with Applications & 1 & 2.4 \\
Decision Support Systems & 1 & 2.4 \\
Engineering Optimization & 1 & 2.4 \\
Hawaii International Conference on System Sciences & 1 & 2.4 \\
Industrial \& Engineering Chemistry Research & 1 & 2.4 \\
Information Systems Frontiers & 1 & 2.4 \\
International Journal of Computers, Communications and Control & 1 & 2.4 \\
International Journal of Production Economics & 1 & 2.4 \\
International Journal of Project Management & 1 & 2.4 \\
Manufacturing Science and Technology & 1 & 2.4 \\
Naval Research Logistics & 1 & 2.4 \\
Operations Research & 1 & 2.4 \\
Production and Operations Management & 1 & 2.4 \\
Scientia Iranica & 1 & 2.4 \\
\hline Total & $\mathbf{4 2}$ & $\mathbf{1 0 0}$ \\
\hline
\end{tabular}

Table 2: Number of publications per year.

\begin{tabular}{|c|c|c|}
\hline Year & References & \% Total \\
\hline 2014 & 3 & 7.1 \\
\hline 2013 & 4 & 9.5 \\
\hline 2012 & 3 & 7.1 \\
\hline 2011 & 9 & 21.4 \\
\hline 2010 & 8 & 19.0 \\
\hline 2009 & 4 & 9.5 \\
\hline 2008 & 2 & 4.8 \\
\hline 2007 & 2 & 4.8 \\
\hline 2006 & 1 & 2.4 \\
\hline 2005 & 2 & 4.8 \\
\hline 2004 & 1 & 2.4 \\
\hline 2002 & 1 & 2.4 \\
\hline 2001 & 2 & 4.8 \\
\hline Total & 42 & 100 \\
\hline
\end{tabular}

Table 3: Validation method.

\begin{tabular}{lcc}
\hline Method & References & \% \\
\hline Case study & 31 & 73.8 \\
Real application & 11 & 26.2 \\
\hline Total & $\mathbf{4 2}$ & $\mathbf{1 0 0}$ \\
\hline
\end{tabular}


model characteristics. However, we added three new categories to appropriately characterise the research topic: (1) the OPP; (2) characterisation of customer orders and(3) LHP and uncertainty characteristics modelling (Fig. 3). The structural dimensions used to analyse the literature are those described below.

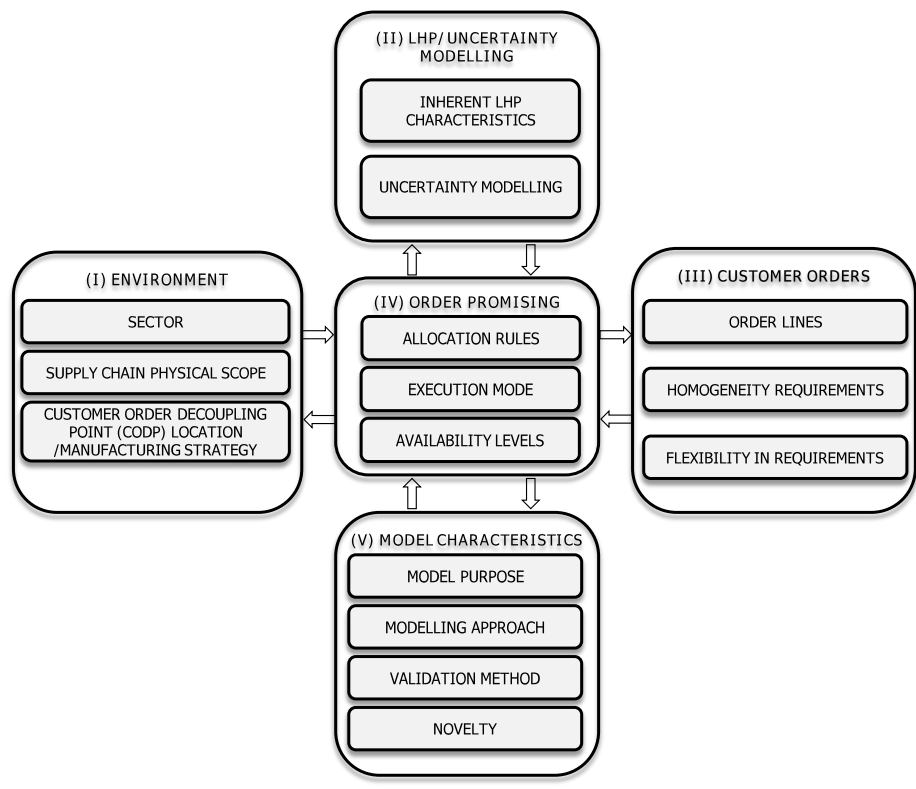

Figure 3: Structural dimensions for the analysis.

\subsection{Environment}

This structural dimension was similar to that proposed by Mula et al. 13 . We included the sector category because LHP affects many sectors in different ways. So it would be interesting to know the extent to which LHP characteristics and/or uncertainty were taken into account in the OPP in each sector. The physical scope of the supply chain refers to the nodes and stages of the supply chain considered when promising orders. Finally, the location of the decoupling point defines the manufacturing strategy that strongly determines the availability levels checked when promising orders. 


\subsection{LHP/uncertainty modelling}

This structural dimension aims to first describe if the paper considers some LHP characteristics; if it does, then the objective is to describe if LHP characteristics are modelled under deterministic or uncertainty conditions. This classification is based on the uncertainty category of the taxonomy proposed by Mundi and Alemany [5]. Since LHP involves inherent uncertainty, we were also interested in analysing papers on OPP modelling uncertainty in any way because they can provide useful information for modelling LHP characteristics under uncertainty conditions.

\subsection{Customer orders}

The objective of this dimension was to describe the customer order characteristics that the OPP model deals with from an LHP perspective. For LHP contexts, knowing if customer orders require one product or more in their orders is crucial. So when the model considers more than one product in a single order, or even more than one product per order (customer order lines), it is identified. This aspect is related to the homogeneity requirement in customers' orders: among product components, among units of the same product, or even among products in the same order. Customers can also specify the value of homogeneity attributes (e.g., quality or specific size). The homogeneity requirement can be subject to a certain degree of flexibility: for example, some delay in delivery or price variations can be accepted.

\subsection{Order promising}

This structural dimension is based mainly on the concepts set by the modelled OPP promising process and on relating it with LHP characteristics. As LHP can force customers to be classified into different classes, questions such as allocation rules to customers when there is not enough uncommitted availabilities for all requests become important. In shortage situations, less lucrative order books FGs and/or components, which could be assigned later to a more lucrative order, are quite likely. In order to make more profit, it might be useful to allocate a quota of components to specific customer classes (as is well-known from yield management and flight ticketing) [14. The way and criteria to such quotas to customer classes are defined as allocation rules (Fig. 3).

The execution mode refers to the periodicity in which the uncommitted available quantities are assigned to incoming orders. It is strongly affected by the response time required by the customer and the characteristics of the OPP itself. Two basic execution modes are distinguished: "batch order processing" and real-time or "single-order processing". In the batch mode, an order is not promised immediately upon request, but is held back. It is then assigned the different uncommitted availability, together with several other orders in a "batch". This execution mode is possible when the customer is willing to wait at least the batching interval time. 
Yet when customers expect an immediate answer for their order query, single order promising is necessary. Thus each single order has to be processed in real time and uncommitted availabilities are consumed in a first-come first-served (FCFS) manner. For these cases, allocation rules in shortage situations are necessary.

When a new customer order request arrives during the OPP, it is usual to check whether there are enough uncommitted quantities of different availability levels for the requested due date. The availability levels to be checked depend on the supply chain's manufacturing strategy, which depends on the Customer Order Decoupling Point (CODP) location. Upstream of the CODP, manufacturing is driven by forecasts, while manufacturing is driven by customer orders downstream of the CODP. The availability levels to be checked can differ [10:

- Available to Promise (ATP): it is the quantity of the items still not promised stored at the CODP, and can be either available on inventory stock or planned to receive (from the Master Production Schedule or from planned receptions).

- Capable to Promise (CTP): it is the total available capacity still not promised of the resources involved in order fulfilment, either real or planned. It includes not only manufacturing resources, but also the raw materials required for orders.

- Deliver to Promise (DTP): it is the total capacity of distribution resources (storage and transportation), real or planned, that is still not promised.

To be able to promise due dates with customers, the companies that follow the MTS strategy should check if there is enough uncommitted FGs availability (ATP) for the due dates, and perhaps enough capacity of the not yet committed distribution resources (DTP), to ensure on time delivery. For ATO and MTO strategies, apart from DTP, it is necessary to check at least the uncommitted availability of the items stored at the CODP (ATP) and the capacity of manufacturing resources downstream of the CODP to convert CODP items into FGs (CTP).

\subsection{Model characteristics}

Finally, this structural dimension remains as shown by Mula et al. [13], but includes the novelty category of the proposed OPP model. The model purpose identifies if the model's objective is to minimise cost, maximise profit, or some other option. Finally, the modelling approach attempts to describe the applied modelling method; for example, linear or stochastic programming.

Fig. 3 shows the relation among the defined dimensions. It is clear that the order promising category works as the central convergence point, and that it shares information with all the other categories. The objective of this taxonomy is to identify the main research work done to date, which includes mathematical models in the OPP, while also finding the best way to consider uncertainty variables in this 
process, and to also determine the main characteristics and functional requirements to be considered to establish future models that integrate LHP characteristics and uncertainty into the OPP. We are convinced that correct LHP modelling during the OPP will improve the performance, customer satisfaction and competitiveness of these supply chains.

\section{Material evaluation}

Having defined the structural dimensions to analyse the existing literature, this section reports the material evaluation results. Our aim is twofold, to draw conclusions about: (1) the characteristics of the OPP problems that have modelled LHP and/or uncertainty in some element and (2) the modelling technique used. The obtained results allow the identification of differences among existing models in terms of defined structural dimensions and elements, and of existing gaps in the literature.

\subsection{Environment}

This structural dimension provides the researcher/practitioner with an overview of the research advances made in a specific sector and other closely related ones. All the categories that integrate this structural dimension shown in Fig. 3 are as follows.

\subsubsection{Sector}

This section aims to address the specific sector which the research paper belongs to. Ten possibilities were identified:

- Meat (ME)

- Fresh Food (FF)

- Ceramic tile (CT)

- Computer (COM)

- Chemical (CHE)
- Technological (TEC)

- Construction (CON)

- Steel mill (SM)

- Mould (MO)

- Generic (GEN)

As we can see, a category called Generic was included for the articles that did not model any specific sector, but established models to be applied generically.

Table 4 shows the classification of the reviewed literature from these ten categories. The majority of papers pertained to the generic category (67\%), which was followed by the technological $(10 \%)$ and computer $(7 \%)$ categories, while ceramic tile represented $5 \%$, and all the rest only $2 \%$. This result coincides with the fact that most papers were case studies, as denoted in Table 3 . This means that the literature in this research field has paid less attention to real applications and 
Table 4: Literature reviewed per sector.

\begin{tabular}{|c|c|c|c|c|c|c|c|c|c|}
\hline Reference & TEC & COM & CT & FF & CHE & CON & SM & MO & GEN \\
\hline Alemany et al. 12] & & & $\mathrm{X}$ & & & & & & \\
\hline Alemany et al. 2$]$ & & & $\mathrm{X}$ & & & & & & \\
\hline Aouam and Brahımi 15] & & & & & & & & & $\mathrm{X}$ \\
\hline Arredondo and Martinez 16] & & & & & & & & & $\mathrm{X}$ \\
\hline Baker 17] & & & & & & & & & $\mathrm{X}$ \\
\hline Behdan1 et al. 18] & & & & & $\mathrm{X}$ & & & & \\
\hline Bui et al. 19] & & & & & & & & & $\mathrm{X}$ \\
\hline Chaharsooghi et al. 201 & & & & & & & & & $\mathrm{X}$ \\
\hline Chamodrakas et al. 21 & & & & & & & & & $\mathrm{X}$ \\
\hline Chen et al. 221 & & $\mathrm{X}$ & & & & & & & \\
\hline Chen et al. 23 & & $\mathrm{X}$ & & & & & & & \\
\hline Cheng and Cheng 24] & & & & & & & & & $\mathrm{X}$ \\
\hline Chiang and $\mathrm{Wu} 25$ & & & & & & & & & $\mathrm{x}$ \\
\hline Gharehgozli et al. 26] & & & & & & & & & $\mathrm{X}$ \\
\hline Halim and Muthusamy 27] & & & & & & & & & $\mathrm{X}$ \\
\hline Hemmati et al. 28] & & & & & & & & & $\mathrm{X}$ \\
\hline Herbots et al. 29 & & & & & & & & & $\mathrm{X}$ \\
\hline Herbots et al. 30 & & & & & & & & & $\mathrm{X}$ \\
\hline Hing et al. 31 & & & & & & & & & $\mathrm{X}$ \\
\hline Ishii et al. 32 & & & & & & $\mathrm{X}$ & & & \\
\hline Ivanescu et al. 33] & & & & & & & & & $\mathrm{X}$ \\
\hline Jung 34] & $\mathrm{X}$ & & & & & & & & \\
\hline Jung $\overline{35]}$ & $\mathrm{X}$ & & & & & & & & \\
\hline Kalantari et al. 36] & & & & & & & & & $\mathrm{X}$ \\
\hline Khataie et al. 37 & & & & & & & & & $\mathrm{X}$ \\
\hline Kilic et al. 38$]$ & & & & $\mathrm{X}$ & & & & & \\
\hline Kleywegt and Papastavrou 39] & $\mathrm{X}$ & & & & & & & & \\
\hline Lecic-Cvetkovic et al. 40] & & & & & & & & & $\mathrm{X}$ \\
\hline $\mathrm{Li}$ et al. 41$]$ & & & & & & & & & $\mathrm{X}$ \\
\hline Lin and Chang 42 & & & & & & & & & $\mathrm{X}$ \\
\hline Lin et al. 43] & $\mathrm{X}$ & & & & & & & & \\
\hline Liu et al. 44 & & & & & & & & $\mathrm{X}$ & \\
\hline Manavizadeh et al. 45] & & & & & & & & & $\mathrm{X}$ \\
\hline Martínez and Arredondo 46] & & & & & & & & & $\mathrm{X}$ \\
\hline Pibernik and Yadav 47] & & & & & & & & & $\mathrm{X}$ \\
\hline Portougal and Trietsch 48 & & & & & & & & & $\mathrm{X}$ \\
\hline Slotnick 49] & & & & & & & $\mathrm{X}$ & & \\
\hline Watanapa and Techanitisawad 50] & & & & & & & & & $\mathrm{X}$ \\
\hline Wullink et al. 51] & & & & & & & & & $\mathrm{X}$ \\
\hline Yang and Fung 52 & & & & & & & & & $\mathrm{X}$ \\
\hline Zhang and Tseng 53 & & & & & & & & & $\mathrm{X}$ \\
\hline Zhao et al. 54] & & $\mathrm{X}$ & & & & & & & \\
\hline Total & 4 & 3 & 2 & 1 & 1 & 1 & 1 & 1 & 28 \\
\hline$\%$ & 10 & 7 & 5 & 2 & 2 & 2 & 2 & 2 & 67 \\
\hline
\end{tabular}


has focused more on general case studies. Therefore, the analysis of this structural element indicates the need to develop mathematical programming models that support the OPP in LHP and/or uncertainty environments for more realistic supply chains.

\subsubsection{Supply chain physical scope}

This section characterises the scope of the literature in terms of the supply chain stages comprised by the reference. The four main supply chain stages were identified as follows:

- Supply (SUP)

- Manufacturing (MAN)
- Storage and Distribution (S\&D)

- Sales (SA)

The classification of the references among the four supply chain stages is offered on the left-hand side of Table 5. As there are references that include more than one supply chain stage, the percentages at the bottom of the table do not necessarily add up to $100 \%$. Thus in all the papers (100\%), the OPP included the manufacturing stage. Bui et al. [19], Jung 35], Khataie et al. [37, Kleywegt and Papastavrou 39], Lin et al. 43, and Lin et al. 55 consider the MAN-S\&D configuration; of these authors, Khataie et al. 37 also includes a SUP stage, thus its configuration is SUP-MAN-S\&D, with which $12 \%$ includes a storage and distribution stage. A all the papers, $7 \%$ include a sales stage $2,12,21$ with just the MAN-SA configuration. Finally, only two references (5\%), Ishii et al. [32] and Khataie et al. 37], include a supply stage, with the SUP-MAN and the SUP-MAN-S\&D configuration, respectively. Only one paper includes the supply and manufacturing combination, one mentions the supply-manufacturing-Storage \& Distribution combination, one considers Manufacturing-Storage \& Distribution-Sales, and one contemplates the Manufacturing-Sales combination. Finally, four papers combine Manufacturing-Storage \& Distribution.

The results show that the OPP mathematical models consider the manufacturing stage to be the central one, and there is a marked trend of including only one other, and preferably downstream of the manufacturing stage, nearer to customers. This aspect can be explained by the fact that model complexity grows when addressing more supply chain stages. At the same time, it shows the necessity of working in more integrated supply chain scenarios, which agrees with considering more real applications. 


\subsubsection{Manufacturing strategy}

The customer order decoupling point (CODP) defines the supply chain manufacturing strategy. Our study identified all the references with the CODP located in the production stage of the supply chain. Regarding the manufacturing strategy, three options were addressed based on the concepts of Alarcón et al. [10]:

- Make-to-order (MTO)

- Make-to-stock (MTS)

- Assembly-to-order (ATO)

The right-hand side of Table 5 shows the literature classification. Of all the references, $79 \%$ include an MTO strategy, while $21 \%$ had an MTS, which means that these two categories are the commonest; only $2 \%$ deals with ATO. One interesting case is the mixture of both MTO-MTS strategies, where a combination of a fraction of already promised orders and an estimation of the rest appear. Only Kalantari et al. [36] deal with this scenario, and only Zhao et al. [54 consider the ATO strategy. The rest of the papers contemplate either MTO or MTS strategies separately. The percentages do add up to $100 \%$ because only one reference conducted a hybrid study between the MTO and MTS strategies.

The predominance of the studies that dealt with the MTO strategy can also be interpreted as companies with LHP and/or high levels of uncertainty, which chose the MTO strategy as a means to reduce their negative effects on both customers and supply chains. Inherent LHP uncertainty makes known the real quantities of each subtype (homogeneous sublot) exactly in a lot, which is impossible until they are produced and classified. This can lead to a shortage situation in MTS environments because there are not enough homogeneous quantities to match real customer orders in terms of homogeneity requirements. In MTO contexts, production starts by a real customer order and it is possible to stop production when both quantity and homogeneity requirements are satisfied in the customer order. This strategy increases the customer service level and decreases the stock level of what remains of subtype.

\subsubsection{Findings}

From Table 5, we deduced that there was a variety of combinations when delimiting the physical scope of the supply chain to model the OPP: it ranged from those models that contemplated only one supply chain stage to those that even included three. Table 6 shows the percentages of the papers that dealt with the different physical scopes of supply chain. The majority of the literature focused on the manufacturing stage, which is normal considering that the OPP bases its operability mainly on planned production quantities and capacity production availability. However, the literature that has dealt with a more integrated supply chain approach, which is the current research stream, is evidenced. We also 
note from Table 5 that very little literature on LHP has dealt with manufacturing strategies like Assembly to Order, and others have not been found in the reviewed literature; e.g., Configure to Order or Build to Order [11]. They are still relatively under-researched because most papers have focused mainly on the Make to Order manufacturing configuration.

Table 5: Physical scope of the supply chain and the CODP location/Manufacturing strategyclassification.

\begin{tabular}{|c|c|c|c|c|c|c|c|}
\hline \multirow[t]{2}{*}{ Reference } & \multirow{2}{*}{$\begin{array}{l}\text { Supply } \\
\text { SUP }\end{array}$} & \multicolumn{2}{|c|}{ Chain Physical } & \multirow{2}{*}{$\frac{\text { Scope }}{\text { SA }}$} & \multicolumn{3}{|c|}{ Manufacturing Strategy } \\
\hline & & MAN & S\&D & & MTO & MTS & ATO \\
\hline Alemany et al. 12] & & $\mathrm{X}$ & & $\mathrm{X}$ & & $\mathrm{X}$ & \\
\hline Alemany et al. & & $\mathrm{X}$ & & $\mathrm{X}$ & & $\mathrm{X}$ & \\
\hline Aouam and Brahimi 15] & & $\mathrm{X}$ & & & $\mathrm{X}$ & & \\
\hline Arredondo and Martinez 16$]$ & & $\mathrm{X}$ & & & $\mathrm{X}$ & & \\
\hline Baker 17] & & $\mathrm{X}$ & & & $\mathrm{X}$ & & \\
\hline Behdanı et al. 18] & & $\mathrm{X}$ & & & $\mathrm{X}$ & & \\
\hline Bui et al. 19] & & $\mathrm{X}$ & $\mathrm{X}$ & & $\mathrm{X}$ & & \\
\hline Chaharsooghi et al. 201 & & $\mathrm{X}$ & & & $\mathrm{X}$ & & \\
\hline Chamodrakas et al. 21 & & $\mathrm{X}$ & & $\mathrm{X}$ & $\mathrm{X}$ & & \\
\hline Chen et al. 22] & & $\mathrm{X}$ & & & $\mathrm{X}$ & & \\
\hline Chen et al. & & $\mathrm{X}$ & & & $\mathrm{X}$ & & \\
\hline Cheng and Cheng 24] & & $\mathrm{X}$ & & & $\mathrm{X}$ & & \\
\hline Chiang and $\mathrm{Wu} 25$ & & $\mathrm{X}$ & & & $\mathrm{X}$ & & \\
\hline Gharehgozli et al. 26] & & $\mathrm{X}$ & & & $\mathrm{X}$ & & \\
\hline Halim and Muthusamy 27] & & $\mathrm{X}$ & & & $\mathrm{X}$ & & \\
\hline Hemmati et al. 28] & & $\mathrm{X}$ & & & $\mathrm{X}$ & & \\
\hline Herbots et al. 29 & & $\mathrm{X}$ & & & $\mathrm{X}$ & & \\
\hline Herbots et al. 30 & & $\mathrm{X}$ & & & $\mathrm{X}$ & & \\
\hline Hing et al. 31 & & $\mathrm{X}$ & & & $\mathrm{X}$ & & \\
\hline Ishii et al. 32 & $\mathrm{X}$ & $\mathrm{X}$ & & & $\mathrm{X}$ & & \\
\hline Ivanescu et al. 33 & & $\mathrm{X}$ & & & $\mathrm{X}$ & & \\
\hline Jung 34] & & $\mathrm{X}$ & & & $\mathrm{X}$ & & \\
\hline Jung 35 & & $\mathrm{X}$ & $\mathrm{X}$ & & & $\mathrm{X}$ & \\
\hline Kalantari et al. 36] & & $\mathrm{X}$ & & & $\mathrm{X}$ & $\mathrm{X}$ & \\
\hline Khataie et al. 37 & $\mathrm{X}$ & $\mathrm{X}$ & $\mathrm{X}$ & & & $\mathrm{X}$ & \\
\hline Kilic et al. 38 & & $\mathrm{X}$ & & & $\mathrm{X}$ & & \\
\hline Kleywegt and Papastavrou 39] & & $\mathrm{X}$ & $\mathrm{X}$ & & $\mathrm{X}$ & & \\
\hline Lecic-Cvetkovic et al. 40] & & $\mathrm{X}$ & & & & $\mathrm{X}$ & \\
\hline Li et al. 41] & & $\mathrm{X}$ & & & $\mathrm{X}$ & & \\
\hline Lin and Chang 42 & & $\mathrm{X}$ & & & $\mathrm{X}$ & & \\
\hline Lin et al. 43] & & $\mathrm{X}$ & $\mathrm{X}$ & & & $\mathrm{X}$ & \\
\hline Liu et al. 44 & & $\mathrm{X}$ & & & $\mathrm{X}$ & & \\
\hline Manavizadeh et al. 45] & & $\mathrm{X}$ & & & $\mathrm{X}$ & & \\
\hline Martínez and Arredondo 46] & & $\mathrm{X}$ & & & $\mathrm{X}$ & & \\
\hline Pibernik and Yadav 47] & & $\mathrm{X}$ & & & & $\mathrm{X}$ & \\
\hline Portougal and Trietsch 48] & & $\mathrm{X}$ & & & $\mathrm{X}$ & & \\
\hline Slotnick 49] & & $\mathrm{X}$ & & & $\mathrm{X}$ & & \\
\hline Watanapa and Techanitisawad 50] & & $\mathrm{X}$ & & & $\mathrm{X}$ & & \\
\hline Wullink et al. 51] & & $\mathrm{X}$ & & & $\mathrm{X}$ & & \\
\hline Yang and Fung 52 & & $\mathrm{X}$ & & & & $\mathrm{X}$ & \\
\hline Zhang and Tseng 53 & & $\mathrm{X}$ & & & $\mathrm{X}$ & & \\
\hline Zhao et al. 54 & & $\mathrm{X}$ & & & & & $\mathrm{X}$ \\
\hline Total & 2 & 42 & 5 & 3 & 33 & 9 & 1 \\
\hline$\%$ & 5 & 100 & 12 & 7 & 79 & 21 & 2 \\
\hline
\end{tabular}


Table 6: Supply chain configuration of the reviewed literature.

\begin{tabular}{lcc}
\hline SC Confguration & References & $\mathbf{\%}$ \\
\hline SUP-MAN & 1 & 2 \\
SUP-MAN-S\&D & 1 & 2 \\
MAN & 33 & 79 \\
MAN-S\&D & 4 & 10 \\
MAN-SA & 3 & 7 \\
\hline Total & $\mathbf{4 2}$ & 100 \\
\hline
\end{tabular}

\subsection{LHP/uncertainty modelling}

The main purpose of this section was to identify existing research on the OPP mathematical programming models that include some LHP characteristic under both deterministic or uncertainty conditions. Since LHP usually involves uncertainty, we extended our review to uncertainty OPP models to identify the main uncertainty variables modelled to support the OPP.

The first step was merely to separate papers according to which considered LHP or not, and which of them considered uncertainty or not. We obtained four possible combinations: LHP-deterministic, LHP-uncertainty, NON-LHP-deterministic and NON-LHP-uncertainty. There were no references for the NON-LHP-deterministic combination because it was beyond the scope of this research (see Table 7). Indeed the majority of existing models for the OPP can be developed for that combination. It is highlighted that the criteria to include/exclude papers in/from the LHP category were followed because they modelled some LHP characteristic, although they did not refer to them as LHP (for instance, different qualities of the same FG).

Table 7 shows the classification of the literature according to the four above combinations. The majority $(71.4 \%)$ of the reviewed references did not take into account LHP characteristics, but instead modelled some uncertainty source, and $16.7 \%$ of the references considered LHP in a deterministic way. Finally, the papers that modelled LHP under uncertainty represented the minority group, with just $11.9 \%$ of the reviewed references. From these results, we deduced that LHP is a very under-researched topic as regards the OPP, and that uncertainly is the aspect that has been considered the most.

\subsubsection{Modelling inherent LHP characteristics}

This section more specifically analyses the papers identified in Table 7 that dealt with LHP (LHP-deterministic and LHP-uncertainty). The inherent LHP characteristics modelled by each paper follow the classification provided in Section 2 (also see Table 8).

We found 12 papers that modelled some inherent LHP characteristic in a deterministic or uncertain manner. Table 8 offers the results of the literature classification, where the percentages correspond to the quantity of papers that belong to each 
Table 7: Classification based on LHP/uncertainty modelling.

\begin{tabular}{|c|c|c|c|}
\hline & Deterministic & Uncertainty & \\
\hline LHP & $\begin{array}{l}\text { Alemany et al. 12] } \\
\text { Alemany et al. } 16.7 \% \\
\text { Chen et al. 22] } \\
\text { Chen et al. 23] } \\
\text { Lin et al. } 43] \\
\text { Manavizadeh et al. } 45] \\
\text { Zhao et al. 54] }\end{array}$ & $\begin{array}{l}\text { Lecic-Cvetkovic et al. } 40] \\
\text { Pibernik and Yadav [47] } \\
\text { Watanapa and Techanitisawad 50] } \\
\text { Yang and Fung [52] } \\
\text { Zhang and Tseng [53] }\end{array}$ & $11.9 \%$ \\
\hline NON LHP & Beyond the scope & 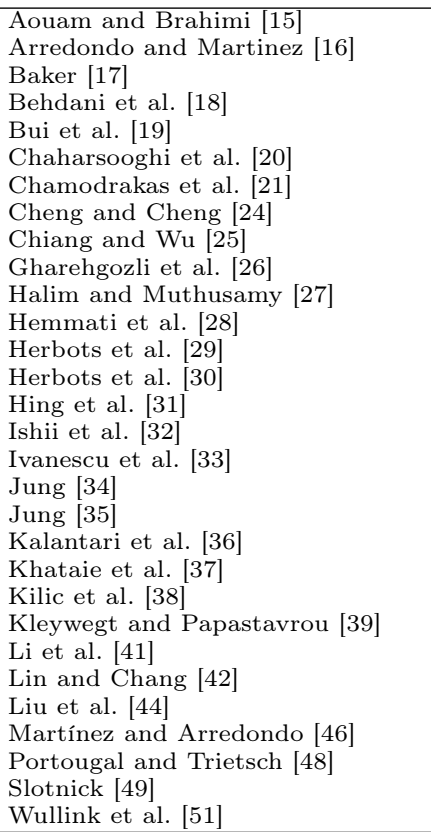 & $71.4 \%$ \\
\hline Total & $16.7 \%$ & 35 & $83.3 \%$ \\
\hline
\end{tabular}


quadrant, compared to the total depicted in Table 7 that is, Table 7 shows that seven references $(16.7 \%)$ were deterministic models and considered LHP, while Table 8 reveals that seven references were classified according to the modelled LHP characteristic and the supply chain stage where LHP was located. Likewise, the five references (11.9\%) depicted in Table 7 as models that actually considered LHP in an uncertainty environment are classified respectively in Table 8 . The percentages in Table 8 do not necessarily add up to $100 \%$ as there was the possibility that one same reference simultaneously modelled more than one LHP type, and did so in more than one supply chain stage (e.g. Manavizadeh et al. [45], under deterministic conditions).

Table 8: LHP modelled types.

\begin{tabular}{|c|c|c|c|c|c|c|c|}
\hline & & Supply (Sp) & & Process $(\mathrm{Pr})$ & & Demand $(\mathrm{Dm})$ & \\
\hline \multirow[t]{3}{*}{ Deterministic } & Sub types (ST) & 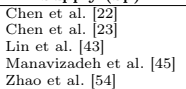 & $71 \%$ & $\begin{array}{l}\text { Lin et al. 43] } \\
\text { Manavizacen et al. 45] }\end{array}$ & $29 \%$ & $\begin{array}{l}\text { Alemany et al. 12] } \\
\text { Alemany et al. [2] } \\
\text { Lin et al. [43] } \\
\text { Manavizacein et al. } 45] \\
\text { Zhao et al. [54] }\end{array}$ & $71 \%$ \\
\hline & Subtype quantity (SQ) & $\begin{array}{l}\text { Chen et al. } \\
\text { Chen et al. } 25] \\
\text { Lin et al. [45] } \\
\text { Manavizacen et al. } 45] \\
\text { Zhao et al. } 541\end{array}$ & $71 \%$ & $\begin{array}{l}\text { Lin et al. [43] } \\
\text { Manavizacen et al. } 45]\end{array}$ & $29 \%$ & $\begin{array}{l}\text { Alemany et a1. } 12] \\
\text { Alemany et al. } 21 \\
\text { Lin et al. [43] } \\
\text { Manavizacen et al. } 45] \\
\text { Zhao et al. [54] }\end{array}$ & $71 \%$ \\
\hline & Subtype value (SV) & $\begin{array}{l}\text { Chen et al. } 24] \\
\text { Manavizaden et al. 45] }\end{array}$ & $29 \%$ & & & & \\
\hline \multirow[t]{3}{*}{ Uncertainty } & Sub types (ST) & $\begin{array}{l}\text { Yang and Fung } 521 \\
\text { Zhang and Tseng }\end{array}$ & $40 \%$ & Zhang and Tseng 53] & $20 \%$ & $\begin{array}{l}\text { Lecic-Cvetkovic et al, } 40] \\
\text { Pibernik and Yadav } 47 \\
\text { Watanapa and Techanitsawad } \\
\text { Yang and Fung [52] } \\
\text { Zhang and Tseng } 53]\end{array}$ & $100 \%$ \\
\hline & Subtype quantity (SQ) & $\begin{array}{l}\text { Yang and Fung } 52 \\
\text { Zhang and Tseng }\end{array}$ & $40 \%$ & Zhang and Tseng 53] & $20 \%$ & $\begin{array}{l}\text { Lecic-Cvetkovic ed at } \\
\text { Pibernik and Yadav } 44] \\
\text { Watanapa and Techanilsawad [50] } \\
\text { Yang and Fung [52] } \\
\text { Zhang and Tseng } \\
\text { [3] }\end{array}$ & $100 \%$ \\
\hline & Subtype value (SV) & Zhang and Tseng 53] & $20 \%$ & & & $\begin{array}{l}\text { Watanapa and Tecinanitisawad [50] } \\
\text { Zhang and Tseng [53] }\end{array}$ & $40 \%$ \\
\hline
\end{tabular}

In the deterministic context, supply and demand were the main stages that dealt with LHP, and subtypes (ST) and subtype quantity (SQ) were the most modelled LHP characteristics.

For the LHP-deterministic case, Alemany et al. [2, 12] propose models that considered the existence of subtypes in FG ATP quantities and allocation to incoming orders as a result of three different master production schedule (MPS) levels (lacking, adjusted and excess supply). Chen et al. 22, 23 explicitly consider LHP, but present characteristics in the production process, like raw material compatibility, which can generate subtypes of products in supply. Lin et al. [43] and Lin et al. 55 present a typical case in the technological sector where multiple types of FGs were assembled from common raw components; the different "grades", which are variations between components and specifications, can generate variations in FG consistency. Manavizadeh et al. [45] show a combined model to accept and sequence orders with a different price range according to the product subtype (quality level) for each specific customer type. Finally, Zhao et al. [54 present assemble-to-order models in the computer sector, where FGs were assembled from different subtypes of raw materials according to customer preferences.

For the LHP-uncertainty case, Lecic-Cvetkovic et al. [40] and Pibernik and Yadav 47] present models where ATP was divided hypothetically into subtypes defined 
by product quality. Then these product subtypes were used to fulfil specific orders according to customer type; the incoming order and demand patterns were considered random. Watanapa and Techanitisawad [50] develop a model for order acceptance based on the bidding context, where customers were classified into categories, and winning a bid was calculated as a probability function. Yang and Fung [52] model the order acceptance problem in MTS environments, where demand and supply were uncertain and customers were classified into categories according to the importance of their profit level. Zhang and Tseng [53] introduce customer flexibility as the ranges where the conditions of customer orders were accepted; these ranges were then modelled as customer preference functions to interpret the grade at which the variable value belonged to the range. One of these flexibility ranges was about "product specification", where customers could specify acceptable ranges in product attributes, like grades.

We conclude from Table 8 that no OPP models had dealt with the subtype state (SS) in either the deterministic or the uncertainty context. However, there were sectors (e.g. horticultural) where the perishability factor changes the value of the subtype attributes (e.g. freshness) with time. Assigning different values per subtype (e.g. qualities) (SV) is another under-researched area from both the deterministic and uncertain viewpoints. The most modelled LHP characteristics were ST and SQ for both the supply and demand stages, and in both deterministic and uncertain contexts.

\subsubsection{Uncertainty modelling}

As mentioned throughout, uncertainty is unavoidably present in LHP contexts. We were interested in studying sources of uncertainty modelled during the OPP. This aspect, and the very few works in the literature that have modelled LHP in the OPP, are the reasons why the third quadrant of Table 7, composed by OPP uncertainty models that did not model any LHP characteristic, are considered. The importance of these models lies in their utility to provide different methods to deal with uncertainty during the OPP in order to integrate them with LHP characteristics into future research works (as the LHP-uncertainty quadrant appears to be clearly lacking in research, as seen in Tables 9 and 10 . This section highlights the uncertainty considered in such models. Eight main aspects modelled under uncertainty are highlighted:

- Demand (DM)

- Processing time (PT)

- Customer priority (CP)

- Product selling price (PSP)
- Capacity consumed (CC)

- Earliness and tardiness (ET)

- Raw materials supply (RM)

- Transportation capacity (TC)

Table 9 provides the classification of the papers based on the above aspects and modelled under uncertainty. Aouam and Brahimi [15], Arredondo and Martinez 
[16], Chaharsooghi et al. [20], Hemmati et al. [28], Herbots et al. 29, 30], Hing et al. [31], Kleywegt and Papastavrou [39], and Martínez and Arredondo 46 mainly focus on modelling uncertainty in demand, which they do based on aspects like order frequency of arriving, order characteristics (price and lead time) and customer profile prioritisation. Chamodrakas et al. [21], Kalantari et al. [36], and Lin and Chang [42 work with specific models that include uncertainty in the customer type and priority definition, while Cheng and Cheng 24 and Khataie et al. 37 include it in the product selling price.

Table 9: Uncertainty modelling.

\begin{tabular}{|c|c|c|c|c|c|c|c|c|}
\hline \multirow[t]{2}{*}{ Reference } & \multicolumn{8}{|c|}{ Uncertainty modeling } \\
\hline & $\overline{D M}$ & PT & $\mathrm{CP}$ & PSP & $\mathrm{CC}$ & ET & RM & TC \\
\hline Aouam and Brahimi 15 & $\mathrm{X}$ & & & & & & & \\
\hline Arredondo and Martinez [16] & $\mathrm{X}$ & & & & & & & \\
\hline Baker 17] & & $\mathrm{X}$ & & & & & & \\
\hline Behdani et al. 18] & & $\mathrm{X}$ & & & & & & \\
\hline Bui et al. 19] & & & & & & & $\mathrm{X}$ & \\
\hline Chaharsooghı et al. 20] & $\mathrm{X}$ & & & & & & & \\
\hline Chamodrakas et al. 21 & & & $\mathrm{X}$ & & & & & \\
\hline Cheng and Cheng 24$]$ & & & & $\mathrm{X}$ & & & & \\
\hline Chiang and $\mathrm{Wu} 25$ & & & & & $\mathrm{X}$ & & & \\
\hline Gharehgozli et al. 26] & & & & & & & & \\
\hline Halim and Muthusamy 27] & & & & & & & $\mathrm{X}$ & \\
\hline Hemmati et al. 28] & $\mathrm{X}$ & & & & & & & \\
\hline Herbots et al. 29 & $\mathrm{X}$ & & & & & & & \\
\hline Herbots et al. 30$]$ & $\mathrm{X}$ & & & & & & & \\
\hline Hing et al. 31 & $\mathrm{X}$ & & & & & & & \\
\hline Ishii et al. 32 & $\mathrm{X}$ & & & & & & & \\
\hline Ivanescu et al. 33] & & $\mathrm{X}$ & & & & & & \\
\hline Jung 34] & & & & & & $\mathrm{x}$ & & \\
\hline Jung 35] & & & & & & & & $\mathrm{X}$ \\
\hline Kalantari et al. 36] & & & $\mathrm{X}$ & & & & & \\
\hline Khataie et al. 37$]$ & & & & $\mathrm{X}$ & & & & \\
\hline Kilic et al. 38$]$ & & $\mathrm{X}$ & & & & & & \\
\hline Kleywegt and Papastavrou 39] & $\mathrm{X}$ & & & & & & & \\
\hline Li et al. 41] & $\mathrm{X}$ & $\mathrm{X}$ & & & & & & \\
\hline Lin and Chang 42] & & & $\mathrm{X}$ & & & & & \\
\hline Liu et al. 44] & & & & & $\mathrm{X}$ & & & \\
\hline Martínez and Arredondo 46] & $\mathrm{X}$ & & & & & & & \\
\hline Portougal and Trietsch 48] & $\mathrm{x}$ & $\mathrm{X}$ & & & & $\mathrm{X}$ & & \\
\hline Slotnick 49] & & $\mathrm{X}$ & & & & & & \\
\hline Wullink et al. 51] & & $\mathrm{X}$ & & & & & & \\
\hline Total & 12 & 8 & 3 & 2 & 2 & 2 & 2 & 1 \\
\hline$\%$ & 40 & 26.7 & 10 & 6.7 & 6.7 & 6.7 & 6.7 & 3.3 \\
\hline
\end{tabular}

The second main group of papers in this quadrant focus on processing time and capacity consumed under uncertainty. Baker [17], Behdani et al. [18], Ivanescu et al. [33], Kilic et al. [38, Slotnick [49], and Wullink et al. [51] model uncertainty in the processing time, while Li et al. [41] and Portougal and Trietsch [48 also consider uncertainty in processing times, but add earliness, tardiness and demand arrivals as uncertain variables. Chiang and $\mathrm{Wu} 25$ and Liu et al. 44 use models whose uncertainty modelling is based on the installed capacity consumed. Jung 35] includes produced quantities and transportation capacity uncertainties. 
Table 10: Order lines and homogeneity requirements of reviewed references.

\begin{tabular}{|c|c|c|c|c|c|}
\hline \multirow[t]{2}{*}{ Reference } & \multicolumn{2}{|c|}{ Order Lines } & \multicolumn{3}{|c|}{ Homogeneity requirements } \\
\hline & SL & ML & AFG & AC & None \\
\hline Alemany et al. 12] & & $\mathrm{X}$ & $\mathrm{X}$ & & \\
\hline Alemany et al. 2 & & $\mathrm{X}$ & $\mathrm{X}$ & & \\
\hline Aouam and Brahimi 15 & $\mathrm{X}$ & & & & $\mathrm{X}$ \\
\hline Arredondo and Martinez 16$]$ & & $\mathrm{X}$ & & & $\mathrm{x}$ \\
\hline Baker 17] & $\mathrm{X}$ & & & & $\mathrm{X}$ \\
\hline Behdani et al. 18] & $\mathrm{X}$ & & & & $\mathrm{X}$ \\
\hline Bui et al. 19] & $\mathrm{X}$ & & & & $\mathrm{X}$ \\
\hline Chaharsooghi et al. 201 & $\mathrm{X}$ & & & & $\mathrm{X}$ \\
\hline Chamodrakas et al. 21 & $\mathrm{X}$ & & & & $\mathrm{X}$ \\
\hline Chen et al. 22] & $\mathrm{X}$ & & & & $\mathrm{X}$ \\
\hline Chen et al. 23 & $\mathrm{X}$ & & & $\mathrm{X}$ & \\
\hline Cheng and Cheng 24] & $\mathrm{X}$ & & & & $\mathrm{X}$ \\
\hline Chiang and $\mathrm{Wu} 25]$ & $\mathrm{X}$ & & & & $\mathrm{X}$ \\
\hline Gharehgozli et al. 26] & $\mathrm{X}$ & & & & $\mathrm{X}$ \\
\hline Halim and Muthusamy 27] & $\mathrm{X}$ & & & & $\mathrm{X}$ \\
\hline Hemmati et al. 28 & $\mathrm{X}$ & & & & $\mathrm{X}$ \\
\hline Herbots et al. 29 & $\mathrm{X}$ & & & & $\mathrm{X}$ \\
\hline Herbots et al. 30 & $\mathrm{X}$ & & & & $\mathrm{X}$ \\
\hline Hing et al. 31 & $\mathrm{X}$ & & & & $\mathrm{X}$ \\
\hline Ishii et al. 32 & $\mathrm{X}$ & & & & $\mathrm{X}$ \\
\hline Ivanescu et al. 33] & $\mathrm{X}$ & & & & $\mathrm{X}$ \\
\hline Jung 34] & & $\mathrm{X}$ & & & $\mathrm{X}$ \\
\hline Jung 35 & $\mathrm{X}$ & & & & $\mathrm{X}$ \\
\hline Kalantari et al. 36] & & $\mathrm{X}$ & & & $\mathrm{X}$ \\
\hline Khataie et al. 37 & $\mathrm{X}$ & & & & $\mathrm{X}$ \\
\hline Kilic et al. 38 & $\mathrm{X}$ & & & & $\mathrm{X}$ \\
\hline Kleywegt and Papastavrou 39] & $\mathrm{X}$ & & & & $\mathrm{X}$ \\
\hline Lecic-Cvetkovic et al. 40] & $\mathrm{X}$ & & & & $\mathrm{X}$ \\
\hline Li et al. 41] & $\mathrm{X}$ & & & & $\mathrm{X}$ \\
\hline Lin and Chang 42 & $\mathrm{X}$ & & & & $\mathrm{X}$ \\
\hline Lin et al. 43] & & $\mathrm{X}$ & $\mathrm{X}$ & & \\
\hline Liu et al. $\overline{44}$ & $\mathrm{X}$ & & & & $\mathrm{X}$ \\
\hline Manavizadeh et al. 45] & $\mathrm{X}$ & & & $\mathrm{X}$ & \\
\hline Martínez and Arredondo 46] & & $\mathrm{X}$ & & & $\mathrm{X}$ \\
\hline Pibernik and Yadav [4] & $\mathrm{X}$ & & & & $\mathrm{X}$ \\
\hline Portougal and Trietsch 48 & $\mathrm{X}$ & & & & $\mathrm{X}$ \\
\hline Slotnick 49] & $\mathrm{X}$ & & & & $\mathrm{X}$ \\
\hline Watanapa and Techanitisawad 50] & $\mathrm{X}$ & & & & $\mathrm{X}$ \\
\hline Wullink et al. 51 & & $\mathrm{X}$ & & & $\mathrm{X}$ \\
\hline Yang and Fung [52] & & $\mathrm{X}$ & & & $\mathrm{X}$ \\
\hline Zhang and Tseng 53 & $\mathrm{X}$ & & & & $\mathrm{X}$ \\
\hline Zhao et al. 54] & $\mathrm{X}$ & & $\mathrm{X}$ & & \\
\hline Total & 33 & 9 & 4 & $\mathbf{2}$ & 36 \\
\hline$\%$ & 78.6 & 21.4 & 9.5 & 4.8 & 85.7 \\
\hline
\end{tabular}


Finally, the uncertainty modelling of the remaining models include a variety of approaches. Gharehgozli et al. [26] evaluate uncertainty in relation to the ideal hypothetical performance of the order in profit terms by the fuzzy topsis method. Halim and Muthusamy 27] present a model with uncertainty in the supplied quantities of raw materials. Ishii et al. [32] propose a model for order acceptance in a bidding process, where demand becomes uncertain due to the engineer man hours needed to evaluate incoming orders. Jung [34] consider uncertainty in earliness, tardiness and lost sales penalty costs, represented as a linear function. Finally, Bui et al. [19 propose a model where uncertainty in raw materials availability can cause shortage and rejection of incoming orders and, thus, a renegotiation process is required.

\subsubsection{Findings}

From this section, we show that the research which deals with OPP modelling in the presence of either uncertainty or LHP is badly lacking. We identified 30 papers that consider uncertainty purely in their modelling, and only 12 papers contemplate LHP. We found only five papers when we overlapped both aspects. From these results, we proved our hypothesis which states that research work is lacking in the above three possibilities. Based on this finding, we stress the need for more research that overlaps OPP modelling, LHP characteristics and the uncertainty consideration (not just due to LHP inherent uncertainty, but because to other variables like demand, customer type and processing times).

\subsection{Customer orders}

The main intention of the OPP is to respond to the requests specified by customers in their orders as efficiently as possible for the supply chain. In LHP contexts, customer orders present other requirements apart from traditional ones, which have a great impact on the OPP.

\subsubsection{Order lines}

Order lines refer to the number of individual requests expressed by customers in their orders. Orders can be composed of one line (single product), known as a single line (SL), or can include multiple lines (ML) for the same or different products. The models that deal with ML orders are more complex to solve than SL ones because all their lines must be served to complete an order. LHP entails the additional difficulty of ensuring the homogeneity requirement (see Section 5.3.2.

Table 10 classifies the reviewed papers into these two groups. This produced a huge difference between SL and ML, which proves that research has focused on simpler models with SL orders. However, there are numerous real situations in which customer orders include ML. It is worth stressing that most ML references 
appear later than 2011, so it can be considered a relatively recent characteristic in the OPP with uncertainty.

\subsubsection{Homogeneity requirements}

As the LHP management problem arises from the homogeneity requirement imposed by customers, it is crucial to identify the customisable parameters of the order proposals that affect LHP. As in most companies, knowing the requested products, the unit measure per product (which may depend on the customer class: units, pallets or trucks), the quantity and the due date from the customer order is essential. However, LHP introduces a new customised aspect into order proposals: the homogeneity type required by the customer among ordered products. The customer may require uniformity among the components of a given product (AC), like pearls in a necklace, or between units of the same FG (AFG), like ceramic tiles. In both $\mathrm{AC}$ and $\mathrm{AFG}$, customers may, or may not, specify the value of the homogeneity attributes required (e.g., quality level or tone of tiles). Based on this new customised order characteristic, the literature was classified into three groups: AC, AFG and None (Table 10).

According to Table 10 , only two references (4.8\%) consider homogeneity among components and 9.5\% consider it in FGs. In cases like Alemany et al. [2, 12], as they are applications for the ceramic tile sector, homogeneity refers to quality, colour and calibre. In Lin et al. [43] and Lin et al. [55], the customer can customise the FG from the available components or options (grades) in the technological thinfilm transistor liquid crystal display (TFT-LCD) sector. In Zhao et al. [54], the Assembly to Order strategy allows customers to specify their preferred components in the computer sector; computers have to be assembled from the raw materials supplied by different suppliers with the same functionality. This means that $85.7 \%$ (36 of 42) of the papers do not consider any homogeneity requirement.

There are papers, like those by Watanapa and Techanitisawad [50] and Yang and Fung [52], which identify the group of papers that consider some LHP characteristics (see Table 7), but they do not appear in this list with any homogeneity requirement because, even when LHP is present, the customer order does not explicitly offer the possibility of specifying the specific product subtype requested. In these cases, the supply chain is responsible for serving orders with homogeneous products, even when the end customer does not specify it. 


\subsubsection{Flexibility in requirements}

When a customer order cannot be satisfied in accordance with one specified value or more for the customisable aspects of the order proposal, the company can propose alternative solutions, which should be negotiated with the customer. The possible solutions depend on the flexibility provided by customers to accomplish their requests.

Basically, there are two possibilities for the analysed literature; considering some flexibility in customer requirements or not considering it at all. Six different types of flexibility in requirements were identified from papers that considered some flexibility in requirements:

- Delay accepted (DA): in some cases, customers accept being served some time periods later for the specified due date. However to reflect customer dissatisfaction, it is usual to associate a penalty cost per period delayed.

- Range of dates available (RDA): there are customers who, instead of providing an exact due date, define a range or set of due dates within which the order can be delivered. Then providers are free to decide about which due date they deliver the product.

- Range of quantity accepted (RQA): customers can either specify an exact quantity to be delivered or define a range of quantity based on the initial one requested, or on a minimum and maximum quantity to be delivered. In this case, delivery occurs just once with the total quantity that the provider promises within the range.

- Renegotiation (RNG): when the initial requests of an order cannot be accomplished, it is necessary to offer alternative solutions to customers, which are not previously defined, in order to reach an agreement and to not lose orders.

- Range of price accepted (RPA): for this case, customers specify a range of price that they are willing to pay for the product. Then the provider can decide the best option to maximise its profit without risking customer satisfaction with the price set.

- Split orders (SO): in some situations, especially for high-volume orders, customers can accept partial deliveries on different due dates.

Table 11 shows the classification of the reviewed papers in accordance with the flexibility type in requirement types. As seen, $38 \%$ of the research works do not consider any flexibility requirement. In these models, the initial conditions must be respected and there is no possibility of violating them; if this happens, the order is rejected. However, $62 \%$ of the papers consider some flexibility in requirements. The delay accepted (DA) is the most widely used type of flexibility requirement (26.2\%), followed by split orders (SO) (19\%), range of dates available (RDA), range of quantity accepted (RQA) (14.3\%) and renegotiation (RNG) (14.3\%). Finally, 
the less modelled flexibility type is the range in price accepted (RPA), used in only $2.4 \%$ of cases, which is normal considering that customers are very sensitive to variations in price.

Table 11: Flexibility in requirements and other requirements of the reviewed references.

\begin{tabular}{|c|c|c|c|c|c|c|c|}
\hline \multirow[t]{2}{*}{ Reference } & \multicolumn{7}{|c|}{ Flexibility in requeriments } \\
\hline & DA & SO & RDA & RQA & RNG & RPA & None \\
\hline Alemany et al. 12$]$ & $\mathrm{X}$ & & & & & & \\
\hline Alemany et al. 2 & & & & & & & $\mathrm{X}$ \\
\hline Aouam and Brahimi 15] & & $\mathrm{X}$ & & & & & \\
\hline Arredondo and Martinez 16] & & & & & $\mathrm{X}$ & & \\
\hline Baker 17] & & & & & & & $\mathrm{X}$ \\
\hline Behdani et al. 18] & $\mathrm{X}$ & & $\mathrm{X}$ & & & & \\
\hline Bui et al. 19] & & & & & $\mathrm{X}$ & & \\
\hline Chaharsooghi et al. 20] & & & & & & & $\mathrm{X}$ \\
\hline Chamodrakas et al. 21 & & & & & & & $\mathrm{X}$ \\
\hline Chen et al. 22] & & & $\mathrm{X}$ & $\mathrm{X}$ & & & \\
\hline Chen et al. 23$]$ & & & & $\mathrm{X}$ & & & \\
\hline Cheng and Cheng 24] & & & $\mathrm{X}$ & $\mathrm{X}$ & & & \\
\hline Chiang and Wu 25 & & & & & & & $\mathrm{X}$ \\
\hline Gharehgozli et al. 26] & $\mathrm{X}$ & & & & & & \\
\hline Halim and Muthusamy 27] & & $\mathrm{X}$ & & & & & \\
\hline Hemmati et al. 28] & $\mathrm{X}$ & & & & & & \\
\hline Herbots et al. 29 & & & & & & & $\mathrm{X}$ \\
\hline Herbots et al. 30 & & & & & & & $\mathrm{X}$ \\
\hline Hing et al. 31 & & & & & & & $\mathrm{X}$ \\
\hline Ishii et al. $32 \mid$ & & & & & & & $\mathrm{X}$ \\
\hline Ivanescu et al. 33] & & & & & & & $\mathrm{X}$ \\
\hline Jung 34] & $\mathrm{X}$ & $\mathrm{X}$ & $\mathrm{X}$ & $\mathrm{X}$ & & & \\
\hline Jung 35] & $\mathrm{X}$ & & & & $\mathrm{X}$ & & \\
\hline Kalantari et al. 36] & $\mathrm{X}$ & & & & $\mathrm{X}$ & & \\
\hline Khataie et al. 37] & & $\mathrm{X}$ & & & & & \\
\hline Kilic et al. 38$]$ & & & & & & & $\mathrm{X}$ \\
\hline Kleywegt and Papastavrou 39] & & & & & & & $\mathrm{X}$ \\
\hline Lecic-Cvetkovic et al. 40] & $\mathrm{X}$ & $\mathrm{X}$ & & & & & \\
\hline Li et al. 41] & & & & & & & $\mathrm{X}$ \\
\hline Lin and Chang 42] & & & & $\mathrm{X}$ & & & \\
\hline Lin et al. 43 & & $\mathrm{X}$ & & & & & \\
\hline Liu et al. 44] & & & & & $\mathrm{X}$ & & \\
\hline Manavizadeh et al. 45] & $\mathrm{X}$ & & & & & & \\
\hline Martínez and Arredondo 46] & & & & & $\mathrm{X}$ & & \\
\hline Pibernik and Yadav 47] & & & & & & & $\mathrm{X}$ \\
\hline Portougal and Trietsch 48] & & & & & & & $\mathrm{X}$ \\
\hline Slotnick [4] & & & & & & & $\mathrm{X}$ \\
\hline Watanapa and Techanitisawad 50] & & & $\mathrm{X}$ & & & $\mathrm{X}$ & \\
\hline Wullink et al. 51] & $\mathrm{X}$ & & & & & & \\
\hline Yang and Fung 52$]$ & & $\mathrm{X}$ & & & & & \\
\hline Zhang and Tseng 53] & $\mathrm{X}$ & & $\mathrm{X}$ & $\mathrm{X}$ & & & \\
\hline Zhao et al. 54] & & $\mathrm{X}$ & & & & & \\
\hline Total & 11 & 8 & 6 & 6 & 6 & 1 & 16 \\
\hline$\%$ & 26.2 & 19.0 & 14.3 & 14.3 & 14.3 & 24.0 & 38.1 \\
\hline
\end{tabular}




\subsubsection{Findings}

The literature review revealed some interesting findings. Firstly, we observed that research into LHP in the OPP is badly lacking. The considered order characteristics also tended to be as simple as possible: only one order line without considering the homogeneity requirement. This offers an excellent opportunity in research to include more realistic characteristics of customer requests by taking into account homogeneity requirements, flexibility in requirements, customer orders integrated by multiple order lines, etc.

\subsection{Order promising}

During the OPP, a different set of activities was formed to allocate the existing availability levels to customer requests.

\subsubsection{Allocation rules}

Allocation rules refer to the different methodologies followed by the reviewed models to assign the uncommitted availability levels to the customer order proposal. In this case, we considered only the allocation rules that were explicitly modelled. There are some cases, for example, when minimising the inventory keeping cost, an indirect attempt was made to first serve those orders with the nearest due date at the same time. Such examples normally include the rules that have been implicitly contemplated in the objective function. In our case, we aimed to identify specific factors in either the objective function or the restriction equations where an allocation rule was explicitly modelled. Four different possibilities were identified:

- Pre-allocation by customer type (PCT): when different customer classes are defined in a company, it is possible to reserve certain quantities of the uncommitted availabilities to each customer class (allocation ATP). This preallocation is done to prevent a low-priority customer order from consuming an uncommitted product or capacity that will be needed later to serve another high-priority customer order. A customer hierarchy can be created by either considering profit-related variables, like sales or cost, or qualitative variables, like loyalty, potential and longevity.

- Allocation from the most adjusted subtype (AMAS): is a classification for those references that consider LHP and have several product subtypes. Then the rule consists in assigning the product to the incoming order from the most adjusted subtype group which is, for example: if the order requests 10 units, then the product must be taken from the subtype group nearest to 10 .

- First-In-First-Out (FIFO): is applied mainly to perishable products when an order must be fulfilled with the oldest available product (minor remaining shelf-life). 
- Pre-allocation by the nearest due date (PNDD): is applied when incoming orders are ranked based on their due date and the fulfilment process occurs in that order.

Table 12 shows how the literature is classified into the aforementioned categories, where we can see how the majority $(71.4 \%)$ of papers do not consider any explicit allocation rule. So these models simply assumed that the product was available and could be taken whenever needed for the fulfilment process with any type of predefined specific rule. The main allocation rule applied in the literature was preallocation by customer type (PCT), $19 \%$ of the references apply it, followed by the second, third and fourth, which were FIFO and PNDD with $4.8 \%$ each. Finally, AMAS obtained $2.4 \%$ and was the least used allocation rule. The percentages in Table 12 do not necessarily have to add up to $100 \%$ because Watanapa and Techanitisawad 50 combine the FIFO and PNDD rules.

\subsubsection{Execution mode}

The execution mode refers to the OPP being activated under these conditions:

- Single order processing (SOP): in this case, the OPP provides a response to each individual customer order proposal, usually in real time, and orders are promised in the arrival sequence.

- Batch order processing (BOP): the OPP process is executed at certain time intervals, known as a batching interval, which is considered to promise all the customer orders that arrive within the batching interval.

The results of this classification are provided in Table 12. Here we see that batch order processing is the most widely used execution mode as $78.6 \%$ of all the reviewed papers contemplate it. SOP obtains less than half the BOP references, with just 26.2\%. There are references like Alemany et al. [2] and Arredondo and Martinez 16 that consider the two execution modes.

\subsubsection{Availability levels}

Table 13 shows the classification results for the availability levels. The percentages in this table were calculated over the total number of reviewed papers, and the combination of more than one availability level category means that the percentages do not add up to $100 \%$. Here the majority of models belonged to the CTP classification (81\%), so the vast majority of studies apply an MTO manufacturing strategy. As $45 \%$ of the papers consider ATP and $21 \%$ correspond necessarily to the MTS strategy, only $24 \%$ of the others correspond to the MTO case. This means that only $24 \%$ of MTO cases combine the CTP and ATP availability levels. Finally, DTP only includes $2 \%$ of the references. This means that of the five papers in Table 5 that consider the distribution stage, only one deals with the limited capacity of distribution resources when promising orders to customers. 
Table 12: Allocation rules and the execution mode of the reviewed literature.

\begin{tabular}{|c|c|c|c|c|c|c|c|}
\hline \multirow[t]{2}{*}{ Reference } & \multicolumn{5}{|c|}{ Allocation rules } & \multicolumn{2}{|c|}{ Execution mode } \\
\hline & PCT & FIFO & PNDD & AMAS & None & BOP & SOP \\
\hline Alemany et al. 12] & & & & $\mathrm{X}$ & & $\mathrm{X}$ & $\mathrm{X}$ \\
\hline Alemany et al. 2 & & & $\mathrm{X}$ & & & $\mathrm{X}$ & \\
\hline Aouam and Brahımi 15] & $\mathrm{X}$ & & & & & $\mathrm{X}$ & \\
\hline Arredondo and Martinez 16] & & & & & $\mathrm{X}$ & $\mathrm{X}$ & $\mathrm{X}$ \\
\hline Baker 17] & & & & & $\mathrm{X}$ & $\mathrm{X}$ & \\
\hline Behdanı et al. 18] & & & & & $\mathrm{X}$ & $\mathrm{X}$ & \\
\hline Bui et al. 19] & & & & & $\mathrm{X}$ & $\mathrm{X}$ & \\
\hline Chaharsooghi et al. 20 & & & & & $\mathrm{X}$ & $\mathrm{x}$ & \\
\hline Chamodrakas et al. 21 & & & & & $\mathrm{X}$ & $\mathrm{X}$ & \\
\hline Chen et al. 22] & & & & & $\mathrm{X}$ & $\mathrm{X}$ & \\
\hline Chen et al. $\overline{23}$ & & & & & $\mathrm{X}$ & $\mathrm{x}$ & \\
\hline Cheng and Cheng 24] & & & & & $\mathrm{X}$ & $\mathrm{x}$ & \\
\hline Chiang and $\mathrm{Wu} 25]$ & $\mathrm{X}$ & & & & & $\mathrm{X}$ & \\
\hline Gharehgozli et al. 26] & $\mathrm{X}$ & & & & & $\mathrm{X}$ & \\
\hline Halim and Muthusamy 27] & & & & & $\mathrm{x}$ & $\mathrm{x}$ & \\
\hline Hemmati et al. 28] & & & & & $\mathrm{x}$ & $\mathrm{X}$ & \\
\hline Herbots et al. 29 & & & & & $\mathrm{X}$ & $\mathrm{X}$ & \\
\hline Herbots et al. 30 & & & & & $\mathrm{x}$ & $\mathrm{x}$ & \\
\hline Hing et al. 31 & & & & & $\mathrm{X}$ & $\mathrm{x}$ & \\
\hline Ishii et al. 32 & & & & & $\mathrm{X}$ & & $\mathrm{X}$ \\
\hline Ivanescu et al. 33 & & & & & $\mathrm{X}$ & $\mathrm{X}$ & \\
\hline Jung 34 & $\mathrm{X}$ & & & & & $\mathrm{X}$ & \\
\hline Jung 35 & & & & & $\mathrm{X}$ & $\mathrm{x}$ & \\
\hline Kalantari et al. 36] & $\mathrm{X}$ & & & & & $\mathrm{X}$ & \\
\hline Khataie et al. 3 & & & & & $\mathrm{X}$ & $\mathrm{X}$ & \\
\hline Kilic et al. 38$]$ & & $\mathrm{X}$ & & & & & $\mathrm{X}$ \\
\hline Kleywegt and Papastavrou 39] & & & & & $\mathrm{X}$ & & $\mathrm{X}$ \\
\hline Lecic-Cvetkovic et al. 40] & $\mathrm{X}$ & & & & & $\mathrm{X}$ & \\
\hline Li et al. 41] & & & & & $\mathrm{X}$ & & $\mathrm{X}$ \\
\hline Lin and Chang 42] & & & & & $\mathrm{X}$ & $\mathrm{X}$ & \\
\hline Lin et al. 43] & & & & & $\mathrm{X}$ & $\mathrm{X}$ & \\
\hline Liu et al. 44 & & & & & $\mathrm{X}$ & & $\mathrm{X}$ \\
\hline Manavizadeh et al. 45] & & & & & $\mathrm{X}$ & $\mathrm{X}$ & \\
\hline Martínez and Arredondo 46] & & & & & $\mathrm{X}$ & $\mathrm{X}$ & \\
\hline Pibernik and Yadav 47 & $\mathrm{X}$ & & & & & & $\mathrm{X}$ \\
\hline Portougal and Trietsch 48] & & & & & $\mathrm{X}$ & $\mathrm{x}$ & \\
\hline Slotnick 49] & & & & & $\mathrm{X}$ & $\mathrm{x}$ & \\
\hline Watanapa and Techanitisawad [50] & & $\mathrm{X}$ & $\mathrm{X}$ & & & & $\mathrm{X}$ \\
\hline Wullink et al. 51] & & & & & $\mathrm{X}$ & $\mathrm{X}$ & \\
\hline Yang and Fung 52$]$ & $\mathrm{X}$ & & & & & & $\mathrm{X}$ \\
\hline Zhang and Tseng [53] & & & & & $\mathrm{X}$ & & $\mathrm{X}$ \\
\hline Zhao et al. 54] & & & & & $\mathrm{X}$ & $\mathrm{X}$ & \\
\hline Total & 8 & 2 & 2 & 1 & 30 & 33 & 11 \\
\hline$\%$ & 19.0 & 4.8 & 4.8 & 2.4 & 71.4 & 78.6 & 26.2 \\
\hline
\end{tabular}


Table 13: Availability levels of the reviewed literature.

\begin{tabular}{|c|c|c|c|}
\hline \multirow[t]{2}{*}{ Reference } & \multicolumn{3}{|c|}{ Availability levels } \\
\hline & CTP & ATP & DTP \\
\hline Alemany et al. 12 & & $\mathrm{X}$ & \\
\hline Alemany et al. & & $\mathrm{X}$ & \\
\hline Aouam and Brahimi 15 & $\mathrm{X}$ & & \\
\hline Arredondo and Martinez 16 & $\mathrm{X}$ & & \\
\hline Baker 17 & $\mathrm{X}$ & & \\
\hline Behdanı et al. 18 & $\mathrm{X}$ & & \\
\hline Bui et al. 19 & $\mathrm{X}$ & $\mathrm{X}$ & \\
\hline Chaharsooghi et al. 20 & $\mathrm{X}$ & & \\
\hline Chamodrakas et al. 21 & $\mathrm{X}$ & & \\
\hline Chen et al. 22 & $\mathrm{X}$ & $\mathrm{X}$ & \\
\hline Chen et al. $\overline{23}$ & $\mathrm{X}$ & $\mathrm{X}$ & \\
\hline Cheng and Cheng 24 & $\mathrm{X}$ & $\mathrm{X}$ & \\
\hline Chiang and $\mathrm{Wu} 25$ & $\mathrm{X}$ & $\mathrm{X}$ & \\
\hline Gharehgozli et al. 26 & $\mathrm{X}$ & $\mathrm{X}$ & \\
\hline Halim and Muthusamy 27 & $\mathrm{X}$ & $\mathrm{X}$ & \\
\hline Hemmati et al. 28 & $\mathrm{X}$ & & \\
\hline Herbots et al. 29 & $\mathrm{X}$ & & \\
\hline Herbots et al. $\overline{30}$ & $\mathrm{X}$ & & \\
\hline Hing et al. 31 & $\mathrm{X}$ & & \\
\hline Ishii et al. 32 & $\mathrm{X}$ & & \\
\hline Ivanescu et al. 33 & $\mathrm{X}$ & & \\
\hline Jung 34 & $\mathrm{X}$ & $\mathrm{X}$ & \\
\hline Jung $\overline{35}$ & & $\mathrm{X}$ & $\mathrm{X}$ \\
\hline Kalantari et al. 36 & $\mathrm{X}$ & $\mathrm{X}$ & \\
\hline Khataie et al. 37 & $\mathrm{X}$ & $\mathrm{X}$ & \\
\hline Kilic et al. 38 & $\mathrm{X}$ & $\mathrm{X}$ & \\
\hline Kleywegt and Papastavrou 39 & $\mathrm{X}$ & & \\
\hline Lecic-Cvetkovic et al. 40 & & $\mathrm{X}$ & \\
\hline Li et al. 41 & $\mathrm{X}$ & & \\
\hline Lin and Chang 42 & $\mathrm{X}$ & & \\
\hline Lin et al. 43 & & $\mathrm{X}$ & \\
\hline Liu et al. $\overline{44}$ & $\mathrm{X}$ & & \\
\hline Manavizadeh et al. 45 & $\mathrm{X}$ & & \\
\hline Martínez and Arredondo 46 & $\mathrm{X}$ & & \\
\hline Pibernik and Yadav 47 & & $\mathrm{X}$ & \\
\hline Portougal and Trietsch 48 & $\mathrm{X}$ & & \\
\hline Slotnick 49 & $\mathrm{X}$ & & \\
\hline Watanapa and Techanitisawad 50 & $\mathrm{X}$ & & \\
\hline Wullink et al. 51 & $\mathrm{X}$ & & \\
\hline Yang and Fung 52 & & $\mathrm{X}$ & \\
\hline Zhang and Tseng 53 & $\mathrm{X}$ & & \\
\hline Zhao et al. 54 & & $\mathrm{X}$ & \\
\hline Total & 34 & 19 & 1 \\
\hline$\%$ & 81 & 45 & 2 \\
\hline
\end{tabular}




\subsubsection{Findings}

From the analysis of the order promising taxonomy category, we highlight that a relatively short research work was identified in the order promising explicit allocation rules, which helped make uncommitted availability assignation more efficient to achieve more tangible benefits specifically in our LHP research topic. This finding can address a future research area. Furthermore, the Capable to Promise (CTP) concept appears as the most widely used availability level technique as the majority of studies were MTO manufacturing strategy cases. Available to Promise (ATP) was the second group of papers, which were also related to the MTS manufacturing strategy. Delivery to Promise (DTP) was the least researched area in the reviewed literature. The DTP consideration needs further research if the OPP for more realistic supply chains is to be investigated. Finally, it might be useful to place more emphasis on developing models that consider both batching order promising and single order promising since more realistic process conditions are normally a combination of both.

\subsection{Model characteristics}

This section analyses the mathematical models in the reviewed literature by the model purpose, the modelling approach and the validation method as a basis to compare them and summarise their differences. In general terms, we sought to answer the following questions:

- What is the model objective or purpose? We intended to describe the general purpose of the model in terms of what was maximised or minimised in the objective function. The main objective (s) of each model was/were identified.

- What is the modelling approach? The modelling approach refers to the mathematical modelling techniques that have been applied to the modelled problems; for example, linear programming, and mixed integer linear programing, among others. Here we aimed to specify the modelling approach applied in each reviewed work.

- What kind of data or scenarios are used to validate the model? We intended to specify if the developed model was validated by practical experiments and executions by using data from a real supply chain (Real case) or generated dummy data (Case study). 


\subsubsection{Purpose}

Mula et al. 13 propose the analysis as the purpose of the literature based on quantitative aspects related to costs, customer service and inventories. We based our classification on these aspects, but we also focused on the cost and customer service parameters. The above authors use several categories, but we chose the following for our study; minimisation of costs (MC), maximisation of profits (MP), maximisation of service levels (MSL). Another important OPP objective is due date achievement (DDA), which includes those models that aim to minimise the ratio between the promised due date and delivery due date. We also included an "Other" category, where we identified and described some other approaches that the literature can consider.

Table 14 provides the classification results. As expected, maximisation of profits (MP) was the commonest objective function in the literature as more than half $(57 \%)$ the papers considered this parameter as their objective function. This objective makes sense when supply does not suffice to comply with all customer orders and a selection among the most profitable ones must be made. Minimisation of cost (MC) was the second model purpose identified (26\%) after considering factors like inventory holding cost, delay in delivery cost, production cost, human resource cost and ordering cost. The groups of due date achievement and service level maximisation represented just $7 \%$ and $5 \%$ of all the papers, respectively. Finally, we identified seven references with additional modelling approaches. Alemany et al. 2] aims to maximise profits (MP), and simultaneously the number of exhausting ATPs. The intention of this last objective was to reduce the very low levels of subtypes stocks that cannot be used to serve a complete order. Chamodrakas et al. 21 assign a priority level to customers, that is used for sequencing the incoming orders. Ivanescu et al. [33] base their objective on calculating the makespan of a set of jobs so that a new order arrives and is evaluated with previous promised orders. Then if the new order makes the makespan go up to reach the period time length, the order is rejected, otherwise it is accepted. Khataie et al. [37] aim to minimise residual capacity besides MP, while Lin and Chang [42 minimise the total quantity of the product generated on the production line in the MIP model. Finally, Liu et al. [44 use maximisation of capacity resource usage, and Manavizadeh et al. 45 maximise work overload and minimise cost with the sequencing model.

\subsubsection{Validation method}

Table 3 shows how the majority of the papers are case studies. In these sections, we describe which are case studies or real applications one by one. Table 14 presents the classification results. Of all the papers, $74 \%$ use dummy data in practical experiments to validate the developed model. This fact implies that even when the reviewed literature considers some of our required characteristics (LHP and/or uncertainty), they are not applied enough to real cases to prove the 
Table 14: Purpose of the model and validation method.

\begin{tabular}{|c|c|c|c|c|c|c|c|}
\hline \multirow[t]{2}{*}{ Reference } & \multicolumn{5}{|c|}{ Model Characteristics - Purpose } & \multicolumn{2}{|c|}{ Validation Method } \\
\hline & MP & MC & DDA & MSL & Other & & \\
\hline Alemany et al. 12] & $\mathrm{X}$ & & & & $\mathrm{X}$ & & $\mathrm{X}$ \\
\hline Alemany et al. 21 & $\mathrm{x}$ & & $\mathrm{x}$ & & & & $\mathrm{x}$ \\
\hline Aouam and Brahimi 15] & & $\mathrm{x}$ & & & & $\mathrm{x}$ & \\
\hline Arredondo and Martinez 16] & $\mathrm{x}$ & & & & & $\mathrm{x}$ & \\
\hline Baker 17] & & & $\mathrm{X}$ & & & $\mathrm{x}$ & \\
\hline Behdani et al. 18] & & $\mathrm{x}$ & & & & $\mathrm{x}$ & \\
\hline Bui et al. 19] & $\mathrm{x}$ & & & & & $\mathrm{x}$ & \\
\hline Chaharsooghi et al. 200 & $\mathrm{x}$ & & & & & $\mathrm{x}$ & \\
\hline Chamodrakas et al. 21$]$ & & & & & $\mathrm{x}$ & $\mathrm{x}$ & \\
\hline Chen et al. 22] & $\mathrm{x}$ & & & & & & $\mathrm{x}$ \\
\hline Chen et al. $\overrightarrow{23}$ & $\mathrm{X}$ & & & & & & $\mathrm{x}$ \\
\hline Cheng and Cheng 24] & $\mathrm{x}$ & & & & & $\mathrm{x}$ & \\
\hline Chiang and Wu 25$]$ & $\mathrm{x}$ & & & & & $\mathrm{x}$ & \\
\hline Gharehgozli et al. 26] & $\mathrm{x}$ & & & & & $\mathrm{x}$ & \\
\hline Halim and Muthusamy 27] & & $\mathrm{x}$ & & & & $\mathrm{x}$ & \\
\hline Hemmati et al. 28] & $\mathrm{X}$ & & & & & $\mathrm{x}$ & \\
\hline Herbots et al. $29 \overline{1}$ & $\mathrm{x}$ & & & & & $\mathrm{x}$ & \\
\hline Herbots et al. 30 & $\mathrm{x}$ & & & & & $\mathrm{x}$ & \\
\hline Hing et al. 31 & $\mathrm{x}$ & & & & & $\mathrm{x}$ & \\
\hline Ishii et al. $\overline{32]}$ & $\mathrm{x}$ & & & & & $\mathrm{x}$ & \\
\hline Ivanescu et al. 33] & & & & & $\mathrm{x}$ & $\mathrm{x}$ & \\
\hline Jung 34] & & $\mathrm{x}$ & & & & & $\mathrm{x}$ \\
\hline Jung 35 & & $\mathrm{x}$ & & & & & $\mathrm{x}$ \\
\hline Kalantarl et al. 36] & & $\mathrm{x}$ & & & & $\mathrm{x}$ & \\
\hline Khataie et al. 37$]$ & $\mathrm{x}$ & & & & $\mathrm{x}$ & $\mathrm{x}$ & \\
\hline Kilic et al. 38$]$ & $\mathrm{X}$ & & & & & $\mathrm{x}$ & \\
\hline Kleywegt and Papastavrou 39] & $\mathrm{X}$ & & & & & & $\mathrm{x}$ \\
\hline Lecic-Cvetkovic et al. [0] & & & & $\mathrm{x}$ & & $\mathrm{x}$ & \\
\hline Li et al. 41] & & $\mathrm{x}$ & & & & $\mathrm{x}$ & \\
\hline Lin and Chang 42] & & & & & $\mathrm{x}$ & $\mathrm{x}$ & \\
\hline Lin et al. 43$]$ & $\mathrm{X}$ & & & & & & $\mathrm{x}$ \\
\hline Liu et al. & & & & & $\mathrm{x}$ & & $\mathrm{x}$ \\
\hline Manavizadeh et al. 45] & & $\mathrm{x}$ & & & $\mathrm{x}$ & $\mathrm{x}$ & \\
\hline Martínez and Arredondo 46] & $\mathrm{x}$ & & & & & $\mathrm{x}$ & \\
\hline Pibernik and Yadav 47$]$ & & & & $\mathrm{x}$ & & $\mathrm{x}$ & \\
\hline Portougal and Trietsch 48] & & $\mathrm{x}$ & & & & $\mathrm{x}$ & \\
\hline Slotnick 49] & $\mathrm{x}$ & & & & & & $\mathrm{x}$ \\
\hline Watanapa and Techanitisawad 50] & $\mathrm{x}$ & & & & & $\mathrm{x}$ & \\
\hline Wullink et al. 51$]$ & & $\mathrm{x}$ & & & & $\mathrm{x}$ & \\
\hline Yang and Fung 52 & $\mathrm{x}$ & & & & & $\mathrm{x}$ & \\
\hline Zhang and Tseng 53] & $\mathrm{x}$ & & & & & $\mathrm{x}$ & \\
\hline Zhao et al. 54] & & $\mathrm{x}$ & $\mathrm{X}$ & & & & $\mathrm{X}$ \\
\hline Total & 24 & 11 & 3 & 2 & 7 & 31 & 11 \\
\hline$\%$ & 57 & 26 & 7 & $\mathbf{5}$ & 17 & 74 & 26 \\
\hline
\end{tabular}


real benefits that correct LHP and uncertainty handling during the OPP can offer supply chain management. Hence $26 \%$ of the real applications are mainly works from the technological and computer sectors Chen et al. [22, 23], Jung [34, 35], Kleywegt and Papastavrou [39], Lin et al. [43], Zhao et al. [54], and Lin et al. [55], while Alemany et al. 2, 12, work in the ceramic tile sector, Liu et al. [44] study the mould sector, and Slotnick 49] investigate the steel industry. This result generally reveals the need to conduct more research with real applications in sectors that are strongly affected by LHP, like horticultural, products for human consumption and perishables, given the critical importance of product status with passing of time.

\subsubsection{Modelling approach}

In order to classify the literature according to the modelling approach, we identified the following possibilities based on Mula et al. [13]:

- Linear programming (LP)

- Mixed integer linear programming (ILP)

- Non-linear programming (NLP)

- Mixed integer nonlinear programming (INLP)

- Multi-objective integer linear programming (MOILP)
- Fuzzy mathematical programming (FMP)

- Stochastic/probabilistic programming (SP)

- Heuristics and metaheuristics (HEU)

- Hybrid models (HYB)

We also included the following possibilities based on the reviewed papers:

- Simulation (SIM)

- Markov Decision Problem (MDP)
- Artificial Neural Network (ANN)

- Dynamic programming (DP)

Table 15 shows the classification results. One interesting finding was that the majority of the references were hybrid models HYB, which means that more than one of the aforementioned approaches was combined. In Table 15, all the hybrid cases indicated the specific combinations contemplated after considering each separate approach, even if they formed part of a hybrid model, and stochastic programming (SP) was the main approach used as $33 \%$ of the papers considered it. This was followed by mixed integer linear programming (ILP; 26\%), simulation (SIM; 19\%), heuristics and metaheuristics (HEU; 17\%), and fuzzy mathematical programming (FMP; 17\%). One interesting aspect about simulation is that all the models in which it appears were hybrid, which might prove that simulation is more widely used as a support tool to other approaches other than the main model approach. Markov Decision Problem, dynamic programming, non-linear programming and 
multiobjective integer linear programming oscillated between $12 \%$ and $5 \%$. At the bottom of the group, we find the least used approaches: pure linear programming (LP), mixed integer non-linear programming (INLP), and artificial neural network (ANN).

Table 15: Modelling approach.

\begin{tabular}{|c|c|c|c|c|c|c|c|c|c|c|c|c|c|}
\hline \multirow[t]{2}{*}{ Reference } & \multicolumn{13}{|c|}{ Model Characteristics - Modelling approach } \\
\hline & HYB & SP & ILP & SIM & HEU & FMP & MDP & DP & NLP & MOLIP & LP & INLP & ANN \\
\hline Alemany et al. 12 & & & & & & & & & & $\mathrm{X}$ & & & \\
\hline Alemany et al. & & & & & & & & & & $\mathrm{x}$ & & & \\
\hline Aouam and Branımi 15] & $\mathrm{x}$ & $\mathrm{x}$ & & & & & & & $\mathrm{x}$ & & & & \\
\hline Arredondo and Martinez 16] & $\mathrm{x}$ & & & $\mathrm{x}$ & & & $\mathrm{x}$ & & & & & & \\
\hline Baker 17] & $\mathrm{x}$ & $\mathrm{x}$ & & & & & & & & & & $\mathrm{x}$ & \\
\hline Behdani et al. 18] & & & & $\mathrm{x}$ & & & & & & & & & \\
\hline Bui et al. 19] & & & $\mathrm{x}$ & & & & & & & & & & \\
\hline Chaharsoogh1 et al. 20] & $\mathrm{x}$ & $\mathrm{x}$ & $\mathrm{x}$ & & & & & & & & & & \\
\hline Chamodrakas et al. 21] & & & & & & $\mathrm{x}$ & & & & & & & \\
\hline Chen et al. 22 & & & $\mathrm{x}$ & & & & & & & & & & \\
\hline Chen et al. $\overline{231}$ & & & $\mathrm{x}$ & & & & & & & & & & \\
\hline Cheng and Cheng 24] & $\mathrm{X}$ & & & & $\mathrm{x}$ & $\mathrm{x}$ & & & & & & & \\
\hline Chiang and $\mathrm{Wu} 25$ & & & & & & & $\mathrm{x}$ & & & & & & \\
\hline Gharehgozli et al. 26] & $\mathrm{x}$ & & & & & & & & & & & & \\
\hline Halim and Muthusamy 27] & & & & & & $\mathrm{x}$ & & & & & & & \\
\hline Hemmati et al. 28] & & $\mathrm{x}$ & & & $\mathrm{x}$ & & & & & & & & \\
\hline Herbots et al. 29 & & $\mathrm{x}$ & & & & & & & & & & & \\
\hline Herbots et al. $\overline{30}$ & $\mathrm{x}$ & $\mathrm{x}$ & & $\mathrm{x}$ & & & & $\mathrm{x}$ & & & & & \\
\hline Hing et al. 31 & $\mathrm{x}$ & & & & $\mathrm{x}$ & & $\mathrm{x}$ & & & & & & $\mathrm{x}$ \\
\hline Ishii et al. 32] & $\mathrm{x}$ & & & $\mathrm{x}$ & & & & & $\mathrm{x}$ & & & & \\
\hline Ivanescu et al. 33] & $\mathrm{x}$ & $\mathrm{x}$ & & $\mathrm{x}$ & & & & & & & & & \\
\hline \begin{tabular}{l|l|} 
Jung & 34 \\
Jung & 35 \\
\end{tabular} & & & & & & & & & & & $\mathrm{x}$ & & \\
\hline Jung 35] & & & & & & $\mathrm{x}$ & & & & & & & \\
\hline $\begin{array}{l}\text { Kalantarl et al. } 36] \\
\text { Khataie et al. } 37\end{array}$ & $\mathrm{x}$ & & $\mathrm{x}$ & & & $\mathrm{x}$ & & & & & & & \\
\hline $\begin{array}{l}\text { Khataie et al. } \\
\text { Kilic et al. } 38\end{array}$ & & & & & & & & & & $\mathrm{x}$ & & & \\
\hline Kilic et al. 38$]$ & & & & & & & & & $\mathrm{x}$ & & & & \\
\hline Kleywegt and Papastavrou 39] & & & & & & & $\mathrm{x}$ & & & & & & \\
\hline Lecic-Cvetkovic et al. 40] & & & & & & & & & & & $\mathrm{x}$ & & \\
\hline Li et al. 41] & & & & & & $\mathrm{x}$ & & & & & & & \\
\hline Lin and Chang 42] & $\mathrm{x}$ & & $\mathrm{x}$ & & & $\mathrm{x}$ & & & & & & & \\
\hline Lin et al. 43] & & & $\mathrm{x}$ & & & & & & & & & & \\
\hline Liu et al. $\overline{44]}$ & & $\mathrm{x}$ & & & & & & & & & & & \\
\hline Manavizadeh et al. 45] & $\mathrm{x}$ & & $\mathrm{x}$ & & $\mathrm{x}$ & & & & & & & & \\
\hline Martínez and Arredondo 46] & $\mathrm{x}$ & $\mathrm{x}$ & & $\mathrm{x}$ & & & & $\mathrm{x}$ & & & & & \\
\hline Pibernik and Yadav 47] & & & & $\mathrm{x}$ & & & & & & & & & \\
\hline Portougal and Trietsch 48] & & $\mathrm{X}$ & & & & & & & & & & & \\
\hline Slotnick 49] & $\mathrm{x}$ & $\mathrm{x}$ & & & & & $\mathrm{x}$ & $\mathrm{x}$ & & & & & \\
\hline Watanapa and Techanitisawad 50] & $\mathrm{x}$ & $\mathrm{x}$ & & & $\mathrm{x}$ & & & & & & & & \\
\hline Wullink et al. $51 \mid$ & $\mathrm{x}$ & $\mathrm{X}$ & $\mathrm{x}$ & & $\mathrm{x}$ & & & & & & & & \\
\hline Yang and Fung [52] & $\mathrm{x}$ & $\mathrm{x}$ & & $\mathrm{x}$ & $\mathrm{X}$ & & & $\mathrm{x}$ & & & & & \\
\hline Zhang and Tseng 53] & & & $\mathrm{x}$ & & & & & & & & & & \\
\hline Zhao et al. 54] & & & $\mathrm{x}$ & & & & & & & & & & \\
\hline Total & 18 & 14 & 11 & 8 & 7 & 7 & 5 & 4 & 3 & 3 & 2 & 1 & 1 \\
\hline$\%$ & 43 & 33 & 26 & 19 & 17 & 17 & 12 & 10 & 7 & 7 & 5 & 2 & 2 \\
\hline
\end{tabular}

\subsubsection{Novelty}

Tables 16, 17 and 18 briefly describe the main novelty contributed by all the reviewed references. 
Table 16: Novelty Part I.

\begin{tabular}{|c|c|}
\hline Reference & Novelty \\
\hline $\begin{array}{l}\text { Alemany et } \\
\text { al. 12] }\end{array}$ & $\begin{array}{l}\text { It considers LHP and allocation rules to ATP handling. The problem involves the production } \\
\text { stage. The model can clarify specifically from which production line the product is taken to reach } \\
\text { a customer order. The allocation rule consists in taking the product to fulfil each order from the } \\
\text { most adjusted subtype in the quantity at the time of being allocated. The applied rule obtains } \\
\text { better results than the traditional way of just maximising profits or minimising costs. }\end{array}$ \\
\hline $\begin{array}{l}\text { Alemany et } \\
\text { al. 2] }\end{array}$ & $\begin{array}{l}\text { It studies reallocations in the OPP of a ceramic tile industry affected by LHP. This model shows } \\
\text { a novel way to oblige all the lines in one same order to be fulfilled by a product of the same } \\
\text { homogeneous sublot. }\end{array}$ \\
\hline $\begin{array}{l}\text { Aouam and } \\
\text { Brahimi }[15]\end{array}$ & $\begin{array}{l}\text { It incorporates the integration of: (i) production planning and order acceptance decisions; (ii) a } \\
\text { robust optimisation approach to model demand uncertainty; (iii) two production modes based on } \\
\text { capacity utilisation, which reflect the effects of saturation; (iv) multiple customer classes. The } \\
\text { proposed model provides the planner with sufficient flexibility to decide between highly profitable, } \\
\text { yet risky, orders or less profitable ones, but possibly more stable orders. There is uncertainty in } \\
\text { production planning and a penalty is applied if an order fails (shortage). }\end{array}$ \\
\hline $\begin{array}{l}\text { Arredondo } \\
\text { and Mar- } \\
\text { tinez } 16]\end{array}$ & $\begin{array}{l}\text { It considers uncertainty in demand and capacity. The model is able to learn about the behaviour } \\
\text { of orders in a mixture of product, price, size and due date by using locally weighed regression and } \\
\text { the so-called reinforced learning RL. Accordingly, it can decide to accept or reject the incoming } \\
\text { order. }\end{array}$ \\
\hline Baker 17] & $\begin{array}{l}\text { t examines a basic stochastic sequencing model with due dates as a decision in a single machine } \\
\text { cenario to make due dates as tight as possible, while meeting service level constraints. It is solved } \\
\text { py a branch and bound and heuristics method. No orders can be rejected, and they must all } \\
\text { pe scheduled. The model considers that processing times are an uncertain variable and achieves }\end{array}$ \\
\hline
\end{tabular}

Behdani et It shows the main characteristics of the negotiation process and applies them to order acceptance. al. 18] The modelling process consists in the following steps: an order is sent to the enterprise from the customer. This order is accepted to be delivered within a time range. Then the global sales department asks the productions plants for the nearest response time to the order. The order is then accepted for the nearest plant that can deliver the product. The rejected orders enter the negotiation process to await a new due date or delivered quantity.

Bui et al. It considers the ATP and CTP functions as part of the OPP in a MILP model that can consider 19] negotiation with the customer, whose order is in danger of being denied. The model considers different groups of orders according to their level of commitment. In the model, an order can be rejected because of unavailability of raw components.

Chaharsooghi It considers the role of flexibility in the dynamic choosing of the price, lead time and segmentation et al. 20] of customers in Make to Order environments, with a limited production capacity and a multiperiod horizon with a stochastic demand function. The model contemplates a single machine resource that can be considered the system bottleneck. Orders are classified into categories according to their price and lead time characteristics.

Chamodrakas It deals with the issue of uncertainty in the customer type by employing the method proposed by et al. 21] Yong (2006), Fuzzy TOPSIS, which permits the evaluation of a set of qualitative and quantitative attributes of a variable. In this case, customer type is uncertain, and they all are ranked according to a fuzzy TOPSIS application over a set of possible alternatives. Then orders are sequenced based on the assigned customer importance.

Chen et al. The model uses ATP to provide individual order delivery dates for a group of customer orders 22] that arrives within a predefined batching interval. It takes into account realistic supply chain constraints, such as material compatibility, substitution preferences, capacity utilisation and material reserve. A flexible range for the due date and quantity to be promised is considered.

Chen et al. It introduces an interesting point of view of the distinct types of raw materials with the same 23] functionality, but cannot be mixed in the same FG. In fact the model considers the possibility of customers selecting their preferred raw materials, even when some have the same utility, functionality, but differences in quality and price.

Cheng and It integrates biding decisions into the OPP with Available to Promise (ATP), Capable to Promise

Cheng 24] (CTP) and Profitable to Promise (PTP) considerations, and production planning to enhance supplier profitability and service level. A buyer opens a bid with a job to be achieved for only one supplier. Suppliers must then consider a group of biddings in which they participate and must follow the ATP allocation process to decide which orders can be handled. Fuzzy constraints interpret the bid price perceived by suppliers for the customer order.

Chiang and It presents a model into which ATP functions and customer type, plus uncertain capacity conWu 25] sumption and random demand, are all integrated. Modelling is based on Markov chains, while the admission policy depends on the remaining capacity and the generated revenue. Orders enter a batching interval with a probability distribution. The so-called optimal reward-threshold policy is presented as the main contribution of this paper.

Gharehgozli It proposes a hybrid method between the analytic hierarchy process and fuzzy TOPSIS to solve et al. 26] the OPP problem by considering uncertainty in the selection criteria. At the beginning, incoming orders are evaluated according to their due date and the expected arrival time of the material required. Accordingly, pre-accepted orders are placed in a pool of orders, which are then evaluated by the Analytic Hierarchy Process (AHP) - TOPSIS method.

Halim and The main objective is to integrate uncertainty into supply into the production process considered to Muthusamy promise incoming orders. The authors present a fuzzy linear programming approach to interpret 27] uncertainty in supply. Fuzzy equations are translated into their equivalent crisp by using the possibility-necessity measure. 
Table 17: Novelty Part II.

\begin{tabular}{|c|c|}
\hline Reference & Novelty \\
\hline $\begin{array}{l}\text { Hemmati et } \\
\text { al. 28] }\end{array}$ & $\begin{array}{l}\text { Incoming orders are prioritised and then evaluated according to their capacity consume and due } \\
\text { dates. The model uses the TOPIS method to prioritise incoming orders. Then orders are evaluated } \\
\text { by the rough-cut capacity method to make the first selection. From this step, high- and low-priority } \\
\text { orders are accepted or rejected based on total available capacity. In the third step, an assessment } \\
\text { according to the due date and arrival material time is made to set the final feasible due date. }\end{array}$ \\
\hline $\begin{array}{l}\text { Herbots } \\
\text { et al. [29] }\end{array}$ & $\begin{array}{l}\text { It allows to aggregate regular and non-regular capacity in the presence of uncertainties in order } \\
\text { arrival patterns. The model applies stochastic dynamic programming to determine a profit threshold } \\
\text { for accept/reject decisions, and to deterministically allocate a single bottleneck resource to accepted } \\
\text { orders. }\end{array}$ \\
\hline $\begin{array}{l}\text { Herbots } \\
\text { et al. 30] }\end{array}$ & $\begin{array}{l}\text { investigates dynamic order acceptance and capacity planning with limited regular and non-regular } \\
\text { apacity to maximise the profits of accepted orders. It also assesses how the plan affects payout, } \\
\text { me and reinvestment revenues. The model uses Stochastic Dynamic Programming and is solved by } \\
\text { heuristic Roll-out Algorithm implemented by simulation. }\end{array}$ \\
\hline $\begin{array}{l}\text { Hing et al. } \\
31]\end{array}$ & $\begin{array}{l}\text { It introduces Reinforcement Learning (RL) as a tool for order acceptance. RL is a method based on } \\
\text { semi-Markov Decision Problems in which learning steps must be conducted with the behaviour of an } \\
\text { uncertain variable (arrival of orders in this case). The decision policies found by RL are compared } \\
\text { with heuristics. In this case, RL uses a neural network as a method to learn. }\end{array}$ \\
\hline $\begin{array}{l}\text { Ishii et al. } \\
{[32]}\end{array}$ & $\begin{array}{l}\text { It presents a novel way to solve the order acceptance problem based on the engineering man hours } \\
\text { needed to estimate project execution costs. Orders are analysed according to the total man hours } \\
\text { needed to calculate the cost of execution associated with them. Based on these hours, accep- } \\
\text { tance/rejection takes place. }\end{array}$ \\
\hline $\begin{array}{l}\text { Ivanescu } \\
\text { al. 33] }\end{array}$ & $\begin{array}{l}\text { The model uses multiple regression integrated into the makespan method to estimate the total fi- } \\
\text { nalisation time of a set of orders and to promise them according to that due date. Uncertainty in } \\
\text { demand is considered by using random order arriving. Then Earlang probability distribution is used } \\
\text { to describe the processing times. Accepted orders are those that do not make the makespan go up } \\
\text { and reach the time length used as a limit. }\end{array}$ \\
\hline Jung 34] & $\begin{array}{l}\text { incorporates both customer priority and variance of penalty cost together into the OPP. Indicated } \\
\text { nalties are earliness, tardiness and lost sales. These penalties vary linearly with time and depend } \\
\text { customer priority. }\end{array}$ \\
\hline Jung 35] & $\begin{array}{l}\text { presents an ATP model based on both fuzzy pair-wise comparison and fuzzy linear programming } \\
\text { hich enables decision makers to generate delivery dates to incoming orders by taking into account } \\
\text { eir preferences for multiple performance measures, and uncertainty in production and transporta- } \\
\text { on. Different performance measures can be assessed by linguistic values, represented as triangular } \\
\text { imbers. }\end{array}$ \\
\hline $\begin{array}{l}\text { Kalantari et } \\
\text { al. 36] }\end{array}$ & $\begin{array}{l}\text { The OPP in MTO/MTS hybrid environments is modelled by using an integrated fuzzy TOPSIS } \\
\text { method to rank orders priority according to customer type and an MILP model to set a proposed } \\
\text { due date and price per order. The paper faces uncertainty in customer type and order priority. } \\
\text { Customer type is ranked by the fuzzy TOPSIS method. Then the availability of resources and } \\
\text { materials is checked by the MILP model. The proposed due date and price can be initially negotiated } \\
\text { with customers. }\end{array}$ \\
\hline $\begin{array}{l}\text { Khataie } \\
\text { et al. 37] }\end{array}$ & $\begin{array}{l}\text { The model is based on the Profitable to Promise concept. The modelling approach includes the } \\
\text { activity-based cost method to calculate overhead costs. Orders are promised, based on the profit } \\
\text { generated for them. Modelling is done through a combination of System Dynamics (SD) simulation } \\
\text { and mixed integer linear programming. }\end{array}$ \\
\hline $\begin{array}{l}\text { Kilic et al. } \\
{[38]}\end{array}$ & $\begin{array}{l}\text { It shows the order acceptance process in food processing systems. The main idea is to consider the } \\
\text { profit that the order generates for the enterprise and, based on that, deciding whether the order } \\
\text { is accepted or rejected. The effects of the stochasticity of the resource requirements of orders are } \\
\text { also analysed. The paper points out the idea that the randomness of raw materials required to fulfil } \\
\text { an order can generate shortage, and possibly loss of revenue. The paper indirectly uses PTP as a } \\
\text { methodology to decide acceptance. A heuristic method is developed to solve the model. }\end{array}$ \\
\hline $\begin{array}{l}\text { Kleywegt } \\
\text { and Pa- } \\
\text { pastavrou } \\
\text { 39] }\end{array}$ & $\begin{array}{l}\text { The Dynamic and Stochastic Knapsack Problem is presented, which consists in a variation of the } \\
\text { original Knapsack model, but incorporates the stochastic modelling of variables like resource con- } \\
\text { sumption and demand arrival. The model seeks to determine an optimal policy to accept and } \\
\text { maximise the expected accumulated value of incoming orders. }\end{array}$ \\
\hline $\begin{array}{l}\text { Lecic- } \\
\text { Cvetkovic } \\
\text { et al. } 40]\end{array}$ & $\begin{array}{l}\text { It faces random demand from different customer types. The algorithm consists in dividing the set } \\
\text { of customers into subgroups according to their activity. Then ATP is divided into subgroups. These } \\
\text { subgroups work as a stock from which specific sets of customers must be served. The ATP subgroups } \\
\text { can be formed according to product quality to ensure best quality for more high-priority customers. }\end{array}$ \\
\hline Li et al. [41] & $\begin{array}{l}\text { It deals with the due date quotation in a single machine by minimising the earliness and tardiness } \\
\text { penalties. It considers that uncertainty is inherent to demand arriving and takes the uncertainties } \\
\text { in the processing time as probabilistic random functions, and competition time, earliness and tardi- } \\
\text { ness as triangular fuzzy numbers. It contemplates and solves precedence constraints by applying a } \\
\text { polynomial time algorithm. }\end{array}$ \\
\hline $\begin{array}{l}\text { Lin and } \\
\text { Chang } 42]\end{array}$ & $\begin{array}{l}\text { It presents a model capable of prioritising customers and setting selling prices by applying fuzzy } \\
\text { mathematical programming. The flexible quantity concept is introduced and supported by the Fuzzy- } \\
\text { TOPSIS method. Flexible quantity emerges when an order cannot be fully served with the total } \\
\text { quantity ordered by the customer. So it is possible to propose a new quantity for customers, who } \\
\text { have to decide if they accept that new quantity or not. This paper considers uncertainty in customer } \\
\text { types. }\end{array}$ \\
\hline Lin et & $\begin{array}{l}\text { It presents an ATP model with the thin-film transistor liquid crystal display (TFT-LCD) technology. } \\
\text { Multiple products assembled from common raw components exist according to customer specifica- } \\
\text { tions. Customers can choose suppliers. In this case, the same TFT-LCD model can have different } \\
\text { "grades", which are variations between components and specifications, even when the FG belongs to } \\
\text { only one general type. }\end{array}$ \\
\hline
\end{tabular}


Table 18: Novelty Part III.

\begin{tabular}{|c|c|}
\hline Reference & Novelty \\
\hline Liu et al. & $\begin{array}{l}\text { It presents a multi agent system framework where an agent is a unit responsible for doing "some- } \\
\text { thing" in an information shared network. In this case, six agents are defined to deal with the } \\
\text { due date quotation in a process where the manufacturer must respond to a bid request with its } \\
\text { feasible due date. The defined agents are: Order management, Production Planning, Capacity } \\
\text { Adjustment, Resource Agent, Algorithm Agent, and Data Mining and Information Retrieving. }\end{array}$ \\
\hline $\begin{array}{l}\text { Manavizadeh } \\
\text { et al. 45] }\end{array}$ & $\begin{array}{l}\text { This paper first assesses incoming orders based on managing experience. Then an MILP model } \\
\text { computes the feasible price and due date for previously accepted orders to make a counterproposal } \\
\text { to the customer. The renegotiation process is finally applied; if the customer accepts the coun- } \\
\text { terproposal, the order is accepted and sequenced in the production process, if not, the order is } \\
\text { rejected. Incoming orders are prioritised based on customer type. Customers are able to specify, } \\
\text { based on their priority, what specific components they require for their products. }\end{array}$ \\
\hline $\begin{array}{l}\text { Martínez } \\
\text { and }\end{array}$ & $\begin{array}{l}\text { It presents revenue management by maximising profits under uncertainty in MTO production } \\
\text { systems using an intelligent decision rule to dynamically control the orders inflow. It considers }\end{array}$ \\
\hline $\begin{array}{l}\text { Arredondo } \\
{[46]}\end{array}$ & $\begin{array}{l}\text { uncertainty in demand, including the order incoming arrival time, and even the main characteristics } \\
\text { of the order, such as the number of lines or quantity requested. }\end{array}$ \\
\hline Plbernik & It presents an algorithm to calculate the amount of inventory to be reserved in an MTS system \\
\hline and Yadav & $\begin{array}{l}\text { with multiple inventory receipts in the planning horizon under random demand and due date } \\
\text { conditions. Customers have differentiated priority. The procedure consists in dividing ATP into } \\
\text { subgroups that serve as stock from where a specific type of customers must be fulfilled. }\end{array}$ \\
\hline Portougal & It presents a stochastic method to set due dates in a single machine environment where processing \\
\hline $\begin{array}{l}\text { and } \\
\text { etsch }\end{array}$ & $\begin{array}{l}\text { times are random. The expected tardiness and earliness are uncertain and penalised. The expected } \\
\text { due date is calculated by stochastic density functions described by mean, variance and standard } \\
\text { deviation. }\end{array}$ \\
\hline Slotnick 49] & $\begin{array}{l}\text { It presents a model for lead time policies in the steel sector. Acceptance of incoming orders is based } \\
\text { on the processing time in the bottleneck required for them. There are uncertainties in demand } \\
\text { arrivals and processing times. Orders of the same product type can request different variations in } \\
\text { range and tonnage, so that a kind of subgroups appears in the finished product, which can only } \\
\text { be processed separately in the bottleneck of the production process. }\end{array}$ \\
\hline $\begin{array}{l}\text { Watanapa } \\
\text { and }\end{array}$ & $\begin{array}{l}\text { It presents a model where a bidding decision must be made and the bidder must reply with a pro- } \\
\text { posal of due date and price. The model is presented as a combination of stochastic programming }\end{array}$ \\
\hline $\begin{array}{l}\text { Techani- } \\
\text { tisawad } \\
50]\end{array}$ & $\begin{array}{l}\text { with a heuristic-search algorithm to solve it. A probability of winning bid is calculated by consider- } \\
\text { ing the quantity of bidders, their expected activity and customer type. Customers can be classified } \\
\text { according to characteristics like product quality. Orders are classified into two subgroups: normal } \\
\text { and time-sensitive (urgent). Two different rules are defined to allocate the product for these two } \\
\text { classes of orders: FIFO for normal orders and Early-Due-Date EDD for urgent ones }\end{array}$ \\
\hline $\begin{array}{l}\text { Wullink } \\
\text { et al. [51] }\end{array}$ & $\begin{array}{l}\text { It presents a model to handle order acceptance by considering capacity loading and uncertainty } \\
\text { in processing times. The model is called Flexible Resource Loading problem under Uncertainty } \\
\text { FRLU. The model includes the concepts of "order plan", which is a vector that defines the order } \\
\text { in which the order takes place through the available resources in the production process, whereas } \\
\text { the "loading schedule" concept defines the fraction of order completed during each time period. } \\
\text { Uncertainty is modelled as a stochastic function. Due to the scale of the problem, it is solved by } \\
\text { a heuristic method combined with linear programming and a Branch-and-Price algorithm. }\end{array}$ \\
\hline Yang and & Demand and supply are uncertain and customers are classified into categories according to their \\
\hline Fung [52] & $\begin{array}{l}\text { level of importance. This paper introduces a novel combination among dynamic programming, the } \\
\text { stochastic approach, heuristics and simulation. As inventory replenishment is a random function, } \\
\text { there can be variations in planned quantities because of either their flash production characteristic } \\
\text { or quality differences. }\end{array}$ \\
\hline $\begin{array}{l}\text { Zhang and } \\
\text { Tseng [53] }\end{array}$ & $\begin{array}{l}\text { This paper deals with "customer flexibility" in the OPP. Customer flexibility is defined as the } \\
\text { situation in which the initial variables of the order, e.g. product quantity and due date, can be } \\
\text { varied in the promising steps from their initial values to make a counterproposal to the customer } \\
\text { without sacrificing the satisfaction level. The procedure consists in defining an acceptance range for } \\
\text { each customer order variable (under uncertainty) in which the customer has a certain indifference } \\
\text { and can accept variations. These ranges are then modelled as customer preference functions, } \\
\text { whose aim is to interpret the grade into which the variable value belongs to the range. Finally this } \\
\text { interpretation is incorpored into the MILP. }\end{array}$ \\
\hline Zhao et al. & $\begin{array}{l}\text { An MIP model is developed to solve the OPP in an Assembly to Order (ATO) environment. There } \\
\text { is uncertainty in the incoming pattern of orders. There are subtypes in the raw components that } \\
\text { are used to assemble computers. Components are supplied by different suppliers, even when they } \\
\text { have the same functionality. }\end{array}$ \\
\hline
\end{tabular}




\subsubsection{Findings}

Fig. 4 shows a comparison of the mathematical approach with the uncertainty characteristics modelled (see Table 9p. The numbers represent the quantities of papers that match each combination. The main combinations are the hybrid modelling approach with uncertainty in demand, processing times and customer priority parameters. Then by considering each modelling pproach separately (non-hybrids), stochastic programming appears to be the main tool applied to model customer priority, raw material supply, processing times and demand uncertainty factors. Since the stochastic programing method normally requires such a huge amount of information to identify statistical trends in uncertainty variables, analysing the other approaches is worthwhile. Our main finding was that fuzzy mathematical programming appeared to be the second tool applied, with a wide variety of characteristics modelled (customer priority, transportation capacity, raw materials supply, product selling price, processing times and demand). This is a good option since fuzzy mathematical programming does not normally require such a quantity of information to represent an uncertain variable and can thus be applied, as seen, in almost all cases of uncertainty in the OPP. Finally, a group of modelling approaches, Simulation, Linear programming, and Markov decision programming, showed similar participation, but MDP and simulation focussed more on demand, and integer linear programming (ILP) centred more on customer priority. All the other modelling approaches offered less representativeness.

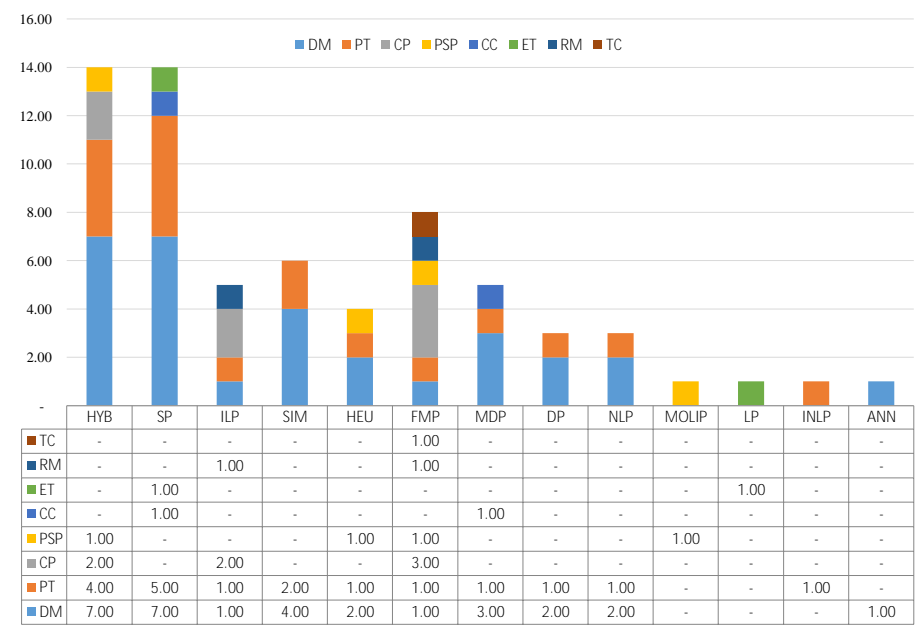

Figure 4: Modelling approach versus the modelled uncertainty characteristics. 
In relation to what happens with LHP modelling, Fig. 5 shows a comparison made between the modelling approach and the LHP characteristics modelled in deterministic and uncertainty environments. This is the comparison of Table 8 versus the modelling approach.

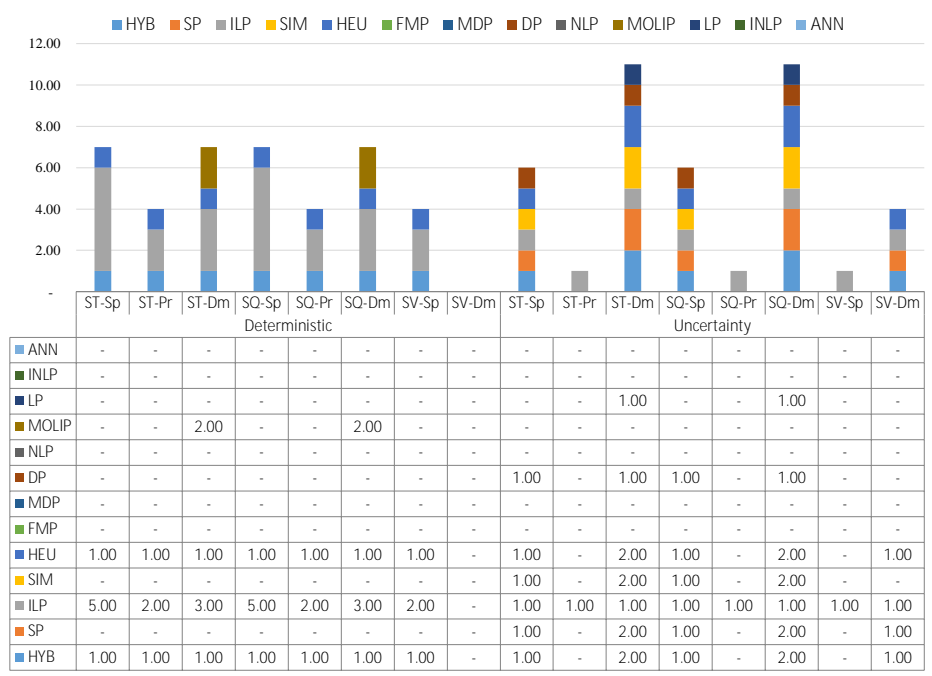

Figure 5: Modelling approach versus the modelled LHP characteristics.

Subtype and subtype quantity in supply/demand combination were the most considered options in the deterministic environment, modelled basically according to ILP. Subtype, subtype quantity and the subtype value in the process and supply were also modelled mainly according to ILP. In the uncertainty context, another scenario appeared: subtype and subtype quantity in supply/demand were also the commonest combinations, but the variety of modelling approaches increased considerably, which is interesting since the combination of uncertainty and LHP was defined as a relatively recent and lacking research line; indeed the used modelling approach is yet to be well-defined. In this sense, for example, it is interesting to see how the FMP approach was not applied in LHP uncertainty modelling, but was identified as a tool to consider in the uncertainty modelling of the OPP (according to Fig. 4). This might be a good option for further research. The other combinations in the uncertainty context in Fig. 5 present a similar behaviour that relates to the variety of modelling applied. Yet as always, none can be considered to be the most outstanding. 


\section{Conclusions. Identifying areas for further research}

The reason that motivated this research is that very few studies have dealt with LHP characteristics for the OPP despite there being relevant sectors affected by them. The objective of this review was to identify which elements affect the OPP in LHP environments and under uncertainty conditions, which have been addressed in different mathematical programming models, and their main characteristics.

In order to analyse and compare them in a structured manner, a framework was defined, which comprised five structural dimensions: environment, order promising, customer orders, LHP/uncertainty modelling and model characteristics. All these categories were divided into subcategories (Fig. 3), where the reviewed literature was classified. Forty-two papers were selected, mainly from scientific journals. The conclusions drawn from this work are presented below, along with the poorly studied characteristics and identified gaps. According to them all, the future research directions that are worth investigating are defined as challenges in this field.

From LHP/uncertainty modelling (Table 7), we confirm our first hypothesis, which stated very few models have supported the OPP in LHP contexts. Only $28.6 \%$ of the reviewed literature works consider some LHP characteristics, $16.7 \%$ do so by applying a deterministic approach in modelling, while $11.9 \%$ do so by contemplating uncertainty. The main finding was that no paper deals with the LHP subtype state characteristic from either a deterministic or an uncertainty perspective. This offers a huge opportunity for further research work to address a practically new research area. The LHP subtype state characteristic affects mainly those sectors with products that present perishability conditions, such as the food and hortofruticulture sectors. According to Table 4, very little research work has focussed on these sectors, which supports the idea that this is a new research field. Although there are many planning models for these sectors that consider the perishability feature, as far as we know, it has not been dealt with for the OPP. Conducting research in this area can be considered a challenge because the features of the handled products, obtained directly from nature, make LHP an unavoidable factor which must be considered as much as possible to conduct more realistic models. In horticultural supply chains, presence of uncertainty is completely inherent to LHP given the perishability factor of the products in them, which confers not only initial characteristics of quality, colour, size, flavour, hygiene, etc., but also changes with time, and a maximum expected shelf life. This is critical when products are destined to human consumption because it can have a direct impact on consumer health. So a very narrow fault range is allowed when planning and modelling.

Of the $16.7 \%$ of the papers that consider LHP under deterministic conditions, it was determined that the most modelled LHP characteristics are subtype definition and subtype quantity. The subtype value lacks both process and demand. Of the $12 \%$ of the references that contemplate LHP in an uncertainty environment, demand is the most modelled one in all the LHP characteristics. However, we affirm that it is lacking in all the LHP dimensions because only five papers present this 
combination. The most modelled characteristics are subtype definition, subtypes quantity and subtype value, and all in demand.

As very few papers have dealt with LHP and its inherent uncertainty in the OPP, it was necessary to include $71.4 \%$ of the reviewed papers, which merely combined the OPP with uncertainty modelling in some variables, even when they did not explicitly relate to LHP. Thus these papers can become worthy input for future research work by helping lead to tools and the basis to consider uncertainty in LHP modelling. The vast majority of all the reviewed papers focus on demand uncertainty. Some papers model interesting uncertainty variables, which can be associated with LHP modelling, like customer priority in those cases where priority is based on the product's quality (subtype definition), the product selling price when different prices are associated with product subtypes (subtype value), and uncertainty in raw materials when raw material can be separated into subtypes (subtypes in supply). Yet according to the data in Table 9, more research work in uncertainty modelling in the OPP process in variables other than demand is needed. Even when LHP can be modelled deterministically, it is important to consider that LHP is usually accompanied by uncertainty in real situations (in the definition of subtypes, value, state, etc.). Hence we can state that the best way to study LHP is to consider its inherent uncertainty at the same time. The present work anticipates this necessity and, because of this, LHP and uncertainty are considered to set the basis for the future explicit combination of both topics in order promising models, which is a research line proposed herein.

From a general literature view, we draw the following conclusions: given that around $75 \%$ of the reviewed papers have been published since 2009, the topic of this work is a relatively recent research area and authors focus more on case studies $(73.8 \%$ of the papers reviewed) than real applications. The absence of real applications is enforced by the fact that, although LHP is present in several sectors, the majority of papers pertain to the generic category $(67 \%)$. The results also showed that OPP mathematical models consider the manufacturing stage to be the central one, with a marked trend to include only another one, preferably downstream of the manufacturing stage, nearer to customer. Since considering more supply chain stages increases model complexity, a study should be done to assess to what extent not modelling LHP characteristics and/or uncertainty ones upstream and/or downstream of the manufacturing stage can affect the OPP. Then a balance between accuracy in model formulation and solving complexity should be struck before incorporating additional stages.

In the environment category, the majority of the papers consider the Make to Order manufacturing strategy as $79 \%$ of them work on this classification. Although the OPP is severely affected by the manufacturing strategy (CODP location), it assumes this aspect as given. Therefore, it would be interesting to investigate not only the effect of LHP modelling, but also the impact of CODP location on reducing LHP uncertainty. 
The customer orders category shows that more than $85 \%$ of the reviewed papers do not consider any homogeneity requirement in their order requests. This finding confirms our main hypothesis about LHP consideration lacking in the OPP if uncertainty is present. The need for more complex considerations about the customer order nature was also identified; considering more order lines (79\% of the papers consider only one line per order); more flexibility in customer requirements (38.1\% do not consider any customer flexibility), like due date and price ranges; considering additional customer requirements, like minimum lead time, a portion of shelf life or minimum service level ( $81 \%$ do consider no additional requirement). This aspect once again implies that even when the reviewed literature considers some of our required characteristics (LHP and/or uncertainty), they do not apply them to enough real cases to prove the practical benefits that correct LHP and uncertainty handling in the OPP can confer supply chain management. Hence we point out that more research work into real applications is needed, especially in the sectors that are strongly affected by LHP, like horticultural, wood, marble and ceramics.

In the order promising category, it is clear that the majority of models do not consider any explicit allocation rule ( $71 \%$ do not consider it), not even when allocation rules are designed to achieve a more efficient product assignation to incoming orders. In LHP environments, serving one customer order for one specific sublot or another can imply that the following orders can, or cannot, be served. Another important aspect is that since batching order promising (BOP) was identified as the main execution mode, it might be necessary to consider the single order promising (SOP) execution mode in more cases because it confers more realistic conditions to certain kinds of supply chain sectors, like e-business. Finally, this category showed that CTP and ATP were the most widely used techniques at the order promising availability levels. So it is worth highlighting the importance of considering more options like Deliver-To-Promise. Despite it being true that all these features are included in modelling, the scale and complexity of resolution can still grow, which might imply more considerable realistic conditions in models and more adaptability to possibilities which, in real life, can suddenly change according to decision makers' requirements, or changes in the company's strategy. So including them in future works is recommended. The result will probably be more integral models that are less susceptible to changes, but are easier to adapt to multiple supply chain types. If complexity grows exponentially, another research line might lead to alternative resolution methodologies: e.g. metaheuristics.

The model characteristics category reveals that most of the reviewed articles focus on maximisation of profits as the main objective (see Table 14. It might well be interesting to consider multiobjective models in order to, for example, consider the impact of allocation rules, or even flexibility in customer requirements, or the service level. There is also the possibility of obtaining better results for customer satisfaction and supply chain efficiency in relation to the use and handling of available quantities to promise, and without sacrificing a considerable percent- 
age of generated profits. To assess this possibility, we must apply multiobjective scenarios. Regarding the modelling approach, stochastic programming appears to be the main tool applied to model uncertainty in the OPP. Other techniques, like heuristics and simulation, appear in second place. The utilisation of the fuzzy set theory can be considered a novel way to model uncertainty in supply chain problems and to be integrate into LHP concepts.
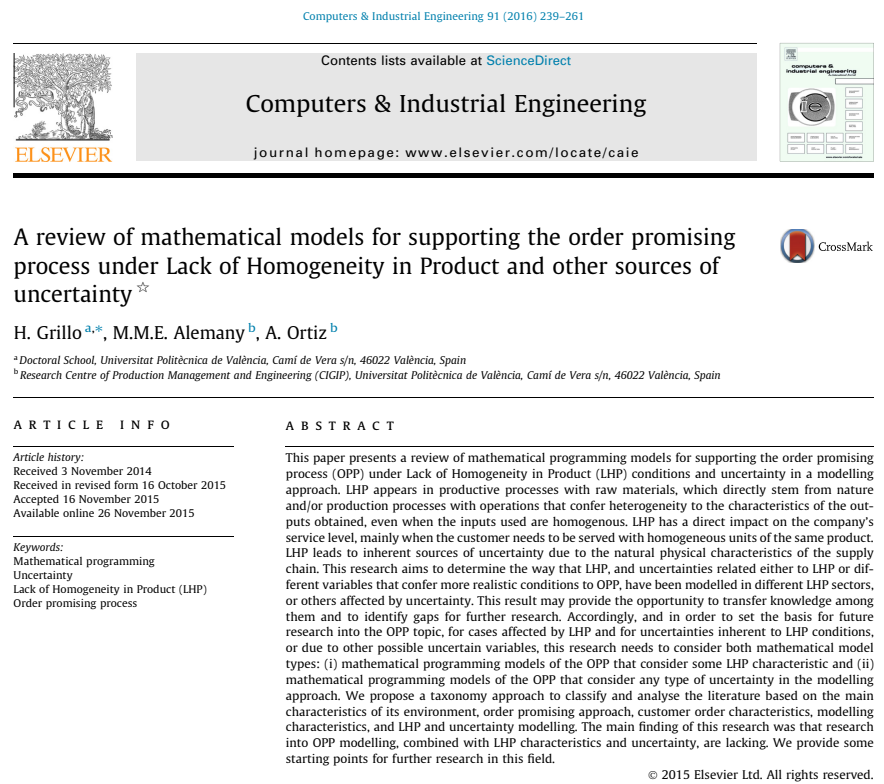

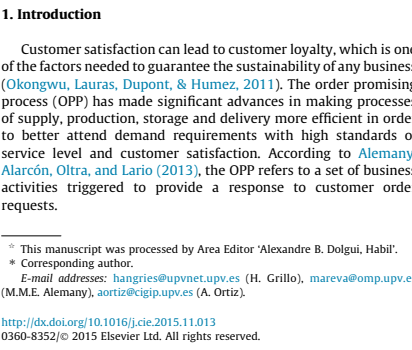

1. Introduction

Customer satisfaction can lead to customer loyalty, which is on

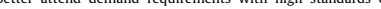
larcón, Oltra, and Lario (2013), the OPP refers to a set of business requests.

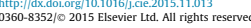

Figure 6: Publication data.

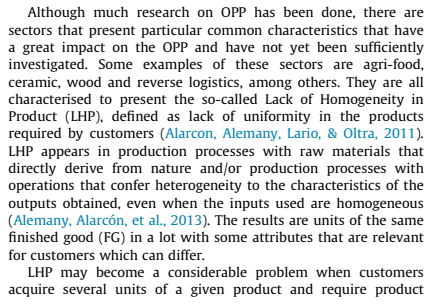

Although much research on OPP has been done, there are sectors that present particular common characteristics that have a great impact on the OPP and have not yet been sufficiently
investigated. Some examples of these sectors are agri-food, investigated. Some examples of these sectors are agri-food,
ceramic, wood and reverse logistics, among others. They are all ceramic, wood and reverse logistics, among others. They are all
characterised to present the so-called Lack of Homogeneity in Product (LHP), defined as lack of uniformity in the products required by customers (Alarcon, Alemany, Lario, \& Oltra, 2011). LHP appears in production processes with raw materials that directly derive from nature and/or production processes with operations that confer heterogeneity to the characteristics of the outputs obtained, even when the inputs used are homogeneous (Alemany, Alarcón, et al., 2013). The results are units of the same finished good $(\mathrm{FG})$ in a lot with some attributes that are relevant
for customers which can differ. for customers which can differ.

the customers acquire several units of a given product and require product

Finally we conclude that since LHP appears in several sectors, not anticipating it and its inherent uncertainty by their proper modelling may lead to promising customer orders that cannot be finally served in the promised terms as homoge- 
neous quantities might be lacking. Given the problem characteristics and the very few papers conducted in this field, it is necessary to design optimisation tools to support the OPP in order to reduce negative LHP effects. These models should also address more realistic cases in the dimensions that relate with supply chain characteristics, LHP modelling and customer order features. As more realistic models usually imply greater complexity, and information is not always exactly known, future modelling approaches should combine accuracy and simplicity (e.g., the fuzzy modelling approach).

\section{Publication data}

Figure 6 shows the first page of the article published in the Computers \& Industrial Engineering journal (ISSN: 0360-8352).

\section{Acknowledgement}

This research has been partly supported by Spanish Ministry of Economy and Competitiveness Project 'Methods and models for operations planning and order management in supply chains characterised by uncertainty in production due to the lack of product uniformity' (PLANGES-FHP) (Ref. DPI2011-23597), and by the Ministry of Science, Technology and Telecommunications, Government of Costa Rica (MICITT), through the program of innovation and human capital for competitiveness (PINN) (Contract No. PED-019-2015-1).

\section{Bibliography}

[1] U. Okongwu, M. Lauras, L. Dupont, and V. Humez. "A decision support system for optimising the order fulfilment process". In: Production Planning \& Control 23.8 (2011), pp. 581-598. DOI: 10.1080/09537287.2011.566230

[2] M. M. E. Alemany, F. Alarcon, R. F. Oltra, and F. C. Lario. "Optimal inventory reallocation to customer orders in ceramic tile companies characterized by the lack of homogeneity in the product (LHP)". In: Boletin De La Sociedad Espanola De Ceramica Y Vidrio 52.1 (2013), pp. 31-41. DOI: $10.3989 /$ cyv.42013

[3] F. Alarcón, M. M. E. Alemany, F. C. Lario, and R. F. Oltra. "The lack of homogeneity in the product (LHP) in the ceramic tile industry and its impact on the reallocation of inventories". In: Boletin De La Sociedad Espanola De Ceramica Y Vidrio 50.1 (2011), pp. 49-57. DOI: $10.3989 /$ cyv.072011

[4] A. Boza, M. M. E. Alemany, F. Alarcón, and L. Cuenca. "A model-driven DSS architecture for delivery management in collaborative supply chains with lack of homogeneity in products". In: Production Planning \& Control 25.8 (2013), pp. 650-661. DOI: 10.1080/ 09537287.2013 .798085

[5] I. Mundi and M. M. E. Alemany. "Literature review of master planning models with lack of homogeneity in the product characteristics under uncertainty context". In: 7th International Conference on Industrial Engineering and Industrial Management. XVII Congreso de Ingeniería de Organización. Valladolid, Spain. 2013. 
[6] D. Peidro, J. Mula, R. Poler, and J.-L. Verdegay. "Fuzzy optimization for supply chain planning under supply, demand and process uncertainties". In: Fuzzy Sets and Systems 160.18 (2009), pp. 2640-2657. DOI: 10.1016/j.fss.2009.02.021

[7] J. Meredith. "Theory building through conceptual methods". In: International Journal of Operations \& Production Management 13.5 (1993), pp. 3-11. DoI: 10.1108/01443579310028120

[8] G. Davoli, S. A. Gallo, M. W. Collins, and R. Melloni. "A stochastic simulation approach for production scheduling and investment planning in the tile industry". In: International Journal of Engineering, Science and Technology 2.9 (2010), pp. 107-124. DOr: 10.4314/ ijest.v2i9.64006

[9] S. Seuring and M. Müller. "From a literature review to a conceptual framework for sustainable supply chain management". In: Sustainability and Supply Chain Management 16.15 (2008), pp. 1699-1710. DOI: 10.1016/j.jclepro.2008.04.020

[10] F. Alarcón, M. M. E. Alemany, A. Ortiz, and F. C. Lario. “"Order promising” y conceptos asociados: revisión de significados e interpretaciones y propuesta para su clasificación". In: IX Congreso de Ingeniería de Organización. 2005, p. 138.

[11] F. Alarcón, M. M. E. Alemany, and A. Ortiz. "Conceptual framework for the characterization of the order promising process in a collaborative selling network context". In: International Journal of Production Economics 120.1 (2009), pp. 100-114. Dor: 10.1016/ j.ijpe.2008.07.031

[12] M. M. E. Alemany, F. C. Lario, A. Ortiz, and F. Gomez. "Available-To-Promise modeling for multi-plant manufacturing characterized by lack of homogeneity in the product: An illustration of a ceramic case". In: Applied Mathematical Modelling 37.5 (2013), pp. 33803398. DOI: $10.1016 / \mathrm{j} . \mathrm{apm} .2012 .07 .022$

[13] J. Mula, D. Peidro, M. Díaz-Madroñero, and E. Vicens. "Mathematical programming models for supply chain production and transport planning". In: European Journal of Operational Research 204.3 (2010), pp. 377-390. DOI: 10.1016/j.ejor.2009.09.008

[14] C. Kilger and H. Meyr. "Demand fulfilment and ATP". In: Supply chain management and advanced planning. Springer, 2008, pp. 181-198. DOI: 10.1007/978-3-540-74512-9_10

[15] T. Aouam and N. Brahimi. "Integrated production planning and order acceptance under uncertainty: A robust optimization approach". In: European Journal of Operational Research 228.3 (2013), pp. 504-515. DOr: 10.1016/j.ejor.2013.02.010

[16] F. Arredondo and E. Martinez. "Learning and adaptation of a policy for dynamic order acceptance in make-to-order manufacturing". In: Computers 83 Industrial Engineering 58.1 (2010), pp. 70-83. DOI: $10.1016 /$ j.cie.2009.08.005

[17] K. R. Baker. "Setting optimal due dates in a basic safe-scheduling model". In: Computers \&5 Operations Research 41 (2014), pp. 109-114. Dor: 10.1016/j.cor.2013.07.022

[18] B. Behdani, A. Adhitya, Z. Lukszo, and R. Srinivasan. "Negotiation-based approach for order acceptance in a multiplant specialty chemical manufacturing enterprise". In: Industrial Es Engineering Chemistry Research 50.9 (2011), pp. 5086-5098. Dor: 10.1021/ie101554b

[19] T. Bui, H.-J. Sebastian, and Ieee. "Integration of multi-criteria decision analysis and negotiation in order promising". In: 43rd Hawaii International Conference on Systems Sciences Vols 1-5. Proceedings of the Annual Hawaii International Conference on System Sciences, 2010, pp. 1115-1124. DOI: 10.1109/HICSS.2010.237

[20] S. Chaharsooghi, M. Honarvar, and M. Modarres. "A multi-stage stochastic programming model for dynamic pricing and lead time decisions in multi-class make-to-order firm". In: Scientia Iranica 18.3 (2011), pp. 711-721. DOI: 10.1016/j.scient.2011.05.018

[21] I. Chamodrakas, N. Alexopoulou, and D. Martakos. "Customer evaluation for order acceptance using a novel class of fuzzy methods based on TOPSIS". In: Expert Systems with Applications 36.4 (2009), pp. 7409-7415. DOI: 10.1016/j.eswa.2008.09.050 
[22] C. Y. Chen, Z. Y. Zhao, and M. O. Ball. "Quantity and due date quoting available to promise". In: Information Systems Frontiers 3.4 (2001), pp. 477-488. Dor: 10.1023/a: 1012837207691 .

[23] C. Y. Chen, Z. Y. Zhao, and M. O. Ball. "A model for batch advanced available-to-promise". In: Production and Operations Management 11.4 (2002), pp. 424-440. DOI: $10.1111 / \mathrm{j}$. 1937-5956.2002.tb00470.x

[24] C. Cheng and C. Cheng. "Available-to-promise based bidding decision by fuzzy mathematical programming and genetic algorithm". In: Computers \& Industrial Engineering 61.4 (2011), pp. 993-1002. DOI: $10.1016 /$ j.cie.2011.06.012

[25] D. M.-H. Chiang and A. W.-D. Wu. "Discrete-order admission ATP model with joint effect of margin and order size in a MTO environment". In: International Journal of Production Economics 133.2 (2011), pp. 761-775. DOI: 10.1016/j.ijpe.2011.04.032

[26] A. H. Gharehgozli, M. Rabbani, N. Zaerpour, and J. Razmi. "A comprehensive decisionmaking structure for acceptance/rejection of incoming orders in make-to-order environments". In: The International Journal of Advanced Manufacturing Technology 39.9-10 (2008), pp. 1016-1032. DOI: 10.1007/s00170-007-1275-6

[27] T. Halim and K. Muthusamy. "Fuzzy Available-to-Promise system modelling under supplier uncertainty". In: Manufacturing Science and Technology, Pts 1-8. Ed. by W. Fan. Vol. 383-390. Advanced Materials Research. 2012, pp. 4535-4540. Dor: $10.4028 / \mathrm{www}$. scientific.net/AMR.383-390.4535

[28] S. Hemmati, M. Ebadian, and A. Nahvi. "A new decision making structure for managing arriving orders in MTO environments". In: Expert Systems with Applications 39.3 (2012), pp. 2669-2676. DOI: $10.1016 /$ j.eswa.2011.08.122

[29] J. Herbots, W. Herroelen, and R. Leus. "Dynamic order acceptance and capacity planning on a single bottleneck resource". In: Naval Research Logistics 54.8 (2007), pp. 874-889. DOI: $10.1002 /$ nav. 20259

[30] J. Herbots, W. Herroelen, and R. Leus. "Single-pass and approximate dynamic-programming algorithms for order acceptance and capacity planning". In: Journal of Heuristics 16.2 (2010), pp. 189-209. DOI: 10.1007/s10732-008-9096-9

[31] M. M. Hing, A. v. Harten, and P. C. Schuur. "Reinforcement learning versus heuristics for order acceptance on a single resource". In: Journal of Heuristics 13.2 (2007), pp. 167-187. DOI: $10.1007 / \mathrm{s} 10732-006-9006-\mathrm{y}$

[32] N. Ishii, Y. Takano, and M. Muraki. "An order acceptance strategy under limited engineering man-hours for cost estimation in Engineering-Procurement-Construction projects". In: International Journal of Project Management 32.3 (2014), pp. 519-528. Dor: 10.1016/j . ijproman.2013.07.009

[33] C. V. Ivanescu, J. C. Fransoo, and J. M. Bertrand. "Makespan estimation and order acceptance in batch process industries when processing times are uncertain". In: OR Spectrum 24.4 (2002), pp. 467-495. DOI: 10.1007/s00291-002-0108-0

[34] H. Jung. "An available-to-promise model considering customer priority and variance of penalty costs". In: The International Journal of Advanced Manufacturing Technology 49.14 (2010), pp. 369-377. DOI: 10.1007/s00170-009-2389-9

[35] H. Jung. "An available-to-promise process considering production and transportation uncertainties and multiple performance measures". In: International Journal of Production Research 50.7 (2012), pp. 1780-1798. DOI: 10.1080/00207543.2011.561373

[36] M. Kalantari, M. Rabbani, and M. Ebadian. "A decision support system for order acceptance/rejection in hybrid MTS/MTO production systems". In: Applied Mathematical Modelling 35.3 (2011), pp. 1363-1377. DOI: $10.1016 / \mathrm{j}$.apm.2010.09.015 
[37] A. H. Khataie, A. A. Bulgak, and J. J. Segovia. "Activity-based costing and management applied in a hybrid decision support system for order management". In: Decision Support Systems 52.1 (2011), pp. 142-156. DOI: $10.1016 /$ j.dss.2011.06.003

[38] O. A. Kilic, D. P. van Donk, J. Wijngaard, and S. A. Tarim. "Order acceptance in food processing systems with random raw material requirements". In: Or Spectrum 32.4 (2010), pp. 905-925. DOI: $10.1007 / \mathrm{s} 00291-010-0213-4$

[39] A. J. Kleywegt and J. D. Papastavrou. "The dynamic and stochastic knapsack problem with random sized items". In: Operations Research 49.1 (2001), pp. 26-41. DOI: 10.1287/ opre.49.1.26.11185

[40] D. Lecic-Cvetkovic, N. Atanasov, and S. Babarogic. "An algorithm for customer order fulfillment in a make-to-stock manufacturing system". In: International Journal of Computers Communications 86 Control 5.5 (2010), pp. 783-791. DOI: 1841-9836.

[41] J. Li, X. Yuan, E. Lee, and D. Xu. "Setting due dates to minimize the total weighted possibilistic mean value of the weighted earliness-tardiness costs on a single machine". In: Computers \& Mathematics with Applications 62.11 (2011), pp. 4126-4139. DOI: 10.1016/ j.camwa.2011.09.063

[42] H. Lin and W. Chang. "Order selection and pricing methods using flexible quantity and fuzzy approach for buyer evaluation". In: European Journal of Operational Research 187.2 (2008), pp. 415-428. DOI: $10.1016 /$ j.ejor.2007.03.003

[43] J. Lin, I. Hong, C.-H. Wu, and K.-S. Wang. "A model for batch available-to-promise in order fulfillment processes for TFT-LCD production chains". In: Computers \& Industrial Engineering 59.4 (2010), pp. 720-729. DOI: 10.1016/j.cie.2010.07.026

[44] J. Liu, Q. Chen, N. Mao, and Z. Lin. "A multi-agent-based mould due date setting approach in stochastic production". In: International Journal of Production Research 49.5 (2011), pp. 1353-1371. DOI: 10.1080/00207543.2010.518737

[45] N. Manavizadeh, A. Hasani Goodarzi, M. Rabbani, and F. Jolai. "Order acceptance/rejection policies in determining the sequence in mixed model assembly lines". In: Applied Mathematical Modelling 37.4 (2013), pp. 2531-2551. DOI: $10.1016 / \mathrm{j} . \mathrm{apm} .2012 .06 .012$

[46] E. Martínez and F. Arredondo. "Order acceptance for revenue management and capacity allocation in make-to-order batch plants". In: Computer Aided Chemical Engineering. Ed. by S. Pierucci and G. Buzzi Ferraris. Vol. 28. 2010, pp. 1189-1194. Dor: 10.1016/S15707946(10) 28199-3

[47] R. Pibernik and P. Yadav. "Inventory reservation and real-time order promising in a maketo-stock system". In: OR Spectrum 31.1 (2009), pp. 281-307. DoI: 10.1007/s00291-0070121-4

[48] V. Portougal and D. Trietsch. "Setting due dates in a stochastic single machine environment". In: Computers \& Operations Research 33.6 (2006), pp. 1681-1694. Dor: 10.1016/ j.cor.2004.11.014.

[49] S. A. Slotnick. "Optimal and heuristic lead-time quotation for an integrated steel mill with a minimum batch size". In: European Journal of Operational Research 210.3 (2011), pp. 527-536. DOI: $10.1016 / \mathrm{j}$. ejor.2010.09.031

[50] B. Watanapa and A. Techanitisawad. "Simultaneous price and due date settings for multiple customer classes". In: European Journal of Operational Research 166.2 (2005), pp. 351368. DOI: $10.1016 /$ j.ejor.2004.02.011

[51] G. Wullink, A. J. R. M. Gademann, E. W. Hans, and A. van Harten. "Scenario-based approach for flexible resource loading under uncertainty". In: International Journal of Production Research 42.24 (2004), pp. 5079-5098. DOI: 10.1080/002075410001733887

[52] W. Yang and R. Y. Fung. "Stochastic optimization model for order acceptance with multiple demand classes and uncertain demand/supply". In: Engineering Optimization 46.6 (2014), pp. 824-841. DOI: 10.1080/0305215X.2013.800056 
[53] Q. Zhang and M. Tseng. "Modelling and integration of customer flexibility in the order commitment process for high mix low volume production". In: International Journal of Production Research 47.22 (2009), pp. 6397-6416. Dor: 10.1080/00207540802266474

[54] Z. Zhao, M. O. Ball, and M. Kotake. "Optimization-based available-to-promise with multistaget resource availability". In: Annals of Operations Research 135.1 (2005), pp. 65-85. DOI: $10.1007 / \mathrm{s} 10479-005-6235-7$

[55] K. Lin, P. Chang, K.-C. Hung, and P.-F. Pai. "A simulation of vendor managed inventory dynamics using fuzzy arithmetic operations with genetic algorithms". In: Expert Systems with Applications 37.3 (2010), pp. 2571-2579. DOI: 10.1016/j.eswa.2009.08.020 


\title{
Chapter III
}

\section{A Fuzzy Order Promising Model With Non Uniform Finished Goods}

\begin{abstract}
Traditionally, the homogeneity of available units of the same finished good $\left(F G_{i}\right)$ to be promised to customers has been assumed. However, contexts with lack of homogeneity in the product (LHP), are characterised by units of the same $F G_{i}$, which differ in some characteristics that are relevant for customers and give rise to different subtypes. For instance, in the ceramic industry, tiles are classified based on quality, tone and gage, because of functional and aesthetical reasons related to their joint installation. LHP imposes new constraints in the order promising process because customers need homogeneous units. However, the final amount of the homogeneous units in planned lots is uncertain when promising orders, because they will only be known once produced and classified. In this sense, we introduce homogeneity constraints including fuzzy sets; specifically, we address the interaction among fuzzy homogeneity coefficients that represent the fraction of each homogeneous sublot. Therefore, modelling uncertainty in interdependent technological coefficients in a dynamic context, is one of the main novelties of our proposal. Thus, in this paper, in order to reliably meet the homogeneity required by customers, a fuzzy model is proposed to support the promising process in LHP contexts after taking into account uncertainty in planned homogeneous sublots. The fuzzy model is translated into an alpha-parametric equivalent crisp model. Here, it is important to highlight another important novelty of the paper related to the proposed methodology to analyse the suitability of the minimum degree of possibility (the $\alpha$-cut), by an adapted TOPSIS-based fuzzy procedure. Finally, the experimental design, which is inspired in the ceramic sector, proves both, the validity of the model and a better
\end{abstract}


performance of the fuzzy model compared to the deterministic one, in several executions with forecasts of the real size of homogeneous sublots.

Keywords: Order promising, lack of homogeneity in the product, uncertainty, interdependent fuzzy coefficients, fuzzy TOPSIS, ceramic sector.

\section{Introduction}

Lack of homogeneity in the product (LHP) appears in certain industries like ceramics, textile, wood, marble, horticulture, tanned hides and leather goods. In fruit supply chains for example, LHP mainly targets the non-uniformity of raw materials (fruit obtained directly from nature). There are several classification (sorting and grading) activities which aim to eliminate waste and classify, for example, fruits into several qualities based on different attributes: size, weight, ripeness, damage, colour, shape and firmness [1]. In the ceramic sector, the LHP origin is due to the non-uniformity of raw materials (clays) and some components (enamels), along with some uncontrollable productive variables (e.g. humidity and temperature). Since customers require homogeneity in the units of the same ceramic wall or tile, these companies locate one classification stage at the end of the process. In this stage, ceramic pieces are classified into subtypes based on the following attributes: quality, tone and gage $[2]$.

The order promising process (OPP) refers to a set of business activities triggered to provide a response to customer order requests $\sqrt{3}$ and has been widely studied and applied in multiple areas and computational applications (see for example Alemany et al. [4, 5], Alarcón et al. [6], and Bui et al. [7], among others). The OPP bases its functionality in the concept of available-to-promise (ATP) [8, which compares the quantities of product requested in the order proposals from the customers, with the amounts of product either in stock or planned to have (for future periods of time) according with the master production schedule (MPS). Based on the availability, OPP answers to each order proposal with an acceptance/rejection decision.

When the OPP is affected by the LHP, the typical way of calculating the accumulated ATP from MPS will not be valid, and it must be treated in terms of subtype. Different subtypes of the same finished good $\left(F G_{i}\right)$ cannot be used to promise a specific customer order. These LHP characteristics complicate system management in different ways: (i) the customer homogeneity requirement introduces new constraints to be accomplished, which makes the identification of not only an optimal solution, but also a feasible one, more difficult; (ii) after each classification stage, the quantity of each subtype in the production lots will be known only after production has finished and $F G_{i}$ have been classified. Therefore, companies with LHP face a new kind of uncertainty: uncertainty in the homogeneous quantities of each subtype available in the planned production lots. This aspect becomes a problem when customer commitments are made according to the ATP that derives from the planned lots in MPS, whose homogeneity characteristics are unknown at 
the time of promising orders. In this sense, and according to Alemany et al. [9], two main novel aspects are modelled in this paper: 1) appearance of LHP subtypes among units in the same production lot, which represents the most general case in LHP environments; and 2) uncertainty in the homogeneous quantities of each subtype in production lots. As ATP quantities derive from planned production lots, the commitment of customer orders is based on uncertain homogeneous ATP quantities (ATP-LHP). To model the above two aspects, technological coefficients that represent the fraction of planned production lots, which are considered homogeneous, are defined. However, these fractions are not independent because they must always add up to one; i.e. the sum of all the homogeneous sublots of a lot equals the original lot. Therefore, we focus on the uncertainty that is inherent to the homogeneity of the product through fuzzy interdependent technological coefficients in a dynamic environment, what is not studied until now in models for ATP-LHP. In order to manage the uncertainty in non-homogenous lots through interdependent coefficients, a fuzzy model based on an extension of the work by Alemany et al. 9 is proposed. The solution methodology employed to solve this fuzzy model has been established by Jiménez et al. [10 and applied in works like Peidro et al. 11 to model supply chain problems. Since this procedure serves to translate the original fuzzy model into an $\alpha$-parametric equivalent crisp model, a methodology is needed to evaluate the suitability of the alpha cuts that the decision maker (DM) wants to execute; bear in mind that the alpha parameter is also a measure of the risk that the final solutions might have when applied to a real situation. Since our model only considered total profit in the objective function, we added four more indicators to integrally evaluate the suitability of alpha. Seeing that none of the above methodologies specified how to handle multiple performance indicators when the weight of each one was not exactly known by the DM, and it could be considered ambiguous (fuzzy), we adapted the fuzzy TOPSIS methodology by Yong 12 to include the decision maker's needs, but in a qualitative/quantitative way combined with a set of performance indicators, in order to find better degrees of the minimum value of alpha. The idea is to evaluate the indicators based on linguistic values for two aspects: the weight that the DM wishes to assign to each indicator; the linguistic performance finally obtained by each one. These linguistic variables were represented by triangular fuzzy numbers. In this sense, we have identified relevant fuzzy TOPSIS proposals using triangular fuzzy numbers ( $13-16$ among others), which demonstrate the validity of using them in a fuzzy TOPSIS environment.

Our experiments in the ceramic sector were conducted to compare the deterministic and fuzzy ATP-LHP models against different forecasts of reality. To do this, an auxiliary model was formulated to determine which of the customer orders, which were initially promised by the two corresponding models, could be finally served when the real and exact homogeneity quantities of each subtype in lots were known. With this methodology we seek to decrease the ambiguity in the final decision of the $\alpha$-parametric system. The experiments showed model validity 
and proved that the fuzzy model provides higher profits than the deterministic one in both planned and real situations.

The main contributions of this paper are: (i) to provide a fuzzy model to reliably meet the homogeneity required by customers in the LHP context with fuzzy interdependent coefficients to consider fuzzy lots in the order promising process (OPP). More specifically, we address the interaction among fuzzy parameters; (ii) to translate the fuzzy model into an alpha parametric equivalent crisp model to analyze the suitability of minimum degree of possibility by a TOPSIS based fuzzy procedure. The use of a TOPSIS approach to evaluate fuzzy solutions is one of the main novelties of this paper as an alternative way to rank fuzzy numbers, which are not the most adequate ones when the weights among the different criteria are fuzzy for the DM; and (iii) to propose and experiment a real world problem based on the ceramic sector.

The rest of the paper is arranged as follows: Section 2 briefly reviews the related work. Section 3 formulates the fuzzy ATP-LHP model. Section 4 describes the solution methodology adopted. Section 5 reports the experimental design carried out in the ceramic sector and evaluates the proposed model. Finally, Section 6 offers conclusions and further research.

\section{Related work}

Alemany et al. [9] proposed a deterministic ATP model for multi-plant manufacturing characterised by LHP. The model considers two objectives placed together within a single objective by the weighted sum method: 1) the maximisation of gross margin; and 2) the maximisation of exhausted ATP. The second objective implements an allocation rule of ATP to customer orders, which consists in reserving from the most adjusted discrete ATP quantity in order to exhaust the maximum number of ATP. Based on the above model, and to continue one of its future research lines, this paper presents a fuzzy mixed integer linear programming model for order promising in LHP multi-plant manufacturing contexts based on ATP quantities. The main differences between these two works are described below. The principal objective of this paper is to assess the impact of modelling inherent LHP uncertainty in production lots. For this reason, the fuzzy model proposed herein only considers the gross margin maximisation objective. Not taking into account the second objective allows the elimination of several integer and binary variables, which cuts computational times and makes more in-depth experimentation possible.

Several options are available to model uncertainties in supply chain problems. In mathematical modelling, one of the commonest approaches is to use probability distributions [17-20]. The main advantage of this approach is that it achieves high quality results based on historical data [11], but its performance diminishes when a long data record is not available 21. However, probability distributions that de- 
rive from past evidence are not always available or reliable. So whenever statistical data are unreliable, or are not even available, stochastic models may not be the best choice [22]. The fuzzy set theory [23] and the possibility theory [24 may be simpler and less data-demanding alternatives than the probability theory to deal with supply chain uncertainties [11, 25]. The fuzzy set theory also offers specific good performance by modelling uncertainty that relates to vagueness, imprecision and lack of information about the performance of the uncertain number. Using fuzzy sets when some of their certain parts cannot be fully controlled or reliably measured is normally recommended. For LHP contexts, the existence of uncontrollable productive factors makes the knowledge of the homogeneous quantities of each subtype available in future planned lots imprecise [9]. Accordingly, it is possible to model LHP by the fuzzy set theory.

As Alemany et al. 9 focus on modelling LHP in the OPP deterministically; in this paper we incorporate the uncertainty inherent to LHP. A similar fuzzy study in Alemany et al. 26] employs the same basis of the model of Alemany et al. [9], but to evaluate the so-called "shortage planning", which also belongs to the OPP, but seeks to evaluate a group of already promised orders and rearrange the ATP allocation to avoid possible shortages and failures with orders already promised with assigned due dates that are pending to be delivered. In this work, we reformulate the model of Alemany et al. [9] to improve its readability and to more efficiently solve it by eliminating some dependent binary variables.

In order to handle the right-hand side fuzzy technological coefficients, we base the development of the equivalent crisp model on the representation method found in Jiménez et al. [10]. The present research assumes that lots have been previously defined, and our interest resides on anticipating as much as possible the size of ATP-LHP quantities based on homogeneous sublots, with the aim of making reliable commitments to customers that ensure to serve them not only on time with the right quantities as usual, but also with the homogeneity terms required. Furthermore, our ATP model has been validated in a dynamic environment, by means of simulations runs requiring the updating of homogeneous ATP-LHP quantities based on customer orders committed.

Since the $\alpha$-cut represents the minimum possibility degree allowed to the possibility distribution of a fuzzy set, through the projection of alpha on its support, it is possible to obtain an equivalent crisp interval. The translation of a fuzzy model into an equivalent $\alpha$-parametric crisp model implies considering and evaluating different values of alpha in order to find suitable degrees of it, as a balance of the DM requirements in terms of the objective function and the risk in the solutions obtained due to the uncertainty conferred by the minimum possibility degree. Regarding the different methodologies that have been developed to evaluate the suitability of alpha in fuzzy mathematical programming models based on $\alpha$-cuts, readers are referred to the following works: Mula et al. [21], Gen et al. 27], Peidro and Vasant 28], Cadenas and Verdegay [29], and Peidro et al. [30. Most of them basically do not implement a quantitative methodology to approach a suitable 
$\alpha$-cut, but instead propose an interactive process where the final selection of the $\alpha$-cut is based on the DM 's criteria.

Since we aim to add complementary performance indicators to integrally examine the suitability of different $\alpha$-cuts, a novel adaptation of fuzzy-TOPSIS is used to evaluate their appropriateness for our proposal. TOPSIS is a method that has been widely applied in cases where no exact idea and data are available of ideal weight and performance among indicators (i.e. see Yong [12], Chu [31], Chamodrakas et al. 32, and Nakhaeinejad and Nahavandi [33, among others). As a result, this methodology ranks $\alpha$-cuts evaluated for the equivalent crisp model, which we expect to be better than the original deterministic model.

\section{The FMILP-ATP-LHP Model}

\subsection{Description of the problem}

The OPP refers to the set of business activities that are triggered to provide a response to customer order requests, which are usually expressed in terms of ordered quantities and due dates. Traditionally, the homogeneity of different available units of the same finished good $\left(F G_{i}\right)$ to be promised to customers has been assumed. This characteristic has allowed the accumulation of uncommitted $F G_{i}$ availabilities (available-to-promise: ATP) from different resources and time periods to meet the same customer order. However, this homogeneity assumption is not valid for manufacturing contexts with lack of homogeneity in the product (LHP) 9 . LHP contexts are characterised by units of the same $F G_{i}$ existing with some different relevant characteristics for customers, which gives rise to different subtypes of that same $F G_{i}$. Since customers require homogeneity among the units of the same $F G_{i}$ in their orders, several classification activities are located at the different points during the productive process to sort $F G_{i}$ into their respective subtypes.

The next section describes the assumptions and notation used for the Fuzzy ATPLHP model (FMILP-ATP-LHP), as well as its mathematical formulation.

\subsection{Assumptions}

Based on Alemany et al. 9], we formulate the FMILP-ATP-LHP model by considering the following assumptions:

- The MPS lots processed on each production line are assumed to be composed of homogeneous sublots, whose exact size will not be known with certainty until they are finally produced and classified. To reflect this fact, fuzzy beta coefficients are defined, which represent the fraction of each lot of the same $F G_{i}$ subtype (i.e. homogeneous sublots) that can be considered. For example, let's assume that three different subtypes can appear in lots of a certain $F G_{i}$ and that the three fractions of this lot are considered to be: 0.7 , 
0.2 and 0.1 . If we assume a lot size of $3,000 \mathrm{~m}^{2}$, the above fractions lead to three homogeneous sublots of $2,100 \mathrm{~m}^{2}, 600 \mathrm{~m}^{2}$ and $300 \mathrm{~m}^{2}$, respectively.

- The fractions of the homogeneous sublots (beta coefficients) can be dependent on the $F G_{i}$, production line and the time period.

- The sum of the beta coefficients for each $F G_{i}$, production line and time period (i.e. for a specific lot) must exactly add up to one.

- To ensure that orders are reserved from the homogeneous quantities of one same $F G_{i}$ (i.e. from the same subtype), it is not possible to serve an order by accumulating ATP-LHP quantities from different time periods, production lines and/or homogeneous sublots. In other words, it is mandatory to completely reserve the requested quantity of an $F G_{i}$ from an order from a single discrete homogeneous ATP-LHP quantity.

- When promising orders, ATP is allocated to orders by only taking into account profits.

- Rergarding to the demand of customer, in Make-To-Order (or mixed with Make-To-Stock) environments, as it is our case, the demand can not be considered uncertain because it is based (or a part of it is based) in order proposals, planned to arrive or already promised. A related study of inventory management with uncertain demand can be found in Shekarian et al. 34 .

\subsection{Notation}

\section{Indices:}

$o$ Customer order proposals waiting to be promised $(o=$ $1, \ldots, O)$.

$i$ The finished goods $\left(F G_{i}\right)$ required in the considered order proposals $(i=1, \ldots, I)$.

$b \quad$ Existing subtypes of all the $F G_{i}(b=1, \ldots, B)$.

$p$ Production plants $(\mathrm{p}=1, \ldots, \mathrm{P})$.

$l$ Production lines (productive resources) $(l=1, \ldots, L)$.

$t$ Time buckets $(\mathrm{t}=1, \ldots, \mathrm{T})$.

$s$ Iteration (interval of model execution) $(s=1, \ldots, S)$. 
Sets:

$O s(s) \quad$ Set of customer order proposals to be promised. It contains those customer order proposals whose arrival time $\left(t a_{o}\right)$ falls within the batching interval under execution $s$.

Osi $(i)$ Subset of customer order proposals from $O s(s)$ that request some quantity of $F G_{i}$.

Is $(s) \quad$ Set of all the $F G_{i}$ requested in the customer order proposals of $O s(s)$.

$I o(o) \quad$ Set of $F G_{i}$ requested in the customer order proposal $o$.

$B i(i) \quad$ Existing subtypes of $F G_{i}$.

$L p(p) \quad$ Set of manufacturing lines $l$ that belong to production plant $p$.

\section{Parameters:}

$t a_{o} \quad$ Arrival date of customer order proposal $o$.

$d d_{o} \quad$ Due date of customer order proposal $o$.

$q_{\text {io }} \quad$ Requested quantity of $F G_{i}$ in customer order proposal $o$.

nol $_{o} \quad$ Number of order lines $\left(F G_{i}\right)$ in customer order proposal $o$.

$p_{o} \quad$ Profit of order $o$.

$h c_{i o} \quad$ Inventory holding costs of quantity $q_{i} o$ per time period.

$b c_{o} \quad$ Backlogging cost of customer order proposal $o$ per delayed time period.

$r c_{o} \quad$ Rejecting cost of customer order proposal $o$.

$L D \max _{o}$ Maximum lateness or delay allowed for customer order proposal $o$ in relation to its due date (expressed as an integer number of the time period length). It is assumed that $L D O \max _{o} \leqslant T-d d_{o}$ (i.e. the real due date for order o cannot be later than the last period of the planning horizon).

$a t p 0_{i}^{b} \quad$ Not yet allocated existing stock of subtype b of $F G_{i}$, which becomes available at the beginning of the planning horizon and can still be promised to customers during iteration $s$.

$a t p B_{i l p t}^{b} \quad$ Not yet allocated homogeneous $F G_{i}$ sublot of subtype $b$, produced on manufacturing line $l$ that belongs to production plant $p$, which becomes available during period $t$. They represent the ATP quantities per $F G_{i}$, production line, time period and homogeneous sublot.

mpsilpt Production lot of $F G_{i}$ on production line $l$ of plant $p$ during period $t$ defined in the MPS.

$t q c_{i l p t}^{b} \quad$ Total committed quantity of $F G_{i}$ to the promised customer orders from the homogeneous sublot of subtype $b$ processed on production line $l$ of plant $p$ during time period $t$ until iteration $s$. 
$\tilde{\beta}_{i l p t}^{b} \quad$ Fuzzy homogeneity coefficients that represent the fraction of each $F G_{i}$ MPS lot subtype $b$ that can be considered homogeneous. Through these coefficients, the splitting of lots into homogeneous sublots is modelled. The sum of these coefficients for each $F G_{i}$, production line $l$ and time period $t$ should equal $1\left(\sum_{b} \tilde{\beta}_{i l p t}^{b}=1\right)$.

\section{Decision variables:}

$U O_{o} \quad$ Binary variable with a value of 1 if customer order proposal $o$ is served, and a value of 0 otherwise.

$R D D_{o} \quad$ Real due date of customer order proposal $o$.

$A D_{i o} \quad$ Number of time periods in advance to due date $d d_{o}$ that is allocated an ATP quantity of $F G_{i}$ to customer order proposal $o$.

$L D_{i o} \quad$ Number of time periods after due date $d d_{o}$ (lateness) that is allocated an ATP quantity of $F G_{i}$ to customer order proposal $o$.

$L D O_{o} \quad$ Number of time periods after due date $d d_{o}$ (lateness) when customer order proposal $o$ is served (it is the maximum $L D_{i o}$ ).

$A S D_{i o} \quad$ Time period at which requested quantity $q_{i o}$ of finished good $i$ of customer order $o$ has been assigned. This period is shorter or longer than the due date of the order if there is an advance or a delay, respectively.

$Y A_{i o} \quad$ Binary variable with a value of 1 if the requested quantity of $F G_{i}$ in customer order proposal $o$ involves reserving an ATP quantity before its due date (i.e., $A D_{i o}>0$ ).

$Y L_{i o} \quad$ Binary variable with a value of 1 if the requested quantity of $F G_{i}$ in customer order proposal $o$ involves reserving an ATP quantity after its due date (i.e., $L D_{i o}>0$ ).

$U_{i o}^{b} \quad$ Binary variable with a value of 1 if the requested quantity of $F G_{i}$ in the customer order proposal $o\left(q_{i o}\right)$ is completely served by $\operatorname{atp} 0_{i}^{b}$, and a value of 0 otherwise.

$U B_{\text {iolpt }}^{b} \quad$ Binary variable with a value of 1 if the requested quantity of $F G_{i}$ in customer order $o\left(q_{i o}\right)$ is completely served by homogeneous subtype $b$ of $a t p B_{i l p t}^{b}$, and a value of 0 otherwise.

$U A T P 0_{i}^{b} \quad$ Updated $a t p 0_{i}^{b}$ of subtype $b$ after committing customer order proposals of iteration $s(O s(s))$.

$U A T P B_{i l p t}^{b} \quad$ Updated homogeneous atp $B_{i l p t}^{b}$ after committing customer order proposals of iteration $s(O s(s))$. 


\subsection{Model formulation}

Objective function

In comparison to Alemany et al. [9], in this case we only consider the total profit of the committed orders in the objective function of Eq. 11). This objective is calculated as the difference among income through sales and costs of rejecting orders, serving orders with delay and the inventory holding cost incurred when some order lines are reserved in advance to the real due date of the customer order proposal.

Maximise:

$$
\sum_{o \in O s(s)} p_{o} U O_{o}-\left(\sum_{o \in O s(s)} r c_{o}\left(1-U O_{o}\right)+\sum_{o \in O s(s)} b c_{o} L D O_{o}+\sum_{o \in O s(s)} \sum_{i \in I o(o)} h c_{i o}\left(R D D_{o}-A S D_{o}\right)\right) .
$$

\section{Constraints:}

Eq. (2) updates the not yet allocated ATP of subtype $b$ in stock by subtracting the order lines reserved from it in iteration $s$.

$$
U A T P 0_{i}^{b}=a t p 0_{i}^{b}-\sum_{o \in O s i(i)} q_{i o} U_{i o}^{b} \quad \forall i \in I s(s), b \in B i(i) .
$$

Eq. (3) updates the not yet allocated ATP of homogeneous subtype b to be manufactured on production line $\mathrm{l}$ of plant $\mathrm{p}$ during time period $\mathrm{t}$ by subtracting the order lines reserved from it in iteration s.

$$
U A T P B_{i l p t}^{b}=a t p B_{i l p t}^{b}-\sum_{o \in O s i(i)} q_{i o} U B_{\text {iolpt }}^{b} \quad \forall p, l \in L p(p), i \in I s(s), b \in B i(i), t .
$$

Eq. (4) represents the fuzzification of the homogeneous sublots by applying fuzzy coefficient $\tilde{\beta}_{i l p t}^{b}$. Through this constraint, the initial ATP-LHP quantities of the homogeneous subtype are calculated as the difference between the MPS homogeneous sublot $\left(\tilde{\beta}_{i l p t}^{b} m p s_{i l p t}\right)$ and the total quantity committed to accepted orders until previous iteration $s-1$.

$$
a t p B_{i l p t}^{b}=\tilde{\beta}_{i l p t}^{b} m p s_{i l p t}-t q c_{i l p t}^{b} \quad \forall p, l \in L p(p), i \in I s(s), b \in B i(i), t .
$$

Eq. (5) states that one same order line served should be reserved from the product which comes from a single subtype of specific homogeneous sublots. This means that if the order line of $F G_{i}$ in order $o$ is served, no more than one of the binary 
variables $U_{i o}^{b}$ and $U B_{i o l p t}^{b}$ can take the value of 1 . This equation ensures meeting customers' homogeneity requirements.

$$
\sum_{b \in B i(i)} U_{i o}^{b}+\sum_{p, l \in L p(p)} \sum_{b \in B i(i), t} U B_{i o p l t}^{b} \leqslant 1 \quad \forall i \in I o(o), o \in O s(s) .
$$

Eq. (6) ensures, along with Eq. (5), that all the order lines in a same order must be reserved to fulfil that customer order (serving partial orders is not allowed). Otherwise the order is not served.

$$
\sum_{i \in I o(o)}\left(\sum_{b \in B i(i)} U_{i o}^{b}+\sum_{p, l \in L p(p)} \sum_{b \in B i(i), t} U B_{i o p l t}^{b}\right)=n o l_{o} U O_{o} \quad \forall o \in O s(s) .
$$

Eq. 77 calculates the advance or delay (lateness) of each order line of $F G_{i}$ as regards the due date of its order $o$.

$$
A D_{i o}-L D_{i o}=d d_{o} U O_{o}-\sum_{p, l \in L p(p), t}\left(\sum_{b \in B(i)} U B_{i o p l t}^{b}\right) t \quad \forall i \in \operatorname{Io}(o), o \in O s(s) .
$$

Eq. (8) indicates that the advance cannot be longer than the due date.

$$
A D_{i o} \leqslant d d_{o} Y A_{i o} \quad \forall i \in I o(o), o \in O s(s) .
$$

Eq. (9) indicates that the maximum delay cannot be longer than the maximum one allowed for all the lines in one same order.

$$
L D_{i o} \leqslant L D O \max _{o} Y L_{i o} \quad \forall i \in I o(o), o \in O s(s) .
$$

Eq. (10) ensures that an order line cannot be simultaneously reserved in advance and with delay. Therefore, at the most only one of the binary variables $Y A_{i o}$ and $Y L_{i o}$ can equal 1.

$$
Y A_{i o}+Y L_{i o} \leqslant 1 \quad \forall i \in I o(o), o \in O s(s) .
$$

Eq. (11) states that the delay in order o must equal the maximum delay of the order lines that compose it.

$$
L D_{i o} \leqslant L D O_{i o} \quad \forall i \in I o(o), o \in O s(s) .
$$

Eq. (12) ensures the impossibility of delaying order o if any of its order lines is delayed.

$$
L D O_{o} \leqslant \sum_{i \in I o(o)} L D_{i o} \quad \forall o \in O s(s)
$$


Eq. 13 forces that the delay of an order does not exceed the maximum one allowed for that order.

$$
L D O_{o} \leqslant L D O \max _{o} U O_{o} \quad \forall o \in O s(s) .
$$

Eq. (14) calculates the real delivery date of each order based on its due date and its delay. As observed from this equation, an order cannot be delivered before its due date, even though some of its order lines were reserved in advance. In this last case, the order lines will be hold in inventory until the real delivery date of the order.

$$
R D D_{o}=d d_{o} U O_{o}+L D O_{o} \quad \forall o \in O s(s)
$$

Through Eq. [15), the assignation time period of order line i, which belongs to customer order o, is calculated.

$$
A S D_{i o}=d d_{o} U O_{o}-A D_{i o}+L D_{i o} \quad \forall i \in \operatorname{Io}(o), o \in O s(s) .
$$

Finally, Eq. 16 shows the definition of the variables.

$$
\begin{aligned}
& U O_{o}, Y A_{o}, Y L_{i o}, U B_{i o l p t}^{b}, U_{i o}^{b} \quad \text { Binary, } \\
& R D D_{o}, A D_{i o}, L D_{i o}, L D O_{o}, A S D_{i o} \quad \text { Integer, } \\
& U A T P 0_{i}^{b}, U A T P B_{i l p t}^{b} \quad \text { Continuous. }
\end{aligned}
$$

As observed, only the homogeneity coefficients $\left(\tilde{\beta}_{i l p t}^{b}\right)$ are considered under uncertainty. Additionally, other technological coefficients and cost parameters can be considered uncertain according to the real world problem to be modelled. Examples of these coefficients are backlogging costs, $b c_{o}$, and costs of rejecting customer orders, $r c_{o}$, which are usually estimated in practice based on a percentage of the order profit and customer priority. Nevertheless, the uncertain consideration of such parameters are beyond the scope of this model, which mainly focuses on the uncertain modelling inherent to the LHP in the homogeneous sublots of each subtype, as represented by the $\tilde{\beta}_{i l p t}^{b}$ parameter.

\section{Solution methodology}

\subsection{Transforming the FMILP-ATP-LHP model into an equivalent $\alpha$-parametric crisp model}

As described in Section 3.3, the fuzzy nature of Eq. (4) requires an appropriate methodology to handle the right-hand side fuzzy coefficient. Since our topic relates specifically to the handling of fuzzy homogeneous sublots, we initially applied the 
methodology by Jiménez et al. [10 to model the quantities of the homogeneous product obtained after subdividing the original heterogeneous lot (which is the function of Eq. (4) by using trapezoidal fuzzy numbers, which can adequately represent the fuzzy nature inherent to the sublots in the FMILP-ATP-LHP problem. The objective is to translate the fuzzy constraints of our model into equivalent crisp ones. One of the main reasons for selecting this method was that it has been evidently validated for solving linear programming models, where technological coefficients are generally fuzzy numbers on the left/right-hand side of equations, which is our case. This approach responds to the following question as to how the feasibility of "decision vector $\mathrm{x}$ " is defined when constraints involve fuzzy numbers. It is important to highlight, that we herein extend the approach of Jiménez et al. [10] by using the TOPSIS methodology instead of fuzzy number ranking to evaluate the fuzzy solution. This is explained in the next section. According to the methodology, Eq. (4) can be expressed in our model as follows by considering $\tilde{\beta}_{i l p t}^{b}=\left(\beta_{i l p t}^{b 1}, \beta_{i l p t}^{b 2}, \beta_{i l p t}^{b 3}, \beta_{i l p t}^{b 4}\right)$ :

$$
\begin{aligned}
& a t p B_{i l p t}^{b} \leqslant\left[\frac{\alpha}{2}\left(\frac{\beta_{i l p t}^{b 1}+\beta_{i l p t}^{b 2}}{2}\right)+\left(1-\frac{\alpha}{2}\right)\left(\frac{\beta_{i l p t}^{b 3}+\beta_{i l p t}^{b 4}}{2}\right)\right] m p s_{i l p t}-t q c_{i l p t}^{b} \\
& a t p B_{i l p t}^{b} \geqslant\left[\frac{\alpha}{2}\left(\frac{\beta_{i l p t}^{b 3}+\beta_{i l p t}^{b 4}}{2}\right)+\left(1-\frac{\alpha}{2}\right)\left(\frac{\beta_{i l p t}^{b 1}+\beta_{i l p t}^{b 2}}{2}\right)\right] m p s_{i l p t}-t q c_{i l p t}^{b}
\end{aligned}
$$

Both Eqs. 17 18 defined $\forall p, l \in L p(p), i \in I s(s), b \in B i(i), t$.

The fuzzy coefficients of the equivalent crisp model are represented as $\alpha$-parametric values, which can vary in a predefined interval based on the alpha parameter. The alpha parameter value belongs to the interval [0, 1]. Low alpha values represent high levels of uncertainty, and vice versa, and modelling an alpha that equals 1 means completely deterministic performance. This representation permits the $\tilde{\beta}_{i l p t}^{b}$ coefficients to be represented by trapezoidal fuzzy numbers, but also by triangular ones by taking $\beta_{\text {ilpt }}^{b 2}=\beta_{\text {ilpt }}^{b 3}$.

A novel aspect when modelling LHP uncertainty by fuzzy beta coefficients, similar to that done in Alemany et al. [26], consists in ensuring that they all add up to 1 because they represent the fraction of an MPS lot. Therefore, the sum of the homogeneous subtypes should equal the corresponding lot of the MPS. One frequent way to model this aspect in a deterministic context consists in adding one constraint to ensure that the sum of the beta coefficients equals 1 . However, this way of defining beta coefficients cannot be used when they are considered fuzzy because they represent a range of values and, therefore, do not take a unique value. In this case, it is not possible to formulate a constraint over beta coefficients to ensure they add up to 1. Alternatively, we opted to define a new Eq. (19), which is derived by summing up Eq. (4) over the b parameter, and then applying the property of $\sum_{b} \tilde{\beta}_{i l p t}^{b}=1$. The resulting Eq. 19 ensures that beta coefficients are adjusted in their membership function to add up to 1 and that, at the same 
time, the quantity allocated to the different customer orders does not exceed the uncommitted available quantity that derives from each lot in the MPS. In short, Eq. (19) guarantees that the sum of the homogeneous sublots obtained through the defuzzification of fuzzy numbers by Eqs. $17 \sqrt[18]{18}$ equals the MPS lot. This could be used for any fuzzy equation like Eq. (4) when technological coefficients are interdependent.

$$
\sum_{b} a t p B_{i l p t}^{b}=m p s_{i l p t}-\sum_{b} t q c_{i l p t}^{b} \quad \forall p, l \in \operatorname{Lp}(p), i \in I s(s), t .
$$

Although other studies have modelled uncertainty in technological coefficients, they are assumed to be independent. Therefore, modelling uncertainty in dependent technological coefficients like this one is, therefore, one of the contributions of our paper. Thus the equivalent crisp model obtained by the transformation of the FMILP-ATP-LHP model is as follow:

Maximise: Eq. (1)

Subject to: Eqs. (2,3), 5,19

The above equivalent crisp model is an $\alpha$-parametric mixed integer linear program model, where alpha represents the minimum possibility degree allowed in the fuzzy sets applied to represent the homogeneity interdependent coefficients. If the DM seeks a high degree of satisfaction of the constraints, the alpha value should be set close to 1 . In this case, the feasible set solution becomes smaller and, consequently, the optimal objective value worsens. So the DM must find a balanced solution between two objectives in conflict to improve the objective function value and to improve the degree of satisfaction of the constraints [10]. That is, the DM must evaluate which pair ( $\alpha$, Profit) offers better results as a balance between the objective value, but at the same time the possibility degree allowed and the unreliability that it confers to the solution obtained. The next section reports a solution approach to support the DM in making the most satisfactory choice.

\subsection{Methodology for alpha level evaluation based on fuzzy TOPSIS}

Since the FMILP-ATP-LHP model is transformed into an equivalent $\alpha$-parametric crisp model according to Section 4.1, the next step must be to evaluate the suitability of the different alpha values considered. We contemplate a parametrisation of alpha within range $[0,1]$ by evaluating the following possibilities $[0,0.1,0.2$, $0.3,0.4,0.5,0.6,0.7,0.8,0.9,1]$, which is a wide range of solutions. As mentioned in Section 2 different methodologies for analysing and defining the alpha value have been reported in the literature. In our case, we wish to use an interactive procedure that allows the DM to add his/her preferences and requirements while evaluating alpha values. There are some possibilities; for example, the interactive method of Jiménez et al. [10]. In this case, our intention was for the DM to have 
the chance to add additional measures to support the decision more comprehensively (i.e. see Mula et al. 21] and Peidro et al. [11]) because the final values of the total profit generated in the model's objective function are strongly affected by the uncertainty of the homogeneous sublots. So each change made in the alpha value can become very sensitive. In order to validate models, we propose using the following group of measurable parameters:

(i) Profit $(€)$ : it is the original objective function of the equivalent crisp model.

(ii) Inventory holding cost $(€)$ : it is one of the factors of the objective function that is interesting for evaluating separately because it represents a huge fraction of the total cost.

(iii) Rejecting cost $(€)$ : it is important to analyse this factor of the objective function because it represents the penalty of not serving orders. The ideal situation is that rejecting costs never exists.

(iv) Number of served orders: this factor is important because, in this sense, not necessarily serving a lot of orders means achieving the best profit results. This is because not all the orders can generate the same profit. So the model must attempt to serve the most valuable ones, while also serving as much orders as possible to maintain the customer service level.

(v) Alpha risk: this is the risk of the alpha value. It is important to take it into account given the fact that low alpha values can lead the model to produce better profit results, but these are the most risky solutions in terms of the real feasibility of implementation.

In order to evaluate the suitability of each alpha scenario, we adapted the fuzzy TOPSIS method presented by Yong [12], where an interactive method based on multiple indicators was used to select plant location. Here the idea is to evaluate the indicators based on linguistic values for two aspects: the weight that the DM wishes to allocate to each indicator; the linguistic performance finally obtained by each one. These linguistic variables are interpreted by a fuzzy number. Although the methodology presented by Yong [12 used triangular fuzzy numbers, and we maintain that type of fuzzy sets in this work, other like trapezoidal are also recommended because they allow to measure interval rating scales (see for example [35, 36] for centroid-based measures). TOPSIS method is of widespread use in cases where no exact idea and data of the ideal weight and performance among indicators are available (i.e. see [32, 33]). Our methodology can be summarised as follows:

Step 1: Execute the auxiliary equivalent crisp model obtained by applying the procedure described in Section 4.1 and by considering the feasibility interval $0 \leqslant$ $\alpha_{k} \leqslant 1$, where the discrete alpha values are defined by $M=\left\{\alpha_{k}=0.1 k \mid k=\right.$ $0,1,2, \ldots, 10\} \subset[0,1]$, and for each case, obtain the value of indicators (i) to (iv).

Step 2: Define the linguistic criteria for the evaluation of the weights that DM can assign to each indicator. In this case, we used the data in Table 1 . 
Table 1: Linguistic variables for the weight of each indicator

\begin{tabular}{|l|c|cccc|}
\cline { 3 - 6 } \multicolumn{2}{c|}{} & \multicolumn{4}{c|}{ Triangular fuzzy } \\
\hline Linguistic value & Abbreviation & $\mathrm{a}$ & $\mathrm{b}$ & $\mathrm{c}$ & Graden mean $\left(W_{j}\right)$ \\
\hline Very low & VL & 0 & 0.1 & 0.3 & 0.1167 \\
Low & $\mathrm{L}$ & 0.1 & 0.3 & 0.5 & 0.3000 \\
Medium & $\mathrm{M}$ & 0.3 & 0.5 & 0.7 & 0.5000 \\
High & $\mathrm{H}$ & 0.5 & 0.7 & 0.9 & 0.7000 \\
Very high & VH & 0.7 & 0.9 & 1 & 0.8833 \\
\hline
\end{tabular}

Step 3: Define the linguistic criteria for the ratings to be used to evaluate the performance of each indicator. In our case, we used the values in Table 2

Table 2: Linguistic variables for ratings

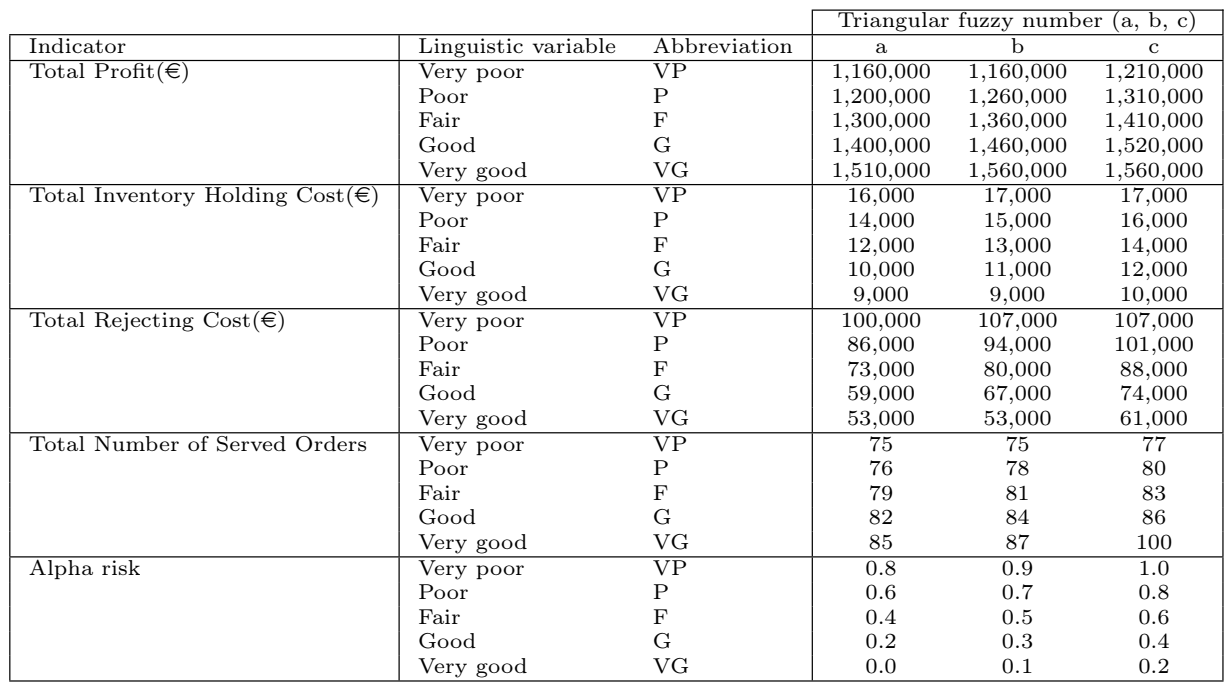

Step 4: Compute the graded mean integration representation of the fuzzy numbers of the linguistic variables $[12$. Given,

$i=$ the index of the alternatives to evaluate. Here this index corresponds to the number of alpha scenarios.

$j=$ the index of the attributes of the criteria to be taken into account when evaluating scenarios $i$. In this methodology, index $j$ corresponds to performance indices (i) to (iv).

If triangular fuzzy number $T_{j}=\left(a_{j}, b_{j}, c_{j}\right)$ represents the linguistic variables of the weights, according to the procedure of Yong [12, the graded mean for the 
weight assigned to each criteria j can be estimated with Eq. 20 . The results of this calculation are shown in Table 1.

$$
W_{j}=\frac{1}{6}\left(a_{j}+4 b_{j}+c j\right) .
$$

Now for the linguistic variables of the performance ratings, let us consider triangular fuzzy number $T_{i j}=\left(a_{i j}, b_{i j}, c_{i j}\right)$, which represents the linguistic interpretation/rating of the performance of each alternative $i$ compared to criteria $j$. Then the converted criteria $r_{i j}^{*}=\left(o_{i j}, p_{i j}, q_{i j}\right)$ can be calculated as shown below to translate the fuzzy number into a comparable one depending on whether the criterion is minimisation or maximisation,

For maximisation:

$$
o_{i j}=\frac{a_{i j}}{c_{j}^{*}}, p_{i j}=\frac{b_{i j}}{c_{j}^{*}}, q_{i j}=\frac{c_{i j}}{c_{j}^{*}} \text { where } c_{j}^{*}=\min \left(c_{i j}\right) .
$$

For minimisation:

$$
o_{i j}=\frac{a_{j}^{*}}{c_{i j}}, p_{i j}=\frac{a_{j}^{*}}{b_{i j}}, q_{i j}=\frac{a_{j}^{*}}{a_{i j}} \text { where } a_{j}^{*}=\min \left(a_{i j}\right) .
$$

Now with the converted fuzzy number it is possible to estimate graded mean integration $R_{i j}=P\left(r_{i j}^{*}\right)[12$ in the following way:

$$
R_{i j}=\left(\frac{1}{6} o_{i j}+\frac{4}{6} p_{i j}+\frac{1}{6} q_{i j}\right) .
$$

The data of values $\mathrm{a}, \mathrm{b}$ and $\mathrm{c}$ in Table 2 were obtained from previous test runs of the model, where we obtained a logic minimum and minimum value of each indicator, and based on them, we estimated the linguistic values.

Step 5: Build the weighted decision matrix. The weighted decision matrix is a tool used to calculate the final resulting performance of each weighted criteria. It is calculated by multiplying the weights allocated by the DM to each criterion (graded mean of Table 1 per criterion), and the resulting rating of that criterion according to the linguistic variables (graded mean of the resulting qualification obtained by the criterion according to Table 2). In general, the weighted decision matrix comes as:

$$
S_{i j}=W_{j} \otimes R_{i j}=\left[z_{i j}\right]_{i x j} .
$$

According to the procedure, the weighted decision matrix must be normalised as:

$$
N_{i j}=\left[n_{i j}\right]_{i x j} \text { where } n_{i j}=\frac{z_{i j}}{\sqrt{\sum_{i}\left(z_{i j}\right)^{2}}} .
$$


Step 6: Determine the ideal and negative-ideal solutions. Ideal $\left(A^{+}\right)$and negativeideal $\left(A^{-}\right)$solutions could be found, which are to be taken into account as a parameter to define what evaluated alternative is either far from or near to that ideal solution; based on that, the final decision must be taken. The ideal and negative-ideal solutions can be computed as:

$$
\begin{aligned}
& A^{+}=\left(n_{1}^{+}, n_{2}^{+}, \ldots, n_{j}^{+}\right), \\
& A^{-}=\left(n_{1}^{-}, n_{2}^{-}, \ldots, n_{j}^{-}\right),
\end{aligned}
$$

where $n_{j}^{+}=\max _{i}\left(n_{i j}\right)$ and $n_{j}^{-}=\min _{i}\left(n_{i j}\right)$.

Step 7: Compute the distance of each alternative evaluated from $A^{+}$and $A^{-}$. The distance from each alternative from the ideal and ideal-negative solutions is computed with Eqs. 27.28.

$$
\begin{aligned}
& d_{i}^{+}=\sqrt{\sum_{j}\left(n_{i j}-n_{j}^{+}\right)^{2}} . \\
& d_{i}^{-}=\sqrt{\sum_{j}\left(n_{i j}-n_{j}^{-}\right)^{2}} .
\end{aligned}
$$

Step 8: Calculate the closeness coefficients. The closeness coefficient computes the final performance of each evaluated alternative compared to the ideal and negative-ideal solutions. Thus, the better the closeness coefficient is, the more suitable the alternative is. It can be calculated as follows:

$$
C C_{i}=\frac{d_{i}^{-}}{d_{i}^{+}+d_{i}^{-}} .
$$

\section{Experimental design}

The experiments carried out in this section aim to validate the FMILP-ATP-LHP model in the ceramic sector, and to compare the solutions obtained by the deterministic and the fuzzy model in different execution modes in different forecasts of reality. The following subsections describe the input data of the models, the experimental methodology and the analysis of results. 


\subsection{Data}

The experimental data of this paper mainly coincide with those presented in Alemany et al. [9], which was inspired in the ceramic sector: two plants are considered, one with two production lines and the other with one production line, which are all capable of processing four $F G_{i}$. For each $F G_{i}$, three subtypes are considered. The model horizon $(\mathrm{T})$ comprises eight periods. The sale prices per $m^{2}\left(p i_{i}\right)$, backlog costs per $m^{2}\left(b c_{i}\right)$ and inventory holding costs per $m^{2}$ of $F G_{i}$ and period $\left(\right.$ huci $\left._{i}\right)$ are shown in Table 3. It is also shown in Table 3 the configuration of each of the three classes of orders considered.

The arrival of 100 order proposals was simulated. The same 100 order proposals were considered to be the input to all the problem types. Parameters $p_{o}, b c_{o}$, $h c_{o}$ and $r c_{o}$ for each order were calculated by multiplying quantity $q_{i o}$ by the corresponding unitary parameters $p_{i}, b c i_{i}, h u c i_{i}$ and $r c i_{i}$, and then by summing up all the $F G_{i}$ included in the customer order proposal.

Table 3: Input data

\begin{tabular}{|c|c|c|c|c|c|c|c|}
\hline & \multicolumn{4}{|c|}{$\begin{array}{l}\text { Sales price, backlog cost, holding } \\
\text { cost and rejecting cost }\left(€ / \mathrm{m}^{2}\right)\end{array}$} & \multicolumn{3}{|c|}{ Classes of orders $\left(\mathrm{m}^{2}\right)$} \\
\hline Finished goods & $p i_{i}$ & $b c i_{i}$ & $h u c i_{i}$ & $r c i_{i}$ & Ord A & Ord B & Ord C \\
\hline FG1 & 18 & 0.9 & 0.072 & 2.7 & 15 & 300 & 1500 \\
\hline FG2 & 16 & 0.85 & 0.065 & 2.4 & 60 & 400 & 2000 \\
\hline FG3 & 12 & 0.7 & 0.06 & 1.8 & 30 & 200 & 1000 \\
\hline FG4 & 10 & 0.5 & 0.055 & 1.5 & 90 & 300 & 1500 \\
\hline
\end{tabular}

The quantities of each order line for each $F G_{i}$ were randomly generated from the same three classes of orders as in Table 3, which can be assimilated with final customers, independent distributors and construction firms. The arrival time of each order $\left(t a_{o}\right)$ was generated as follows: $t a_{o}=t a_{o-1}+$ random $[0,0.06]$ periods, whereas its associated due date $\left(d d_{o}\right)$ was generated randomly from among $\left[t a_{o}\right.$, T]. The maximum delay $\left(L D O \max _{o}\right)$ was established during two periods for all the orders. The FMILP-ATP-LHP model was run in five batching modes: SingleOrder Processing (SOP), which consists in executing the model each time an order arrives; Batch-Order Processing (BOP), which consists in accumulating orders in a window of time and then executing the model. The batching intervals considered were $B=1$ period $(B O P 1), B=2$ periods ( $B O P 2), B=4$ periods ( $B O P 4)$, and a global one $(\mathrm{GOP})$, which is the equivalent to a Batch Order with $\mathrm{B}=8$ periods. In this research, and in order to better represent reality, the number of order lines that integrate each customer order proposal is not fixed to three order lines as in Alemany et al. [9], but was randomly generated among one to four lines after taking into account the following proportions: $47 \%$ of 1 order line, $18 \%$ of 2 order lines, $9 \%$ of 3 order lines and $26 \%$ of 4 order lines. Only the adjusted supply scenario was considered because with proper performance, companies must adjust 
supply and demand. For the Adjusted Supply, the MPS lots of each $F G_{i}$ were generated as $+/-10 \%$ of the requested quantities of this $F G_{i}$ in customer orders.

Finally given the new assumptions of this research, it was necessary to define additional parameters that represent the fractions of homogeneous sublots: beta coefficients. In this research fuzzy beta coefficients are represented by a triangular membership function, whose central values are $0.7,0.2$ and 0.1 with a variation of $+/-50 \%$ for all the $F G_{i}$, production lines and time periods. Finally, the alpha parameter varies from 0 to 1 with increments of 0.1 .

\subsection{Evaluation of Deterministic and Fuzzy Decisions: Experimental Methodology}

The experiments were designed for the purpose of evaluating the reliability and quality of the solutions obtained by the deterministic and fuzzy model. The deterministic model coincides with the FMILP-ATP-LHP model in that it considers beta coefficients $\left(\tilde{\beta}_{i l p t}^{b}\right)$ to be deterministic, which is the same as making $\alpha=1$ in the equivalent crisp FMILP-ATP-LHP model. The experimental methodology followed is represented in Figure 1

The input data described in Subsection 5.1 was used to solve the deterministic and FMILP-ATP-LHP model in the SOP, BOP1 (batching interval of one period), BOP2 (batching interval of two periods), BOP4 (batching interval of four periods) and GOP execution modes. Execution modes different from the GOP one, requires the FMILP-ATP-LHP model to be solved several times in a dynamic context and the ATP-LHP quantities to be updated after each execution. The methodology in Subsection 4.2 was applied in each execution mode to evaluate the suitability of alpha.

After evaluating the alpha degrees for each execution mode (SOP, BOP1, BOP2, BOP4 and GOP), our methodology proposes to select the most suitable in each case, given all the steps in the procedure, in order to compare deterministic and fuzzy scenarios. The solution (output) of the deterministic and fuzzy model provided the set of customer orders committed $\left(U O_{o}=1\right)$ and the real due date promised to customers $\left(R D D_{o}\right)$ based on an estimation of the homogeneous sublots (beta parameters).

Due to the fuzziness of the beta parameters, the real size of the homogeneous sublots can only be known when they are finally produced and classified. Therefore, discrepancies among planned and real homogeneity quantities are normal. This can lead to the fact that previously committed orders cannot be served because there are not enough homogeneous quantities. At this point we distinguished between the planned customer orders committed $\left(U O_{o}=1\right)$, which corresponded to the solution of the deterministic and fuzzy model with the planned value of the beta coefficients, and those that could really be served $\left(U O R_{o}=1\right)$ when the real value of the beta coefficients was known (the real size of the homogeneous sublots). To determine which customer orders could really be served $\left(U O R_{o}=1\right)$ from those 


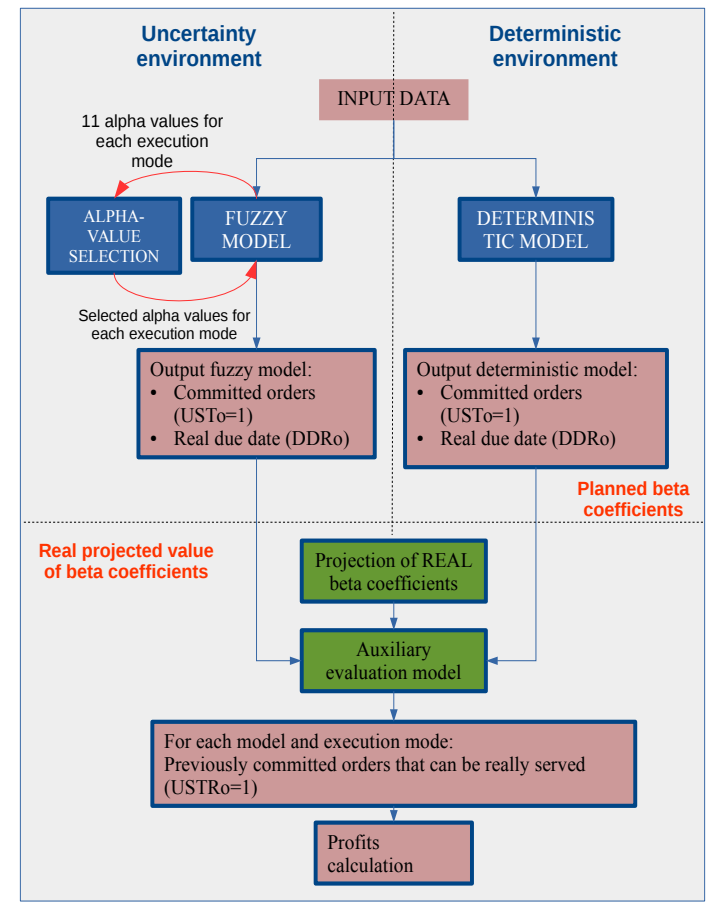

Figure 1: Experimental methodology

committed by the deterministic and fuzzy model, the real values of the beta coefficients $\left(B r_{i l p t}^{b}\right)$ were forecasted inside the triangular function for each $F G_{i}$ MPS lot $\left(m p s_{i l p t}\right)$ to ensure that they all added up to one. Such forecasting intends to simulate a real situation when MPS lots are finally produced and classified. Then an auxiliary evaluation model is formulated whose input is the customer orders previously committed for the deterministic and the fuzzy model $\left(U O_{o}=1\right)$, their real due date $\left(R D D_{o}\right)$ and the real projected value of beta coefficients $\left(B r_{i l p t}^{b}\right)$. The solution of the auxiliary evaluation model determines which orders can finally be served $\left(U O R_{o}=1\right)$ according to a real estimation of homogeneous sublots.

The mathematical formulation of the auxiliary evaluation model was almost the same as the FMILP-ATP-LHP model, and the batching interval equalled the planning horizon $(\mathrm{s}=\mathrm{T})$, but with an additional constraint that did not allow previous committed orders to be served by the fuzzy model (i.e $U O R_{o} \leqslant U O_{o}$ ) due to the differences between the planned $\left(\tilde{\beta}_{i l p t}^{b}\right)$ and real homogeneous sublots $\left(B r_{i l p t}^{b}\right)$. For this auxiliary evaluation model, it was assumed that all the MPS lots were uncommitted and, after their real splitting into homogeneous sublots by applying 
the coefficients, they should be allocated to previous committed orders. This evaluation was made with an "n" number of real forecasts of the beta values to obtain significant results. Based on these results, the average real profit was calculated.

\subsection{Application of the experimental methodology}

\subsubsection{Alpha evaluation for the FMILP-ATP-LHP model}

In this step of the experimental methodology, the DM's most satisfactory alpha value for the FMILP-ATP-LHP was selected. Following the steps described in Subsection 4.2, the steps 1 to 3 were undertaken by defining 11 possible alpha values from 0 to 1 with increments of 0.1 , and by executing the model. The linguistic values for the weight of each criterion with its specific graded mean are defined in Table 1. Then the FMILP-ATP-LHP model was executed for the 11 alpha values, and the indicators reported in Table 4 were obtained. According to the step 4 of our methodology, the graded mean for the ratings was computed by allocating the linguistic evaluation according to the result of each indicator in relation to the ranges for the fuzzy numbers in Table 2. Then the graded mean integration was obtained by applying Eq. 23. The results are shown in Table 4

According to the step 5, the weighted decision matrix and the normalised weighted decision matrix have to be computed by applying Eq. (24) and Eq. (25), respectively. Table 5 presents the results of these calculations. In the step 6 , the ideal $\left(A^{+}\right)$and negative-ideal $\left(A^{-}\right)$solutions were computed by applying Eq. 26. Table 6 shows the results of this calculation. The step 7 also specified that the distance from each alternative (alpha scenario) to the $A^{+}$and $A^{-}$solutions can be computed by applying Eqs. (27) and (28). Table 7 shows the results.

Finally by applying Eq. 29, the closeness coefficient in the step 8 of our methodology was computed to make the final decision. Table 8 offers the results of this calculation where we can see how alpha scenario 0.8 is the most suitable. This means that a minimum possibility degree of alpha around 0.8 represents a reasonable measure of risk, considering the combination between the needs of DM in terms to improve the deterministic performance, but with a good expectation of reliability of the final solution obtained.

Other methods reported in the literature to evaluate the alpha level intend the DM to decide the most appropriate value according to an established set of indicators [21, 30], an overall degree of satisfaction of the set of solutions [28 or by proposing a fixed alpha level value 29]. In this case, adopting any of the previous solution methods implies the DM having to make a decision according to the set of indicators shown in Table 4. which can lead to an ambiguous decision because some maximisation indicators usually present better values that come closer to 0 , while minimisation come closer to 1 . The proposed methodology incorporates the DM into two main points, i.e. defining the set of indicators to be considered in the TOPSIS problem, even when the results of these indicators come from the model, 
and determining the risk values for the alpha levels. It is here where the proposed methodology proves superior to quantitatively suggest suitable alpha values rather than leaving the complete decision to the DM.

Table 4: Profits (€) of the FMILP-ATP-LHP model

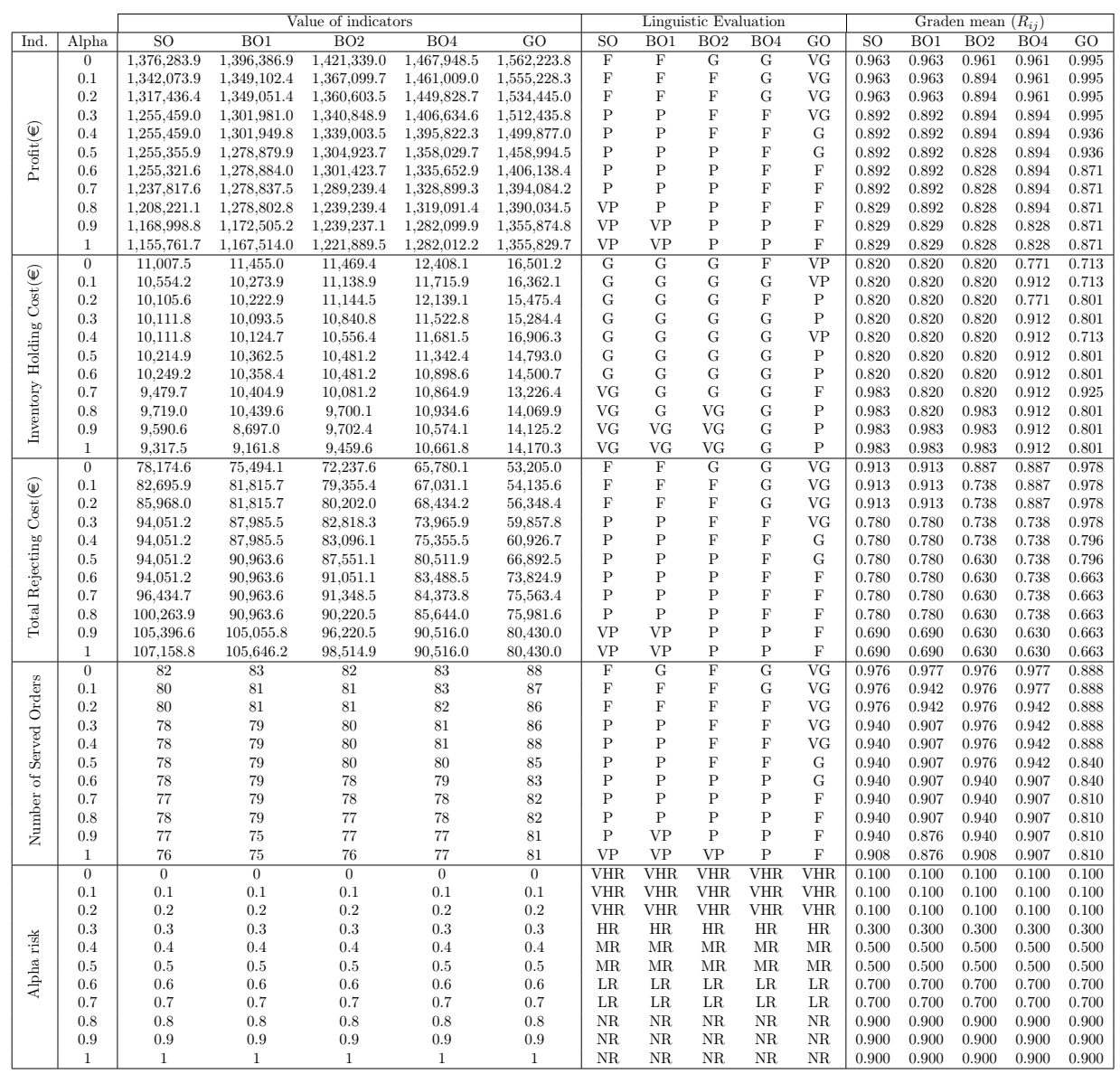

The main finding is that the procedure was able to identify an alpha-level that either reached at least the closeness coefficient of the deterministic model, or even surpassed it during all the batching modes executions. This revealed consistency in the performance of the model in terms of the uncertainty handled across the executed batching modes. Then the TOPSIS-based procedure showed good performance for finding an acceptable balance between the uncertainty risk and the DM's requirements in those cases where the weights that the DM wishes to allocate to each performance indicator used to make the final decision are not completely 
Table 5: Decision matrix

\begin{tabular}{|c|c|c|c|c|c|c|c|c|c|c|c|}
\hline \multirow[b]{2}{*}{ Ind. } & \multirow[b]{2}{*}{ Alpha } & \multicolumn{5}{|c|}{ Weighted decision matrix } & \multicolumn{5}{|c|}{ Normalised matrix } \\
\hline & & SO & BO1 & $\mathrm{BO} 2$ & $\mathrm{BO} 4$ & GO & SO & BO1 & $\mathrm{BO} 2$ & $\mathrm{BO} 4$ & GO \\
\hline \multirow{11}{*}{ 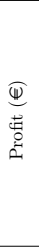 } & 0 & 0.851 & 0.851 & 0.848 & 0.848 & 0.879 & 0.324 & 0.322 & 0.335 & 0.321 & 0.323 \\
\hline & 0.1 & 0.851 & 0.851 & 0.789 & 0.848 & 0.879 & 0.324 & 0.322 & 0.312 & 0.321 & 0.323 \\
\hline & 0.2 & 851 & 0.851 & 0.789 & 0.848 & 0.879 & 0.324 & 0.322 & 0.312 & 0.321 & 0.323 \\
\hline & 0.3 & 0.788 & 0.788 & 0.789 & 0.789 & 0.879 & 0.300 & 0.299 & 0.312 & 0.299 & 0.323 \\
\hline & 0.4 & 0.788 & 0.788 & 0.789 & 0.789 & 0.828 & 0.300 & 0.299 & 0.312 & 0.299 & 0.304 \\
\hline & 0.5 & 788 & 0.788 & 0.731 & 0.789 & 0.828 & 0.300 & 0.299 & 0.289 & 0.299 & 0.304 \\
\hline & 0.6 & 788 & 0.788 & 0.731 & 0.789 & 0.769 & 0.300 & 0.299 & 0.289 & 0.299 & 0.283 \\
\hline & 0.7 & 0.788 & 0.788 & 0.731 & 0.789 & 0.769 & 0.300 & 0.299 & 0.289 & 0.299 & 0.283 \\
\hline & 0.8 & 732 & 0.788 & 0.731 & 0.789 & 0.769 & 0.279 & 0.299 & 0.289 & 0.299 & 0.283 \\
\hline & 0.9 & 732 & 0.732 & 0.731 & 0.731 & 0.769 & 0.279 & 0.277 & 0.289 & 0.277 & 0.283 \\
\hline & 1 & 732 & 0.732 & 0.731 & 0.731 & 0.769 & 0.279 & 0.277 & 0.289 & 0.277 & 0.283 \\
\hline \multirow{11}{*}{ 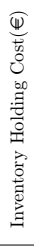 } & 0 & 410 & 0.410 & 0.410 & 0.385 & 0.357 & 0.280 & 0.290 & 0.285 & 0.262 & 0.272 \\
\hline & 0.1 & 410 & 0.410 & 0.410 & 0.456 & 0.357 & 0.280 & 0.290 & 0.285 & 0.310 & 0.272 \\
\hline & 0.2 & 410 & 0.410 & 0.410 & 0.385 & 0.401 & 0.280 & 0.290 & 0.285 & 0.262 & 0.306 \\
\hline & 0.3 & 0.410 & 0.410 & 0.410 & 0.456 & 0.401 & 0.280 & 0.290 & 0.285 & 0.310 & 0.306 \\
\hline & 0.4 & 410 & 0.410 & 0.410 & 0.456 & 0.357 & 0.280 & 0.290 & 0.285 & 0.310 & 0.272 \\
\hline & 0.5 & 410 & 0.410 & 0.410 & 0.456 & 0.401 & 280 & 0.290 & & 0.310 & .306 \\
\hline & 0.6 & 410 & 0.4 & 0.4 & & & & & & 0.310 & 0.306 \\
\hline & 0.7 & 492 & 0.410 & 0.410 & 0.4 & 0.462 & 0.336 & 0.290 & & 0.310 & 0.353 \\
\hline & 0.8 & 492 & 0.410 & 492 & & & 336 & 0.290 & & 0.310 & 0.306 \\
\hline & 0.9 & 492 & 0.492 & 0.492 & 0.456 & 0.401 & 0.336 & 0.348 & 0.342 & 0.310 & 0.306 \\
\hline & 1 & 492 & 0.492 & 0.492 & 0.456 & 0.401 & 0.336 & 0.348 & 0.342 & 0.310 & 0.306 \\
\hline \multirow{11}{*}{ 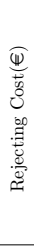 } & 0 & 457 & 0.457 & 0.443 & 0.443 & 0.48 & 0.343 & 0.343 & 0.38 & 0.350 & 0.362 \\
\hline & 0.1 & 457 & 0.457 & 0.369 & 0.443 & 0.489 & 0.343 & 0.343 & 0.319 & 0.350 & 0.362 \\
\hline & 0.2 & 457 & 0.457 & 0.369 & 0.443 & 0.4 & .343 & 0.343 & 0.3 & 0.350 & 0.362 \\
\hline & 0.3 & 390 & 0.390 & 59 & 0.3 & & 293 & 0.293 & & 0.291 & 0.362 \\
\hline & 0 & 90 & $0.3 \mathrm{~s}$ & & & & & & & 0.291 & 0.295 \\
\hline & 0 & 90 & & 0.3 & & & & 0.293 & & 0.291 & 0.295 \\
\hline & 0.6 & 90 & & & & & & & & 0.291 & 0.246 \\
\hline & 0.7 & 390 & 0.3 & 5 & & & 33 & 0.293 & & 0.291 & 0.246 \\
\hline & 0.8 & 390 & 0.390 & 0.315 & 0.369 & 0.33 & 0.293 & 0.293 & 0.2 & 0.291 & 0.246 \\
\hline & 0.9 & 345 & 0.345 & 0.315 & 0.31 & 0.3 & 0.259 & 0.259 & 0.2 & 0.249 & 0.246 \\
\hline & 1 & 345 & 0.345 & 0.315 & 0.315 & 0.332 & 0.259 & 0.259 & 0.27 & 0.249 & 0.246 \\
\hline \multirow{11}{*}{ 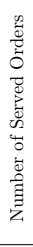 } & 0 & 862 & 0.863 & 0.862 & 0.863 & 0.78 & 0.311 & 0.322 & 0.3 & 0.316 & 0.314 \\
\hline & 0.1 & 862 & 0.832 & 0.862 & 0.863 & 0.785 & 0.311 & 0.311 & 0.3 & 0.316 & 0.314 \\
\hline & 0.2 & 862 & 0.832 & 862 & 0.832 & O & 0.311 & 0.311 & & 0.304 & 0.314 \\
\hline & 0.3 & 830 & 0.80 & 0. & 0.8 & & 99 & 0.299 & & 0.304 & 0.314 \\
\hline & 0.4 & 830 & 0.80 & 0.8 & & & & & & & 314 \\
\hline & & & & & & & & & & & 97 \\
\hline & & & & & & & & & & & 0.297 \\
\hline & & & & & & & & & & & 0.287 \\
\hline & 0 . & & 0.8 & & & & & 0.299 & & 0.293 & 0.287 \\
\hline & 0.9 & & 0.77 & 0.8 & 0.8 & & 0.299 & 0.289 & 0.2 & 0.293 & 0.287 \\
\hline & 1 & & 0.77 & & 0.8 & & 0.289 & 0.289 & 0.28 & 0.293 & 0.287 \\
\hline \multirow{11}{*}{ 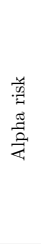 } & 0 & & 0.0 & $0.0^{\prime}$ & 0.0 & & 0.050 & 0.050 & 0.0 & 0.050 & 0.050 \\
\hline & & & 0.07 & & 0.0 & .070 & 0 & 0.050 & 0.0 & 0.050 & 0.050 \\
\hline & 0.2 & 970 & 0.070 & 0.070 & 0.070 & 0.070 & 0.050 & 0.050 & 0.0 & 0.050 & 0.050 \\
\hline & 0.3 & 210 & 0.210 & 0.210 & 0.210 & 0.210 & 0.149 & 0.149 & 0.149 & 0.149 & 0.149 \\
\hline & 0.4 & 50 & 0.350 & 0.3 & 0.350 & & 0.249 & 0.249 & 0.249 & 0.249 & 0.249 \\
\hline & 0.5 & 350 & 0.350 & 0.3 & 0.350 & & 0.249 & 0.249 & & 0.249 & 0.249 \\
\hline & 0.6 & 490 & 0.490 & & & & & & & 0.349 & 0.349 \\
\hline & & 490 & 0.490 & 0.4 & 0.490 & & 0.349 & 0.349 & 0.3 & 0.349 & 0.349 \\
\hline & & & 0.63 & & 0.6 & & & 0.4 & & 0.448 & 0.448 \\
\hline & & & & & & & & 0.448 & & 0.448 & 0.448 \\
\hline & 1 & 0.630 & 0.630 & 0.630 & 0.630 & 0.630 & 0.448 & 0.448 & 0.448 & 0.448 & 0.448 \\
\hline
\end{tabular}


Table 6: Ideal and negative-ideal solutions

\begin{tabular}{|lcccccc|}
\hline Ind. & Solution & SO & BO1 & BO2 & BO4 & GO \\
\hline Profit $(€)$ & $A^{+}$ & 0.324 & 0.322 & 0.335 & 0.321 & 0.323 \\
& $A^{-}$ & 0.279 & 0.277 & 0.289 & 0.277 & 0.283 \\
\hline Inventory Holding Cost $(€)$ & $A^{+}$ & 0.336 & 0.348 & 0.342 & 0.310 & 0.353 \\
& $A^{-}$ & 0.280 & 0.290 & 0.285 & 0.262 & 0.272 \\
\hline Rejecting Cost $(€)$ & $A^{+}$ & 0.343 & 0.343 & 0.383 & 0.350 & 0.362 \\
& $A^{-}$ & 0.259 & 0.259 & 0.272 & 0.249 & 0.246 \\
\hline Number of Served Orders & $A^{+}$ & 0.311 & 0.322 & 0.308 & 0.316 & 0.314 \\
& $A^{-}$ & 0.289 & 0.289 & 0.286 & 0.293 & 0.287 \\
\hline Alpha risk & $A^{+}$ & 0.448 & 0.448 & 0.448 & 0.448 & 0.448 \\
& $A^{-}$ & 0.050 & 0.050 & 0.050 & 0.050 & 0.050 \\
\hline
\end{tabular}

Table 7: Distance from ideal solutions

\begin{tabular}{|c|ccccc|ccccc|}
\cline { 2 - 10 } \multicolumn{1}{c|}{} & \multicolumn{3}{c|}{$d^{+}$} & & \multicolumn{3}{c|}{$d^{-}$} \\
\hline Alpha & SO & BO1 & BO2 & BO4 & GO & SO & BO1 & BO2 & BO4 & GO \\
\hline 0.0 & 0.402 & 0.403 & 0.403 & 0.401 & 0.407 & 0.098 & 0.101 & 0.122 & 0.113 & 0.126 \\
0.1 & 0.402 & 0.403 & 0.408 & 0.399 & 0.407 & 0.098 & 0.098 & 0.056 & 0.123 & 0.126 \\
0.2 & 0.402 & 0.403 & 0.408 & 0.402 & 0.401 & 0.098 & 0.098 & 0.056 & 0.111 & 0.131 \\
0.3 & 0.309 & 0.310 & 0.312 & 0.306 & 0.303 & 0.108 & 0.108 & 0.114 & 0.121 & 0.164 \\
0.4 & 0.214 & 0.216 & 0.218 & 0.209 & 0.226 & 0.203 & 0.203 & 0.207 & 0.211 & 0.208 \\
0.5 & 0.214 & 0.216 & 0.239 & 0.209 & 0.217 & 0.203 & 0.203 & 0.200 & 0.211 & 0.209 \\
0.6 & 0.127 & 0.130 & 0.166 & 0.120 & 0.166 & 0.302 & 0.302 & 0.299 & 0.306 & 0.301 \\
0.7 & 0.115 & 0.130 & 0.166 & 0.120 & 0.161 & 0.307 & 0.302 & 0.299 & 0.306 & 0.310 \\
0.8 & 0.069 & 0.083 & 0.121 & 0.067 & 0.135 & 0.404 & 0.401 & 0.403 & 0.404 & 0.400 \\
0.9 & 0.096 & 0.101 & 0.121 & 0.113 & 0.135 & 0.402 & 0.403 & 0.403 & 0.401 & 0.400 \\
1.0 & 0.098 & 0.101 & 0.122 & 0.113 & 0.135 & 0.402 & 0.403 & 0.403 & 0.401 & 0.400 \\
\hline
\end{tabular}

Table 8: Closeness coefficient and final alpha scenario selection

\begin{tabular}{|c|ccccc|}
\cline { 2 - 6 } \multicolumn{1}{c|}{} & \multicolumn{5}{c|}{ Closeness coefficient $\left(C C_{i}\right)$} \\
\hline Alpha & SO & BO1 & BO2 & BO4 & GO \\
\hline 0.0 & 0.195 & 0.200 & 0.233 & 0.219 & 0.237 \\
0.1 & 0.195 & 0.195 & 0.121 & 0.235 & 0.237 \\
0.2 & 0.195 & 0.195 & 0.121 & 0.217 & 0.246 \\
0.3 & 0.258 & 0.258 & 0.268 & 0.284 & 0.352 \\
0.4 & 0.487 & 0.485 & 0.487 & 0.502 & 0.479 \\
0.5 & 0.487 & 0.485 & 0.456 & 0.502 & 0.491 \\
0.6 & 0.703 & 0.699 & 0.642 & 0.719 & 0.644 \\
0.7 & 0.728 & 0.699 & 0.642 & 0.719 & 0.658 \\
$\mathbf{0 . 8}$ & $\mathbf{0 . 8 5 5}$ & $\mathbf{0 . 8 2 8}$ & $\mathbf{0 . 7 6 9}$ & $\mathbf{0 . 8 5 8}$ & $\mathbf{0 . 7 4 8}$ \\
0.9 & 0.808 & 0.800 & 0.769 & 0.781 & 0.748 \\
1.0 & 0.805 & 0.800 & 0.767 & 0.781 & 0.748 \\
\hline Best Alpha & $\mathbf{0 . 8}$ & $\mathbf{0 . 8}$ & $\mathbf{0 . 8}$ & $\mathbf{0 . 8}$ & $\mathbf{0 . 8}$ \\
\hline
\end{tabular}


clear (or ambiguous), which can be represented by fuzzy linguistic variables, which was done. In the next section we validate the benefits of applying our uncertainty model versus the original deterministic one.

\subsubsection{Evaluating the Deterministic and Fuzzy Solutions}

In this section, the reliability and quality of the decisions made with the deterministic and fuzzy model with the corresponding suggested alpha values (see Table 8 and Fig. 2 were evaluated. The objective was to measure how many customer orders initially committed by the deterministic and fuzzy model could actually be served when the MPS lots were finally produced and classified into homogeneous sublots. To do this, the auxiliary model is executed by taking the committed orders of the model as inputs when evaluating their real due date, the initial MPS lots and a real forecast of the beta parameters per lot (i.e. homogeneous sublots). Forecasting the beta parameters for each MPS lot was done based on their triangular distribution and by ensuring that their sum equalled one.

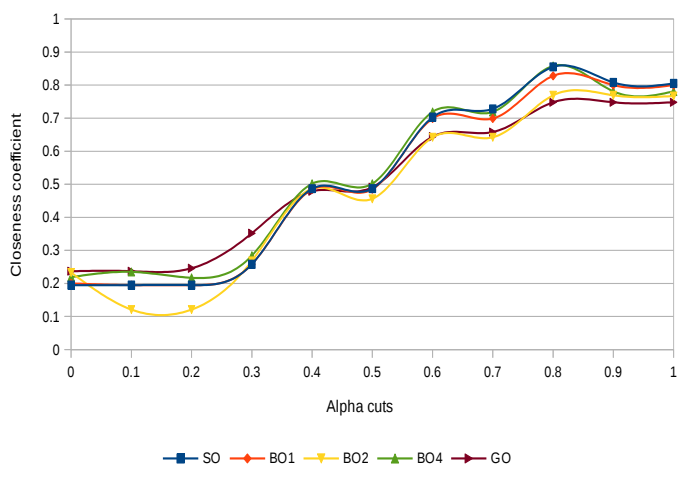

Figure 2: Closeness coefficient trend

For our case the beta coefficients considered for all the lots equalled 0.7, 0.2 and 0.1 for the deterministic model. For the fuzzy model, these beta values were considered the central values of their triangular membership function, while the upper and lower limits were calculated as $\pm 50 \%$ of the central value, respectively; e.g., by assuming a forecast value of the beta parameters for a certain lot that equalled 0.76-0.25-0.12. The sum of the real forecast beta parameters equalled 1.13, but as previously shown, their sum should equal one. Therefore, a readjustment was required to ensure that their sum equalled one. This readjustment was made proportionally to the initial real value as follows: Beta1 $=0.76 / 1.13=0.673$, Beta $2=0.25 / 1.13=0.221$, Beta $3=0.12 / 1.13=0.106$, by ensuring that the sum of 
Beta $1+$ Beta $2+$ Beta $3=0.673+0.221+0.106=1$. For this experiment, 60 forecasts of the real values of the beta coefficients for all the MPS lots were made, which led to 60 real scenarios with which to evaluate the decisions of the deterministic and fuzzy model made for each execution mode by solving the auxiliary evaluation model. In all, $60^{*} 2^{*} 5=600$ auxiliary model runs took place.

Table 9 shows a comparison of the profits obtained by the deterministic and the FMILP-ATP-LHP model by taking the planned value of beta coefficients and the mean of the performance indicators obtained for the auxiliary evaluation model as input, and by taking the promised orders of the above models and the forecast real value of the beta coefficients also as input. The auxiliary evaluation model intends to simulate which orders will really be served when the MPS lots are finally produced and classified and the real size of homogeneous sublots are known. Table 9 shows the values of the performance indicators obtained by the deterministic and fuzzy model in all the execution modes, and according to a planned and a real situation. "\%Dif" represents the improvement percentage of the fuzzy model vs. the deterministic one: $\%$ Dif $=\frac{\text { Ind fuzzy }- \text { Ind det }}{I n d_{d e t}}$.

Table 9: Planned vs. real projected profits for all the execution modes

\begin{tabular}{|c|c|c|c|c|c|c|c|}
\hline & \multirow[t]{2}{*}{ Batching mode } & \multicolumn{3}{|c|}{$\begin{array}{l}\text { Planned situation (FMILP-ATP- } \\
\text { LHP) model }\end{array}$} & \multicolumn{3}{|c|}{$\begin{array}{l}\text { Real situation. Auxiliary evalua- } \\
\text { tion model (Average of } 60 \text { execu- } \\
\text { tions) }\end{array}$} \\
\hline & & Det & Fuzzy & \%Dif & Det & Fuzzy & $\%$ Dif \\
\hline \multirow[t]{6}{*}{ Profit(€) } & SO & $1,155,761.7$ & $1,208,221.1$ & $4.5 \%$ & $1,156,522.8$ & $1,203,286.4$ & $4.0 \%$ \\
\hline & BO1 & $1,167,514.0$ & $1,278,802.8$ & $9.5 \%$ & $1,167,310.8$ & $1,263,090.6$ & $8.2 \%$ \\
\hline & $\mathrm{BO} 2$ & $1,221,807.7$ & $1,239,239.4$ & $1.4 \%$ & $1,221,067.7$ & $1,231,826.1$ & $0.9 \%$ \\
\hline & $\mathrm{BO} 4$ & $1,282,081.8$ & $1,319,091.4$ & $2.9 \%$ & $1,272,869.4$ & $1,302,396.5$ & $2.3 \%$ \\
\hline & GO & $1,355,846.0$ & $1,390,034.5$ & $2.5 \%$ & $1,326,406.5$ & $1,348,083.7$ & $1.6 \%$ \\
\hline & Average & $1,236,602.2$ & $1,287,077.9$ & $4.1 \%$ & $1,228,835.4$ & $1,269,736.7$ & $3.3 \%$ \\
\hline \multirow[t]{6}{*}{ Inventory Holding Cost $(€)$} & $\mathrm{SO}$ & $9,317.5$ & $9,719.0$ & $4.3 \%$ & $8,089.9$ & $8,783.1$ & $8.6 \%$ \\
\hline & BO1 & $9,161.8$ & $10,439.6$ & $13.9 \%$ & $8,072.2$ & $9,989.0$ & $23.7 \%$ \\
\hline & $\mathrm{BO} 2$ & $9,541.4$ & $9,700.1$ & $1.7 \%$ & $8,988.7$ & $9,210.5$ & $2.5 \%$ \\
\hline & $\mathrm{BO} 4$ & $10,592.2$ & $10,934.6$ & $3.2 \%$ & $10,051.8$ & $10,561.6$ & $5.1 \%$ \\
\hline & GO & $14,154.0$ & $14,069.9$ & $-0.6 \%$ & $13,701.9$ & $13,819.3$ & $0.9 \%$ \\
\hline & Average & $10,553.4$ & $10,972.6$ & $4.0 \%$ & $9,780.9$ & $10,472.7$ & $7.1 \%$ \\
\hline \multirow[t]{6}{*}{ Rejecting Cost $(€)$} & SO & $107,158.8$ & $100,263.9$ & $-6.4 \%$ & $107,219.6$ & $101,029.6$ & $-5.8 \%$ \\
\hline & BO1 & $105,646.2$ & $90,963.6$ & $-13.9 \%$ & $105,814.8$ & $93,071.8$ & $-12.0 \%$ \\
\hline & $\mathrm{BO} 2$ & $98,514.9$ & $90,220.5$ & $-8.4 \%$ & $98,683.5$ & $97,251.3$ & $-1.5 \%$ \\
\hline & $\mathrm{BO} 4$ & $90,516.0$ & $85,644.0$ & $-5.4 \%$ & $91,788.1$ & $87,870.2$ & $-4.3 \%$ \\
\hline & GO & $80,430.0$ & $75,981.6$ & $-5.5 \%$ & $84,328.9$ & $81,486.1$ & $-3.4 \%$ \\
\hline & Average & $96,453.2$ & $88,614.7$ & $-8.1 \%$ & $97,567.0$ & $92,141.8$ & $-5.6 \%$ \\
\hline \multirow[t]{6}{*}{ Number of Served Orders } & $\mathrm{SO}$ & 76 & 78.0 & $2.6 \%$ & 75 & 76 & $1.3 \%$ \\
\hline & BO1 & 75 & 79.0 & $5.3 \%$ & 73 & 77 & $5.5 \%$ \\
\hline & $\mathrm{BO} 2$ & 76 & 77.0 & $1.3 \%$ & 74 & 75 & $1.4 \%$ \\
\hline & $\mathrm{BO} 4$ & 77 & 78.0 & $1.3 \%$ & 75 & 76 & $1.3 \%$ \\
\hline & GO & 81 & 82.0 & $1.2 \%$ & 78 & 79 & $1.3 \%$ \\
\hline & Average & 77 & 79 & $2.3 \%$ & 75 & 77 & $2.1 \%$ \\
\hline
\end{tabular}

The results showed that the consideration of the fuzzy beta coefficients provided higher profits for all the execution modes (3.2\% on average in both planned and real situations) than when considering them deterministic ( $\%$ Dif $>0)$, with relevance in BOP1 where the increase even became $7.7 \%$ for the real situation and $7.9 \%$ for the planned one. As profits were higher, consequently the inventory holding cost 
Table 10: Model size and computational efficiency

\begin{tabular}{|c|c|c|c|c|c|c|c|c|c|c|}
\hline & \multicolumn{2}{|c|}{$\mathrm{SO}$} & \multicolumn{2}{|c|}{ BO1 } & \multicolumn{2}{|c|}{$\mathrm{BO} 2$} & \multicolumn{2}{|c|}{$\mathrm{BO} 4$} & \multicolumn{2}{|c|}{ GO } \\
\hline Indicator & Det & Fuzzy & Det & Fuzzy & Det & Fuzzy & Det & Fuzzy & Det & Fuzzy \\
\hline Constraints & 901 & 1,285 & 1,198 & 1,582 & 1,515 & 1,899 & 1,831 & 2,215 & 2,780 & 3,164 \\
\hline Iterations & 464 & 440 & 813 & 1,172 & 2,555 & 2,140 & 7,004 & 4,670 & 19,357 & 89,879 \\
\hline Nonzeros & 2,017 & 2,593 & 15,292 & 15,868 & 29,414 & 29,990 & 43,536 & 44,112 & 85,902 & 86,478 \\
\hline Variables & 1,056 & 1,056 & 3,785 & 3,785 & 6,689 & 6,689 & 9,592 & 9,592 & 18,302 & 18,302 \\
\hline Integers & 174 & 174 & 2,903 & 2,903 & 5,807 & 5,807 & 8,710 & 8,710 & 17,420 & 17,420 \\
\hline Binary & 1,004 & 1,004 & 3,602 & 3,602 & 6,365 & 6,365 & 9,128 & 9,128 & 16,578 & 16,578 \\
\hline Solution time (s) & 0.5 & 0.5 & 0.5 & 0.5 & 1.0 & 1.0 & 1.0 & 2.0 & 8.0 & 23.0 \\
\hline
\end{tabular}

was also higher because more products to be sold were handled. This was true not only in the planned situation, but also when a real forecast of the homogeneous sublots (real beta values) was made.

We obtained a saving in rejecting costs of around $8 \%$, which is an important factor to consider in order to increase customer satisfaction. This result was achieved with the only difference of 2-3 more orders served by the fuzzy model on average vs. the deterministic one. This aspect means that when the real size of the homogeneous sublots was known, it was not possible to serve all the previous committed orders by both the deterministic and fuzzy models. However, the fuzzy model always provided higher profits than the deterministic one.

In general terms, the percentages of the differences in the fuzzy model vs. the deterministic model remained relatively stable for the whole set of indicators and batching modes. This allowed the original difference in the planned situations to be achieved, even when the open variety of the forecast real beta cases was wide, and confirmed the suitability of our fuzzy model and the TOPSIS-based procedure.

Table 10 shows the size of the models and the computational efficiency to obtain the optimal solution of the deterministic and fuzzy models for all the execution modes. As observed, despite the large size of the fuzzy model, the computational effort was not significantly greater than that of the deterministic model.

Finally, in order to explore alternative solutions for solving bigger size instances (when the number of orders increases considerably), the development of heuristic and meta-heuristics solution algorithms could be considered. In this case, readers are referred to Senvar et al. 37] and Grillo et al. [38]. 


\section{Conclusions}

In this paper, the problem of promising orders under uncertainty in the homogeneous sublots was modelled. The need to model LHP in ATP quantities calculated from MPS lots derives from customers who require homogeneity among the ordered units of the same $F G_{i}$. Given LHP inherent uncertainty, the exact size of the homogeneous sublots in the MPS is not known until they are produced and classified. This can lead to a situation in which previous orders promised cannot be served because there are not enough homogeneous quantities.

To anticipate real homogeneous sublots and to prevent this situation as much as possible, LHP uncertainty in production lots was modelled by fuzzy numbers and an equivalent crisp $\alpha$-parametric model was obtained where alpha suitability was handled through an adapted fuzzy TOPSIS-based method using an additional set of performance indicators. The homogeneous sublots were represented by defining beta coefficients, which mean that the fraction of a lot could be considered homogeneous. These coefficients were not independent because, for a specific lot, the sum of the beta coefficients should equal one. To deal with uncertainty in interdependent coefficients for order promising models in a dynamic environment is one of the contributions of this paper, which results in a fuzzy model based on an extension of the work by Alemany et al. 9. This fuzzy model is solved by using the Jiménez et al. 10] approach which resulted in an alpha parametric crisp system. Then, another important contribution of the paper was the evaluation of candidate solutions obtained varying the alpha parameter. In order to suggest a suitable degree of alpha, we adapted the fuzzy TOPSIS methodology to include the decision maker's needs, but in a qualitative/quantitative way combined with a set of performance indicators. With this methodology we decreased the ambiguity in the final decision of the alpha-parametric system.

Experimentation in the ceramic sector was designed to achieve the following objectives: 1) to validate the FMILP-ATP-LHP model; and 2) to assess the impact of modelling LHP uncertainty in profits and additional performance indicators in planned and realistic situations in a dynamic context. The results obtained for the first objective were in accordance with those reported in the literature and, therefore, validated the model. So the lower the alpha value (high risk and uncertainty level), the more profits obtained; and the wider the batching interval of the FMILP-ATP-LHP model, the more profits made. As regards the second experimental objective, it was found that the LHP uncertainty consideration provided more stability and consistency in performance compared to the deterministic approach, and not only in a planned environment, but also in a realistic one. Sixty forecasts of the real value of beta coefficients were made to simulate a real situation of homogeneous sublots, once produced. Then which orders promised by the fuzzy and the deterministic versions of the model could actually be served, when the real size of the homogeneous sublots is known, was checked. The results showed relative consistency between the originally planned values of the indicators com- 
pared to the real values that could be achieved with the finally served orders in a hypothetical real situation. Furthermore, the difference in the profits between the deterministic and the fuzzy versions increased in a real environment for narrower batching intervals. Therefore based on these results, we concluded that the fuzzy model outperformed the deterministic one. Finally, the experiments we carried out showed that the fuzzy model did not require much more computation effort, and this fact is another advantage of using it.

The advantages of using this procedure are summarised as: (i) it is simple enough to be computed and handled in relatively the same computing time as the deterministic one; (ii) a fuzzy procedure that can be applied to handle inherent LHP uncertainty where production lots are not homogeneous. Then the obtained fuzzy model is more realistic than the deterministic one, and is able to obtain more efficient results; (iii) it can be used to handle dependent fuzzy coefficients, where the sum should equal one; (iv) it is a TOPSIS-based fuzzy-adapted procedure based on a linguistic evaluation of a set of performance indicators, and can be applied to evaluate the suitability of the alpha-parametric equivalent crisp model developed to translate the FMILP-ATP-LHP model. This methodology shows good adaptation to the DM's requirements in cases where the existence of multiple criteria to evaluate alpha scenario suitability is not clear or is ambiguous, and the weight assigned to each criterion is no exact variable. The procedure shows consistency and good performance.

Even when we initially focused on modelling uncertainty in homogeneous sublots, which was our main topic due to the LHP effect, future research lines can include another kind of fuzziness, like selling prices, cost factors, customer type and arrival orders trend. The model can also be directly modelled as a multiobjective one but, in this case, a new approach for the fuzzification and integration of objectives must be followed. The development of heuristic or meta-heuristic solution algorithms for large sizing problems will be a forthcoming work. Furthermore, to integrate the real time problem with the proposed model using fuzzy based decision or inference system (see for example 39).

\section{Publication data}

Figure 3 shows the first page of the paper published in the International Journal of Fuzzy Systems, (ISSN:1562-2479). 


\section{A Fuzzy Order Promising Model With Non-Uniform Finished Goods}

H. Grillo ${ }^{1} \cdot$ M. M. E. Alemany ${ }^{2} \cdot$ A. Ortiz $^{2} \cdot$ J. Mula $^{3}$

Received: 10 December 2016/Revised: 8 February 2017/Accepted: 20 March 2017

Abstract Traditionally, the homogeneity of available units of the same finished good $\left(\mathrm{FG}_{i}\right)$ to be promised to customers has been assumed. However, contexts with lack of homogeneity in the product (LHP) are characterised by units of the same $\mathrm{FG}_{i}$, which differ in some characteristic that are relevant for customers and give rise to different that are relevant for customers and give rise to different
subtypes. For instance, in the ceramic industry, tiles are subtypes. For instance, in the ceramic industry, tiles are
classified based on quality, tone and gage, because of classified based on quality, tone and gage, because of
functional and aesthetical reasons related to their joint functional and aesthetical reasons related to their joint
installation. LHP imposes new constraints in the order installation. LHP imposes new constraints in the order
promising process because customers need homogeneous promising process because customers need homogeneous
units. However, the final amount of the homogeneous units units. However, the final amount of the homogeneous units in planned lots is uncertain when promising orders, because
they will only be known once produced and classified. In they will only be known once produced and classified. I
this sense, we introduce homogeneity constraints including fuzzy sets; specifically, we address the interaction amon fuzzy homogeneity coefficients that represent the fractio of each homogeneous sublot. Therefore, modelling uncertainty in interdependent technological coefficients in a dynamic context is one of the main novelties of our proposal. Thus, in this paper, in order to reliably meet the homogeneity required by customers, a fuzzy model is proposed to support the promising process in LHP context:

\begin{tabular}{|c|c|}
\hline & $\begin{array}{l}\text { H. Grillo } \\
\text { hgrilloe@gmail.com }\end{array}$ \\
\hline & $\begin{array}{l}\text { Doctoral School, Universitat Politècnica de València, Camí } \\
\text { de Vera s } / n, 46022 \text { València, Spain }\end{array}$ \\
\hline & $\begin{array}{l}\text { Research Centre of Production Management and Engineering } \\
\text { (CIGIP), Universitat Politècnica de València, Camí de Vera } \\
\text { s/n, } 46022 \text { València, Spain }\end{array}$ \\
\hline & $\begin{array}{l}\text { Research Centre of Production Management and Engineering } \\
\text { (CIGIPI), Universitat Politèncica de València, Plaza Ferrándiz } \\
\text { CIarbonell. }\end{array}$ \\
\hline
\end{tabular}

Published online: 01 June 2017 after taking into account uncertainty in planned homogeneous sublots. The fuzzy model is translated into an alphaparametric equivalent crisp model. Here, it is important to highlight another important novelty of the paper related to the proposed methodology to analyse the suitability of the the proposed methodology to analyse the suitability of the minesters Topsis-based fazzy procedure. Fhally, the experiment design, which is in pred in the coranic sector pros bo the validity of the model and a better performance of the fuzzy model compared to the deterministic one, in severa executions with forecasts of the real size of homogeneou sublots.

Keywords Order promising · Lack of homogeneity in the product - Uncertainty - Interdependent fuzzy coefficients Fuzzy TOPSIS - Ceramic secto

1 Introduction

Lack of homogeneity in the product (LHP) appears in certain industries like ceramics, textile, wood, marble, horticulture, tanned hides and leather goods. In fruit supply chains for example, LHP mainly targets the non-uniformity of raw materials (fruit obtained directly from nature). of raw materials (fruit obtained directly from nature).
There are several classification (sorting and grading) activities which aim to eliminate waste and classify, fo example, fruits into several qualities based on differe antion, shape and firmess [1]. Th the ceramic sector, the LHP origin due to the non-uniformity of raw materials (clays) an some components (enamels), along with some uncontrolable productive variables (e.g. humidity and temperature). Since customers require homogeneity in the units of the same ceramic wall or tile, these companies locate on

黑 Springer

Figure 3: Publication data. 


\section{Acknowledgement}

This research is partly supported by: The Ministry of Science, Technology and Telecommunications of the of Costa Rica Government (MICITT), through the Programme of Innovation and Human Capital for Competitiveness (PINN)(Contract no. PED-019-2015-1); and the Spanish Ministry of Economy and Competitiveness Projects "Methods and models for operations planning and order management in supply chains characterised by uncertainty in production due to the lack of product uniformity" (PLANGES-FHP) (Ref. DPI2011-23597) and "Operations design and Management of Global Supply Chains" (GLOBOP) (Ref. DPI2012-38061-C02-01).

\section{Bibliography}

[1] O. Ahumada and J. R. Villalobos. "Operational model for planning the harvest and distribution of perishable agricultural products". In: International Journal of Production Economics 133.2 (2011), pp. 677-687. DOI: 10.1016/j.ijpe.2011.05.015

[2] G. Davoli, S. A. Gallo, M. W. Collins, and R. Melloni. "A stochastic simulation approach for production scheduling and investment planning in the tile industry". In: International Journal of Engineering, Science and Technology 2.9 (2010), pp. 107-124. DOI: 10.4314/ ijest.v2i9.64006

[3] H. Grillo, M. M. E. Alemany, and A. Ortiz. "A review of mathematical models for supporting the order promising process under Lack of Homogeneity in Product and other sources of uncertainty". In: Computers $\mathcal{E}$ Industrial Engineering 91 (2016), pp. 239-261. DOI: $10.1016 / \mathrm{j}$.cie.2015.11.013

[4] M. M. E. Alemany, F. Alarcón, A. Ortiz, and F. C. Lario. "Order promising process for extended collaborative selling chain". In: Production Planning \& Control 19.2 (2008), pp. 105-131. DOI: $10.1080 / 09537280801896011$

[5] M. M. E. Alemany, A. Ortiz, A. Boza, and V. S. Fuertes-Miquel. "A model driven decision support system for reallocation of supply to orders under uncertainty in ceramic companies". In: Technological and Economic Development of Economy 21.4 (2015), pp. 596-625. DOI: $10.3846 / 20294913.2015 .1055613$

[6] F. Alarcón, M. M. E. Alemany, and A. Ortiz. "Conceptual framework for the characterization of the order promising process in a collaborative selling network context". In: International Journal of Production Economics 120.1 (2009), pp. 100-114. DOI: 10.1016/ j.ijpe.2008.07.031

[7] T. Bui, H.-J. Sebastian, and Ieee. "Integration of multi-criteria decision analysis and negotiation in order promising". In: 43rd Hawaii International Conference on Systems Sciences Vols 1-5. Proceedings of the Annual Hawaii International Conference on System Sciences, 2010, pp. 1115-1124. DOI: 10.1109/HICSS.2010.237

[8] M. O. Ball, C.-Y. Chen, and Z.-Y. Zhao. "Available to Promise". In: Handbook of Quantitative Supply Chain Analysis: Modeling in the E-Business Era. Ed. by D. Simchi-Levi, S. D. Wu, and Z.-J. Shen. Boston, MA: Springer US, 2004, pp. 447-483. DOI: 10.1007/9781-4020-7953-5_11

[9] M. M. E. Alemany, F. C. Lario, A. Ortiz, and F. Gomez. "Available-To-Promise modeling for multi-plant manufacturing characterized by lack of homogeneity in the product: An illustration of a ceramic case". In: Applied Mathematical Modelling 37.5 (2013), pp. 33803398. DOI: $10.1016 / \mathrm{j} . \mathrm{apm} .2012 .07 .022$ 
[10] M. Jiménez, M. Arenas, A. Bilbao, and M. V. Rodríguez. "Linear programming with fuzzy parameters: An interactive method resolution". In: European Journal of Operational Research 177.3 (2007), pp. 1599-1609. DOI: 10.1016/j.ejor.2005.10.002

[11] D. Peidro, J. Mula, M. Jiménez, and M. del Mar Botella. "A fuzzy linear programming based approach for tactical supply chain planning in an uncertainty environment". In: European Journal of Operational Research 205.1 (2010), pp. 65-80. DOI: 10.1016/j.ejor. 2009.11.031.

[12] D. Yong. "Plant location selection based on fuzzy TOPSIS". In: The International Journal of Advanced Manufacturing Technology 28.7-8 (2006), pp. 839-844. DOI: 10.1007/s00170004-2436-5

[13] C.-T. Chen. "A fuzzy approach to select the location of the distribution center". In: Fuzzy sets and systems 118.1 (2001), pp. 65-73. DOr: 10.1016/S0165-0114(98)00459-X

[14] C.-T. Chen. "Extensions of the TOPSIS for group decision-making under fuzzy environment". In: Fuzzy sets and systems 114.1 (2000), pp. 1-9. DOI: 10.1016/S0165-0114(97) 00377-1

[15] Y.-M. Wang and T. M. Elhag. "Fuzzy TOPSIS method based on alpha level sets with an application to bridge risk assessment". In: Expert systems with applications 31.2 (2006), pp. 309-319. DOI: $10.1016 /$ j.eswa.2005.09.040

[16] T.-C. Wang and T.-H. Chang. "Application of TOPSIS in evaluating initial training aircraft under a fuzzy environment". In: Expert Systems with Applications 33.4 (2007), pp. 870880. DOI: $10.1016 / \mathrm{j}$.eswa. 2006.07 .003

[17] A. Gupta and C. D. Maranas. "Managing demand uncertainty in supply chain planning". In: 2nd Pan American Workshop in Process Systems Engineering 27.8-9 (2003), pp. 12191227. DOI: $10.1016 / \mathrm{S} 0098-1354(03) 00048-6$

[18] H. M. S. Lababidi, M. A. Ahmed, I. M. Alatiqi, and A. F. Al-Enzi. "Optimizing the supply chain of a petrochemical company under uncertain operating and economic conditions". In: Industrial 83 Engineering Chemistry Research 43.1 (2004), pp. 63-73. DoI: 10.1021/ ie030555d

[19] T. Santoso, S. Ahmed, M. Goetschalckx, and A. Shapiro. "A stochastic programming approach for supply chain network design under uncertainty". In: European Journal of Operational Research 167.1 (2005), pp. 96-115. Dor: 10.1016/j.ejor.2004.01.046

[20] M. S. Sodhi. "Managing demand risk in tactical supply chain planning for a global consumer electronics company". In: Production and Operations Management 14.1 (2009), pp. 69-79. DOI: $10.1111 / \mathrm{j} .1937-5956.2005 \cdot \mathrm{tb} 00010 \cdot \mathrm{x}$

[21] J. Mula, D. Peidro, and R. Poler. "The effectiveness of a fuzzy mathematical programming approach for supply chain production planning with fuzzy demand". In: International Journal of Production Economics 128.1 (2010), pp. 136-143. DoI: 10.1016/j.ijpe.2010.06. 007

[22] J. Wang and Y.-F. Shu. "Fuzzy decision modeling for supply chain management". In: Fuzzy Sets and Systems 150.1 (2005), pp. 107-127. DOI: 10.1016/j.fss.2004.07.005

[23] R. E. Bellman and L. A. Zadeh. "Decision-making in a fuzzy environment". In: Management Science 17.4 (1970), pp. 141-164. DOI: $10.1287 / \mathrm{mnsc.17.4.B141}$

[24] D. Dubois and H. Prade. Possibility theory: an approach to computerized processing of uncertainty. Springer Science \& Business Media, 2012.

[25] D. Dubois, H. Fargier, and P. Fortemps. "Fuzzy scheduling: Modelling flexible constraints vs. coping with incomplete knowledge". In: Fuzzy Sets in Scheduling and Planning 147.2 (2003), pp. 231-252. DOI: 10.1016/S0377-2217(02)00558-1 
[26] M. M. E. Alemany, H. Grillo, A. Ortiz, and V. S. Fuertes-Miquel. "A fuzzy model for shortage planning under uncertainty due to lack of homogeneity in planned production lots". In: Applied Mathematical Modelling 39.15 (2015), pp. 4463-4481. DOI: 10.1016/j . apm.2014.12.057

[27] M. Gen, Y. Tsujimura, and K. Ida. "Method for solving multiobjective aggregate production planning problem with fuzzy parameters". In: Computers $\mathcal{E}$ Industrial Engineering 23.1-4 (1992), pp. 117-120. DOI: $10.1016 / 0360-8352$ (92) 90077-W

[28] D. Peidro and P. Vasant. "Transportation planning with modified S-curve membership functions using an interactive fuzzy multi-objective approach". In: Applied Soft Computing 11.2 (2011), pp. 2656-2663. DOI: $10.1016 / \mathrm{j}$.asoc. 2010.10.014

[29] J. Cadenas and J. Verdegay. "Using fuzzy numbers in linear programming". In: IEEE Transactions on Systems, Man and Cybernetics, Part B (Cybernetics) 27.6 (1997), pp. 10161022. DOI: $10.1109 / 3477.650062$

[30] D. Peidro, J. Mula, R. Poler, and J.-L. Verdegay. "Fuzzy optimization for supply chain planning under supply, demand and process uncertainties". In: Fuzzy Sets and Systems 160.18 (2009), pp. 2640-2657. DOI: 10.1016/j.fss.2009.02.021

[31] T.-C. Chu. "Facility location selection using fuzzy TOPSIS under group decisions". In: International journal of uncertainty, fuzziness and knowledge-based systems 10.06 (2002), pp. 687-701. DOI: 10.1142/S0218488502001739

[32] I. Chamodrakas, N. Alexopoulou, and D. Martakos. "Customer evaluation for order acceptance using a novel class of fuzzy methods based on TOPSIS". In: Expert Systems with Applications 36.4 (2009), pp. 7409-7415. DOI: 10.1016/j.eswa.2008.09.050

[33] M. Nakhaeinejad and N. Nahavandi. "An interactive algorithm for multi-objective flow shop scheduling with fuzzy processing time through resolution method and TOPSIS". In: The International Journal of Advanced Manufacturing Technology 66.5-8 (2013), pp. 10471064. DOI: $10.1007 / \mathrm{s} 00170-012-4388-5$

[34] E. Shekarian, E. U. Olugu, S. H. Abdul-Rashid, and E. Bottani. "A Fuzzy Reverse Logistics Inventory System Integrating Economic Order/Production Quantity Models". In: International Journal of Fuzzy Systems 18.6 (2016), pp. 1141-1161. DOI: 10.1007/s40815015-0129-x

[35] G. Büyüközkan, I. B. Parlak, and A. C. Tolga. "Evaluation of Knowledge Management Tools by Using An Interval Type-2 Fuzzy TOPSIS Method". In: International Journal of Computational Intelligence Systems 9.5 (2016), pp. 812-826. DOI: 10.1080/18756891. 2016.1237182

[36] B. Pardha Saradhi, N. R. Shankar, and C. Suryanarayana. "Novel Distance Measure in Fuzzy TOPSIS for Supply Chain Strategy Based Supplier Selection". In: Mathematical Problems in Engineering 2016 (2016). DOI: 10.1155/2016/7183407

[37] O. Senvar, E. Turanoglu, and C. Kahraman. "Usage of metaheuristics in engineering: a literature review". In: Meta-Heuristics Optimization Algorithms in Engineering, Business, Economics, and Finance (2013), pp. 484-528. Dor: 10.4018/978-1-4666-2086-5.ch016

[38] H. Grillo, D. Peidro, M. M. E. Alemany, and J. Mula. "Application of particle swarm optimisation with backward calculation to solve a fuzzy multi-objective supply chain master planning model". In: International Journal of Bio-Inspired Computation 7.3 (2015), pp. 157-169. DOI: $10.1504 /$ IJBIC.2015.069557

[39] R. Rajavel and M. Thangarathanam. "Adaptive Probabilistic Behavioural Learning System for the effective behavioural decision in cloud trading negotiation market". In: Future Generation Computer Systems 58 (2016), pp. 29-41. DOI: 10.1016/j.future.2015.12.007 


\title{
Chapter IV
}

\section{A fuzzy model for shortage planning under uncertainty due to lack of homogeneity in planned production lots}

\begin{abstract}
Lack of homogeneity in the product (LHP) affects several sectors like horticulture, reverse logistics, furniture, ceramics and leathers, among others. Productive processes with LHP are characterized by manufacturing units of the same finished good (FG) with certain attributes that differ and are relevant to customers. This aspect leads to the existence of different subtypes of the same FG in each production lot, which provides homogeneous sublots. Due to inherent LHP uncertainty, the size of each homogeneous sublot is not known until produced. LHP becomes a problem when customers order several units of the same $F G$ and require homogeneity among them; i.e., being served with the same subtype. Like inherent LHP uncertainty, discrepancies between planned homogeneous quantities and the real ones is quite usual. This means it is impossible to serve committed orders with the previously defined requirements of quantity, homogeneity and due date, which brings about a shortage situation. In this paper, a fuzzy mixed integer linear programming model is proposed to support shortage planning in environments with LHP (LHP-FSP model). The LHP-FSP model aims to maximize the profits of served orders by reallocating the quantities of subtypes in stock and the uncertainty future ones in the master plan among the already committed orders. One of the main contributions of the paper is to model the fuzzy interdependent coefficients that rep-
\end{abstract}


resent the fraction of each homogeneous sublot. Finally, experiments based on realistic data from a ceramic company have been designed to validate the model and to analyze its behavior in different scenarios.

Keywords: Fuzzy; Mathematical programming model; Shortage planning; Order promising; Lack of homogeneity in product; Uncertainty.

\section{Introduction}

The ability to effectively match demand and supply is fundamental to nearly all supply chain management processes [1. Rapid responses to customer needs, a high level of customer service and flexibility to handle uncertainties and fluctuations in both demand and supply are becoming strategic differentiators in the modern marketplace 2]. To achieve these objectives, demand fulfillment \& ATP (Available-To-Promise), which include order promising and shortage planning [3], are vitally important. The order promising process (OPP) refers to the set of business activities that are triggered to provide a response to customer order requests. These activities are related to the acceptance/rejection of customer orders, and to set delivery dates (due date assignment, due date determination, or due date quotation [3]). In the OPP, it is necessary to compute if there are enough ATP quantities. Gartner 4] defines ATP as the uncommitted portion of a company's inventory or planned production, a figure that is frequently calculated from the Master Production Schedule (MPS), and is maintained as a tool for order promising. Depending on the decisions to be made during the OPP, it is possible to distinguish between order acceptance/rejection 3 .5 due date assignment and order scheduling $[3]$, among others.

In the short term, the customer orders previously committed by ATP allocation should be completed for delivery in order to meet the promised due date. Yet for different reasons, like existing supply chain (SC) uncertainties and other unforeseen events, there may not be enough available stock in the right quantities to cover these orders on time [6], which leads to a shortage situation. In the short run, not meeting customer requirements in terms of delivery dates and delivery quantities can, for example, cause lost sales and contractual penalties. Long-term impacts can lower customer retention rates and reduce the future sales potential, which may result in poorer customer lifetime values [7].

These shortage situations are more likely to appear in SCs that promise orders under high levels of uncertainty. Uncertainty refers to the unpredictability of the environmental or organizational variables that have an impact on corporate performance. A variety of uncertainty factors affect distinct organizations in different ways. In fact, SCs with lack of homogeneity in the product (LHP) have unique characteristics with inherent sources of uncertainty that have a great impact on order promising and order delivery processes. LHP is present in transformation processes that provide non uniform units of the same FG [8]. In these processes, 
the final homogeneous quantities for each FG in a lot will not be known until produced. Therefore, it can be stated that the planned homogeneous sublots of each finished good are subject to uncertainty. Vorst and Beulens 9 define inherent sources of uncertainty as those brought about by the SC's natural physical characteristics and they identify three possible causes:

1. Intrinsic product characteristics in LHP contexts caused by the non homogeneity of the raw materials directly obtained from nature.

2. Technological characteristics of processes, which in LHP contexts, are characterized by the existence of uncontrollable factors during transformation activities (like humidity, temperature, etc.) that have an impact on some FG attributes.

3. Logistic actor characteristics, which indicate customer preferences in some FG attributes; for instance, due to consumer eating habits.

LHP causes non homogeneity of FGs as regards certain attributes that are relevant to customers. LHP becomes a problem when customers order several units of the same FG and require homogeneity among them. In order to comply with homogeneity specifications, LHP SCs include some classification stages for sorting units of the same FGs into homogeneous subsets (subtypes). The classification criteria of an FG into subtypes depend on each sector. For instance, in the horticulture sector, the main attributes for sorting and grading fresh fruit are size, weight, ripeness, damage, color, shape and firmness [10], while, color and grain constitute the classification criteria to ensure uniformity of furniture parts in the furniture sector.

After each classification stage, the quantity of each subtype in the production lots will be known only after production has finished and FGs have been classified. Therefore, SCs with LHP will face a new kind of uncertainty: uncertainty in the homogeneous quantities of each subtype that will be available in planned production lots. This lack of homogeneity becomes a problem when customer orders are reserved based on uncommitted planned quantities (ATP), whose final homogeneity characteristics are not known when promising orders. Due to inherent LHP uncertainty, the appearance of discrepancies between planned homogeneous quantities and real ones is usual, which can make it impossible to serve committed orders according to the previously defined quantity, homogeneity and due date.

Faced with this shortage situation, it is necessary to find alternative solutions in order to cushion the negative effect on the SC and customers. Indeed, shortage planning refers to the activities to be carried out should unavailable stock of components or FGs exist [3]. These activities may include decisions on stock and planned quantities reallocation among committed orders [11, outsourcing [12], substitutive products [13] or negotiation with customers (late supply, partial shipments, etc.). A company should be able to anticipate stock-out situations and should actively manage the allocation and re-allocation of available products based on customer requirements and priorities and contractual relationships [7]. 
Some research has been published for order management in the LHP field. Alemany et al. 8 proposes a deterministic MILP model for promising customer order proposals (acceptance/rejection and due date assignment) based on the ATPLHP quantities deriving from stocks and master plan lots in order to maximize profits and exhausted ATPs. With the above model, the finally rejected and committed customer orders and their promised due date are obtained. However, as explained before, discrepancies between planned and real homogeneous quantities can lead to a shortage situation, where all previously committed orders cannot be served with the initial assignment made by the order promising process. So a shortage situation occurs. In this paper a shortage planning model is proposed that takes all previously committed orders during the OPP as inputs, for instance, by a model as in 8]. The proposed shortage planning model decides about reallocating subtypes in both the updated stocks and homogeneous quantities in master plan lots, and provides the orders that can actually be served with the actual subtypes in stocks and master plan quantities. Therefore, the problem addressed in this paper differs from that of [8], although it can take its solution as an input. In this paper, LHP inherent uncertainty in production lots is also addressed and gives rise to a fuzzy model instead of a deterministic one as in 8. Yet as far as we know, there is only one shortage planning model $[6]$ that deals with LHP through stock reallocation among customer orders. In this paper, we extend this previous model by incorporating the following main novel aspects: (1) reallocating planned production lots in addition to stock among customer orders; (2) LHP modeling by considering splitting the master plan production lots into homogeneous sublots of different FG subtypes; (3) inherent LHP uncertainty modeling in master plan subtype quantities; and (4) incorporating the late delivery possibility. The contributions of this paper are described in more detail below.

In a stock-out situation, Boza et al. [6] consider only the reallocation of stocks among orders. It is assumed that orders without reserved stock will not be served and will, therefore, not contribute to profits. However, not serving an order with the current stock does not mean that it will not be eventually served: it will also depend on the homogeneous availability quantities in future planned lots up to its due date. Not taking planned lots into account can lead to a solution where stock is assigned to orders with high profits, but with more long-term due dates instead of serving orders with less profit, but with nearer due dates. If the future planned production quantities in the master plan are taken into account, the orders with more long-term due dates can be reserved from planned quantities. This enables their previously reserved stock to be reassigned to those orders with more immediate due dates, for which finding alternative solutions is more difficult.

As in Boza et al. [6], LHP is modeled in inventory on hand by considering the existence of subtypes of the same FG. LHP is also modeled in the Master Production Schedule (MPS) by considering that each planned lot is divided into homogeneous sublots of different subtypes. To achieve customer homogeneity requirements, the quantity of an FG requested in a customer order should be completed with units 
from either the same sublot or only one subtype of existing stocks. These authors adopt a deterministic approach because the quantities of the subtypes of each FG in stock are known with certainty (i.e., production was finished and classification into subtypes was done before stocking them). Yet when considering the master plan, the future homogeneous quantities of each subtype in the planned lots will not be known until their production has finished and FGs have been classified into subtypes. However, in order to reassign the realistic LHP homogeneous of the master plan quantities among customer orders, it is necessary to consider uncertainty in future homogeneous available quantities.

The literature includes several approaches for modeling SC uncertainties. Chen and Paulraj [14] group uncertainty in the SC into three areas: suppliers, manufacturers and customers. Most SC planning research 15 20 models SC uncertainties with probability distributions, which are usually predicted from historical data 21]. However, probability distributions deriving from past evidence are not always available or reliable 22 . So whenever statistical data are unreliable, or are not even available, stochastic models may not be the best choice 23]. The Fuzzy Set Theory 24] and the Possibility Theory 25 may be simpler, less data-demanding alternatives than the Probability Theory to deal with SC uncertainties [21, 26].

The Fuzzy Set Theory provides a means for representing uncertainties [27] and is a marvelous tool for modeling uncertainty associated with vagueness, imprecision and/or lack of information on a particular element of the problem at hand. In general terms, collecting precise data is very hard because the system's environment is unstable or such collection entails high information costs. Negrín and Campos 28] recommend using The Fuzzy Set Theory when certain system parts to be controlled are unknown and cannot be reliably measured (possibly with errors), which is the case of LHP. For LHP contexts, the unpredictable characteristics of the raw materials directly obtained from nature and the fact that uncontrollable productive factors exist make knowledge of the homogeneous quantities of each subtype available in future planned lots imprecise, and it is not feasible or is very costly to measure them reliably. This is the reason why LHP uncertainty has been modeled by fuzzy sets.

In fuzzy mathematical programming, all or some parameters can be fuzzy. Leung and Lam [29] classified fuzzy mathematical programming models into four categories: (a) precise objective and fuzzy constraints; (b) fuzzy objective and precise constraints; (c) fuzzy objective and fuzzy constraints; and (d) robust programming.

The model for dealing with LHP uncertainty proposed in this paper can be classified as the first category; i.e., precise objective and fuzzy constraints since fuzzy technological coefficients exist. All the consulted literature assumes the independence of these fuzzy technological coefficients. As mentioned earlier, in LHP productive contexts, each planned lot is divided into homogeneous sublots of different subtypes. To model this aspect, technological coefficients representing the fraction 
of a lot that will be considered homogeneous are defined. However, these fractions are not independent because they should always sum up to one; i.e., the sum of all the homogeneous sublots will equal the original planned lot. We have no knowledge of any research that has dealt with fuzzy interdependent coefficients; therefore their modeling is another contribution of this paper.

In short, this paper bridges the following gaps found in the literature: (1) it proposes a shortage planning model for solving a problem that, to our knowledge, has not been previously addressed: reassignment of stocks and master plan quantities among committed customer orders in LHP manufacturing contexts under uncertainty; (2) LHP inherent uncertainty is modeled by the Fuzzy Set Theory, whose application has been restricted to independent coefficients. In this paper, Fuzzy Sets are applied to interdependent coefficients to represent the fraction of each homogeneous sublot in a lot that should sum up to one. This aspect has implied formulating additional constraints when defining the equivalent crisp model; (3) finally, the effect of different homogeneity degrees (LHP scenarios) and their inherent uncertainty on performance measures has been analyzed. The results show that the uncertain model provides better results than the deterministic one for all LHP scenarios. Furthermore, the results are worse the larger the number of homogeneous sublots (more fragmented) and the more similar they are in size.

The rest of the paper is structured as follows: Section 2 describes the problem under study, whereas Section 3 presents the proposed fuzzy model formulation. Section 4 provides details of the solution methodology used and applies it to a ceramic SC in Section 5. Finally, Section 6 reports the main conclusions.

\section{Shortage planning problem characteristics}

The characteristics of the problem under study are similar to those described in Boza et al. [6], but contain considerable differences, introduced by considering the planned lots in the master plan for their reassignment among customer orders and their inherent LHP uncertainty. The SC's physical configuration is assumed to be composed of several production plants that manufacture according to an MTS strategy. Each production plant is composed of several parallel production lines that are able to process all FGs. The customer orders proposals that arrive are committed during the OPP based on the ATP deriving from the stock and planned production quantities by a model like the one, for instance, in Alemany et al. [8]. After the planned production lots in the master plan have been manufactured, they are classified into the corresponding subtypes. At this time, checks are made to see if there is a sufficient amount of the uniform subtypes obtained to serve promised orders. Owing to LHP uncertainty, discrepancies between planned and real homogeneous quantities are more likely to occur. Indeed this situation means that it is quite usual that all the orders with immediate delivery dates cannot be completely served with reserved stock as previously planned. 
In order to better understand this LHP situation, let's assume the existence of a planned lot of 1800 units and the arrival of two customer orders with requested homogeneous quantities of 700 units and 900 units, respectively. Initially during the OPP, the planned has enough quantity to serve the two customer orders, and even an ATP of 200 units remains free after committing the two customer orders. However, only when the production of the planned lot is finished will the real homogenous quantities be known. Let's assume that the real production for this lot is 1200 homogeneous units of a subtype and 600 homogeneous units of another subtype, instead of the originally homogeneous planned 1800 units. With this updated stock, it will be possible to deliver only one of the two previously committed customer orders with homogeneous quantities. This is because the lot of 600 homogeneous units is not enough to complete the order of 700 units or the order of 900 units, and only the lot of 1200 homogeneous units can be used to deliver one of these orders, but not both. As this situation can emerge for other lots that affect different customer orders in the same company, it is necessary to define a solution procedure to reduce the negative LHP impact on the customer service level and company performance as much as possible.

A more complete, realistic solution consists in reassigning not only the known available real homogeneous quantities per subtype of the inventory on hand, as in Boza et al. [6], but also the planned production lots by modeling their splitting into homogeneous sublots and their inherent uncertainty in order to minimize the negative effects on the SC and its customers. By anticipating homogeneity distribution in lots and its inherent uncertainty, a more realistic and robust reassignment is possible. When discrepancies between the planned homogeneous sublots and real ones occur, the proposed fuzzy shortage planning model intends to answer the following questions: (1) is it possible to serve all the previously committed orders by the OPP? (2) if not, what customer orders should be finally served? (3) what is the new allocation of the updated real homogeneous quantities in stock and expected ones in the master plan among previous orders? (4) what are the resulting ATP quantities to be used as input for promising future incoming customer orders while the OPP is executed?

During the reallocation process, the following assumptions and limitations are considered:

- Each customer order $(o)$ has an associated due date $\left(d d_{o}\right)$, which implies the time bucket when the customer requests FGs in the order to be received.

- Each customer order can be composed of several order lines. For each order line, a quantity a specific FG $i$ is defined as it is not possible that two order lines requesting the same FG in the same order exist. All the lines of the same order have the same due date.

- The requested quantity of a certain FG $i$ in an order line $\left(q_{i o}\right)$ should be served through the homogeneous units of this product, but the subtype is not specified by customers. This assumption is quite usual when normal 
sales are for the customers requiring first quality FGs and only require the uniformity of other functional or esthetical attributes (like gage and tone in ceramic companies). The sales of FGs of no first quality are managed by an alternative process that gives rise to the "push sales" concept. "push sales" come from the company to the customer, while typical "pull sales" come from the customer to the company. The objective followed by "push sales" is to increase the inventory turnover and to lower the inventory level using the price as the main customer negotiation variable. However, the main objectives to be achieved by "pull sales" are maximizing profitability, improving the company's image and the customer service level [30].

- In order to guarantee homogeneity, each order line should be completed from either a unique subtype $(b)$ in stock or a homogeneous sublot as it is not possible to mix different subtypes to serve an order line.

- A customer order can be served provided all its order lines can be served.

- Partial deliveries are not allowed; that is, all the order lines of an order are jointly served.

- The general customer orders considered when reallocating the current LHP stock and planned production lots are all the committed orders with a due date within the planning horizon $(\mathrm{T})$.

- Orders with immediate delivery dates are those with a shorter due date than the delivery horizon $\left(h_{e}\right)$; i.e., $d d_{o} \leqslant h_{e}$. The delivery horizon $\left(h_{e}\right)$ represents a period length immediately after the current point of time required to prepare orders to be immediately delivered. This concept helps identify the orders that should be prepared immediately for delivery $\left(O h_{e}(o)\right)$ in order to meet promised customer due dates.

- In order to represent the variety of customer classes and contractual relationships, the model allows the definition of the priority orders that should be served before any others, despite their profit or due date. If there are not enough homogeneous quantities of FGs, it is possible to allow some delay on the initial promised due date to certain customer orders considered less strategic for the company.

- Stock quantities are expressed in terms of the subtypes known with certainty because they have already been manufactured and classified.

- The production lots defined in the master plan are divided into homogeneous sublots that are assumed to be of different subtypes, although no subtypes are specified. Defining subtypes in sublots is not necessary because customer orders do not require a specific subtype, but need only be served for just one subtype.

- The sizes of these homogeneous sublots are assumed to be uncertain and are expressed as a fraction of their original planned lot. 
- The objective pursued during reallocation consists in maximizing the gross margin of served orders.

In a real situation, finding not only an optimal solution, but also a feasible one, to the reallocation problem is very hard given the huge volume of committed orders, each with several order lines, plus the existence of different subtypes and homogeneous sublots. In this paper, a fuzzy mixed integer linear programming model to support the decision-making process of reallocating LHP stock and master plan quantities to committed orders, dubbed the LHP fuzzy shortage planning (LHPFSP) model, is proposed. The LHP-FSP model solution provides the decision maker with already committed orders that can be served after the reallocation procedure and their real delivery date. For served orders, the delivery date will equal the promised due date if no delay has been allowed. For each served order, the solution indicates if it should be served from either LHP stock or from planned homogeneous sublots. If reserved from stock, the specific product subtype from the current LHP inventory used is also reported. The LHP-FSP model computes each subtype's remaining current inventory, as well as the uncommitted quantities for each FG in planned sublots that has not been reserved for any order after reallocation; i.e., real and planned ATP-LHP quantities, respectively, that will be used later as an input for the OPP. The model formulation is detailed in the next section.

\section{$3 \quad$ Fuzzy shortage planning LHP model formulation}

The fuzzy mixed integer programming model (LHP-FSP) formulation for shortage planning in LHP manufacturing contexts is described in this section. As mentioned in the Introduction, the LHP-FSP model considers some fuzziness constraints.

\subsection{Nomenclature}

The definitions of indices, sets and parameters, and of decision variables, are provided in Tables 1 and 2, respectively.

\subsection{Objective}

Objective (1) aims to maximize the gross margin in the reallocation process, calculated as the difference of the incomings deriving from served customer orders minus costs due to delays as regards the committed due date and holding costs of reserving the quantities of order lines before their real due date (delivery date).

$$
\operatorname{Max} Z 1=\sum_{o \in O s} p_{o} * U S T_{o}-\left(\sum_{o \in O s} b c_{o} * R D T_{o}+\sum_{o \in O} \sum_{s \in I(o)} h c_{i o}\left(D D R_{o}-D D F_{i o}\right)\right) .
$$


Table 1: Model data.

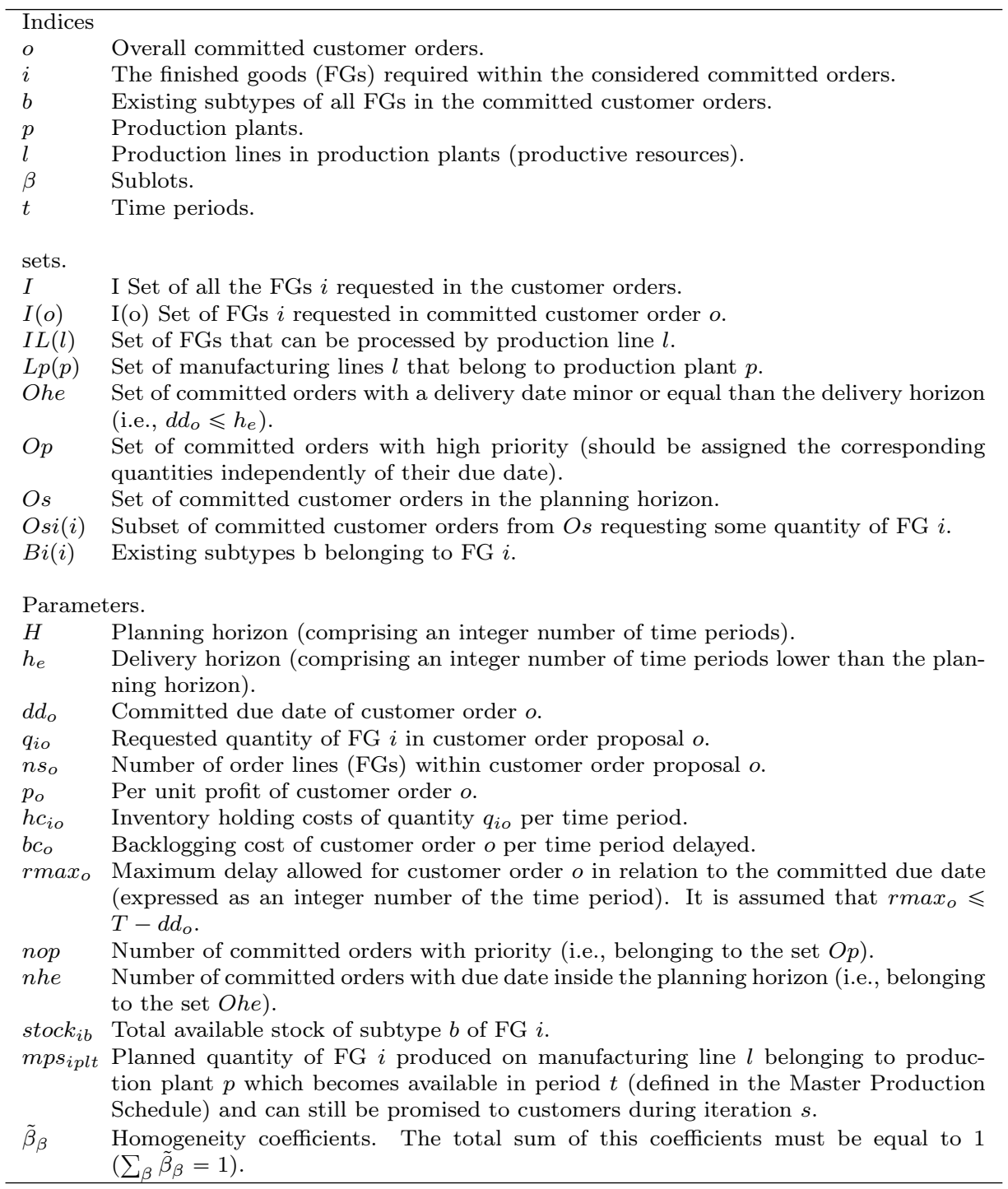


Table 2: Decision variables.

\begin{tabular}{|c|c|}
\hline$A D_{i o}$ & $\begin{array}{l}\text { Number of time periods before due date } d d_{o} \text { that it is assigned to customer order } o \\
\text { either an mps or stock quantity of FG } i \text {. }\end{array}$ \\
\hline$A T P 0_{i b}$ & The available to promise quantity of subtype $b$ of FG $i$ after the reallocation process. \\
\hline$A T P B_{i p l t}^{\beta}$ & $\begin{array}{l}\text { The available to promise quantity of FG } i \text { derived from the homogeneous sublot } b \text { of } \\
\text { the } m p s_{i p l t} \text { after the reallocation process. }\end{array}$ \\
\hline$A T P_{\text {iplt }}$ & $\begin{array}{l}\text { The available to promise quantity of FG } i \text { derived from the } m p s_{i p l t} \text { after the reallo- } \\
\text { cation process. }\end{array}$ \\
\hline$D D F_{i o}$ & Time period in which the quantity $q_{i o}$ of FG $i$ of order $o$ is finally reserved. \\
\hline$D D R_{o}$ & $\begin{array}{l}\text { Real delivery date of customer order } o \text { (this due date will be the same as } d d_{o} \text { if there } \\
\text { is not delay). }\end{array}$ \\
\hline$R D_{i o}$ & $\begin{array}{l}\text { Number of time periods after due date } d d_{o} \text { that is assigned either a mps or stock } \\
\text { quantity of FG } i \text { to the customer order. }\end{array}$ \\
\hline$R D T_{o}$ & $\begin{array}{l}\text { Number of time periods after due date } d d_{o} \text { when customer order } o \text { is served (delay of } \\
\text { order } o \text { ). }\end{array}$ \\
\hline$U 0_{i o b}$ & $\begin{array}{l}\text { Binary variable with a value of } 1 \text { if the requested quantity of FG } i \text { in customer order } \\
o\left(q_{i o}\right) \text { is completely served by } s t o c k_{i b} \text {, and a value of } 0 \text { otherwise. }\end{array}$ \\
\hline$U B_{i o p l t}^{\beta}$ & $\begin{array}{l}\text { Binary variable with a value of } 1 \text { if the requested quantity of } \mathrm{FG} i \text { in customer order } \\
o\left(q_{i o}\right) \text { is completely served by the homogeneous sublot } b \text { of the } m p s_{i p l t} \text {, and a value } \\
\text { of } 0 \text { otherwise. }\end{array}$ \\
\hline$U_{\text {ioplt }}$ & $\begin{array}{l}\text { Binary variable with a value of } 1 \text { if the requested quantity of FG } i \text { in customer order } \\
\text { proposal } o\left(q_{i o}\right) \text { is completely served by } m p s_{i p l t} \text {, and a value of } 0 \text { otherwise. }\end{array}$ \\
\hline$U S_{i o}$ & $\begin{array}{l}\text { Binary variable with a value of } 1 \text { if FG } i \text { in customer order } o \text { is served, and a value } \\
\text { of } 0 \text { otherwise. }\end{array}$ \\
\hline$U S T_{o}$ & $\begin{array}{l}\text { Binary variable with a value of } 1 \text { if customer order } o \text { is served, and a value of } 0 \\
\text { otherwise. }\end{array}$ \\
\hline$Y A_{i o}$ & $\begin{array}{l}\text { Binary variable with a value of } 1 \text { if the requested quantity of FG } i \text { in customer order } \\
o \text { is reserved an mps quantity before its due date (i.e., } A D_{i o}>0 \text { ). }\end{array}$ \\
\hline$Y R_{i o}$ & $\begin{array}{l}\text { Binary variable with a value of } 1 \text { if the requested quantity of } \mathrm{FG} i \text { in customer order } \\
o \text { is reserved and the mps quantity after its due date (i.e., } R D_{i o}>0 \text { ) }\end{array}$ \\
\hline
\end{tabular}




\subsection{Constraints}

One of the features that distinguishes the present model from others in the literature is its management of customer order homogeneity requirements. To ensure that customers are served with homogeneous units of the same FG, the present model does not allow ATP quantities to accumulate from different subtypes or from different sublots and time periods. This aspect is modeled through Eqs. (2)-(5).

Eq. (2) calculates the existing uncommitted quantity of each subtype b of FG i $\left(A T P 0_{i b}\right)$ by subtracting the quantity assigned to the different order lines of customer orders that are finally served $\left(U O_{i o b}=1\right)$ from the existing stock of the subtype.

$$
A T P 0_{i b}=\text { stock }_{i b}-\sum_{o \in O s i(i)} q_{i o} * U O_{i o b} \quad \forall i \in I, b \in B(i) .
$$

Eq. (3) is analogous to Eq. (2), but for the planned lots in the Master Production Schedule (MPS). Through the fuzzy coefficients $\tilde{\beta}_{\beta}$ in constraint $\sqrt{3}$, the homogeneous sublots that will be available in the Master Production Schedule $\left(\right.$ mps $\left._{i p l t}\right)$ are anticipated. The symbol $\sim$ over coefficients $\tilde{\beta}_{\beta}$ means that these values are not known with certainty. At this point, it is not necessary to anticipate each sublot's specific subtype because customers only require homogeneity in the order lines that do not specify the required subtype. Furthermore, constraint (3) calculates the remaining homogeneous quantities of each sublot not assigned to any customer order $\left(A T P B_{i p l t}^{\beta}\right)$.

$$
A T P B_{i p l t}^{\beta}=\tilde{\beta}_{\beta} * m p s_{i p l t}-\sum_{o \in O s i(i)} q_{i o} * U B_{i o p l t}^{\beta} \quad \forall p, l \in L p(p), i \in I L(l), \beta, t .
$$

Eq. (4) forces a customer order line to be served from only one specific homogeneous sublot, should the order be finally served. Eq. (5) establishes that the order line of FG $i$ belonging to order $o$ will be served if it is reserved with a single subtype (real or planned), otherwise it will not be served. Eqs. (2)-(5) ensure homogeneity in reserved units by accomplishing customers' requirement of inherent LHP environments with homogeneity. It is important to highlight that even when all the units of the same lot are homogeneous, the model considers that the lots manufactured with different resources and during distinct time periods are not likely to be homogeneous. For this reason, the model forces a customer order line to be served with only one subtype in stock or with units from only one lot (Eq. (5)).

$$
\begin{gathered}
U_{\text {ioplt }}=\sum_{\beta} U B_{i o p l t}^{\beta} \quad \forall p, l \in L p(p), o \in O s, i \in I(o), t . \\
\sum_{b \in B(i)} U O_{i o b}+\sum_{p, l, t} U_{i o p l t}=U S_{i o} \quad \forall o \in O s, i \in I(o) .
\end{gathered}
$$


Eq. 6) indicates that for order o to be served, it is necessary for all its order lines i to be served. Eq. (6) acts also in the opposite way; that means if the order is not served, it is senseless to reserve any of its order lines independently.

$$
\sum_{i \in I(o)} U S_{i o}=n s_{o} * U S T_{o} \quad \forall o \in O s .
$$

Eq. (7) calculates either the delay $\left(R D_{i o}\right)$ or advance $\left(A D_{i o}\right)$ of reserving the requested amount of each order line of FG $i$ in relation to the committed due date of order $o\left(d d_{o}\right)$. If the order is not served, then none of its lines are served given Eq. 77) and, consequently, neither delays nor advances are calculated. When an order line of FG $i$ in order $o$ is served from stock $\left(\right.$ stock $\left._{i b}\right)$, that is $t=0$, then the advance is $d d_{o}$.

$$
A D_{i o}-R D_{i o}=d d_{o} * U S T_{o}-\sum_{p, l, t} U_{i o p l t} * t \quad \forall o \in O s, i \in I(o) .
$$

Eq. (8) indicates that the advance cannot be longer than the due date and forces the associated binary variable to take a value of 1 when there is an advance. Besides, Eq. (9) obliges the binary variable $Y A_{i o}$ to be 0 when there is no advance.

$$
\begin{gathered}
A D_{i o} \leqslant d d_{o} * Y A_{i o} \quad \forall o \in O s, i \in I(o) . \\
Y A_{i o} \leqslant A D_{i o} \quad \forall o \in O s, i \in I(o) .
\end{gathered}
$$

Eq. 10 indicates that the final order line delay cannot be longer than the maximum permitted for this order $\left(\operatorname{rmax}_{o}\right)$. As observed, this parameter depends on the order, and it is possible to define it for each order according to its importance for the company. Simultaneously if there is a delay for an order, the associated binary variable $Y R_{i o}$ will take the value of 1 . Eq. 111 makes the binary variable $Y R_{i o}$ take a value of 0 if there is no delay.

$$
\begin{gathered}
R D_{i o} \leqslant r \max _{o} * Y R_{i o} \quad \forall o \in O s, i \in I(o) . \\
Y R_{i o} \leqslant R D_{i o} \quad \forall o \in O s, i \in I(o) .
\end{gathered}
$$

Eq. (12) is employed to ensure a delay or advance, or neither, in the delivery of an FG $\mathrm{i}$ in a specific order, but never both at the same time.

$$
Y A_{i o}+Y R_{i o} \leqslant 1 \quad \forall o \in O s, i \in I(o) .
$$

Eq. (13) establishes that the delay in order $o$ equals the maximum delay of the order lines composing it because the order cannot be served until all the order lines are reserved. Eq. (14) ensures the impossibility of delaying order $o$ if any of its order lines is delayed. Eq. (15) forces a situation in that a delay in an order cannot exceed the maximum delay established for this order (should this order 
be served). If the maximum delay permitted is equal to 0 for all orders, this is a specific case in which serving with delays is not allowed.

$$
\begin{gathered}
R D_{i o} \leqslant R D T_{o} \quad \forall o \in O s, i \in I(o) . \\
R D T_{o} \leqslant \sum_{i \in I(o)} R D_{i o} \quad \forall o \in O s . \\
R D T_{o} \leqslant \operatorname{rmax}_{o} * U S T_{o} \quad \forall o \in O s .
\end{gathered}
$$

Eq. 16 defines the real date $\left(D D R_{o}\right)$ on which order o is to be delivered, which is the due date plus the delay in order $o$. Through Eq. (17), the real reservation date of order line $i$ of committed customer order $o$ is defined. The difference between the order delivery date $\left(D D R_{o}\right)$ and the reservation date $\left(D D R_{o}-D D F_{i o}\right)$ provides the number of time periods during which the order line quantity $\left(q_{i o}\right)$ will be stored, which allows holding costs to be precisely calculated.

$$
\begin{array}{cc}
D D R_{o}=d d_{o} * U S T_{o}+R D T_{o} & \forall o \in O s . \\
D D F_{i o}=d d_{o} * U S T_{o}-A D_{i o}+R D_{i o} & \forall o \in O s, i \in I(o) .
\end{array}
$$

Constraint (18) forces orders with due dates within the delivery horizon (i.e., $\left.d d_{o}=1\right)$ to be served. That is, priority is given to assign current available LHP quantities for these orders because, otherwise, an inevitable delay will occur.

$$
\sum_{o \in \text { Ohe }} U S T_{o}=\text { nhe. }
$$

Irrespectively of the order due date and/or profit, the company may wish strategic orders to be served with actual stock and future master plan quantities. Constraint (19) ensures that all the defined priority orders will be served.

$$
\sum_{o \in O P} U S T_{o}=\text { nop }
$$

It is worth stressing that the model may prove infeasible because of the above two constraints (18) and (19). In this case, the Decision Maker (DM) is immediately informed about the impossibility of serving all the orders in the delivery horizon and all the priority ones with the actual homogeneous supply. To achieve a feasible solution, either constraint 19 can be removed from the model or the company reconsiders priority orders. Even after removing constraint $(19)$, the model may remain infeasible, which means there is no possibility of serving all the orders within the delivery horizon. Finally, constraint (20) shows the definition of the variables.

$$
\begin{aligned}
& A T P 0_{i b}, A T P B_{i p l t}^{\beta}, A T P_{i p l t}, C O N T I N U O U S, \\
& A D_{i o}, D D F_{i o}, D D R_{o}, R D_{i o}, R D T_{o}, I N T E G E R, \\
& U O_{i o b}, U B_{i o p l t}^{\beta}, U_{i o p l t}, U S_{i o}, U S T_{o}, Y A_{i o}, Y R_{i o}, B I N A R Y .
\end{aligned}
$$




\section{Solution methodology for the LHP fuzzy shortage planning model}

This section describes the adopted approach to transform the fuzzy mixed-integer linear programming model (LHP-FSP) into an equivalent auxiliary crisp mixedinteger linear programming model. Then it presents the formulation of the resulting auxiliary crisp model.

\subsection{Transforming the fuzzy mixed-integer linear programming model into an equivalent crisp model}

As previously mentioned, the beta coefficients in Eq. (3) are not deterministic parameters because the size of the homogenous sublots in relation to the lot size in the master plan depends on uncontrollable productive factors and/or raw material characteristics. Therefore, they can change in a near region of an initial value. For example, let's assume that B1 is deterministic with a value of 0.4 and that it will always take the same value; in this case, tilde $\sim$ means that B1 is about 0.4. There is a body of literature on models that include fuzzy coefficients, and a well-known one is the Possibility Theory [31]. Research works like $21,22,32,36$ present methods for transforming multiobjective linear models (FMOLIP) with fuzzy coefficients into auxiliary deterministic multiobjective linear programming models (MOLIP). Even Peidro et al. [37] presents a case in which a multiobjective fuzzy model can be transformed into a single objective one.

In this study, the method developed originally by Jiménez et al. [38], and used by Peidro et al. 36] for resolving a fuzzy model, is taken as a reference. One of the main reasons for selecting the method of Jiménez et al. [38] has evidently been its proven validity for solving linear programming models, where technological coefficients are generally fuzzy numbers on the left-right hand side of equations, which is also our case. This approach responds to the following questions:

1. How is the feasibility of decision vector $\mathrm{x}$ defined when constraints involve fuzzy numbers?

2. How is optimality for an objective function with fuzzy coefficients defined?

Our model case perfectly matches the first question; therefore the approach is valid to base it on. Another reason for selecting this methodology is that it permits the DM's interactive participation in all the decision process steps. As shown below, the DM should select a feasibility degree of the constraints by means of the alpha value definition. The lower the feasibility degree is, the better the objective value becomes, and the higher the risk assumed by the DM. Therefore, the DM should balance the assumed level of risk against objective function performance.

This method has also been widely used to resolve supply chain planning fuzzy models, which proves its suitability to deal with such problems. The shortage 
planning problem addressed in this paper can be included in this category. Some recent references that have applied Jiménez et al. [38]'s method in this context are: 39 48.

The adopted approach is described below. Let's consider the following linear programming model with fuzzy parameters in the constraints:

Maximize

$$
z=\sum_{j=1}^{n} c_{j} x_{j} .
$$

Subject to

$$
\begin{gathered}
\sum_{j=1}^{n} \tilde{a}_{i j} x_{j} \geqslant \tilde{b}_{i} \quad i=1,2, \ldots, n . \\
x_{j} \geqslant 0 \quad j=1,2, \ldots, n .
\end{gathered}
$$

where $x_{j}$ is the $j^{\text {th }}$ variable; $c_{j}$ is a crisp coefficient of the objective function; $\left[a_{i j}\right]_{m \times n}$ is the fuzzy technical coefficient matrix of the $i^{t h}$ constraint and the $j^{t h}$ decision variable. Finally, $b_{i}$ is the fuzzy right-hand-side term of the $i^{\text {th }}$ constraint.

Peidro et al. 36 describe how the expected EV value of fuzzy number $\tilde{z}$ can be expressed as a half point within its expected interval, exactly as the following Eq. (24) shows, where $E_{1}$ and $E_{2}$ are the lower and upper values of the expected interval, respectively:

$$
E V(\tilde{z})=\frac{E_{1}^{z}+E_{2}^{z}}{2}
$$

Fuzzy constraints require membership functions, even when uncertainty is included in their technological coefficients. There are several options of membership functions to describe a fuzzy number $z_{i}$. The decision of selecting the trapezoidal (and the triangular particular case) membership function is based on the justification provided by Pedrycz 49], who states that such membership functions adjust well to cases where the fuzzy value presents modal (typical) behaviour with linear distribution along lower and upper bounds, which matches our case very well. Indeed, the beta coefficients representing the fraction of each homogeneous sublots in a lot are comprised between a minimum and maximum value with uniform probability distribution. Pedrycz $[49$ also states that the utilization of triangular membership functions is quite frequent in fuzzy modeling. The main reason is that, under some assumptions of the underlying density probability function, the fuzzy partition built from triangular membership functions leads to entropy equalization. Similarly, the triangular membership functions with the $1 / 2$ overlap level produce the zero value of the reconstruction error.

If fuzzy number $\tilde{z}$ presents a trapezoidal membership function as in Fig. 1, its expected interval can be calculated as expressed in Eq. 25, where $z_{1}$ and $z_{4}$, represent the lower and upper limits of the interval, respectively, and $z_{2}$ and $z_{3}$ 


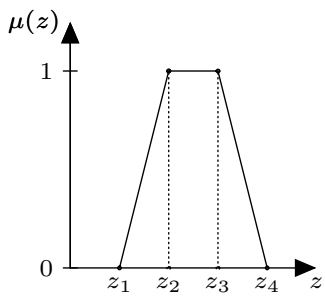

Figure 1: Trapezoidal fuzzy number $\tilde{z}$

represent its intermediate numbers. In trapezoidal membership function terms (see Fig. 1), alpha represents the degree to which the curve progresses toward limits $z_{2}$ and $z_{3}$.

$$
E I(\tilde{z})=\left[E_{1}^{z}, E_{2}^{z}\right]=\left[\frac{z_{1}+z_{2}}{2}+\frac{z_{3}+z_{4}}{2}\right] .
$$

From Peidro et al. [36] perspective, constraint [22] is the equivalent and is formulated as Eq. 26), where a can be defined as the degree of feasibility of solution $x$.

$$
\left[(1-\alpha) E_{2}^{a_{i}}+\alpha E_{1}^{a_{i}}\right] x \geqslant \alpha E_{2}^{b_{i}}+(1-\alpha) E_{1}^{b_{i}} \quad i=1,2, \ldots, n, x \geqslant 0, \alpha \in[0,1] .
$$

Eq. 26 only describes a relation of operator " $\geqslant$ ", but when the operator involved in the constraint is an equality (as in the LHP-FSP model), that is to say, $\sum_{j=1}^{n} \tilde{a}_{i j} x_{j} \geqslant \tilde{b}_{i}$, it is necessary to formulate an additional constraint. When considering trapezoidal fuzzy numbers $\tilde{a}_{i}=\left(a_{1}, a_{2}, a_{3}, a_{4}\right)$ and $\tilde{b}_{i}=\left(b_{1}, b_{2}, b_{3}, b_{4}\right)$, constraint (26) involving operator "=" is divided into two constraints, these being " $\leqslant "$ and " $\geqslant "$, Eqs. 27) and (28), respectively:

$$
\begin{aligned}
& {\left[\left(1-\frac{\alpha}{2}\right) E_{1}^{a_{i}}+\frac{\alpha}{2} E_{2}^{a_{i}}\right] x \leqslant \frac{\alpha}{2} E_{1}^{b_{i}}+\left(1-\frac{\alpha}{2}\right) E_{2}^{b_{i}} \quad i=1,2, \ldots, n, x \geqslant 0, \alpha \in[0,1] .} \\
& {\left[\left(1-\frac{\alpha}{2}\right) E_{2}^{a_{i}}+\frac{\alpha}{2} E_{1}^{a_{i}}\right] x \geqslant \frac{\alpha}{2} E_{2}^{b_{i}}+\left(1-\frac{\alpha}{2}\right) E_{1}^{b_{i}} \quad i=1,2, \ldots, n, x \geqslant 0, \alpha \in[0,1] .}
\end{aligned}
$$

By replacing Eq. 25) in constraints (27) and (28), the following constraints $(29)$ and 30 are obtained:

$$
\begin{aligned}
& {\left[\left(1-\frac{\alpha}{2}\right)\left(\frac{a_{1}+a_{2}}{2}\right)+\frac{\alpha}{2}\left(\frac{a_{3}+a_{4}}{2}\right)\right] x \leqslant \frac{\alpha}{2}\left(\frac{b_{1}+b_{2}}{2}\right)+\left(1-\frac{\alpha}{2}\right)\left(\frac{b_{3}+b_{4}}{2}\right) \quad i=1, \ldots, n, x \geqslant 0, \alpha \in[0,1] .} \\
& {\left[\left(1-\frac{\alpha}{2}\right)\left(\frac{a_{3}+a_{4}}{2}\right)+\frac{\alpha}{2}\left(\frac{a_{1}+a_{2}}{2}\right)\right] x \geqslant \frac{\alpha}{2}\left(\frac{b_{3}+b_{4}}{2}\right)+\left(1-\frac{\alpha}{2}\right)\left(\frac{b_{1}+b_{2}}{2}\right) \quad i=1, \ldots, n, x \geqslant 0, \alpha \in[0,1] .}
\end{aligned}
$$


Finally based on constraints 29 and $(30)$, it is possible to convert the original LHP-FSP fuzzy constraint (3) into auxiliary crisp constraints (31) and (32) due to the fuzzy coefficient by considering $\tilde{B}_{\beta}=\left(B_{\beta}^{1},\left(B_{\beta}^{2},\left(B_{\beta}^{3},\left(B_{\beta}^{4}\right)\right.\right.\right.$ :

$$
A T P B_{i p l t}^{\beta} \leqslant\left[\frac{\alpha}{2}\left(\frac{B_{\beta}^{1}+B_{\beta}^{2}}{2}\right)+\left(1-\frac{\alpha}{2}\right)\left(\frac{B_{\beta}^{3}+B_{\beta}^{4}}{2}\right)\right] m p s_{i p l t}-\sum_{o \in O s i(i)} q_{i o} U B_{i o p l t}^{\beta} \quad \forall p, l \in L p(p), i \in I L(l), \beta, t, \alpha \in[0,1] .
$$

$A T P B_{i p l t}^{\beta} \geqslant\left[\frac{\alpha}{2}\left(\frac{B_{\beta}^{3}+B_{\beta}^{4}}{2}\right)+\left(1-\frac{\alpha}{2}\right)\left(\frac{B_{\beta}^{1}+B_{\beta}^{2}}{2}\right)\right] m p s_{i p l t}-\sum_{o \in O s i(i)} q_{i o} U B_{i o p l t}^{\beta} \quad \forall p, l \in L p(p), i \in I L(l), \beta, t, \alpha \in[0,1]$.

It is important to stress that in both cases, the expected fuzzy number value interval can be represented with a triangular function that differs from the trapezoidal one, and which is also commonly used for this type of analysis. The triangular function is obtained by equating values $z_{2}$ and $z_{3}$ of the trapezoidal membership function. Thus fuzzy number $\tilde{z}$ can be represented as $\tilde{z}=\left(z_{1}, z_{2}, z_{3}, z_{4}\right)$ if the membership function describing it is trapezoidal, and $\tilde{z}=\left(z_{1}, z_{2}, z_{3}\right)$ if it is triangular (where $z_{2}$ triangular $=z_{2}$ trapezoidal $=z_{3}$ trapezoidal $=$ central value). In order to represent the fuzzy beta coefficients by a triangular function, it is necessary to take $B_{\beta}^{2}=B_{\beta}^{3}$ in the trapezoidal function of the previously defined beta.

This paper assumes that the expected fuzzy beta coefficient values can be represented by a triangular function. For instance, if it is assumed that three homogeneous sublots are obtained in proportions $0.7,0.2$ and 0.1 for each lot, these numbers are considered the central values and a triangular fuzzy number is generated for each beta within the $\pm 50 \%$ range from the central value. In this way, the three resulting fuzzy numbers would be $\tilde{B}_{1}=(0.35-0.7-1.05), \tilde{B}_{2}=(0.1-0.2-0.3)$ and $\tilde{B}_{3}=(0.05-0.1-0.15)$.

A novel aspect when modeling LHP uncertainty by fuzzy beta coefficients consists in ensuring that they all sum to 1 because they represent the fraction of an homogeneous sublot in the master plan. Therefore, the sum of the homogeneous sublots of a lot will equal the corresponding lot in the master plan. The most evident way is to model this aspect by adding one constraint and by ensuring that the sum of the betas equals 1 . However, when beta coefficients are considered fuzzy, they are represented by membership functions and do not, therefore, take a unique value. Before performing the different experiments, a decision was made to model this aspect by means of constraint (33), which was obtained by summing constraint (3) and by taking into account that $\sum_{\beta} \tilde{B}_{\beta}=1$. This constraint 33 ensures that beta coefficients are adjusted within their membership function to come to 1 and that, at the same time, the quantity assigned to different customer orders does not exceed the quantity defined in the master plan.

$$
A T P_{i p l t}=m p s_{i p l t}-\sum_{\beta} \sum_{o \in O s i(i)} q_{i o} * U B_{i o p l t}^{\beta} \quad \forall p, l \in L p(p), i \in I L(l), t .
$$




\subsection{The equivalent auxiliary crisp LHP-FSP model}

Therefore, the equivalent auxiliary crisp model obtained by transforming the fuzzy mixed-integer linear programming model is the following:

Max: Eq. (1)

S.t: Eqs. (2), (4)-20, $31-(33)$.

The above LHP-FSP is a crisp alpha-parametric mixed integer linear program model where alpha represents different degrees of feasibility. If the DM sets a high degree of satisfaction for the constraints (with $\alpha$ close to 1 ), the set feasible solution becomes smaller and, consequently, the optimal objective value worsens. So, the DM has to find a balanced solution between two objectives in conflict: to improve both the objective function value and the degree of satisfaction of constraints [38]. In this study, $\alpha$ is defined parametrically to obtain the objective function value for each of these $\alpha \in[0,1]$. Nevertheless, the result is a fuzzy set and the DM must choose which pair $(\alpha, z)$ is optimal if he/she wishes to obtain a crisp solution [22]. The next section reports a solution approach to support the DM in making the most satisfactory choice.

\subsection{Methodology for final solution selection}

Research work has been done to select the solution that best achieves the DM's requirements. Cadenas and Verdegay 32 describe some approaches, such as homogeneous linear functions, fuzzy ranking methods [38, 41, 42, 45, 47 and the Decomposition Theorem [50,51. The present study applies the interactive DM procedure by Jiménez et al. [38, which can be summarized in the following steps. Obtaining a better optimal objective function value implies a lower degree of feasibility of constraints. Then the DM faces two conflicting objectives; improving objective function value and improving the degree of satisfaction of the constraints. Jiménez et al. 38 proposes an interactive way to solve this problem:

1. Defining the levels of acceptance in the feasibility of solutions $\alpha_{k} \in[0,1]$. The best way to reflect the DM involves coming across two conflicting natural languages to define the semantic correspondence for the different degrees of feasibility [38:

- 0 - Unacceptable solution

- 0.1 - Practically an unacceptable solution

- 0.2 - An almost unacceptable solution

- 0.3 - A very unacceptable solution

- 0.4 - Quite an unacceptable solution

- 0.5 - Neither an acceptable nor an unacceptable solution

- 0.6 - Quite an acceptable solution

- 0.7 - A very acceptable solution 
- 0.8 - An almost acceptable solution

- 0.9 - Practically an acceptable solution

- 1 - A completely acceptable solution

According to this scale, set $\mathrm{M}$ is defined as so:

$$
M=\left\{\alpha_{k}=\alpha_{0}+0.1 k \mid k=0,1, \ldots, \frac{1-\alpha_{0}}{0.1}\right\} .
$$

2. By calculating the values of the objective function for each level of feasibility (alpha value), space $O=\left\{z\left(\alpha_{k}\right), \alpha_{k} \in M\right\}$ for the $\alpha_{k}$ acceptable optimal solution of the original problem is obtained.

3. Computing a decision vector that complies with the DM's expectations. In this step, the DM is asked to specify a range within which the objective function can be considered satisfactory. The upper limit of this range is $z^{u}$ and its lower limit is $z^{l}$. Thus it is possible to define a fuzzy set $\mu_{\tilde{G}}\left(z\left(\alpha_{k}\right)\right)$ whose membership function is, in this case, the linear one, Eq. 35.

$$
\mu_{\tilde{G}}\left(z\left(\alpha_{k}\right)\right)= \begin{cases}1 & , \text { if } z\left(\alpha_{k}\right)>z^{u}, \\ \frac{z\left(\alpha_{k}\right)-z^{l}}{z^{u}-z^{l}} & , \text { if } z^{l} \leqslant z\left(\alpha_{k}\right) \leqslant z^{u}, \\ 0 & , \text { if } z\left(\alpha_{k}\right)<z^{l} .\end{cases}
$$

Fuzzy set $\mu_{\tilde{G}}\left(z\left(\alpha_{k}\right)\right)$ represents the degree of accomplishment with the DM's expectations (DM's degree of satisfaction). It is important to mention that another membership function can be used instead of the linear one.

4. Choosing a balanced solution between the degree of feasibility and the degree of satisfaction. Two fuzzy sets are defined, $\tilde{F}$ and $\tilde{S}$, with these membership functions: $\mu_{\tilde{F}}\left(z\left(\alpha_{k}\right)\right)=\alpha_{k}$ and $\mu_{\tilde{S}}\left(z\left(\alpha_{k}\right)\right)=\mu_{\tilde{G}}\left(z\left(\alpha_{k}\right)\right)$, respectively. Next based on the intersection principle of fuzzy sets [52], we can define fuzzy decision $\tilde{D}=\tilde{F} \cap \tilde{S}$ in which the highest value is seen as the best combination between the degree of feasibility and the DM's degree of satisfaction. This value can be found as follows:

$$
\mu_{\tilde{D}}\left(z^{*}\right)=\max _{\alpha_{k} \in M}\left\{\alpha_{k} * \mu_{\tilde{G}}\left(z\left(\alpha_{k}\right)\right)\right\},
$$

where $z^{*} \in O$ is the solution belonging the decision vector, which is proposed as the crisp best option.

In the next section, this solution methodology is applied to a ceramic tile company. 


\section{Computational experiments: application to a ceramic tile company}

In the ceramic sector, LHP appears from different raw material (clay) compositions, the characteristics of some components (frits and enamels) and several other interrelated factors, which are very hard to control during the production process and affect final tile attributes. Technology advancements tend to avoid factors that cause heterogeneity, but they not do completely eliminate variability. Indeed, Heredia and Gras [53] state that the variables which determine process variability transmission as regards the gage dimensional change during the production of a batch mainly depend on: paste composition, moisture atomized powder, pressing pressure, the apparent difference in density between different parts' mould cavity, the temperature and temperature gradients in kilns. They conclude that given the difficulty to detect the presence of these factors, establishing their data analysis method using ANOVA as a periodic process control is suitable. The difficulty of obtaining uniform tiles as regards color due not only to frits and enamels, but also to different chemical processes during cooking, and due to the heterogeneous characteristics of clays, is also known. Davoli et al. [54 affirm that "undesired coloring is one of the most important requirements in the ceramic sector[55]". Although the manufacturer has installed the appropriate equipment so as to avoid such situations, and to eventually improve quality, the paper assumes that LHP exists. Therefore, the objective is to mitigate its negative impact on company performance and customers by adopting an approach purely based on management tools. That is, the presented approach does not discuss technological solutions, but centers on management ones.

The customer orders of these companies are characterized by comprising several quantities of different FGs. Due to the fact that ceramic pavings and coverings are normally presented together, customers require homogeneity among units of the same FG for esthetical (aspect and color) and functional reasons (thickness). For this reason, each ceramic piece has to be inspected and classified based on three attributes when the production process ends: quality (aspect), tone (degree of color) and caliber (thickness) [56.

The data used to validate the model are based on a ceramic tile company's historical information (customer orders, prices, costs, etc.). For confidentiality reasons, the real SC's physical configuration has been altered, although both the new and original structure have respected the assumptions described herein. This information has been used to derive a benchmark data set (Section 5.1) that has allowed to: (a) validate the LHP-FSP model; (b) analyze its behavior in different scenarios; and (c) show the superiority of the solutions obtained by the fuzzy model as compared to the equivalent deterministic one. The problem data, the generation of scenarios and the obtained results are described below. 


\subsection{Problem data description}

The present study considers a planning horizon of 31 periods, a set of 400 committed orders of which 38 are defined as priority orders and 24 as orders within the delivery horizon; the orders with the delivery horizon are all those whose delivery date is the first planning horizon period. The existence of 10 FGs produced by two plants following a Make-To-Stock strategy is considered. The first production plant has two production lines, while the other has just one. It is also considered that each FG can be classified into three subtypes.

The characteristics of the 400 orders inputted into the model were generated according to the historical data of a portfolio of orders provided by the company. With these historical data, it was verified that the range of lines per order is broad, and there are orders with a single line, while others contain more than 100 lines. However, it can be stated that $99.5 \%$ of orders present between 1 and 10 lines, and that probability is distributed as shown in Fig. 2. With this probability distribution, the number of lines for all 400 orders was considered by applying the Montecarlo methodology. Finally, one of the 10 FGs was randomly allocated. The amount ordered in each line $\left(q_{i o}\right)$ and the due date $\left(d d_{o}\right)$ were randomly selected from the order lines in the portfolio provided by the company for the purpose of reflecting the company's real situation as best as possible.

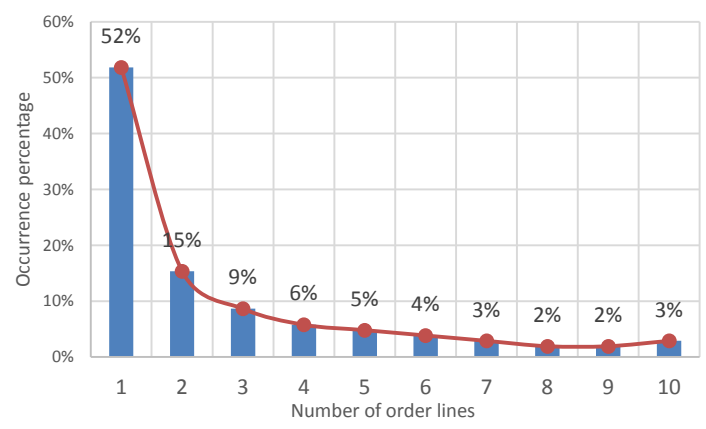

Figure 2: Percentage of number of lines per order.

The sale prices $\left(p v p_{i}\right)$, backlog costs $\left(b c_{i}\right)$ and inventory holding costs $\left(h u c_{i}\right)$ per $m^{2}$ appear in Table 3 . In MTS environments, the costs incurred when producing different lots were defined in the master production plan. The shortage planning model takes master plan quantities as an input and decides about reassigning them jointly with stocks to already committed orders. During this reassignation process, only the holding and backlogging costs to reserve a product(s) for an order before or after its due date, respectively, can be affected. Therefore, having been 
Table 3: Input data $(€)$.

\begin{tabular}{cccc}
\hline Finished good & Selling price $p v p_{i}$ & Backlogging cost $b c_{i}$ & Holding cost $h u c_{i}$ \\
\hline PF1 & 7 & 0.75 & 0.064 \\
PF2 & 18 & 0.65 & 0.052 \\
PF3 & 12 & 0.5 & 0.04 \\
PF4 & 10 & 0.45 & 0.036 \\
PF5 & 5 & 0.45 & 0.036 \\
PF6 & 11 & 0.7 & 0.052 \\
PF7 & 13 & 0.65 & 0.04 \\
PF8 & 12 & 0.5 & 0.036 \\
PF9 & 6 & 0.5 & 0.052 \\
PF10 & 15 & 0.45 & 0.045 \\
\hline
\end{tabular}

previously considered all costs, to calculate the profit of an order based on the selling prices of their products is justified. For this reason, parameters po and bco for each order were calculated by multiplying quantity $q_{i o}$ by the corresponding unitary parameter $p v p_{i}$ and $b c_{i}$, respectively, and then summing up all FGs $i$ included in the customer order proposal.

Supply (initial stock and mps quantities) generation is based on previously defined orders. As the proposed model of this paper deals with shortage situations, only two supply levels are considered: (1) adjusted supply and (2) lacking supply. The possibility, or not, of delaying orders is also modeled: (a) delay and (b) no delay. In all, four possible scenarios were defined: $1 \mathrm{a}, 1 \mathrm{~b}, 2 \mathrm{a}$ and $2 \mathrm{~b}$.

Based on the quantity requested $\left(q_{i o}\right)$ and due date $\left(d d_{o}\right)$ for each order line, a projected supply quantity $\left(p g * q_{i o}\right)$ is derived and assigned randomly to a period within the interval $\left[0, d d_{o}+\operatorname{rmax}_{o}\right]$, and also to the production line with the lowest quantity assigned in order to balance resource utilization. The pg parameter is a random number generated within a predefined interval that represents the order line quantity percentage. When supply is lacking, e.g., $\in[0.85,1]$, it is necessary to ensure that the generated mps quantities are lower than or equal to the requested quantities. Adjusted supply $p g \in[1,1.15]$ represents that mps quantities are higher than or equal to the requested quantities. Finally, the master plan quantities $\left(m p s_{i l p t}\right)$ are derived by summing up all the supply quantities of an FG assigned to a production line within a time period.

\subsection{Generation of scenarios}

Numerical experiments were carried out to: (a) validate the model; (b) assess the impact of LHP on model performance; and (c) analyze model behavior at different degrees of feasibility in comparison to the deterministic model. For this purpose, the model was solved with the input data described in Section 5.1. but in different scenarios. These scenarios were generated based on: (1) the delay allowed in serving orders $\left(\operatorname{rmax}_{o}\right)$; (2) the beta coefficients definition (the LHP impact); and (3) alpha values (the uncertainty impact). 
For the delay, two scenarios were considered: no delay and allowed delay of two periods in no priority orders. In order to solve the problem, alpha was defined parametrically by defining 11 possible alpha values $(0-0.1-0.2-0.3-0.4-0.5$ $-0.6-0.7-0.8-0.9-1)$.

As regards LHP characteristics, five scenarios were generated by modifying the beta parameters. Indeed, LHP is considered mainly in the LHP-FSR model by fuzzy parameters beta $\left(\tilde{B}_{1}, \tilde{B}_{2}\right.$ and $\left.\tilde{B}_{3}\right)$, which represent the percentage of all three homogeneous sublot as regards their corresponding lot in the master plan. It is important to note that the beta factors finally chosen to solve the model will be defined based on the results of the statistics derived from the particular manufacturer's past historical performance. The objective pursued by the definition of several beta scenarios in the experiments carried out was to assess the impact of a different distribution of betas on the objective function and their modeling under uncertainty. In this study, different central values were assigned to these parameters to characterize five LHP situations (scenarios):

- One homogeneous sublot $\left(B_{1}=1, B_{2}=0, B_{3}=0\right)$ : this scenario assumes that every lot in the master plan is completely homogeneous (i.e., only one subtype per lot) although different lots are not assumed homogeneous.

- Two unbalanced homogeneous sublots $\left(B_{1}=0.7, B_{2}=0.3, B_{3}=0\right)$ : this scenario assumes that the master plan lots are expected to be divided into two homogeneous sublots with unequal proportions, as specified by the beta parameters.

- Two balanced homogeneous sublots $\left(B_{1}=0.5, B_{2}=0.5, B_{3}=0\right)$ : for this scenario the master plan lots are divided into two homogeneous sublots with an equal proportion.

- Three unbalanced homogeneous sublots $\left(B_{1}=0.7, B_{2}=0.2, B_{3}=\right.$ $0.1)$ : in this scenario, three homogenous sublots are expected to appear in each lot defined in the master plan, of which one is relatively high.

- Three balanced homogeneous sublots $\left(B_{1}=0.4, B_{2}=0.3, B_{3}=0.3\right)$ : like the above scenario, three homogenous sublots of similar size are expected to appear in each lot defined in the master plan.

By considering that $\tilde{B}_{1}, \tilde{B}_{2}$ and $\tilde{B}_{3}$ are fuzzy numbers with a triangular membership function, it is necessary to specify the central value for each one, as well as the upper and lower limit of variation. The central beta values for each scenario coincide with those set out previously, whereas the upper and lower variation limits are calculated by varying the central value in $\pm 50 \%$, respectively (Table 4). As explained in Section 4.1, constraint (33) should be added to ensure that the sum of all betas equal one for each scenario. 
Table 4: Fuzzy LHP scenarios.

\begin{tabular}{clll}
\hline Case & $\tilde{B}_{1}=\left(b_{11}-b_{12}-b_{13}\right)$ & $\tilde{B}_{2}=\left(b_{21}-b_{22}-b_{23}\right)$ & $\tilde{B}_{3}=\left(b_{31}-b_{32}-b_{33}\right)$ \\
\hline 1 & $(0.5-1-1.5)$ & $(0-0-0)$ & $(0-0-0)$ \\
2 & $(0.15-0.3-0.45)$ & $(0.35-0.7-1.05)$ & $(0-0-0)$ \\
3 & $(0.35-0.7-1.05)$ & $(0.1-0.2-0.3)$ & $(0.05-0.1-0.15)$ \\
4 & $(0-0-0)$ & $(0.25-0.5-0.75)$ & $(0.25-0.5-0.75)$ \\
5 & $(0.2-0.4-0.6)$ & $(0.15-0.3-0.45)$ & $(0.15-0.3-0.45)$ \\
\hline
\end{tabular}

\subsection{Experimental results}

The fuzzy model was implemented by using the GAMS 23.6 software. The experiments were run in an Intel core 2 quad processor, $2.5 \mathrm{GHz}$ with $4 \mathrm{~GB}$ RAM. The Gurobi 4.0 solver was used. The model was run for the cases with and without a delay, and for the 11 alpha values and the five LHP scenarios: in all, $2 * 11 * 5=$ 110 model executions were run. Next the results obtained from the experiments are presented and analyzed. Then the degree of the difficulty in optimally solving them is discussed.

The problem was infeasible for all the executions when constraints 18 and $(19)$ were included. This means that with the FG availability in the problem data, it was not possible to serve all the priority orders and orders in the delivery horizon. Thus these two constraints were removed from the original model and, therefore, the results reported in this section do not consider the above two constraints. It is important to highlight that the GAMS software immediately reports problem infeasibility. This means major time saving for the DM who instantly knows if it is possible to serve all the priority orders and orders in the delivery horizon with the actual supply.

For each LHP scenario, Tables 5 and 6 show the results obtained by solving the model for the 11 alpha values and the two cases with and without a delay. The results of each combination of the above parameters report the objective function (Z) value, as well as improvement in percentage (\% Imp.) if compared to the deterministic model.

As expected for the scenario with only one homogeneous sublot $\left(B_{1}=1, B_{2}=\right.$ $\left.0, B_{3}=0\right)$, the results obtained are the same as the deterministic model and are independent of the alpha value. This is because, when only one beta value differs from zero, it will be always take the value of 1 and no uncertainty in the homogeneous sublots actually exists. Therefore, the solutions of the deterministic and fuzzy models are the same for this scenario in both cases for the delay, which validates the model formulation.

From the results obtained, it is observed that incomes are higher for all the LHP homogeneity scenarios and alpha values in objective function $(Z)$ terms when a delay in serving orders is allowed. Obviously, allowing some delay as regards the previously due date promised to customers provides more flexibility and makes serving more orders possible. However, the company's reliability and image can 
be damaged. Therefore, the DM should define the delay allowed for each order very carefully.

Table 5: Gross margin of served orders with no delay allowed.

\begin{tabular}{|c|c|c|c|c|c|c|c|c|c|c|c|}
\hline \multirow[t]{2}{*}{ Delay } & \multirow[t]{2}{*}{ Alpha } & \multicolumn{2}{|c|}{ Beta $1-0-0$} & \multicolumn{2}{|c|}{ Beta $0.7-0.3-0$} & \multicolumn{2}{|c|}{ Beta $0.5-0.5-0$} & \multicolumn{2}{|c|}{ Beta $0.7-0.2-0.1$} & \multicolumn{2}{|c|}{ Beta $0.4-0.3-0.3$} \\
\hline & & Value & $\%$ Imp. & Value & \% Imp. & Value & \% Imp. & Value & \% Imp. & Value & \% Imp. \\
\hline \multirow[t]{12}{*}{ No delay } & 0 & 932,335 & 0 & 916,939 & 6.6 & 860,245 & 4.7 & 918,240 & 8.7 & 826,192 & 6.2 \\
\hline & 0.1 & 932,335 & 0 & 918,878 & 6.8 & 860,297 & 4.7 & 918,798 & 8.7 & 822,571 & 5.7 \\
\hline & 0.2 & 932,335 & 0 & 909,695 & 5.7 & 859,388 & 4.6 & 909,292 & 7.6 & 821,262 & 5.5 \\
\hline & 0.3 & 932,335 & 0 & 910,184 & 5.8 & 850,306 & 3.5 & 909,830 & 7.7 & 819,587 & 5.3 \\
\hline & 0.4 & 932,335 & 0 & 910,093 & 5.8 & 849,558 & 3.4 & 908,276 & 7.5 & 810,498 & 4.1 \\
\hline & 0.5 & 932,335 & 0 & 901,777 & 4.8 & 849,645 & 3.4 & 899,919 & 6.5 & 801,334 & 3.0 \\
\hline & 0.6 & 932,335 & 0 & 898,673 & 4.4 & 837,188 & 1.9 & 897,181 & 6.2 & 800,072 & 2.8 \\
\hline & 0.7 & 932,335 & 0 & 898,457 & 4.4 & 837,234 & 1.9 & 896,450 & 6.1 & 781,703 & 0.4 \\
\hline & 0.8 & 932,335 & 0 & 895,154 & 4.0 & 835,647 & 1.7 & 885,410 & 4.8 & 781,181 & 0.4 \\
\hline & 0.9 & 932,335 & 0 & 878,971 & 2.2 & 835,015 & 1.6 & 865,357 & 2.4 & 780,465 & 0.3 \\
\hline & 1 & 932,335 & 0 & 863,050 & 0.3 & 824,639 & 0.4 & 846,069 & 0.1 & 778,606 & 0.1 \\
\hline & Det. & 932,335 & & 860,387 & & 821,652 & & 844,915 & & 778,215 & \\
\hline
\end{tabular}

Table 6: Gross margin of served orders with delay of two periods allowed for non priority orders.

\begin{tabular}{|c|c|c|c|c|c|c|c|c|c|c|c|}
\hline \multirow[t]{2}{*}{ Delay } & \multirow[t]{2}{*}{ Alpha } & \multicolumn{2}{|c|}{ Beta $1-0-0$} & \multicolumn{2}{|c|}{ Beta $0.7-0.3-0$} & \multicolumn{2}{|c|}{ Beta $0.5-0.5-0$} & \multicolumn{2}{|c|}{ Beta $0.7-0.2-0.1$} & \multicolumn{2}{|c|}{ Beta $0.4-0.3-0.3$} \\
\hline & & Value & \% Imp. & Value & \% Imp. & Value & \% Imp. & Value & \% Imp. & Value & \% Imp. \\
\hline \multirow{12}{*}{$\begin{array}{l}\text { Delay in } \\
\text { non } \\
\text { priority } \\
\text { orders }\end{array}$} & 0 & 948,986 & 0 & 935,976 & 6.2 & 891,884 & 6.0 & 934,275 & 7.4 & 847,238 & 6.1 \\
\hline & 0.1 & 948,986 & 0 & 931,435 & 5.7 & 891,698 & 5.9 & 936,570 & 7.7 & 842,771 & 5.5 \\
\hline & 0.2 & 948,986 & 0 & 925,260 & 5.0 & 892,229 & 6.0 & 927,594 & 6.6 & 842,222 & 5.4 \\
\hline & 0.3 & 948,986 & 0 & 922,989 & 4.7 & 874,290 & 3.9 & 924,036 & 6.2 & 841,454 & 5.3 \\
\hline & 0.4 & 948,986 & 0 & 927,667 & 5.3 & 874,243 & 3.9 & 926,124 & 6.5 & 834,380 & 4.5 \\
\hline & 0.5 & 948,986 & 0 & 916,328 & 4.0 & 873,994 & 3.8 & 917,484 & 5.5 & 822,953 & 3.0 \\
\hline & 0.6 & 948,986 & 0 & 918,066 & 4.2 & 861,700 & 2.4 & 915,810 & 5.3 & 821,462 & 2.8 \\
\hline & 0.7 & 948,986 & 0 & 917,430 & 4.1 & 861,321 & 2.3 & 915,239 & 5.2 & 805,612 & 0.9 \\
\hline & 0.8 & 948,986 & 0 & 915,737 & 3.9 & 859,201 & 2.1 & 903,560 & 3.9 & 803,966 & 0.7 \\
\hline & 0.9 & 948,986 & 0 & 898,430 & 1.9 & 857,581 & 1.9 & 883,576 & 1.6 & 802,297 & 0.4 \\
\hline & 1 & 948,986 & 0 & 888,720 & 0.8 & 847,978 & 0.7 & 871,709 & 0.2 & 799,065 & 0.0 \\
\hline & Det. & 948,986 & & 881,261 & & 841,667 & & 869,891 & & 798,761 & \\
\hline
\end{tabular}

As regards LHP scenarios, the global objective function (Z) becomes generally worse for the scenarios with more homogeneous sublots (that is, more betas that differ from zero) and more balanced ones (that is, similar sized sublots). Therefore, as expected, the more the fragmented sublots, the fewer orders served with homogeneity requirements. Worse results are also obtained for the scenarios with the same number of homogeneous sublots when sublots are more similar in size (i.e., betas are more balanced). This seems logical because it is possible to serve not only small orders with bigger sublots, but also big ones. However, with smaller sublots, big orders cannot be homogeneously served.

Regarding LHP uncertainty modeling, as expected, the gross margin of served orders is higher for all LHP scenarios when lower alpha values are considered. To better understand fuzzy model behavior, in relation to the alpha parameter, Fig. 3 represents the gross margin value for the delay case for the five LHP scenarios and the 11 alpha values. Thus the curves in Fig. 3 slope downwardly (they obtain a smaller profit) as the alpha value increases and reaches a level that comes very close to that provided by the deterministic model when the alpha value comes close to 1 . 
In order to analyze the impact of modeling uncertainty as compared to the delaybased scenario and level of LHP homogeneity, Table 7 provides the average improvement made for the gross margin value of the deterministic model for each beta case by considering all alpha cases. This table shows that, in general, modeling inherent LHP uncertainty implies considerable improvement for most scenarios with unbalanced sublots.

Fuzzy model size and computational efficiency are offered in Tables 8 and 9 , respectively. Table 8 shows the number of constraints, non zeros, the continuous, integer and binary variables for the deterministic and the fuzzy models that are independent of the defined scenarios. As observed, the fuzzy model formulation increases only the number of constraints as compared with the deterministic model.

Finally, a discussion about the difficulty of optimally solving problems is presented. In order to more efficiently solve the different problems, the default solver parameters were adjusted by several tests to define the maximum allowed solution time to achieve an acceptable GAP below or equal to $0.01 \%$. Consequently, the solution time was set at $3600 \mathrm{~s}$. When solving each problem, the stop condition was: first, to reach a GAP equal to or less than $0.01 \%$ or, alternatively, to exhaust the execution time of $3600 \mathrm{~s}$.

Only 20 of the overall 110 executions reached the GAP of $0.01 \%$ before spending the time limit of $3600 \mathrm{~s}$. The majority (16 of 20 ) corresponded to "Beta: $0.4-0.3$ - 0.3". The 90 remaining executions reached the time limit of $3600 \mathrm{~s}$ with a GAP higher than $0.01 \%$. The mean GAP obtained for each scenario is seen in Table 9 From the results, it can be stated for our experiments that: the gap obtained was smaller for the balanced scenario, higher number of homogeneous sublots and when no delay was allowed.

Table 7: Average percentage of improvement for the gross margin $(Z)$ of the deterministic model.

\begin{tabular}{lcc}
\hline Beta Scenario & \multicolumn{2}{c}{ Gross Margin (Z) } \\
\cline { 2 - 3 } & No delay (\%) & Delay (\%) \\
\hline Beta: $0,7-0,3-0$ & 4.6 & 4.2 \\
Beta: $0.5-0.5-0$ & 2.9 & 3.5 \\
Beta: $0.7-0.2-0.1$ & 6 & 5.1 \\
Beta: $0.4-0.3-0.3$ & 3.1 & 3.2 \\
\hline
\end{tabular}

\subsection{Selecting the final solution to be implemented}

The previous section aimed to validate the model and to analyze its performance in different scenarios. Yet when using the model in the real world, the DM must choose only one solution to be finally implemented. For illustrative purposes, the methodology proposed in this section for selecting the final solution (Section 4.3) was applied to a scenario of three unbalanced homogeneous sublots $(0.7-0.2-$ 


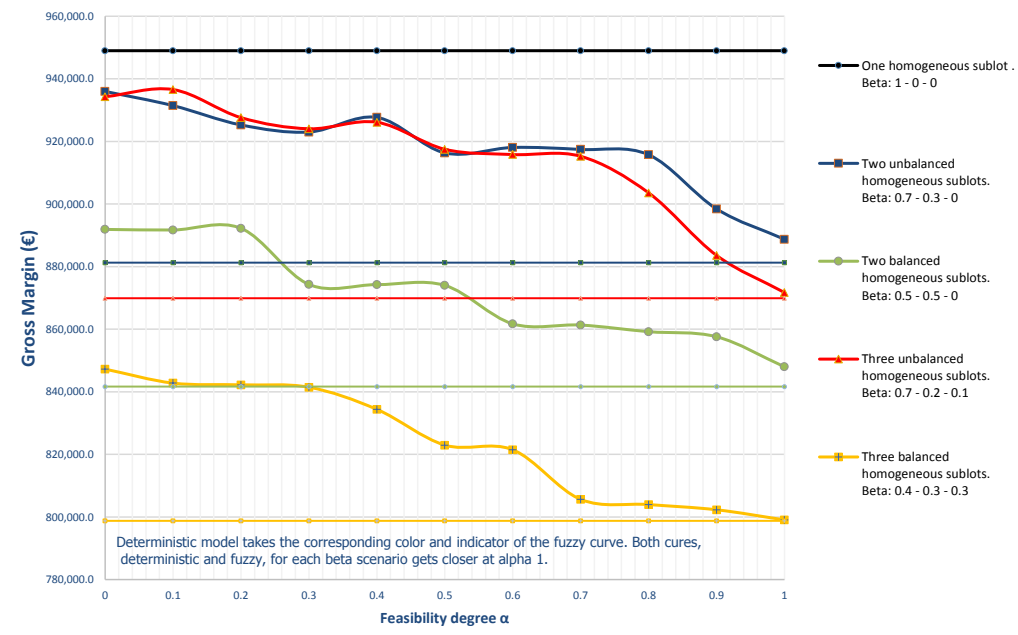

Figure 3: Gross margin for the scenario with delay allowed in the uncertainty and deterministic case. (For interpretation of the references to color in this figure legend, the reader is referred to the web version of this article.)

0.1 ), which is a usual situation for the ceramic case with and without an allowed delay.

First of all, the degree of feasibility (alpha) that the DM is willing to consider should be defined. In this case, it is assumed that the DM will not consider high risks in violating constraints [38]. Thus set $\mathrm{M}$ is defined as:

$$
M=\{0.4,0.5,0.6,0.7,0.8,0.9,1\}
$$

According to the procedure set out in Section 4.3 the next step consists in defining the range within which the gross margin values are acceptable for the DM. Let's assume that the allowable range of variance is $5 \%$ of the deterministic value.

Therefore, values $z^{l}=$ deterministic value and $z^{u}=$ deterministic value ${ }^{*} 1.05 \%$; this rules applies for both cases with and without delay. With this information, we can compute $\mu_{\tilde{G}}\left(z\left(\alpha_{k}\right)\right)$ by using the linear membership function of Eq. 335.

Now it is necessary to define fuzzy sets $\tilde{F}$ and $\tilde{S}$ with the following membership functions: $\mu_{\tilde{F}}\left(z\left(\alpha_{k}\right)\right)=\alpha_{k}$ and $\mu_{\tilde{S}}\left(z\left(\alpha_{k}\right)\right)=\mu_{\tilde{G}}\left(z\left(\alpha_{k}\right)\right)$, respectively. Then we need to specify the intersection of these two sets $\tilde{D}=\tilde{F} \cap \tilde{S}$ by calculating the $\mu_{\tilde{D}}\left(z^{*}\right)$ value. Intersection $\tilde{D}=\tilde{F} \cap \tilde{S}$ is calculated by multiplying $\alpha_{k} * \mu_{\tilde{G}}\left(z\left(\alpha_{k}\right)\right)$ 
Table 8: Number of constraints, non zeros and variable types of the deterministic and fuzzy models.

\begin{tabular}{lcc}
\hline & Deterministic & Fuzzy \\
\hline Constraints & 398,011 & 400,891 \\
Non zeros & $2,322,782$ & $2,596,958$ \\
Binary variables & $1,668,400$ & $1,668,400$ \\
Integer variables & 12,800 & 12,800 \\
Continous variables & 4,140 & 4,140 \\
\% Density & 0.04 & 0.04 \\
\hline
\end{tabular}

Table 9: Mean GAP and CPU time in seconds to solve the deterministic and fuzzy models for all alpha values.

\begin{tabular}{llcccc}
\hline Delay & LHP scenarios & \multicolumn{2}{c}{ Mean GAP (\% MIP best bound) } & \multicolumn{2}{c}{ Mean CPU time (s) } \\
\cline { 3 - 6 } & & Det (\%) & Fuzzy (\%) & Det & Fuzzy \\
\hline \multirow{2}{*}{ No delay } & Beta: $1-0-0$ & 0.79 & 0.79 & 3,600 & 3,600 \\
& Beta: $0.7-0.3-0$ & 0.03 & 0.32 & 3,600 & 3,600 \\
& Beta: $0.7-0.2-0.1$ & 0.01 & 0.17 & 2,620 & 3,225 \\
& Beta: $0.5-0.5-0$ & 0.01 & 0.05 & 3,600 & 3,366 \\
& Beta: $0.4-0.3-0.3$ & 0.01 & 0.02 & 1,140 & 1,313 \\
\hline \multirow{2}{*}{ Delay in } & Beta: $1-0-0$ & 0.97 & 0.97 & 3,600 & 3,600 \\
non & Beta: $0.7-0.3-0$ & 0.22 & 0.43 & 3,600 & 3,600 \\
priority & Beta: $0.7-0.2-0.1$ & 0.03 & 0.29 & 3,600 & 3,600 \\
orders & Beta: $0.5-0.5-0$ & 0.04 & 0.07 & 3,600 & 3,600 \\
& Beta: $0.4-0.3-0.3$ & 0.01 & 0.03 & 995 & 1,957 \\
\hline
\end{tabular}

according to Eq. (36). For instance, if we consider an $\alpha_{k}=0.4$ for the no delay case (Table 10, then the objective function takes the value of $z\left(\alpha_{k}\right)=908.276$. By applying Eq. (35), in which we evaluate the degree of pertinence of $z\left(\alpha_{k}\right)$ within the range defined by $z^{l}$ and $z^{u}$, we obtain $\mu_{\tilde{G}}\left(z\left(\alpha_{k}\right)\right)=1$.

Thus the values of fuzzy sets $\tilde{F}$ and $\tilde{S}$ for this $\alpha_{k}$ are described as $\mu_{\tilde{F}}(z(0.4))=0.4$ and $\mu_{\tilde{S}}(z(0.4))=1$. Therefore, product $\alpha_{k} * \mu_{\tilde{G}}\left(z\left(\alpha_{k}\right)\right)$ is $0.4 * 1=0.4$. This logic is applied for all the alphas defined in set $\mathrm{M}$ for the delay and no delay cases. Table 10 shows the results of calculating all the $\alpha_{k}$ belonging to set M.

From Table 10 , it can be deduced that the best combination between the degree of feasibility and the DM's expectations is achieved for $\alpha_{k}=0.8$ in case of non delay scenario and $\alpha_{k}=0.7$ for the scenario with delay in non priority orders. In this way, solutions in both cases are obtained which offer good performance as far as the DM's expectations being fulfilled are concerned, as well as $\mu_{\tilde{D}}\left(z^{*}(0.8)\right)=0.744$ for a non delay case and $\mu_{\tilde{D}}\left(z^{*}(0.7)\right)=0.699$ for a delay case in priority orders. At the same time, a moderate level of risk is maintained according to the scale defined in Section 4.3, for which $\alpha_{k}=0.7$ and $\alpha_{k}=0.8$ are very acceptable risks.

The methodology employed to select the best alpha value allows the DM to acquire information about the risk of disregarding the constraints, which can be interpreted as the likelihood of the selected solution being feasible when the real situation 
Table 10: Data for the alpha selection procedure. Three unbalanced homogeneous sublots (Beta: $0.7-0.2-0.1$ )

\begin{tabular}{lccccc}
\hline Delay & Alpha & Gross Margin & $\mu_{\tilde{F}}\left(z\left(\alpha_{k}\right)\right)=\alpha_{k}$ & $\mu_{\tilde{S}}\left(z\left(\alpha_{k}\right)\right)=\mu_{\tilde{G}}\left(z\left(\alpha_{k}\right)\right)$ & $\mu_{\tilde{D}}\left(z^{*}\right)=\alpha_{k} * \mu_{\tilde{G}}\left(z\left(\alpha_{k}\right)\right)$ \\
\hline \multirow{5}{*}{ No delay } & 0.4 & 908,276 & 0.4 & 1.000 & 0.400 \\
& 0.5 & 899,919 & 0.5 & 1.000 & 0.500 \\
& 0.6 & 897,181 & 0.6 & 1.000 & 0.600 \\
& 0.7 & 896,450 & 0.7 & 1.000 & 0.700 \\
& $\mathbf{0 . 8}$ & $\mathbf{8 8 5 , 4 1 0}$ & $\mathbf{0 . 8}$ & $\mathbf{0 . 9 3 0}$ & 0.410 \\
Delay in & 0.9 & 865,357 & 0.9 & 0.456 & 0.000 \\
non & 1 & 846,069 & 1 & 0.000 & 0.400 \\
priority & 0.4 & 926,124 & 0.4 & 1.000 & 0.500 \\
orders & 0.5 & 917,484 & 0.5 & 1.000 & 0.600 \\
& 0.6 & 915,810 & 0.6 & 1.000 & 0.699 \\
& 0.7 & $\mathbf{9 1 5 , 2 3 9}$ & $\mathbf{0 . 7}$ & $\mathbf{0 . 9 9 9}$ & 0.585 \\
& 0.9 & 903,560 & 0.8 & 0.731 & 0.245 \\
\hline
\end{tabular}

occurs. In the case studied herein, this reality corresponds to the homogeneous sublot size once the master plan lots have been manufactured. This process enables the DM to determine his/her levels of expectations. Finally based on them, a solution is foreseen that strikes a balance between the degrees of fulfillment of these levels, but which also considers the level of risk in running the selected solution.

\section{Conclusions}

Supply chain shortage planning under uncertainty is a complex topic for which very few research works exist. In LHP environments, uncertainty in homogeneous sublots can frequently lead to discrepancies between planned homogeneous quantities and real ones. This situation means that previously committed orders cannot be served with assigned planned lots in the OPP. That is, a shortage situation occurs.

This paper offers a new shortage planning perspective by means of a novel model to support the reassignment of existing stocks and planned lots. The proposed model takes into account LHP uncertainty in the master plan production lots by means of a fuzzy model (LHP-FSP) whose aim is to maximize the gross margin of served orders. Inherent LHP uncertainty has been modeled by fuzzy beta coefficients. These beta coefficients represent the splitting percentage of each lot in the master plan into homogeneous sublots. Existing research that has dealt with technological coefficient fuzziness has always assumed independence among them. However, in LHP environments, the sum of the betas always equals 1 (i.e., the sum of homogeneous sublots should equal their corresponding lot in the master plan). To model this aspect, it was necessary to formulate an additional constraint.

The LHP-FSP model has been tested using realistic data from a ceramic SC. The experiments have been designed for different scenarios based on allowing, or not, 
a delay in served orders, degree of feasibility (alpha) and LHP scenarios (betas). The obtained results confirm the validity of the model and provide interesting information about its behavior.

Higher gross margins are always obtained for the allowed case of delay because more flexibility in the delivery date means it is possible to serve more orders. One interesting conclusion drawn from the LHP scenarios is that the results become worse as the number of homogeneous sublots increases (more fragmented), and also for the same number of homogeneous sublots when betas are similar (i.e., balanced homogeneous sublots). This is because it is possible to serve big- and small-sized orders with large quantities of homogeneous units available (a smaller number of sublots and unbalanced ones). However, with smaller quantities of homogeneous sublots, only small-sized orders can be served. Finally in accordance with the literature on the topic, better results are obtained when lowering the alpha value for any delay and LHP scenario, and the results are almost the same for the deterministic model and alpha $=1$.

In order to support the DM in finally choosing an alpha value (degree of feasibility) and its associated solution to be implemented, a methodology has been proposed based on the premise that the DM must add his/her expectations for the model objective(s), but by evaluating the feasibility level of the solutions that better achieve the DM's requirements at the same time. The approach results in a balanced solution between these two factors which ensures, on the one hand, that solutions can be achieved in real life while, on the other hand, good performance in model objective terms is accomplished.

\section{Publication data}

Figure 4 shows the first page of the article published in the Applied Mathematical Modelling journal (ISSN: 0307-904X).

\section{Acknowledgement}

This research has been carried out within the project framework funded by the Spanish Ministry of Economy and Competitiveness (Ref. DPI2011-23597) and the Universitat Politècnica de València (Ref. PAID-06-11/1840) entitled "Methods and models for operations planning and order management in supply chains characterized by uncertainty in production due to the lack of product uniformity" (PLANGES-FHP). 
Applied Mathematical Modelling 39 (2015) 4463-4481

\begin{tabular}{cc} 
Contents lists available at ScienceDirect \\
ELSEVIER & Applied Mathematical Modelling \\
\hline
\end{tabular}

A fuzzy model for shortage planning under uncertainty due to lack of homogeneity in planned production lots

M.M.E. Alemany ${ }^{\mathrm{a}, *}$, Hanzel Grillo $^{\mathrm{a}}$, A. Ortiz $^{\mathrm{a}}$, Vicente S. Fuertes-Miquel ${ }^{\mathrm{b}}$

${ }^{2}$ Research Centre on Production Management and Engineering (CIIIP), Universitat Politècnica de València, Camino de Vera S/N, 46022 Valencia, Spain ${ }^{\mathrm{b}}$ Departamento de Ingeniería Hidráulica y Medio Ambiente, Universitat Politècrnica de València, Camino de Vera S/N, 46022 Valencia, Spain

\section{A R T I C L E I N F O}

Article history:

Received 15 January 2014

Received in revised form 10 November 201

Accepted 19 December 2014

Keywords:

Keywords

Fuzzy
Mathematical programming model

Shortage planning
Order promising

Lack of homogeneity in the product

Uncertainty

\begin{abstract}
A B S T R A C T
Lack of homogeneity in the product (LHP) affects several sectors like horticulture, reverse logistics, furniture, ceramics and leathers, among others. Productive processes with LHP are characterized by manufacturing units of the same finished good $(\mathrm{FG})$ with certain different subtypes of the same FG in each production lot, which provides homogeneous sublots. Due to inherent LHP uncertainty, the size of each homogeneous sublot is not known until produced. LHP becomes a problem when customers order several units of the same FG and require homogeneity among them; i.e., being served with the same subtype. Like inherent LHP uncertainty, discrepancies between planned homogeneous quantities and the real ones is quite usual. This means it is impossible to serve committed orders with the previously defined requirements of quantity, homogeneity and due date, which brings about a shortage situation. In this paper, a fuzzy mixed integer linear programming model is proposed to support shortage planning in environments with LHP (LHP-FSP model). The LHP-rSP model aims to maximize the profits of served orders by reallocating the quantities of subtypes in stock and the theertainty future ones in the master plan model the fuzzy interdependent coefficients that represent the fraction of each homogemodel the fuzzy interdependent coefficients that represent the fraction of each homogeneous sublot. Finally, experiments based on realistic data from a ceramic company have
been designed to validate the model and to analyze its behavior in different scenarios. C 2014 Elsevier Inc. All rights reserved.
\end{abstract}

\title{
1. Introduction
}

The ability to effectively match demand and supply is fundamental to nearly all supply chain management processes [1]. Rapid responses to customer needs, a high level of customer service and flexibility to handle uncertainties and fluctuations in both demand and supply are becoming strategic differentiators in the modern marketplace [2]. To achieve these objectives, demand fulfillment \& ATP (Available-To-Promise), which include order promising and shortage planning [3], are vitally important. The order promising process (OPP) refers to the set of business activities that are triggered to provide a response to customer order requests. These activities are related to the acceptance/rejection of customer orders, and to set delivery are enough ATP quantities. Gartner [4] defines ATP as the uncommitted portion of a company's inventory or planned

\footnotetext{
* Corresponding author.

E-mail address: mareva@omp.upv.es (M.M.E. Alemany).

http://dx.doi.org/10.1016/.apm.2014.12.057
}

0307-904X/@ 2014 Elsevier Inc. All rights reserved.

Figure 4: Publication data. 


\section{Bibliography}

[1] Z. Zhao, M. O. Ball, and M. Kotake. "Optimization-based available-to-promise with multistaget resource availability". In: Annals of Operations Research 135.1 (2005), pp. 65-85. DOI: $10.1007 / \mathrm{s} 10479-005-6235-7$.

[2] I. T. Christou and S. Ponis. "A hierarchical system for effective coordination of available-topromise logic mechanisms". In: International Journal of Production Research 47.11 (2009), pp. 3063-3078. DOI: 10.1080/00207540701810786

[3] J. M. Framinan and R. Leisten. "Available-to-promise (ATP) systems: a classification and framework for analysis". In: International Journal of Production Research 48.11 (2010), pp. 3079-3103. DOI: 10.1080/00207540902810544

[4] W. B. Gartner. Handbook of entrepreneurial dynamics: the process of business creation. Sage, 2004. ISBN: 0-7619-2758-1.

[5] M. Kalantari, M. Rabbani, and M. Ebadian. "A decision support system for order acceptance/rejection in hybrid MTS/MTO production systems". In: Applied Mathematical Modelling 35.3 (2011), pp. 1363-1377. DOI: 10.1016/j.apm.2010.09.015

[6] A. Boza, M. M. E. Alemany, F. Alarcón, and L. Cuenca. "A model-driven DSS architecture for delivery management in collaborative supply chains with lack of homogeneity in products". In: Production Planning \& Control 25.8 (2013), pp. 650-661. DOI: 10.1080/ 09537287.2013 .798085

[7] R. Pibernik. "Managing stock-outs effectively with order fulfilment systems". In: Journal of Manufacturing Technology Management 17.6 (2006), pp. 721-736. DOI: 10.1108/ 17410380610678765 .

[8] M. M. E. Alemany, F. C. Lario, A. Ortiz, and F. Gomez. "Available-To-Promise modeling for multi-plant manufacturing characterized by lack of homogeneity in the product: An illustration of a ceramic case". In: Applied Mathematical Modelling 37.5 (2013), pp. 33803398. DOI: $10.1016 / \mathrm{j}$.apm.2012.07.022

[9] J. G. v. d. Vorst and A. J. Beulens. "Identifying sources of uncertainty to generate supply chain redesign strategies". In: International Journal of Physical Distribution E Logistics Management 32.6 (2002), pp. 409-430. DOI: 10.1108/09600030210437951

[10] C. Verdouw, A. Beulens, J. Trienekens, and J. Wolfert. "Process modelling in demanddriven supply chains: a reference model for the fruit industry". In: Computers and Electronics in Agriculture 73.2 (2010), pp. 174-187. DOI: 10.1016/j.compag.2010.05.005

[11] F. Alarcón, M. M. E. Alemany, F. C. Lario, and R. F. Oltra. "The lack of homogeneity in the product (LHP) in the ceramic tile industry and its impact on the reallocation of inventories". In: Boletin De La Sociedad Espanola De Ceramica Y Vidrio 50.1 (2011), pp. 49-57. DOI: 10.3989/cyv.072011

[12] V. Bhakoo, P. Singh, and A. Sohal. "Collaborative management of inventory in australian hospital supply chains: practices and issues". In: Supply Chain Management: An International Journal 17.2 (2012), pp. 217-230. DOI: 10.1108/13598541211212933

[13] A. Balakrishnan and J. Geunes. "Requirements planning with substitutions: exploiting billof-materials flexibility in production planning". In: Manufacturing \& Service Operations Management 2.2 (2000), pp. 166-185. DOI: $10.1287 / \mathrm{msom} .2 .2 .166 .12349$

[14] I. J. Chen and A. Paulraj. "Understanding supply chain management: critical research and a theoretical framework". In: International Journal of Production Research 42.1 (2004), pp. 131-163. DOI: $10.1080 / 00207540310001602865$

[15] A. Alonso-Ayuso, L. F. Escudero, and M. Teresa Ortuño. "BFC, A branch-and-fix coordination algorithmic framework for solving some types of stochastic pure and mixed 0-1 programs". In: European Journal of Operational Research 151.3 (2003), pp. 503-519. DOI: 10.1016/S0377-2217(02)00628-8 
[16] G. Guillén, F. Mele, M. Bagajewicz, A. Espuña, and L. Puigjaner. "Multiobjective supply chain design under uncertainty". In: Chemical Engineering Science 60.6 (2005), pp. 15351553. DOI: $10.1016 / \mathrm{j} . \operatorname{ces} .2004 .10 .023$

[17] A. Gupta and C. D. Maranas. "Managing demand uncertainty in supply chain planning". In: 2nd Pan American Workshop in Process Systems Engineering 27.8-9 (2003), pp. 12191227. DOI: $10.1016 / \mathrm{S} 0098-1354$ (03) 00048-6

[18] H. M. S. Lababidi, M. A. Ahmed, I. M. Alatiqi, and A. F. Al-Enzi. "Optimizing the supply chain of a petrochemical company under uncertain operating and economic conditions". In: Industrial \&S Engineering Chemistry Research 43.1 (2004), pp. 63-73. DOI: 10.1021/ ie030555d

[19] T. Santoso, S. Ahmed, M. Goetschalckx, and A. Shapiro. "A stochastic programming approach for supply chain network design under uncertainty". In: European Journal of Operational Research 167.1 (2005), pp. 96-115. Dor: 10.1016/j.ejor.2004.01.046

[20] M. S. Sodhi. "Managing demand risk in tactical supply chain planning for a global consumer electronics company". In: Production and Operations Management 14.1 (2009), pp. 69-79. DOI: $10.1111 / j .1937-5956.2005 . t b 00010 \cdot x$

[21] D. Peidro, J. Mula, M. Jiménez, and M. del Mar Botella. "A fuzzy linear programming based approach for tactical supply chain planning in an uncertainty environment". In: European Journal of Operational Research 205.1 (2010), pp. 65-80. DOI: 10.1016/j.ejor. 2009.11.031

[22] J. Mula, D. Peidro, and R. Poler. "The effectiveness of a fuzzy mathematical programming approach for supply chain production planning with fuzzy demand". In: International Journal of Production Economics 128.1 (2010), pp. 136-143. DOI: 10.1016/j.ijpe.2010.06. 007.

[23] J. Wang and Y.-F. Shu. "Fuzzy decision modeling for supply chain management". In: Fuzzy Sets and Systems 150.1 (2005), pp. 107-127. DOI: 10.1016/j.fss.2004.07.005

[24] L. Zadeh. "Fuzzy sets". In: Information and Control 8.3 (1965), pp. 338-353. DOI: 10 . 1016/S0019-9958(65) 90241-X

[25] D. Dubois and H. Prade. Possibility theory: an approach to computerized processing of uncertainty. Springer Science \& Business Media, 2012.

[26] D. Dubois, H. Fargier, and P. Fortemps. "Fuzzy scheduling: Modelling flexible constraints vs. coping with incomplete knowledge". In: Fuzzy Sets in Scheduling and Planning 147.2 (2003), pp. 231-252. DOI: 10.1016/S0377-2217(02)00558-1.

[27] A. Baykasoğlu, M. Göçken, and Z. D. Unutmaz. "New approaches to due date assignment in job shops". In: European Journal of Operational Research 187.1 (2008), pp. 31-45. DOI: $10.1016 / j$. ejor. 2007.02 .020

[28] I. H. Negrín and I. L. Campos. Lógica fuzzy para principiantes: cuando la máquina se acerca al pensamiento humano. SUR A, 1997. ISBN: 978-84-920326-3-1.

[29] K. Leung and W. Lam. "Fuzzy concepts in expert systems". In: Computer 21.9 (1988), pp. 43-56. DOI: $10.1109 / 2.14346$

[30] A. Roma and J. Castán. "La cadena de suministro para empresas que en su proceso de producción incorporan materias primas procedentes directamente de la naturaleza". In: $3 r d$ International Conference on Industrial Engineering and Industrial Management. 2009, pp. $1692-1700$

[31] D. Dubois, H. Fargier, and H. Prade. "Possibility theory in constraint satisfaction problems: Handling priority, preference and uncertainty". In: Applied Intelligence 6.4 (1996), pp. 287309. DOI: $10.1007 / \mathrm{BF} 00132735$

[32] J. Cadenas and J. Verdegay. "Using fuzzy numbers in linear programming". In: IEEE Transactions on Systems, Man and Cybernetics, Part B (Cybernetics) 27.6 (1997), pp. 10161022. DOI: $10.1109 / 3477.650062$ 
[33] K. Demirli and A. D. Yimer. "Fuzzy scheduling of a build-to-order supply chain". In: International Journal of Production Research 46.14 (2008), pp. 3931-3958. DOI: 10.1080/ 00207540601113273 .

[34] F. Herrera and J. Verdegay. "Three models of fuzzy integer linear programming". In: European Journal of Operational Research 83.3 (1995), pp. 581-593. DOI: 10.1016/0377$2217(93)$ E0338-X

[35] J. Mula, R. Poler, and J. Garcia-Sabater. "Material requirement planning with fuzzy constraints and fuzzy coefficients". In: Fuzzy Sets and Systems 158.7 (2007), pp. 783-793. DOI: $10.1016 / j . f$ ss .2006 .11 .003

[36] D. Peidro, J. Mula, and R. Poler. "Fuzzy linear programming for supply chain planning under uncertainty". In: International Journal of Information Technology $\&$ Decision Making 09.03 (2010), pp. 373-392. DOI: 10.1142/S0219622010003865

[37] D. Peidro, J. Mula, M. M. E. Alemany, and F.-C. Lario. "Fuzzy multi-objective optimisation for master planning in a ceramic supply chain". In: International Journal of Production Research 50.11 (2012), pp. 3011-3020. DOI: 10.1080/00207543.2011.588267

[38] M. Jiménez, M. Arenas, A. Bilbao, and M. V. Rodríguez. "Linear programming with fuzzy parameters: An interactive method resolution". In: European Journal of Operational Research 177.3 (2007), pp. 1599-1609. DOI: 10.1016/j.ejor.2005.10.002

[39] R. Ghasemy Yaghin, S. Torabi, and S. Fatemi Ghomi. "Integrated markdown pricing and aggregate production planning in a two echelon supply chain: A hybrid fuzzy multiple objective approach". In: Applied Mathematical Modelling 36.12 (2012), pp. 6011-6030. DOI: $10.1016 / \mathrm{j} . \mathrm{apm} .2012 .01 .029$

[40] A. Ghodratnama, R. Tavakkoli-Moghaddam, and A. Azaron. "A fuzzy possibilistic biobjective hub covering problem considering production facilities, time horizons and transporter vehicles". In: The International Journal of Advanced Manufacturing Technology 66.1-4 (2013), pp. 187-206. DOI: 10.1007/s00170-012-4318-6

[41] A. Jindal and K. S. Sangwan. "Closed loop supply chain network design and optimisation using fuzzy mixed integer linear programming model". In: International Journal of Production Research 52.14 (2014), pp. 4156-4173. DOI: 10.1080/00207543.2013.861948

[42] K. Khalili-Damghani, M. Tavana, and M. Amirkhan. "A fuzzy bi-objective mixed-integer programming method for solving supply chain network design problems under ambiguous and vague conditions". In: The International Journal of Advanced Manufacturing Technology 73.9-12 (2014), pp. 1567-1595. DOI: 10.1007/s00170-014-5891-7

[43] M. Lotfi and S. Ghaderi. "Coordination between long-term decision process and day-ahead unit commitment in deregulated markets: A fuzzy hierarchical bi-level modeling approach". In: Applied Mathematical Modelling 37.7 (2013), pp. 5511-5527. DoI: 10.1016/j.apm. 2012. 10.041

[44] S. M. Mousavi, R. Tavakkoli-Moghaddam, and F. Jolai. "A possibilistic programming approach for the location problem of multiple cross-docks and vehicle routing scheduling under uncertainty". In: Engineering Optimization 45.10 (2013), pp. 1223-1249. DOI: 10.1080/0305215X.2012.729053

[45] M. Naderi-Beni, E. Ghobadian, S. Ebrahimnejad, and R. Tavakkoli-Moghaddam. "Fuzzy bi-objective formulation for a parallel machine scheduling problem with machine eligibility restrictions and sequence-dependent setup times". In: International Journal of Production Research 52.19 (2014), pp. 5799-5822. DOI: 10.1080/00207543.2014.916430

[46] M. Nakhaeinejad and N. Nahavandi. "An interactive algorithm for multi-objective flow shop scheduling with fuzzy processing time through resolution method and TOPSIS". In: The International Journal of Advanced Manufacturing Technology 66.5-8 (2013), pp. 10471064. DOI: $10.1007 / \mathrm{s} 00170-012-4388-5$ 
[47] E. Özceylan and T. Paksoy. "Interactive fuzzy programming approaches to the strategic and tactical planning of a closed-loop supply chain under uncertainty". In: International Journal of Production Research 52.8 (2014), pp. 2363-2387. DOI: 10.1080/00207543.2013. 865852

[48] M. S. Pishvaee and J. Razmi. "Environmental supply chain network design using multiobjective fuzzy mathematical programming". In: Applied Mathematical Modelling 36.8 (2012), pp. 3433-3446. DOI: 10.1016/j.apm.2011.10.007

[49] W. Pedrycz. "Why triangular membership functions?" In: Fuzzy Sets and Systems 64.1 (1994), pp. 21-30. DOI: 10.1016/0165-0114(94)90003-5

[50] G. Barbieri, M. A. Lepellere, and H. Weber. "The Hahn decomposition theorem for fuzzy measures and applications". In: Fuzzy Sets and Systems 118.3 (2001), pp. 519-528. DOI: 10.1016/S0165-0114(98)00421-7

[51] J.-S. Yao and K. Wu. "Ranking fuzzy numbers based on decomposition principle and signed distance". In: Fuzzy Sets and Systems 116.2 (2000), pp. 275-288. Dor: 10.1016/S01650114(98)00122-5

[52] R. E. Bellman and L. A. Zadeh. "Decision-making in a fuzzy environment". In: Management Science 17.4 (1970), pp. 141-164. DOI: $10.1287 / \mathrm{mnsc.17.4.B141}$

[53] J. A. Heredia and M. Gras. "Análisis y modelado de la transmisión de variabilidad dimensional en un proceso de producción de baldosas cerámicas". In: Boletín de la Sociedad Española de Cerámica y Vidrio 48.6 (2009), pp. 289-296. DOI: 03663175(ISSN)

[54] G. Davoli, S. A. Gallo, M. W. Collins, and R. Melloni. "A stochastic simulation approach for production scheduling and investment planning in the tile industry". In: International Journal of Engineering, Science and Technology 2.9 (2010), pp. 107-124. DOI: 10.4314/ ijest.v2i9.64006

[55] N. Erginel, B. Dogan, and N. Ay. "The statistical analysis of coloring problems faced in ceramic floor tile industry". In: Key Engineering Materials 264 (2004), pp. 1693-1696. DOI: 10.4028/www.scientific.net/KEM.264-268.1693

[56] I. Tortajada, G. Peris-Fajarnés, M. Aguilar, and P. Latorre. "Análisis del proceso de clasificación cerámico". In: Boletín de la sociedad Española de cerámica y vidrio 45 (2006), pp. 22-27. DOI: 35400013532172.0030 


\title{
Chapter V
}

\section{Modelling pricing policy based on shelf-life of non homogeneous Available-To-Promise in fruit supply chains}

\begin{abstract}
Fruit Supply Chains (SCs) are influenced by uncontrollable natural factors causing heterogeneity in their products, as regards certain attributes that are relevant to customers and vary over time because of the shelf-life. As a consequence customers should be served not only with the required quantity and due date as usual, but also with the quality, freshness and homogeneity specified in their orders. The order promising process (OPP) is based on the uncommitted availability of homogeneous product quantities in planned lots (ATP) that are uncertain. Therefore, there is a risk of not being reliable in the commitments because of discrepancies between the real and planned homogeneous quantities. Furthermore, due to the shelf-life (SL), serving customers with the freshest product introduce the risk of increasing waste because of the aging process. To efficiently manage these risks, this work proposes a mathematical model for handling the heterogeneous ATP in fruit SCs and a pricing policy based on the product SL in the moment of delivery. In order to illustrate the application of the modelling approach, a short numerical example is introduced. The example evidences a conflictive situation when optimizing the assignation of homogeneous ATP between serving orders with fresh and more valuable product, what could lead to increase the risk of having waste because of expiration, and consequently, more costs and less profit.
\end{abstract}


Keywords: Order-promising process, Available-To-Promise, Lack of Homogeneity in the Product, fruit supply chain, perishability.

\section{Introduction}

The order promising process (OPP) presents special features and more complexity in fruit supply chains (SCs), where uncontrollable natural factors like weather, land, water drought, etc. are present. That kind of factors can confer heterogeneity to units of the same product as regards certain attributes relevant to customers. Additionally, due to the perishability, products are not just affected by the non homogeneity but also for the aging process. The order proposals of these SCs require homogeneity in units of the same product, and normally, customers expect to be served with the freshest product, with the quality required, but with a reasonable price. For this reason, the pricing policy can be directly based on the status of the product at the time of delivery. These aspects become a problem when customer orders are promised based on future planned homogeneous quantities; because final characteristics are not known certainly until the product is harvested, classified, packed and transported to the customer. Then, fruit supply chains have inherent uncertainty in the handling of the available to promise (ATP) quantities, due to not just the homogeneity in the product, but also to the shelf life (SL). One of the main challenges when modelling the OPP in fruit SCs, is firstly to estimate the homogeneous ATP quantities derived from the master plan in advanced to be produced and classified. Secondly, due to perishability, those homogeneous ATP quantities deteriorate over time being necessary to provide traceability. Thirdly, the harvesting time and SL, become critically important in terms of the freshness of the product in the moment of delivery. Consequently, it also affects earns obtained, in case the pricing policy is directly linked with the product freshness. Therefore, the main contribution of this paper is to include these challenges combined into the OPP for fruit SCs. To properly handle them, a mathematical programming model for supporting the OPP has been formulated that takes into account the homogeneity required in the ATP, the dynamism conferred to it by the SL and a proper pricing policy linked to the perishability of the product.

The rest of the paper is organized as follows: Section 2 presents a short summary of the related work founded. Section 3 and 4 describes the proposed way to model the ATP in fruit SCs and the modelling of the SL, respectively. Section 5 describes the link assumed between the remaining SL and the pricing policy for the ATP. Section 6 presents a numerical example to show the conflict when freshness and benefit are both them combined for being optimized. Finally, Section 7 exposes the main conclusions and future research lines. 


\section{Related work}

This work aims to introduce less investigated characteristics in the OPP, such as the homogeneous ATP quantities and their perishability in fruit SCs. The homogeneous ATP concept is included in the so called lack of homogeneity in the product (LHP). LHP is defined as the absence of uniformity among units of the same product, that can originate from the incorporation of raw materials directly derived from nature, and/or production processes features that confer heterogeneity to it (Alarcón et al. [1], Alemany et al. 2, 3], Grillo et al. [4], and Mundi et al. [5]). Improper management of non-homogeneous units of the same product and its inherent uncertainty can impact very negative on customer service level. It is established that, due to inherent LHP uncertainty, the planned size of homogeneous sublots and the real ones can differ once produced and classified into subtypes. A variety of other studies, Lin et al. [6], have dealt with some characteristics related with the LHP without explicitly mention it. In the specific case of fruit SCs, the lack of literature is even more evident, being Kilic et al. 77 the closest case validated in the food processing sector. In this paper, the main LHP characteristic appear randomly in raw materials with a strong effect over the finished product. The perishability (SL consuming) is identified as one of LHP types [4, and as a cause of conflictive decisions in order to either maximise the incomes by sells of the product, or minimise the cost as a consequence of avoiding waste. Since customers require homogeneous and fresh products, they hope the price is directly linked on its quality, homogeneity and its freshness (that can be measured as a fraction of consumption of its maximum SL). This is also a lacking area of research because of only a few models have dealt with pricing of perishables (see for example Maihami and Karimi [8] and Tsao and Sheen [9]). Furthermore no one makes it under LHP conditions. The findings from the literature, that serve as a basis for the main contribution of this work could be summarised as follows: (i) when dealing with perishables, there is a lack of literature dealing with OPP in LHP contexts that consider the splitting of ATP into homogeneous quantities; (ii) since customers of fruit SCs specify the subtypes required in their orders, it is necessary to estimate not only the homogeneous ATP quantities, but also the subtype obtained to accomplish with customer requirements; (iii) existing OPP models for fruit SCs do not calculate the remaining SL of homogeneous ATP quantities, in a way that the selling price could be linked to it. The above issues confer specific characteristics to the OPP that in case of not being correctly managed could originate: a) dissatisfaction of customers due to the failure in the freshness desired, and b) even more, high stocks and waste that produces SC inefficacy and loss of profit.

In the next sections the proposed way to characterise homogeneous ATP in fruit SCs is presented, followed by the proposed calculation of the SL. Finally, the combination of both is made to properly model the pricing policy for the homogeneous ATP, based on the SL of the product. 


\section{Modelling the homogeneous Available-To-Promise for fruit supply chains}

With the aim of serving customers in the homogeneity terms required in their orders, fruit supply chains are forced to include different classification steps along the productive process [10]. Therefore, fruit is sorted into homogeneous sublots based on the following characteristics and/or attributes: (i)Variety: it represents the types of the same fruit; (ii) Quality: the product can be classified into quality categories, according to the status it brings from the fields; (iii) Calibre: this criteria refers to the size and volume of the product; (iv) Packaging type: it refers to the different boxing classes that the product can be commercialized and (v) Harvesting time: it represents the time period at which the fruit is collected from fields. Since each of this characteristic can have different values, the specific combination of each attribute can define what is known as a "subtype". Since these attributes can vary with the specific type of fruit, it will be always possible to define the different subtypes as a combination of them. In order to model the homogeneous Available-To-Promise in this kind of SCs, let us define the following nomenclature:

\section{Indices}

$p$ Production plant.

$t$ Time buckets.

$h$ Harvesting time of the product available to promise.

$i$ The product.

$b$ Subtypes, defined as the combination of quality, calibre and packaging type.

$o$ Customer order proposals waiting to be promised.

$r$ Price range defined based on the shelf life.

\section{Parameters}

$m p s_{i}^{p h t} \quad$ Master plan schedule of plant $p$, harvested in $h$, and available in period $t$.

$\beta_{i b}^{p t} \quad$ Homogeneity coefficients that represent the fraction of each lot of product $i$, that can be considered homogeneous subtype $b$. Their sum should equal to $1\left(\sum_{b} \beta_{i b}^{p t}=1 \forall i, t, p\right)$.

$a t p_{i b}^{p h t} \quad$ Planned homogeneous available-to-promise quantity of subtype $b$ of product $i$, harvested during time $\mathrm{h}$ that becomes available during period $t$.

$r q_{i b}^{o} \quad$ Requested quantity of finished subtype $b$, of product $i$, in order proposal $o$.

$a c q_{i b}^{p h t} \quad$ Already committed quantity from each homogeneous sublot at the beginning of the horizon.

Variables

$Y_{i b}^{\text {ophtr }} \quad$ Binary variable with a value of 1 if requested quantity $r q_{i b}^{o}$ is completely served by the $a t p_{i b}^{p h t}$ within price range $r$, and a value of 0 otherwise.

$U A T P_{i b}^{p h t}$ The updated homogeneous $a t p_{i b}^{p h t}$ after taking into account the customer order proposals committed. 
If a multi-plant production stage should serve different customers with the subtype specified in their orders on a required due date, and where the supply stage is taking into account the inclusion of the product's harvesting time, the first step to be done is ensuring a reliable calculation of homogeneous ATP quantities of each subtype. Since ATP quantities are derived from the subdivision of the master plan, through the fraction corresponding to each homogeneous subtype, and subtracting the requested quantity in the proposals that might be committed beforehand and the quantity promised to the incoming order proposals; this can be represented through Eq. (1):

$$
a t p_{i b}^{p h t}=m p s_{i}^{p h t} \beta_{i b}^{p t}-a c q_{i b}^{p h t}-\sum_{o} \sum_{r} r q_{i b}^{o} Y_{i b}^{o p h t r} \quad \forall p, h, t, i, b .
$$

In order to ensure that the ATP defined in Eq.(1) can be served just from the specific subtype required by the customer, and that different subtypes cannot be mixed the Eq. 22 must be considered:

$$
\sum_{p, h, t, r} Y_{i b}^{o p h t r}=1 \quad \forall o, i, b .
$$

As it can be seen in Eqs. (1)-(2), the variable $Y_{i b}^{\text {ophtr }}$ depends on the price range inside the order proposal might be served. As a novel approach, we are connecting the price range of the served orders with the product SL at delivery time. In sections 4 and 5 we will introduce the concepts and explain how to model this approach.

\section{Modelling the shelf-life}

One strategic issue on modelling the ATP for fruit supply chains is the perishability. This factor makes ATP characteristics of each subtype defined in Eq. (1) to change over time while the SL is consuming. If we assume that the SL is predefined for each subtype, the freshness of products committed with customers will depend on the remaining SL in the moment of delivery to customer. To maintain a traceability of the remaining SL is necessary in fruit SC for different reasons: 1) customer satisfaction is strongly influenced by the freshness of the product, 2) in case the freshness will be lower than expected, a discount in the price can restore a proper level of customer satisfaction, and finally, 3) because of the perishability, product waste should occur if its SL is exhausted and it has not been assigned to any customer order. Therefore, to mathematically describe the relationship of homogeneous ATP with its selling price, it is necessary to first calculate the SL. When reserving homogeneous ATP in a specific time period, to be delivered in the customer's place on a due date $\left(d d_{o}\right)$, the SC must take into account the time required for transporting the product from the harvesting point to the packing plants where the classifications and packing operations take place, as well as the 
transporting time since the product is shipped from the plant until it is delivered to the customer. This is necessary to deliver the product with the minimum portion of its SL $\left(s l_{i b}\right)$ already consumed. In terms of calculation, we can define the fraction of already lost SL $\left(L S L^{o b}\right)$, of the ATP in the moment of the delivery to the customer as follows:

$$
L S L^{o b}=\sum_{p, h, t} \sum_{r, i}\left(\frac{\left(d d_{o}-h\right) Y_{i b}^{o p h t r}}{s l_{i b}}\right) \forall o, b .
$$

Where $d d_{o}$ is the due date expected for the subtype $b$ requested in order proposal $o$. Consequently the remaining shelf $\operatorname{life}\left(R S L^{o b}\right)$ as:

$$
R S L^{o b}=1-L S L^{o b} \quad \forall o, b .
$$

Figure 1 shows a short example about the way of calculate Eqs.(3) and (4).

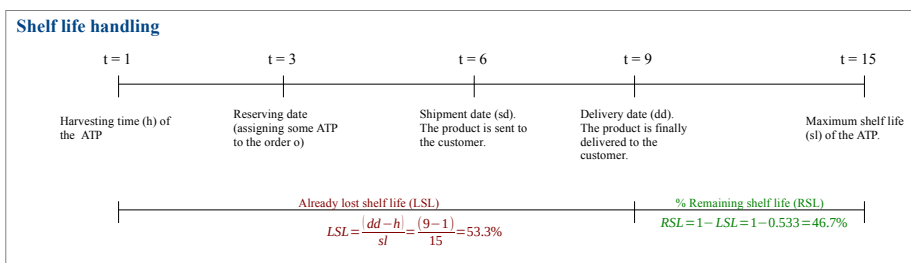

Figure 1: Example of shelf life calculation.

\section{Shelf life-based pricing policy}

It is usual in fruit SCs that products maintain their initial classification over time once classified and packed. This means that no quality level changes are considered. Instead, the selling price of the product is adjusted according to the aging process until the delivery date. This adjustment is made on a discrete basis, where prices are set based on predefined remaining SL intervals.

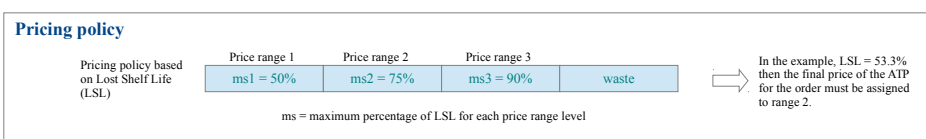

Figure 2: Pricing policy schema.

Let us consider the example in Figure (2), where there are three price ranges of the ATP based on three predefined limits of the already lost shelf life $\left(m s^{r b}\right)$, and a fourth limit where the product is considered waste. Then, if the product has not overpass the first limit of the price range $1\left(m s^{1 b}\right)$, the selling price applied will be 
the highest one. With time passing the product gradually loses part of its SL until reaching the second limit. When overpassing this second limit, the selling price applied should be the second one and so on, until the product becomes waste. Now in terms of modelling this policy, let us consider the following additional parameters:

$m s^{r b}$ Maximum percentage of $L S L^{o b}$ for each price range level $r$, of each subtype $b$. These percentages are defined when the price of ATP lowers from lower ranges to higher ones.

$n r \quad$ Total number of price ranges.

$s p_{i b}^{r} \quad$ Selling price of product $i$, belonging to the subtype $b$, according to price range $r$.

The shelf life-based pricing policy for the assignation of homogeneous ATP should include as minimum, the following components:

\section{Maximise:}

$$
\sum_{o, i, b} \sum_{p, h, t, r} r q_{i b}^{o} s p_{i b}^{r} Y_{i b}^{o p h t r}
$$

Subject to: Eqs.(1)-(2) and,

$$
\begin{gathered}
L S L^{o b}=\sum_{p, h, t} \sum_{r, i}\left(\frac{\left(d d_{o}-h\right) Y_{i b}^{o p h t r}}{s l_{i b}}\right) \quad \forall o, b . \\
L S L^{o b}-m s^{r b} \leqslant 1-\sum_{p, h, t, i} Y_{i b}^{o p h t r} \forall o, b, r . \\
m s^{r b}-L S L^{o b} \leqslant 1-\sum_{p, h, t, i r=r+1} \sum_{i b}^{o p h t r} \forall o, b, r<n r . \\
m s^{r b} \geqslant L S L^{o b} \forall o, b, r=n r .
\end{gathered}
$$

In the above model, Eq. (5) aims to maximise the total sells of the product. Eqs. (1) and (2) specify the computation of the available to promise, while Eq. (6) calculates the remaining SL for the product used to fulfil each specific incoming order. Eqs. (7) and (8) oblige the binary variable to set just one price range for the subtype of product used to fulfil each specific order. Finally, Eq. (9) establishes that product used to fulfil orders cannot exceed the last price range, otherwise it becomes waste. 


\section{Numerical example}

The objective of the numerical example presented in this section is twofold. On one hand, it is shown the utility of the above equations for computing the incomes in case the product price depends on the product's freshness. On the other hand, it is shown that only maximizing incomes through serving customers with the most fresh product at the best price, presents the risk of increasing the waste. This could make impossible to serve future incoming orders. Let us assume the case of one packing plant that has to process four production lots of just one fruit (master plan) during the planning horizon composed by eight periods of time. Each lot is classified into 3 subtypes (b1, b2, b3) according to the $\beta_{i b}^{p t}$ parameter (Table 1 ).

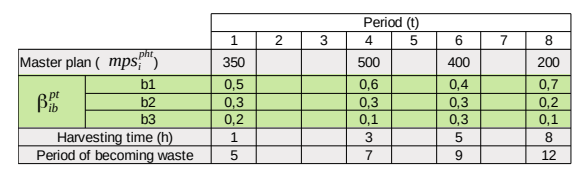

Table 1: Input data.

\begin{tabular}{|c|c|c|c|}
\hline $\begin{array}{c}\text { Price } \\
\text { Range }\end{array}$ & Subtype & $m s^{r}$ & $\begin{array}{c}s_{i b}^{r} \\
€ / \text { unit }\end{array}$ \\
\hline r1 & b1 & 0.3 & $10 €$ \\
\hline r2 & b1 & 0.6 & $8 €$ \\
\hline r3 & b1 & 0.8 & $5 €$ \\
\hline
\end{tabular}

Table 2: Selling price based on price ranges.

At the beginning of the OPP, we assume that no order has been already committed. Suppose a maximum shelf life of 5 periods for all subtype, a pricing policy with 3 ranges (Table 2 and cost of $5 €$ per unit of product expired. Based on the harvesting time, the SL, the last price range, and Eq. 44, it is possible to compute the period at which each lot becomes waste (Table 1). This means that the ATP quantities derived from each lot may only be used to serve orders with a due date before the period at which it expires. Furthermore, due to customer homogeneity requirements, it is not possible to accumulate discrete ATP to serve the same order (Eqs.(1)-(2)). Suppose the sequential arrival of five customer order proposals requesting certain quantities of subtype b1 for different due dates. It is our aim to analyse the results of committing these orders on-line under two different policies: a) to serve orders with the freshest product (Table 3), that is equivalent to sell the product at the highest price range and b) to serve orders with the less fresh product (Table 4). To implement the first policy, it is necessary to reserve the product from the ATP quantity as near as possible from the due date of the order. The column "Lot" in Tables 3 and 4 , show the value of the lot in which the corresponding variable $Y_{i b}^{\text {ophtr }}$ should have a value of 1 . The huge issue in fruit supply chains is that the effect of the non homogeneous product combined with the perishability, brings out an enormous risk of having waste (since the remains of the ATP cannot be mixed in order to have more quantity to fulfill new orders). 
As it can be seen in Table 3, the first policy maximizes the incomes per order but at the same time presents two important drawbacks. First, it is not possible to serve the last order because there is not enough unexpired homogeneous product. Second, if we assume that no more orders arrive during the planning horizon, the remaining ATP of periods 1 and 4 will expire in periods 5 and 7 , respectively. Consequently, this first policy originates a negligible waste of 300 units with a total cost of $1.500 €$.

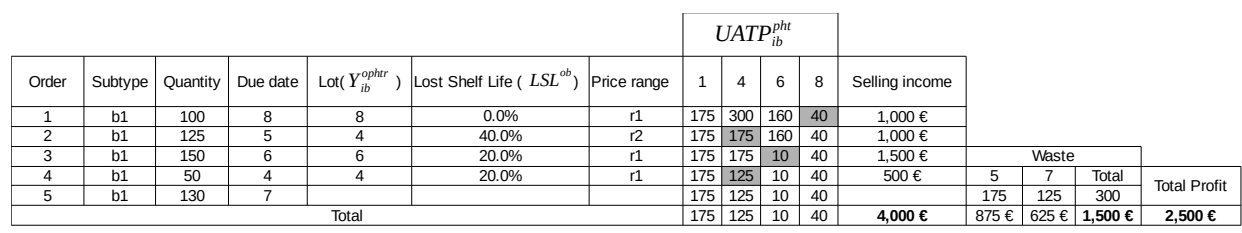

Table 3: Serving order from the freshest product (highest price range/Last-In-FirstOut).

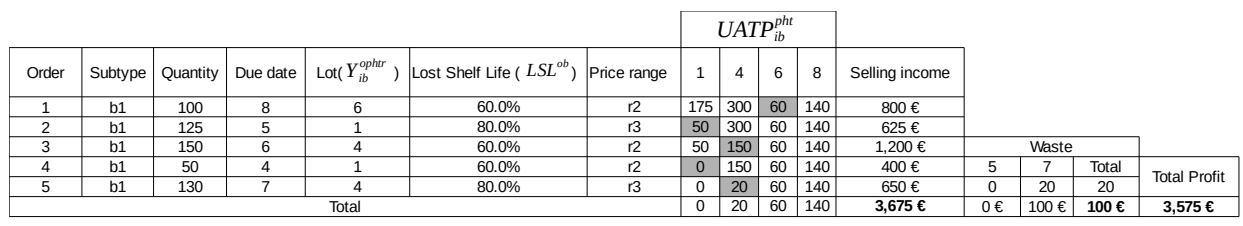

Table 4: Serving order from the less fresh product (lowest price range/First-In-FirstOut).

On the contrary, in order to implement the second policy it is necessary to reserve product from the ATP as far as possible from the due date, but without being expired (Table 4). Through this second policy, it is possible to serve all customer order proposals. Although the incomes per sales are lower as compared with the first policy, the total profit is higher for the second policy because the waste is considerably reduced (only 20 units for a total cost of $100 €$ ).

Then, there is a conflictive situation when deciding on the best balance between being careful in sell out the product as it is near to the maximum shelf life, knowing that it implies to lose a portion of profit, and achieving higher incomes by selling more fresh product but with the risk of not being able to serve some future orders and having more waste. This conflictive decision (due to the LHP, the perishability, and the expected selling prices linked with the shelf life), and the uncertainty involved in its solution, are important issues during the OPP optimization in fruit supply chains. 


\title{
Modelling Pricing Policy Based on Shelf-Life of Non Homogeneous Available-To-Promise in Fruit Supply Chains
}

\author{
Hanzel Grillo ${ }^{(凶)}$, M.M.E. Alemany, and A. Ortiz
}

Centro de Investigación de Gestión e Ingeniería de Producción (CIGIP), Universitat Politècnica de València, Camino de Vera S/N, 46022 Valencia, Spain hangries@upvnet.upv.es

grillo7@gmail.com

Abstract. Fruit Supply Chains (SCs) are influenced by uncontrollable natural factors causing heterogeneity in their products, as regards certain attributes that are relevant to customers and vary over time because of the shelf-life. As a consequence customers should be served not only with the required quantity and due date as usual, but also with the quality, freshness and homogeneity specified in their orders. The order promising process (OPP) is based on the uncommitted availability of homogeneous product quantities in planned lots (ATP) that are uncertain. Therefore, there is a risk of not being reliable in the commitments because of discrepancies between the real and planned homogeneous quantities. Furthermore, due to the shelf-life (SL), serving customers with the freshest product introduce the risk of increasing waste because of the aging process. To efficiently manage these risks, this work proposes a mathematical model for handling the heterogeneous ATP in fruit SCs and a pricing policy based on the product SL in the moment of delivery. In order to illustrate the application of the modelling approach, a short numerical example is introduced. The example evidences a conflictive situation when optimizing the assignation of homogeneous ATP between serving orders with fresh and more valuable product, what could lead to increase the risk of having waste because of expiration, and consequently, more costs and less profit.

Keywords: Order-promising process · Available-To-Promise · Lack of homogeneity in the product - Fruit supply chain · Perishability

\section{Introduction}

The order promising process (OPP) presents special features and more complexity in fruit supply chains (SCs), where uncontrollable natural factors like weather, land, water drought, etc. are present. That kind of factors can confer heterogeneity to units of the same product as regards certain attributes relevant to customers. Additionally, due to the perishability, products are not just affected by the non homogeneity but also for the aging process. The order proposals of these SCs require homogeneity in units of the same product, and normally, customers expect to be served with the freshest product, with the quality required, but with a reasonable price. For this reason, the pricing policy

(c) IFIP International Federation for Information Processing 2016

Published by Springer International Publishing Switzerland 2016. All Rights Reserved H. Afsarmanesh et al. (Eds.): PRO-VE 2016, IFIP AICT 480, pp. 608-617, 2016. DOI: $10.1007 / 978-3-319-45390-3 \_52$

Figure 3: Publication data. 


\section{Conclusion}

To better analyse fruit supply chains and the corresponding order promising process, it is needed to consider the non homogeneity in the product as an inherent characteristic from nature. Subdivision of the ATP into homogeneous sublots has to be performed. Another factor is the perishability that makes even more complicated the analysis because of the risk of having wasted product. Since the customer normally need fresher product, then the pricing policy can be adjusted to the shelf life. This paper describes an approach for modelling the splitting of the ATP into homogeneous sublots can be done, how to calculate the shelf life of the product at the moment of delivery, and based on that, an expected selling price. A numerical example shows a strong conflictive situation when the OPP must decide between the prioritization between profit (as a balance of sells income and waste cost) and the customer service (as a requirement of always have fresh and homogeneous product). To better analyse this conflictive situation, uncertainty methods could be used in future research work.

\section{Publication data}

Figure 3 shows the first page of the article published in the IFIP Advances in Information and Communication Technology (ISSN: 1868-422X).

\section{Acknowledgement}

This research has been supported by the Ministry of Science, Technology and Telecommunications, government of Costa Rica (MICITT), through the program of innovation and human capital for competitiveness(PINN)(Contract number PED-019-2015-1).

\section{Bibliography}

[1] F. Alarcón, M. M. E. Alemany, F. C. Lario, and R. F. Oltra. "The lack of homogeneity in the product (LHP) in the ceramic tile industry and its impact on the reallocation of inventories". In: Boletin De La Sociedad Espanola De Ceramica Y Vidrio 50.1 (2011), pp. 49-57. DOI: $10.3989 /$ cyv.072011.

[2] M. M. E. Alemany, H. Grillo, A. Ortiz, and V. S. Fuertes-Miquel. "A fuzzy model for shortage planning under uncertainty due to lack of homogeneity in planned production lots". In: Applied Mathematical Modelling 39.15 (2015), pp. 4463-4481. DoI: 10.1016/j . apm.2014.12.057

[3] M. M. E. Alemany, F. C. Lario, A. Ortiz, and F. Gomez. "Available-To-Promise modeling for multi-plant manufacturing characterized by lack of homogeneity in the product: An illustration of a ceramic case". In: Applied Mathematical Modelling 37.5 (2013), pp. 33803398. DOI: $10.1016 /$ j.apm.2012.07.022 
[4] H. Grillo, M. M. E. Alemany, and A. Ortiz. "A review of mathematical models for supporting the order promising process under Lack of Homogeneity in Product and other sources of uncertainty". In: Computers \& Industrial Engineering 91 (2016), pp. 239-261. DOI: $10.1016 / \mathrm{j}$.cie.2015.11.013

[5] M. Mundi, M. M. E. Alemany, R. Poler, and V. S. Fuertes-Miquel. "Fuzzy sets to model master production effectively in Make to Stock companies with Lack of Homogeneity in the Product". In: Fuzzy Sets and Systems (2015). Dor: 10.1016/j.fss.2015.06.009

[6] J. Lin, I. Hong, C.-H. Wu, and K.-S. Wang. "A model for batch available-to-promise in order fulfillment processes for TFT-LCD production chains". In: Computers \& Industrial Engineering 59.4 (2010), pp. 720-729. DOI: $10.1016 /$ j.cie.2010.07.026.

[7] O. A. Kilic, D. P. van Donk, J. Wijngaard, and S. A. Tarim. "Order acceptance in food processing systems with random raw material requirements". In: Or Spectrum 32.4 (2010), pp. 905-925. DOI: $10.1007 / \mathrm{s} 00291-010-0213-4$

[8] R. Maihami and B. Karimi. "Optimizing the pricing and replenishment policy for noninstantaneous deteriorating items with stochastic demand and promotional efforts". In: Computers E Operations Research 51 (2014), pp. 302-312. DOI: 10.1016/j.cor.2014.05. 022 .

[9] Y.-C. Tsao and G.-J. Sheen. "Dynamic pricing, promotion and replenishment policies for a deteriorating item under permissible delay in payments". In: Computers EG Operations Research. Part Special Issue: Topics in Real-time Supply Chain Management 35.11 (2008), pp. 3562-3580. DOI: 10.1016/j.cor.2007.01.024

[10] A. Blanco, G. Masini, N. Petracci, and J. Bandoni. "Operations management of a packaging plant in the fruit industry". In: Journal of Food Engineering 70.3 (2005), pp. 299-307. DOI: 10.1016/j.jfoodeng.2004.05.075 


\title{
Chapter VI
}

\section{Mathematical}

\section{modelling of the order-promising process for fruit supply chains considering the perishability and subtypes of products}

\begin{abstract}
This paper proposes a mixed integer mathematical programming model to support the complex order promising process in fruit supply chains. Due to natural factors, such as land, weather or harvesting time, these supply chains present units of the same product that differ in certain relevant attributes to customers (subtypes). This becomes a managerial problem when customers require specific subtypes in their orders. Additionally, the deterioration of the original characteristics of subtypes over time generates waste and gives rise to a shelf life-based pricing policy. Therefore, the developed model should ensure that customers are served not only the quantities and dates, but also the required homogeneity and freshness. The model aims to maximise two conflicting objectives: total profit and mean product freshness. The novelty of the model derives from considering both homogeneity in subtypes as a requirement in customer orders and the traceability of product deterioration over time. Different scenarios are defined according to the weight assigned to each objective, shelf-life length and pricing policy in a rolling horizon scheme. The numerical experiments conducted for a real orange and tangerine supply chain, show the model's
\end{abstract}


validity and the conflicting behaviour of the two objectives. The highest profit is made at the expense of the lowest mean freshness delivered, which is reinforced by the narrower the price variation with freshness. Finally, the positive impact of prolonging the product's shelf life on both objectives is shown.

Keywords: Order-promising process, Available-To-Promise, Lack of Homogeneity in the Product, fruit supply chain, perishability.

\section{Introduction}

Some researchers maintain that the order promising process ( $\left.\mathrm{OPP}^{*}\right)$ is a highly critical task that clearly impacts the customer service level [1]. Others consider it to be one of the most important processes within an organisation to increase customer satisfaction 2]. During the OPP, the role of the Available-To-Promise (ATP) function is to provide a response to customer order requests based on resource availability. Two different execution modes of assigning ATP to orders are usually distinguished [3]: "batch order processing" and real-time or "singleorder processing". Unlike the real-time mode, an order in the batch mode is not promised immediately upon request, but is held back when it is then assigned to ATP, together with several other orders in a "batch". As a result, decisions about the acceptance/rejection of orders, the promised due date and allocation of resources are made [4]. In [1], ATP was defined as stocks on hand or the projected inflows of items stocked at the customer order decoupling point (already in transit or planned by the master production schedule (MPS)), which have not yet been allocated to specific orders and can, thus, be promised to customers in the future. For companies with a make-to-stock strategy, ATP is expressed in terms of finished goods, and the MPS is used as input to calculate it. Hence for these companies, the OPP considers the network design, the supplier selection, and the MPS to be previously defined.

One aspect apart from the manufacturing strategy that strongly influences the OPP is the supply chain type. Indeed the OPP becomes more complex in fruit supply chain (FSC) given its particular features, among which the influence of uncontrollable natural factors (weather, land, water drought, natural disasters, etc.) on the final product confer heterogeneity to the units of the same product, which are also perishable in nature. This generates a managerial problem because orders in such supply chains require homogeneity for units of the same product; e.g., with oranges, the contents of each package must be uniform and contain only oranges of the same origin, variety and/or commercial type, quality, size, and with the same degree of maturity. $\mathrm{A}$

*In advance, all the acronyms included in the text are summarised in Table A1 of Appendix 
The pricing policy may also depend directly on the product's shelf life (SL) upon delivery (freshness). SL is defined as the time period during which the product becomes valueless after losing the initial tacit characteristics that it is supposed to have 5]. In [6] deterioration of products was classified into two categories: random SL, where items deteriorate continuously; fixed SL where items have a certain lifetime period after which they completely deteriorate.

In order to comply with uniformity in customer requirements, FSCs are obliged to include sorting and grading activities to classify products into homogeneous sublots, from which the product is served. Classification criteria depend on each specific fruit, but are usually based on attributes like product variety, quality, size, weight, ripeness, damage, colour, shape and firmness, among others 7]. Quality, one of the most important characteristics for classifying fresh food, is a term defined by the consumer, buyer, grader, or any other client, according to a number of subjective and objective food product measurements [8]; e.g., apples and pears are classified into different qualities according to their degree of defects or damage 9].

As uncertainty in supply exist, the planned size of homogeneous sublots and real ones can differ after being produced and classified. This can lead to previously committed orders promised according to future planned homogeneous quantities not being served on time because not enough product is available. The work in 10 pointed out different sources of supply uncertainty in food processing supply chains and presents various strategies to cope with it. All the previous characteristics pose a potential risk of FSC not reaching an appropriate service level due to not only an inaccurate estimation made in the expected quantities of each subtype in lots, but also improper handling of ATP and their SL. Moreover, high product perishability can result in waste and/or loss [11. Fresh fruit and vegetables account for nearly $20 \%$ of consumer and food service losses [8]. In the European grocery sector, products that are not purchased before their sell-by-date are estimated to result in costs that run into billions of dollars every year 12 .

Thus developing decision support tools for the OPP in FSC is currently a managerial concern and an important research issue at the same time. As shown in Section 2, it can be concluded from the literature review that no OPP model exists for the fruit sector which simultaneously integrates all the above characteristics. To bridge this gap in the literature, the present paper proposes a mixed integer linear programming model to support the OPP for FSC in order to fulfil customer requirements in terms of due dates, quantities, homogeneity and freshness, which considers subtypes, quality and perishability in ATP and the selling price based on freshness. The model aims to optimise two conflicting objectives (maximising profits and maximising mean freshness) by taking into account the dynamic characteristics of ATP due to SL. The proposed model has been tested for promising orders with several lines in different scenarios in a real Spanish FSC that produces and distributes oranges and tangerines. The results showed the model's validity 
and provide some managerial insights into the impact on the model's sensitiveness to objective weights, SL length and price variation between SL ranges.

The rest of the paper is organised as follows. Section 2 presents the most related literature review and the contributions of our work. Section 3 describes the problem under study and the main assumptions. Section 4 provides details of the proposed mathematical programming model, which is validated in Section 5 by applying it to realistic case of a Spanish FSC. Finally, Section 6 presents the main conclusions and future research.

\section{Related work and contributions}

This paper aims to extend previous work on models for OPP by studying the FSC that introduce the following novel characteristics, which have hardly been addressed previously: ATP per subtype, its perishability and its corresponding selling price that depends on freshness. We identify these three OPP novel aspects of FSC as inherent characteristics of the so-called lack of homogeneity in the product (LHP). For this reason, and given the scarce research found on OPP models for FSC, we extend our review to OPP models in LHP contexts, which comprises our first reviewed research stream. As no work in the OPP field was found that addresses all these features, a second research stream was reviewed: operations research models in agri-food supply chains that deal with subtypes and/or their perishability in other processes related mainly to planning, distribution, lotsizing and inventory management. The intention was to identify the contributions made by our work to show the differences between our modelling approach and other existing ones.

\section{$2.1 \quad$ OPP-related models}

A comprehensive review was recently presented about OPP models for sectors with LHP in [13. LHP was defined in [14] as absence of uniformity among units of the same product (subtypes), which differ in terms of certain characteristics that are relevant for customers. One key finding of 13 was that the OPP models which deal with perishability were lacking. Perishability was identified as a research challenge that must be considered to conduct more realistic models. Indeed the OPP literature shows that very few models include some LHP characteristics and their management in the fruit sector. The research of [15] came the closest to our work and dealt with the acceptance/rejection of orders by considering perishability in a food production system with a make-to-order strategy. As a novelty, it presented the consideration of random raw material requirements of orders, penalty costs for shortages and disposal costs that had not yet been addressed in the literature in make-to-order contexts. The work in [16] proposed an OPP mathematical programming model in LHP contexts other than from FSC that estimates the division of lots into homogeneous sublots. The specific subtypes in each sublot 
are not anticipated because orders only need to be served with homogeneous units despite the subtype (i.e. ceramic tiles with the same tone and gage). Due to inherent LHP uncertainty, discrepancies between the planned and real homogeneous sublots would surely appear that could make it impossible to serve orders in the quantity, on the due date and in the homogeneity terms previously agreed on during the OPP. To solve this shortage situation, the research of [17] formulated a model to reallocate stocks to orders, which was later extended by including the re-assignation of the homogeneous sublots derived from the MPS by following two distinct approaches to deal with uncertainty: fuzzy sets and scenarios in a decision support system [4]. They were all validated with realistic data from a ceramic tile supply chain.

\subsection{Operations research models in agri-food supply chains}

A review was conducted of the operational research models applied to FSC in [18]. The conclusion drawn was that FSC requires a new generation of decision models into which new variables, like quality, wastage and prices that depend on freshness, market and seasonality, should be integrated. The work in [19] reviewed the quantitative operations management literature on food distribution by focusing on three important challenges: (i) food safety, (ii) food quality; (iii) sustainability. It noted that approaches capable of coping with multiple products with different SL and supply and demand patterns were lacking. It also encouraged the integration of different sustainability indicators to gain profound insight into the trade-offs among economic, environmental and social performance indicators. The review in 20 highlighted the main contributions made in the field of production and distribution planning for agri-foods based on agricultural crops. One evident finding it identified was that SL features were lacking in the majority of the models developed for planning perishable agri-foods as these features are essential for maintaining the quality and freshness of products. Given the narrow profit margins observed by producers, these authors stressed the relevance of operational models for perishable crops because of the critical impact that their limited SL have on harvesting and transportation decisions. They recognised that developing these models is an immediate need to benefit not only industry, but also the final consumer. A review of the works that have dealt with random SL can be found in [21]. Others like [5 have identified different approaches to deal with SL in production and distribution models: a) impose a make-to-order strategy by increasing the freshness delivered to customers; b) formulate constraints to limit the number of periods that a product can remain in stock; c) control the number of spoiled products and penalise it in the objective function; d) calculate holding costs based on SL being longer for items with a shorter SL; e) attribute a value to the different degrees of freshness to delivered products; f) assign a demand function that varies according to the products with a remaining shelf life (RSL). The different works that have used these approaches are reported below. 
Despite not always being the equivalent, different works have similarly used the terms quality and freshness. For instance, [22] and [23] implicitly managed product quality by limiting the product's SL. Others like 24 considered product quality to be dependent on time and temperature. The authors of [25] combined food quality decay with logistics in a model where the quality (freshness) of a single product was based on the RSL, depending on transportation and stocking temperatures. The novelty of the paper lies in deciding on the duration of storage and transportation jointly at the appropriate temperature for different locations and transportation equipment. The objective was to achieve a trade-off between the logistics and quality preservation costs on the one hand, and the costs of wasted products on the other hand. Quality was introduced into the production cost, but not into the selling price because only minimisation of costs was considered. In [7, crop perishability was handled through storage constraints and the model's objective included a loss function. The works of [11, 26, 27] adopted arc multipliers to capture the perishability (waste) of product flows in a network. The work of 11 also included the disposal of spoiled food products, along with the associated costs throughout the SC. The authors assumed that the product's price in a specific market could depend on the characteristics of demand.

In [5 a model was formulated for integrated production and distribution planning by a multi-objective framework: the first objective minimised total costs, including spoilage costs, while the other maximised the mean fractional RSL of delivered products. A similar approach was adopted in [28], but for the lot-sizing and scheduling problem in make-to-order, and a hybrid make-to-order and maketo-stock strategy. These authors proposed optimising the two following objectives by showing their conflicting nature. The first aim was to minimise total production costs, and the second to maximise the average freshness of delivered products. Other multi-objective models for the production planning and distribution of perishables were found in 29,30 . The work in 31 was to deal with the perishability of both raw materials and finished goods, along with age-dependent demand for a processed food industry in uncertainty scenarios. Demand (not selling price) was assumed to be dependent on product freshness, and the selling price took two different values depending on the type of market in which they were to be finally sold. The authors of 32 presented a stochastic programming model to deal with the uncertainty in the quality of farmers' supply to slaughterhouses, but did not address the perishability issue.

In 33], the inventory models for deteriorating items were classified into inventory models with a fixed SL, a random SL, and deteriorated items according to the proportional inventory. Meanwhile, [8 formulated an inventory model to decide the pricing and lot sizing policy by assuming that quality and physical quantity deteriorated simultaneously and were time-proportional. In $[34]$, dynamic pricing models were presented for perishable products based on their deterioration. The authors of 35] proposed a model to coordinate the production and delivery cycles of deteriorating items to determine not only the period of each buyer's orders, 
but also the actual time of the orders in the manufacturer cycle. The work of 36 considered the economic lot-sizing problem with perishable items, where items had deterministic expiration times that depended on their procurement periods. They showed that when items were perishable, the order in which they were consumed in stock was an important factor to be considered for implementing four different order consumption policies of stocks. The works of [37 40$]$ provided other examples of models dealing with perishability.

\subsection{Contributions of our work}

One conclusion drawn from the literature review is that the OPP in FSC is an area of research that offers a great improvement opportunity. While some studies have dealt with certain relevant features for processes other than the OPP, none has addressed them all simultaneously. This means that they have not done so properly for the specific OPP problem under study. In fact the reviews of [13, 18 21 do not cite any model in the OPP field for FSC. This confirms the finding of [13], and also reinforces the novelty, necessity and importance of our work. Our proposal bridges the following gaps indicated in these recent reviews.

An OPP model for FSC that integrates subtypes and their perishability to bridge the gap identified in 13 . It also incorporates new variables, like quality deterioration, wastage and prices dependent on freshness, into the operational research models applied to FSC to bridge the gap found in [18]. Unlike other authors who have considered that freshness closely resembles quality [25], we include two quality dimensions: an initial classification after which the product is packaged and stocked, and subsequent decreasing freshness. Deterioration of products and their freshness are controlled by the RSL, calculated as the unexpended fraction of its maximum SL at the time of delivery.

We consider multiple products with different SL and the integration of distinct sustainability indicators to gain profound insight into the trade-offs between profits and freshness, as a way to bridge one of the gaps reported in 19 . Having included harvesting time in our modelling approach allows to define different fixed SL for different products and subtypes. Two conflicting objectives, profits and mean delivered freshness, are maximised when deciding on order acceptance/rejection and ATP allocation. The objectives pursued by our OPP model differ from existing ones in several ways. Although maximising profits is a typical OPP objective, we introduce a SL-based pricing policy as a novelty feature (price varies according to delivered freshness) and include disposal costs. The inclusion of a non-monetary objective, such as the maximization of mean freshness, acts as a performance indicator of customer satisfaction. The formulation of this second objective differs from those found in the literature because of the distinct decision made about the order/acceptance rejection being addressed during the OPP. The conflicting nature of freshness and FSC operational costs has been shown by some authors for a fixed horizon $([5,28)$. However, we measure them from a rolling horizon 
perspective: reserving certain orders with the freshest ATP can make allocating the oldest one in future OPP executions impossible. This may occur if the SL of this ATP elapses before the due date of new incoming orders.

Starting from the novelty and necessity of our proposal, the sections below describe the addressed problem and the model proposed to support the OPP for FSCs.

\section{Problem description}

This section presents the main features of the problem under study. Firstly, inputs to the OPP, as regards FSC characteristics, the singularity of products and customisable aspects of order proposals are described. Secondly, the main particularities offered and assumptions made during OPP modelling are presented.

\subsection{The physical FSC configuration}

Physical FSC configuration is composed of several stages (Figure 1): one generic source field, several packing plants and different customers. It is assumed that raw material (fruit) is supplied from only one generic source field and all packing plants are capable of not only processing all types of products and their varieties, but also supplying all customers. Transport time depends on the distance from each packing plant to each customer, and a unitary average transport cost is charged depending on each subtype. However, the transportation time between the source field to packing plants is neglected because raw material is usually harvested and transported on the same day that plants pack them.

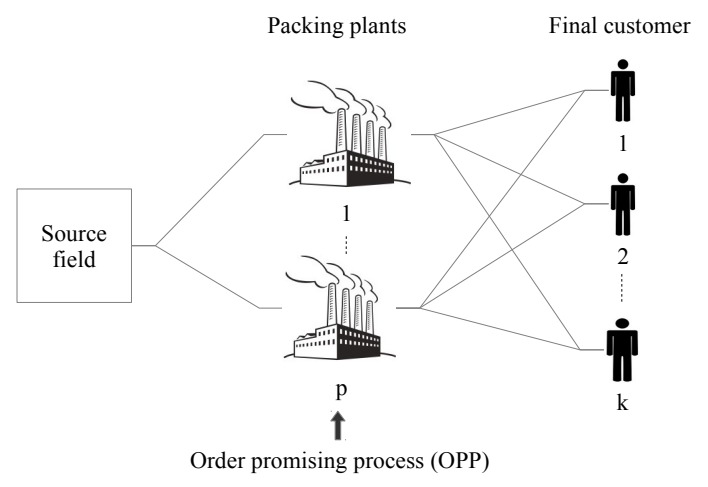

Figure 1: Supply chain configuration.

The production process in packing plants is assumed to be composed of the following sequential operations: 
Raw material reception: Raw material is received and stored after identifying its harvesting time (needed during the packing process and for computing the RSL). Packing: On packing plants, classification activities take place for different products. As a result, lots of the same product are separated into different homogeneous sublots according to the defined criteria (e.g., calibre). Figure 2 presents a general schema of how to split a harvested lot $\left(Q_{i}\right)$ into homogeneous sublots $\left(\beta_{i, b_{n}} Q_{i}\right)$. Beta coefficients $\left(\beta_{i, b_{n}}\right)$ represent the fractions of a lot that can be considered homogeneous. Homogeneous sublots with no minimal quality level are either wasted or sent to prepare by-products, named "derivatives" (e.g., juice).

Distribution: Once the product has been packed, it is sent to the final customer. Since distribution is usually subcontracted, its capacity is not considered to be limited.

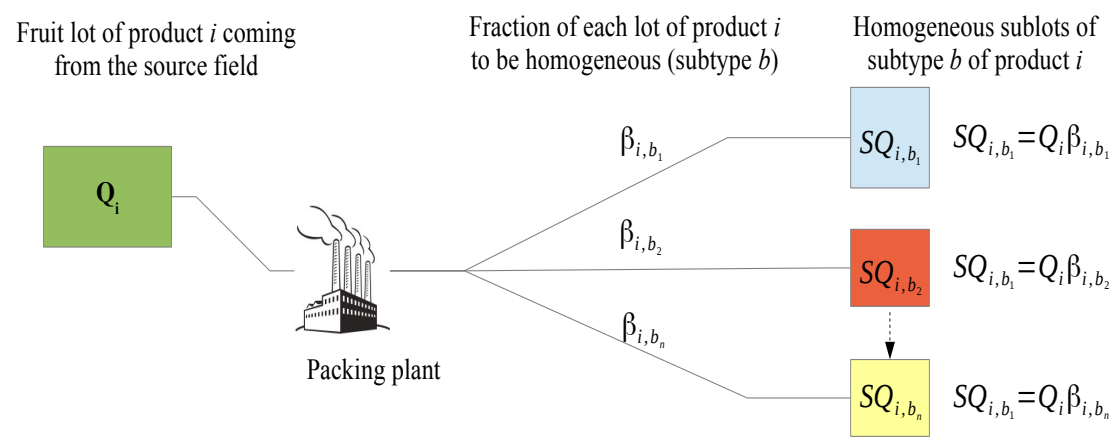

Figure 2: Division of lots of each product $i$ into homogeneous sublots of its different subtypes

\section{$3.2 \quad$ Final products}

Several products are considered. To accomplish customer homogeneity requirements, FSC should classify units according to the subtype's criteria, which are normally based on:

- Variety: it represents types of the same fruit.

- Quality: categories commonly defined according to the degree of defects or damage that each fruit presents.

- Calibre: it refers to the product's size, volume and weight.

- Packaging type: it indicates the different boxing classes in which the product can be commercialised (e.g., boxes, nets or bulk). 
- Harvesting time: it represents the time period during which input fruits are collected from fields (necessary to compute the RSL).

All the above attributes can take different values. For instance, one piece of fruit can present three varieties, two qualities, four calibres, etc. The specific combination of values for each attribute gives rise to the subtype. In relation to the SL of final products, the following assumptions are made:

- It is assumed that ATP presents a fixed SL.

- RSL is computed as the fraction of the product's SL that remains to be consumed, which diminishes with time. It is calculated for the product reserved to fulfil an order line on the delivery date and the remaining ATP at the end of the batching interval.

- A minimum RSL is defined in such a way that any product which exceeds this value is directly wasted. No maximum RSL is defined because customers are willing to always accept the freshest product.

- Once one product has been classified and packed, its initial classification remains. Quality level changes are not considered because it is usually stamped on the package, and it is not allowed to unpack products.

- Instead of considering quality changes, the product's selling price is adjusted according to the RSL (freshness).

- The selling price is considered a step function with as many constant segments as price ranges defined based on the RSL. The value of the price among different segments lowers when the RSL diminishes.

Figure 3 is an overview of the logics adopted herein for handling the RSL by a practical example. It also illustrates the related based pricing policy, where the subtype's price depends directly on its expected RSL on the delivery date.

\subsection{Customer order proposals}

The orders to be committed during the OPP present the following characteristics:

- Orders are composed of several order lines. Customers define the due date on which the order should be delivered. This is the same for all the lines of the order.

- Customers define the specific subtype and quantity requested for each line. The same subtype cannot appear in more than one line.

- Customers do not allow a delay in the delivery of their orders.

- Customers allow partial deliveries of their orders; i.e., it is possible to serve only some lines of the order. However, as explained in Subsection 4.2, the model is easily adaptable to forbid partial deliveries. Partial deliveries of one same line are forbidden. 


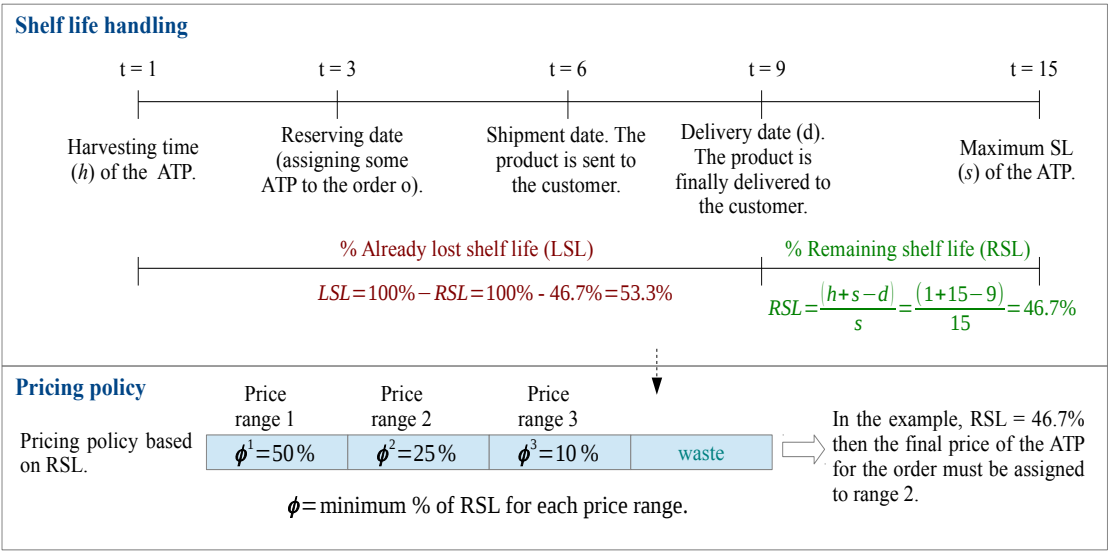

Figure 3: General schema of the SL-based pricing policy.

\subsection{Order promising process (OPP)}

One of the key challenges in this type of industry is to match the supply and demand of different qualities/subtypes. Two decisional processes are critically relevant to achieve this: master planning and the OPP. During master planning, the first attempt to match supply and demand is made by defining the MPS to satisfy mainly demand forecasts.

By taking the MPS, the in-stock inventory and previously committed orders as input, the ATP per subtype should be derived for promising incoming orders. When calculating ATP, it is necessary to consider that the existing real inventory in stock per subtype is known for certain. However due to inherent LHP uncertainty, the exact quantity to be finally obtained per subtype for the MPS is only known once collected and classified. Therefore, it is necessary to estimate splitting lots into homogeneous sublots to calculate the ATP per subtype. The beta coefficients that represent the fractions of each lot per subtype are defined for this very purpose.

Obviously, a proper match between the distribution of beta coefficients and the subtypes requested in the orders strongly affects FSC performance. Certainly, the better supply quantities match the forecast demands during the MPS definition, the better OPP performance. The quantities of each subtype requested by customers are compared with the uncommitted ATP for its due date: if there is enough ATP, it is assigned and updated. Normally several possibilities exist when reserving the ATP for an order line. The final decision affects future commitments, and also product waste because it can reach its maximum SL. One same order line cannot be served from different packing plants. However, different order lines of 
the same order can be served from distinct packing plants, with different harvesting times, provided that the subtype and due date required are accomplished.

Due to uncertainty in demand, forecasts can obviously differ from real orders. These differences can make impossible the commitment of all the orders based on the MPS. For this reason, the model allows us to identify those non-reserved order lines to renegotiate conditions with customers. Since the renegotiation process is beyond the scope of this paper, these order lines are identified and accumulated into bulk by highlighting for which specific lines an agreement is needed. To be able to serve as many order lines as possible, a penalty cost is associated with each non-reserved one. This forces the model to reserve products, even when the complete order cannot be finally fulfilled. A penalty cost is also applied to each not entirely reserved order.

Two objectives are considered: 1) Maximise profit: profit is calculated based on the incomes of committed orders by considering price ranges according to the product's RSL when delivered, minus the total operative costs, including waste costs; 2) Maximise product freshness: this aims to maximise the intangible customer satisfaction objective as the delivered product must be as fresh as possible. These objectives can be conflicting as shown in the following sections.

\section{FSC-OPP model description}

This section presents the definition of indices, sets, parameters and decision variables. Then a mixed integer linear programming model, dubbed as "FSC-OPP" to support the OPP with the characteristics and assumptions described in Section 3 is formulated.

\subsection{Notation}

In order to facilitate model readability, the notation is defined using the following convention: i) indices are represented as single italic lower-case letters; ii) sets are represented with single italic capital letters with the indices they refer to in parentheses; iii) input data (given parameters and parameters computed from other inputs) are represented as single boldface, non-italic lower-case letters with their respective indices; iv) the model's decision variables are represented as boldface, non-italic single-capital letters; and finally, v) the computed variables are represented as italic single-capital letters. The computed variables can be considered secondary variables that are calculated from the model's decision variables through equations. This means that the definition of these auxiliary variables is not mandatory because they can be expressed according to the primary ones. However, defining them is strongly recommended for two important reasons: firstly, they allow a clearer and more compact formulation of the model to improve its understanding; secondly, they provide managers with very valuable information about the solution provided by the model to implement it. The nomenclature that 
composes a block is presented in alphabetical order. It is noteworthy that the FSC-OPP model can be executed in either the real-time mode or the batch mode by properly defining the set of orders to be promised during the current execution.

\section{Indices}

$b \quad$ Subtypes, $b \in\{1, \ldots, B\}$.

$t$ The time periods of the planning horizon, $t \in\{0, \ldots, T\}$.

$h$ Harvesting time of the product, $h \in\{-S L, \ldots, T\}$.

$i$ The products required in the considered order proposals, $i \in\{1, \ldots, I\}$.

$o$ The customer order proposals waiting to be promised, $o \in\{1, \ldots, \Theta\}$.

$p$ Packing plants, $p \in\{1, \ldots, P\}$.

$r$ The number of ranges defined for the RSL of each subtype for which different selling prices are defined. The shorter the SL the product remains, the tighter the range it belongs to and the lower the selling price that can be charged, $r \in\{1, \ldots, R\}$.

\section{Sets}

$I(o) \quad$ Set of products $i$ requested in order $o$.

$B(o) \quad$ Set of all subtypes $b$ requested in each order $o$.

$S(i) \quad$ Set of all subtypes $b$ for each product $i$.

$O \quad$ The set of orders waiting to be promised during the current OPP model's run: i.e., orders with an arrival date within the current batching interval.

\section{Input data}

\section{Order proposals information}

$\mathbf{d}^{o} \quad$ The due date of order $o$, it will be the same for all its order lines.

$\boldsymbol{\eta}^{o} \quad$ The number of subtypes requested in order o. It also coincides with the number of order lines.

$\mathbf{r}_{i b}^{o} \quad$ The requested quantity of subtype $b$ of product $i$ in order $o$. 


\section{Supply/production information}

$\boldsymbol{\beta}_{i b}^{p t} \quad$ The homogeneity coefficients beta that represent the fraction of each lot of product $i$ that can be considered homogeneous subtype $b$. Through these coefficients, the splitting of planned lots of the MPS into homogeneous sublots is modelled. The sum of these coefficients for all subtypes $b$ of product $i$, in each packing plant $p$ during time period $t$, should equal 1: $\sum_{b \in S(i)} \boldsymbol{\beta}_{i b}^{p t}=1 \quad \forall t, p, i$.

$\mathbf{c}_{i b}^{p h t} \quad$ The total committed quantity of subtype $b$, of product $i$ harvested in period $h$ reserved from either the initial inventory (at the beginning of the planning horizon) or the MPS to be processed by packing plant $p$ during time period $t$.

$\mathbf{k}_{i b}^{p h} \quad$ The initial stock of subtype $b$ of product $i$ that belongs to packing plant $p$ harvested during time $h$, made available at the beginning of the planning horizon.

$\mathbf{m}_{i}^{p h t}$ The MPS of product $i$ harvested during time period $h$ to be processed by packing plant $p$ during time period $t$.

$\mathbf{s}_{i b} \quad$ The shelf life of subtype $b$ of product $i$.

Prices

$\boldsymbol{\varphi}_{i b}^{r} \quad$ The unitary selling price of subtype $b$ of product $i$ according to price range $r$.

$\boldsymbol{\nu}_{i} \quad$ The selling price of product $i$ sent for derivatives (by-products).

$\boldsymbol{\phi}_{i b}^{r} \quad$ The minimum fraction of RSL for each price range level $r$ of subtype $b$ of product $i$.

Costs

$\boldsymbol{\vartheta}_{i} \quad$ The unitary cost of discarded product $i$ (rubbish).

$\mathbf{h}_{i b}^{p} \quad$ The unitary holding cost per time period, of subtype $b$ of product $i$ in packing plant $p$.

$\mathbf{n}_{i b}^{o} \quad$ The cost of not reserving the order line that requests subtype $b$ of product $i$ in order $o$.

$\mathbf{t}_{i b}^{o p} \quad$ The unitary transport cost of subtype $b$ of product $i$ from packing plant $p$ to the delivery place of order $o$.

$\boldsymbol{\omega}_{i b}^{p} \quad$ The unitary waste cost of subtype $b$ of product $i$ in packing plant $p$, expired because it exceeds its minimum RSL.

$\mathbf{x}^{o} \quad$ The penalty cost of serving order $o$ partially; i.e., not reserving all its order lines. 


\section{Computed data}

$\mathbf{a}_{i b}^{p h t} \quad$ The ATP of subtype $b$ of product $i$ in packing plant $p$, harvested during period $h$ and packed during period $t$. This quantity represents the part of the available supply (in stock or planned in the MPS) that has not already been reserved to fulfil any order and can, therefore, be used to make future commitments while currently running the OPP model.

$\mathbf{j}_{i}^{p h t} \quad$ The total quantity of product $i$ from $\mathbf{m}_{i}^{p h t}$ directly sent to derivatives (by-products) during period $t$.

$\mathbf{g}_{i}^{p h t}$ The total quantity of product $i$ from $\mathbf{m}_{i}^{p h t}$ directly wasted (rubbish) during period $t$.

$\mathbf{u}_{i b}^{h} \quad$ The portion of the usable RSL of subtype $b$ of product $i$ harvested during period $h$ at the end of the batch interval.

\section{Other information}

$\mathbf{f}^{o p} \quad$ The transport time (freight) from packing plant $p$ to the delivery place of order $o$.

$M \quad$ Very large number.

$\tau \quad$ The number of time periods within the batching interval.

\section{Decision variables}

\section{Accept/reject decisions}

$\mathbf{P}^{o} \quad$ Binary variable that takes a value of 1 if order $o$ is served partially (just some of its lines are served), and a value of 0 otherwise.

$\mathbf{Y}^{o} \quad$ Binary variable that takes a value of 1 if order $o$ is fully served (all the lines in the order are fully served), and a value of 0 otherwise.

$\mathbf{Z}^{o} \quad$ Binary variable with that takes a value of 1 if order $o$ is neither fully nor partially served (none of its lines are served), and a value of 0 otherwise.

Decisions about the assignation of the ATP to orders

$\mathbf{F}_{i b}^{o} \quad$ Binary variable with a value of 1 if the requested quantity of subtype $b$ $\left(\mathbf{r}_{i b}^{o}\right)$ cannot be fulfilled (fail) and the order is sent to the renegotiation bulk.

$\mathbf{R}_{i b}^{\text {ophtr }}$ Binary variable with a value of 1 if the requested quantity of subtype $b\left(\mathbf{r}_{i b}^{o}\right)$ is reserved from $A_{i b}^{p h t}$ within price range $r$, but the order is not completely fulfilled. Then it is sent to the renegotiation bulk, and a value of 0 otherwise.

$\mathbf{W}_{i b}^{\text {ophtr }}$ Binary variable with a value of 1 if the requested quantity of subtype $b$ $\left(\mathbf{r}_{i b}^{o}\right)$ is completely served by $A_{i b}^{p h t}$ within price range $r$, and a value of 0 otherwise. It specifies where the $A_{i b}^{p h t}$ is taken for completely fulfilled orders; packing plant $p$, period $t$ and harvesting time $h$, for subtype $b$ of product $i$ in order $o$, assigned within price range $r$. 
Decisions about wasted product

$\mathbf{E}_{i b}^{p h t} \quad$ Binary variable with a value of 1 if $A_{i b}^{p h t}$ exceeds its minimum $\mathrm{RSL}\left(S_{i b}^{o} \leqslant\right.$ $\left.\phi_{i b}^{r}, \forall r=R\right)$ to be committed at the end of current OPP execution and must be excluded from the next one.

\section{Computed variables}

$A_{i b}^{p h t} \quad$ The updated ATP of subtype $b$ of product $i$ harvested during time $h$ that becomes available during time period $t$ after taking into account all the reserved order quantities while the current OPP model is underway.

$C_{i b}^{o p} \quad$ The shipment date (cargo) of the subtype $b$ of product $i$ in order $o$, from packing plant $p$ to the final customer. This date must consider the order's due date and the transport time from packing plant $p$ assigned to serve the final customer that the order belongs to.

$L_{i b}^{o p} \quad$ The length time before shipment date $\left(C_{i b}^{o p}\right)$ that is assigned an ATP to subtype $b$ of product $i$ in order $o$, in packing plant $p$. This is the time during which the reserved product is stored before being sent to the final customer.

$Q_{i b}^{p h t} \quad$ Total quantity of product that quits from $A_{i b}^{p h t}$ because it expires at the end of current execution $s\left(\mathbf{E}_{i b}^{p h t}=1\right)$. It represents waste.

$S_{i b}^{o} \quad$ The RSL of the product reserved to fulfil subtype $b$ of product $i$ in order $o$ at the time of delivery to the final customer. This is the fraction that represents its freshness.

\subsection{FSC-OPP model formulation}

\subsubsection{Objective Function}

The FSC-OPP model aims to maximise two conflicting objectives: profits of committed orders and their mean freshness.

Objective 1: Maximising profit Eq. (1) calculates profit every time the OPP is executed as the difference between the total income generated by the reserved order lines after taking into account the price ranges based on freshness, and the quantity sold as derivatives, less the total cost. The total cost includes the inventory holding cost of the product reserved from the time period of ATP being assigned to the final shipment date; the inventory holding cost of the remaining ATP; the transport cost of sending the reserved product from the assigned packing plants to customers; the penalty cost for serving orders partially (if allowed) and the opportunity cost of not accepting order lines; the rubbish cost (product directly discarded in classification activities) and the wasting cost because of expiry. 
Max Obj1:

$$
\begin{aligned}
& \sum_{o \in O, p, h} \sum_{t, r, i \in I(o)} \sum_{b \in B(o)} \boldsymbol{\varphi}_{i b}^{r} \mathbf{r}_{i b}^{o}\left(\mathbf{W}_{i b}^{o p h t r}+\mathbf{R}_{i b}^{o p h t r}\right)+\sum_{p, h} \sum_{1 \leqslant t \leqslant \tau} \sum_{i} \boldsymbol{\nu}_{i} \mathbf{j}_{i}^{p h t}-\sum_{o \in O} \sum_{p, i \in I(o)} \sum_{b \in B(o)} \mathbf{h}_{i b}^{p} \mathbf{r}_{i b}^{o} L_{i b}^{o p} \\
& -\sum_{p, h} \sum_{t \leqslant \boldsymbol{\tau}, i} \sum_{b \in S(i)}(\boldsymbol{\tau}-t) \mathbf{h}_{i b}^{p} A_{i b}^{p h t}-\sum_{o \in O, p, h} \sum_{t, r, i \in I(o)} \sum_{b \in B(o)} \mathbf{t}_{i b}^{o p} \mathbf{r}_{i b}^{o}\left(\mathbf{W}_{i b}^{o p h t r}+\mathbf{R}_{i b}^{o p h t r}\right)-\sum_{o \in O} \mathbf{x}^{o} \mathbf{P}^{o} \\
& -\sum_{o \in O, p, h} \sum_{t, r, i \in I(o)} \sum_{b \in B(o)} \mathbf{n}_{i b}^{o} \mathbf{F}_{i b}^{o}-\sum_{p, h} \sum_{1 \leqslant t \leqslant \boldsymbol{\tau}} \sum_{i} \boldsymbol{\vartheta}_{i} \mathbf{g}_{i}^{p h t}-\sum_{p, h} \sum_{1 \leqslant t \leqslant \boldsymbol{\tau}} \sum_{i, b \in S(i)} \boldsymbol{\omega}_{i b}^{p} Q_{i b}^{p h t} .
\end{aligned}
$$

Objective 2: Maximising the product freshness of the reserved order lines

This second objective is defined to reach a high customer satisfaction level: only for accepted orders, the fresher the product delivered to customers, the better their satisfaction level becomes. Eq. (2) shows a linear approach of average freshness per order line of the reserved product. The numerator computes the freshness for the order lines, measured as the sum of their RSL at the time of delivery. To accurately represent average freshness, the denominator should equal the number of reserved order lines instead of the total number of order lines. However, a strict calculation of average freshness brings about a more complicated non-linear model to be solved than its linear approach. The experimental results in Subsection 5.3 show the equivalence between both objective formulations. Eq. (2) provides a value within the interval $[0,1]$, and the objective involves achieving a value that comes as close to 1 as possible.

Max Obj2:

$$
\frac{\sum_{o \in O} \sum_{i, b \in B(o)} S_{i b}^{o}}{\sum_{o \in O} \boldsymbol{\eta}^{o}} .
$$

Global objective function (OF):

The two previous objectives can be conflicting because, although serving fresher products implies higher selling prices, it increases the risk of having more expired product, which cannot allow future incoming orders to be served and which, in turn, results in making a lower total profit. Therefore in order to handle this conflicting situation, the two objectives are combined into a single one by the simple additive weighting method, which involves adding the two scaled objectives according to weights $\sigma_{1}$ and $\sigma_{2}$. Weights are assigned by the decision maker in such a way that the heavier the weight of an objective, the greater its importance. It is also necessary to define them so that $\sigma_{1}+\sigma_{2}=1$. The only objective that needs to be scaled within the interval $[0,1]$ is $O b j 1$. Therefore, it is necessary to divide the real profit from the calculated maximum possible profit $(M a x P)$; e.g., as the profit obtained if all the orders are served as its maximum price, less the decision 
maker's minimum cost goal. Then the global objective function is calculated as follows in Eq. (3):

$$
\operatorname{Max} O F: \sigma_{1} \frac{O b j 1}{\operatorname{MaxP}}+\sigma_{2} O b j 2
$$

\subsubsection{Constraints}

Some calculations should be made on the FSC-OPP model's input data to be used in different constraints. Eq. (4) computes the actual initial ATP from which the orders during the current OPP execution will be promised. Note that this involves the real ATP during period $t=0$ derived from stocks, and the planned ATP for $t \geqslant 1$ derived from the MPS. Splitting each planned lot according to subtypes is done using coefficients $\boldsymbol{\beta}_{i b}^{p t}$. Subtypes $b=B-1$ and $b=B$ are assigned to the product directly sent to derivatives and waste, respectively. This is represented through Eq. (5) and Eq. (6), defined only for the time periods within the batching interval to compute the incomes of derivatives and the cost of waste only once. Eq. (7) calculates the RSL of the $A_{i b}^{p h t}$ (i.e. its freshness) at the end of the current OPP execution, but only for those periods within the batching interval. This is because the remains of the ATP of the batching interval become part of the real stock for the next execution. However, the ATP that expires before that time should be excluded from the calculation (see Eq. 29).

$$
\begin{gathered}
\mathbf{a}_{i b}^{p h t}=\left\{\begin{array}{l}
\mathbf{k}_{i b}^{p h}-\mathbf{c}_{i b}^{p h t} \quad, \quad \text { if } t=0, \\
\boldsymbol{\beta}_{i b}^{p t} \mathbf{m}_{i}^{p h t}-\mathbf{c}_{i b}^{p h t}, \quad \text { if } t \geqslant 1, \\
\mathbf{j}_{i}^{p h t}=\sum_{b=B-1} \boldsymbol{\beta}_{i b}^{p t} \mathbf{m}_{i}^{p h t}, \quad \forall p, h, i, b \leqslant B-2 .
\end{array}\right. \\
\mathbf{g}_{i}^{p h t}=\sum_{b=B} \boldsymbol{\beta}_{i b}^{p t} \mathbf{m}_{i}^{p h t}, \quad \forall p, h, 1 \leqslant t \leqslant \tau, i . \\
\mathbf{u}_{i b}^{h}=\frac{\left(h+\mathbf{s}_{i b}-\boldsymbol{\tau}\right)}{\mathbf{s}_{i b}}, \quad \forall h \leqslant \boldsymbol{\tau}, i, b .
\end{gathered}
$$

Assigning ATP to orders should be done by respecting the constraints presented in the following paragraphs. Through Eq. (8), the ATP that results at the end of the current execution is computed as the difference between the planned lots of each subtype $b$ of product $i$ harvested from the source field during period $h$ to become available during period $t$, less the total quantity of the committed orders during the execution.

$$
A_{i b}^{p h t}=\mathbf{a}_{i b}^{p h t}-\sum_{o \in O} \sum_{r} \mathbf{r}_{i b}^{o}\left(\mathbf{W}_{i b}^{o p h t r}+\mathbf{R}_{i b}^{o p h t r}\right), \quad \forall p, h, t, i, b \leqslant B-2 .
$$


Eq. (9) ensures that one same order line is only one of three: reserved from the ATP, sent to renegotiation or rejected. It also ensures that the price assigned to each order line with the reserved ATP corresponds to only one price range, packing plant and harvesting time.

$$
\sum_{p, h} \sum_{t, r}\left(\mathbf{W}_{i b}^{o p h t r}+\mathbf{R}_{i b}^{o p h t r}\right)+\mathbf{F}_{i b}^{o}=1, \quad \forall o \in O, i, b \in B(o) .
$$

Assignation policies are implemented from Eq. (10) to Eq. (14). Eq. (10) calculates the served orders in such a way that only the orders with the ATP reserved for all its lines are identified as being totally fulfilled. Eq. (11) to Eq. (13) identify both the partially reserved orders and the specific lines that require renegotiation with the customer. Eq. (14) ensures that one order can only be totally served, partially reserved or not be reserved at all.

$$
\begin{gathered}
\sum_{p, h} \sum_{t, r} \sum_{i, b \in B(o)} \mathbf{W}_{i b}^{o p h t r}=\boldsymbol{\eta}^{o} \mathbf{Y}^{o}, \quad \forall o \in O . \\
\sum_{p, h} \sum_{t, r} \sum_{i, b \in B(o)} \mathbf{R}_{i b}^{\text {ophtr }}+\sum_{i} \sum_{b \in B(o)} \mathbf{F}_{i b}^{o}=\boldsymbol{\eta}^{o}\left(\mathbf{P}^{o}+\mathbf{Z}^{o}\right), \quad \forall o \in O . \\
\sum_{p, h} \sum_{t, r} \sum_{i, b \in B(o)} \mathbf{R}_{i b}^{o p h t r}<\boldsymbol{\eta}^{o} \mathbf{P}^{o}, \quad \forall o \in O . \\
\sum_{p, h} \sum_{t, r} \sum_{i, b \in B(o)} \mathbf{R}_{i b}^{o p h t r} \geqslant \mathbf{P}^{o}, \quad \forall o \in O . \\
\mathbf{Y}^{o}+\mathbf{P}^{o}+\mathbf{Z}^{o}=1, \quad \forall o \in O .
\end{gathered}
$$

Eq. 15 calculates the RSL (freshness) of the quantity of reserved ATP for each specific order line at the time it is delivered to the customer (the order's due date).

$$
S_{i b}^{o}=\sum_{p, h} \sum_{t, r}\left(\frac{\left(h+\mathbf{s}_{i b}-\mathbf{d}_{o}\right)\left(\mathbf{W}_{i b}^{\text {ophtr }}+\mathbf{R}_{i b}^{o p h t r}\right)}{\mathbf{s}_{i b}}\right), \quad \forall o \in O, i, b \in B(o) .
$$

Eq. (16) and Eq. (17) define the values of the binary variables responsible for reflecting changes in the selling price of the reserved quantities to orders according to their RSL and their price ranges.

$$
\begin{gathered}
\phi_{i b}^{r}-S_{i b}^{o} \leqslant 1-\sum_{p, h, t}\left(\mathbf{W}_{i b}^{o p h t r}+\mathbf{R}_{i b}^{o p h t r}\right), \quad \forall o \in O, i, b \in B(o), r . \\
S_{i b}^{o}-\phi_{i b}^{r} \leqslant 1-\sum_{p, h, t} \sum_{r=r+1}\left(\mathbf{W}_{i b}^{o p h t r}+\mathbf{R}_{i b}^{o p h t r}\right), \quad \forall o \in O, i, b \in B(o), r<R .
\end{gathered}
$$


Eq. (18) ensures that served orders cannot be fulfilled with the ATP that have a shorter RSL than the minimum allowed for the last price range.

$$
\sum_{p, h, t} \boldsymbol{\phi}_{i b}^{r}\left(\mathbf{W}_{i b}^{o p h t r}+\mathbf{R}_{i b}^{o p h t r}\right) \leqslant S_{i b}^{o}, \quad \forall o \in O, i, b \in B(o), r=R .
$$

Eq. (19) to Eq. (23) are formulated to linearly calculate the expired product because it reaches its minimum RSL. Eq. 19. and Eq. 20 identify $A_{i b}^{p h t}$, which expires at the end of the current execution because its exceeds its minimum RSL, which is allowed to be used to fulfil orders. Variable $\mathbf{E}_{i b}^{p h t}$ can only assume a value of 1 if $A_{i b}^{p h t}$ must be excluded.

$$
\begin{gathered}
\boldsymbol{\phi}_{i b}^{r}-\mathbf{u}_{i b}^{h} \leqslant \mathbf{E}_{i b}^{p h t}, \quad \forall p, h, t \leqslant \tau, r=R, i, b . \\
\mathbf{u}_{i b}^{h}-\boldsymbol{\phi}_{i b}^{r} \leqslant 1-\mathbf{E}_{i b}^{p h t}, \quad \forall p, h, t \leqslant \boldsymbol{\tau}, r=R, i, b .
\end{gathered}
$$

With Eq. 21 to Eq. 23, the $A_{i b}^{p h t}$ at the end of the current OPP execution (for the time periods within the batching interval), which must be ruled out for exceeding its minimum allowed RSL, is identified and quantified in auxiliary variable $Q_{i b}^{p h t}$. The expired $A_{i b}^{p h t}$ is 0 if binary variable $\mathbf{E}_{i b}^{p h t}$ is 0 (i.e., the product has not expired) or equals the existing $A_{i b}^{p h t}$ if $\mathbf{E}_{i b}^{p h t}$ equals 1 (i.e. the product has expired). Therefore, either no quantity of $A_{i b}^{p h t}$ expires or all of it does from a packing plant and for a given harvesting time.

$$
\begin{gathered}
Q_{i b}^{p h t} \leqslant M \mathbf{E}_{i b}^{p h t}, \quad \forall p, h, t \leqslant \tau, i, b . \\
A_{i b}^{p h t}-Q_{i b}^{p h t} \leqslant M\left(1-\mathbf{E}_{i b}^{p h t}\right), \quad \forall p, h, t \leqslant \tau, i, b . \\
Q_{i b}^{p h t} \leqslant A_{i b}^{p h t}, \quad \forall p, h, t \leqslant \tau, i, b .
\end{gathered}
$$

Eq. (24) calculates the shipment date of each order line from the packing plant to the final customer. These data are computed as the order's due date, less the transport time required from the packing plant assigned to fulfil each order line to its respective final customer.

$$
C_{i b}^{o p}=\mathbf{d}^{o}-\sum_{h, t, r} \mathbf{f}^{o p}\left(\mathbf{W}_{i b}^{o p h t r}+\mathbf{R}_{i b}^{o p h t r}\right), \quad \forall o \in O, p, i, b \in B(o) .
$$

Eq. 25 calculates the number of time periods during which each subtype b of product $\mathrm{i}$ is stored while waiting to be sent to the final customer from the time it is reserved.

$$
L_{i b}^{o p}=C_{i b}^{o p}-\sum_{h, t, r} t\left(\mathbf{W}_{i b}^{o p h t r}+\mathbf{R}_{i b}^{o p h t r}\right), \quad \forall o \in O, p, i, b \in B(o) .
$$


Finally, Constraint (26) shows the definition of the nature of the variables.

$$
\begin{aligned}
& \mathbf{Y}^{o}, \mathbf{F}_{i b}^{o}, \mathbf{R}_{i b}^{o p h t r}, \mathbf{W}_{i b}^{o p h t r}, \mathbf{E}_{i b}^{p h t} \text { BINARY, } \\
& C_{i b}^{o p}, L_{i b}^{o p} \quad \text { INTEGER, } \\
& A_{i b}^{p h t}, Q_{i b}^{p h t}, S_{i b}^{o} \quad \text { CONTINOUS. }
\end{aligned}
$$

It is important to highlight that the above OPP model allows the partial fulfilment of orders by serving only some of its order lines completely and computing their corresponding profit. However, partial deliveries result in a poorer customer service level. For this reason, we penalise this situation by including two penalty costs, $\mathbf{n}_{i b}^{o}$ and $\mathbf{x}^{o}$, in the objective function. The $\mathbf{n}_{i b}^{o}$ is the opportunity cost of not accepting the specific order line when requesting subtype $b$ in a customer order, and $\mathbf{x}^{o}$ penalises not serving the entire order (serving it partially). The aim is to allow the FSC-OPP model to serve partial orders. However, given the cost of doing this, it attempts to avoid it and still seeks to serve full orders. It is noteworthy that customer priority can be managed through these costs: the higher the cost, the more prioritised the customer order is when selecting the orders to be served. If desired, the FSC-OPP model can also be easily adapted to forbid the partial fulfilment of orders by including only the additional Eq. 27]:

$$
\sum_{p, h, t, r} \sum_{i, b \in B(o)} \mathbf{R}_{i b}^{o p h t r}=0, \quad \forall o \in O .
$$

Finally, the FSC-OPP model can be easily reformulated to not allow the partial fulfilment of orders, but to identify which order lines can be reserved. This information can be used to renegotiate customer requirements or to find alternative solutions for those order lines that cannot possibly be reserved. To model this last situation, the exclusion of variable $R_{i b}^{o p h t r}$ from the term of profit in the objective function regarding income from sales suffices.

\subsection{Implementing the FSC-OPP model into a dynamic batching mode}

Using this model as a support decision tool for the OPP in a dynamic environment requires executing it in a rolling horizon with a replanning period that equals its batching interval. Some of the decision variables values obtained from the solution of the model during a specific execution $s$ should be used to update the value of some of the model's input data $\left(\mathbf{c}_{i b}^{p h t}\right.$ and $\left.\mathbf{k}_{i b}^{p h}\right)$ in the subsequent execution $s+1$. In order to update $\mathbf{a}_{i b}^{p h t}$ at the beginning of each successive execution, the parameter that includes all the committed quantities $\mathbf{c}_{i b}^{p h t}$ must be recalculated as shown in Eq. 28. In this equation, the total committed quantity of each subtype is updated by considering the quantity already promised at the beginning of execution $s$, and 
the new quantities promised during execution $s$ for all the order lines that this subtype requests.

$$
\mathbf{c}(s+1)_{i b}^{p h t}=\mathbf{c}(s)_{i b}^{p h t}+\sum_{o \in O(s)} \sum_{r} \mathbf{r}_{i b}^{o}\left(\mathbf{W}(s)_{i b}^{o p h t r}+\mathbf{R}(s)_{i b}^{o p h t r}\right), \quad \forall p, h, t, i, b .
$$

Furthermore, $\mathbf{k}_{i b}^{p h}$ must be updated between two consecutive executions. After the time interval $t \in[1, \tau]$, the MPS in the batching interval of the execution $s$ that is produced and classified should be considered. If we assume that the produced lots coincide with those planned in the MPS, the updated ATP for each packing plant, subtype and harvesting time, by ruling out the expired product after execution $s$, must be grouped as the initial stock of the next execution $s+1$. This can be done by applying Eq. 29.

$$
\mathbf{k}(s+1)_{i b}^{p h}=\sum_{t \leqslant \boldsymbol{\tau}}\left(\boldsymbol{\beta}_{i b}^{p t} \mathbf{m}_{i}^{p h t}-Q(s)_{i b}^{p h t}\right), \quad \forall p, h, i, b .
$$

Therefore, these updates are used to calculate $\mathbf{a}(s+1)_{i b}^{p h t}$ at the beginning of the following OPP execution $(s+1)$ through Eq. (4).

Finally, it is important to note that for all the input data $\mathbf{c}_{i b}^{p h t}, \mathbf{k}_{i b}^{p h}$ and $\mathbf{m}_{i}^{p h t}$ for successive executions, index $h$ must be updated because we assume that after current execution $s$, the planning horizon moves $\tau$ periods forward. Then the harvesting time of the current quantities comes $\boldsymbol{\tau}$ periods closer to the current time period; e.g., if during the first execution $(s=1)$ we expect to harvest some product for day $7(h(s=1)=7)$, and the 3-day batching interval has elapsed and the OPP model has been rerun $(s=2)$, the updated harvesting time within the new horizon is $h(s=2)=7-3=4$. The same is valid for negative $h$ (an already harvested, but not yet expired product). This is done by applying the calculation of Eq. (30) to index $h$ of all three parameters.

$$
h(s+1)=h(s)-\tau, \quad \forall h .
$$

\section{Experimental design: application to an orange and tangerine supply chain}

In this section, the validation of the first FSC-OPP model version to allow the partial fulfilment of orders is done by applying it to a real orange and tangerine FSC. The model was solved in different scenarios to gain some managerial insights. It was implemented by using the MPL 4.2 maximal software, combined with an algorithm to execute scenarios and to extract results, developed in Java. MPL (Mathematical Programming Language) is an advanced modelling system that 
allows the model developer to formulate complicated optimisation models clearly, concisely and efficiently. The models developed in MPL can then be solved with any of the multiple commercial optimizers available currently on the market [41]. Experiments were executed by an Intel(R) Core(TM) i7-4510 CPU @ $2.60 \mathrm{GHz}$ processor, with 8 GB RAM, which ran in a Windows 7-64 bit environment. The Gurobi 6.0 solver was used.

\subsection{Input data overview}

The data set used to test the model comes from a Spanish oranges and tangerines FSC. Two packing plants are considered that processes two products (oranges and tangerines) and nineteen subtypes with four price ranges each one. Subtypes required in orders are transported from packing plants to customers incurring in transport costs and times. Customer orders comprise between one and ten order lines. In total eighty-eight incoming orders are considered. The orders are promised twice a week by considering a 3-day batching interval and a 6-day horizon length. The global horizon for the experiments includes seventeen periods subdivided into four OPP executions. The complete data set for the model can be consulted in Appendix B. With all these input data, the OPP model was run under different scenarios described in the following Subsection 5.2 .

\subsection{Experimental design}

The numerical experiments were run to: 1) validate the OPP model, 2) show the level of conflicting between both objectives, 3) evaluate the managerial impact of SL length and price sensitivity to freshness and 4) assess its computational performance. To do this, the model was solved with the input data described in Appendix B, but in different scenarios. These scenarios were defined as:

- Sigma scenarios: the weights (sigma) assigned to each objective in Eq. (3) represent the priority given by the decision maker to each one. To study how sensitive the solutions obtained to these weights and their conflicting nature were, the model was solved with eleven different combinations of the sigmas (sigma scenarios) by parametrising each one in the space $[0,0.1,0.2$, $0.3,0.4,0.5,0.6,0.7,0.8,0.9,1]$, and ensuring that their sum was 1 .

- Shelf-life scenarios: as one of the main objectives of this work was to study how important the SL is for the OPP, we evaluated the model under three different cases: short, normal and long SL. The short (long) case was obtained by cutting (increasing) the SL of the normal case by 2 days (see Table B.1 in Appendix B.

- Price variation scenarios: according to the pricing policy of the FSC under study, four price ranges were defined and linked to product freshness (RSL). We defined three different scenarios: None, Low and High. For the "None" case, the price (R1) remained constant for all the freshness ranges. 
For the "Low" case, a smooth reduction of prices between freshness ranges is considered, meanwhile for the "High" case, a more pronounced reduction of prices is applied (see Table B.7 in Appendix B.

\subsection{Experimental results}

This section reports and analyses the results obtained from solving the model with partial deliveries (Eq. (3) to Eq. (26)) in the above-defined scenarios. The model was executed four times $(s=4)$ in a batch mode for eleven sigma cases, three SL scenarios and three price variation cases, which totals $396\left(4^{*} 11^{*} 3^{*} 3\right)$ executions. The following paragraphs analyse and compare the achieved outcomes.

Fig. 4 graphically shows the values of the model objectives for the three SL scenarios: short, normal and long. Each figure is divided into three graphs that correspond to the level of price variation among the freshness ranges: None, Low and High. The X-axis, for each graph in a specific figure, shows the values of weight $\left(\sigma_{1}\right)$ assigned to model objective Obj.1 (maximising profits). Weight $\left(\sigma_{2}\right)$ assigned to Obj.2 (mean delivered freshness) can be easily calculated by the following equation: $\sigma_{1}+\sigma_{2}=1$.

For each instance, the values of both model objectives (Eq. (1) and Eq. (2)) and the real average delivered product freshness are reported. As seen, our linear formulation of average freshness (Obj.2) (red series) can be considered equivalent to the real average delivered freshness (orange series), because these two curves are completely harmonious. As expected, the real average delivered freshness (orange series) is always higher than Obj.2 (red series) because only the reserved order lines are considered in the denominator of its calculation instead of all the order lines. The next paragraphs analyse model behaviour from different perspectives.

\subsubsection{Interaction between the objectives}

For all three SL scenarios and all three price variations (Fig. 4), the interaction between the model objectives follows the same pattern that confirms the conflicting nature of the objectives: the heavier the weight assigned to the first objective $\left(\sigma_{1}\right)$, the higher the profits and the lower the average freshness attained. The results also show that considering both objectives while executing the OPP is highly recommendable. For extreme cases, where only one of the two objectives is optimised (i.e., $\sigma_{1}=0$ or $\sigma_{1}=1$ ), the best results for this objective are achieved at the expense of the other objective becoming markedly worse, which achieves its worst performance. Note that in each combination of scenarios, the profit curve becomes much flatter than the average freshness curve. This indicates the greater sensitivity of the mean freshness delivered to the weights assigned to each objective.

We can also observe that the narrower the price variation between freshness ranges, the greater the conflicting behaviour between both objectives. This is true because 


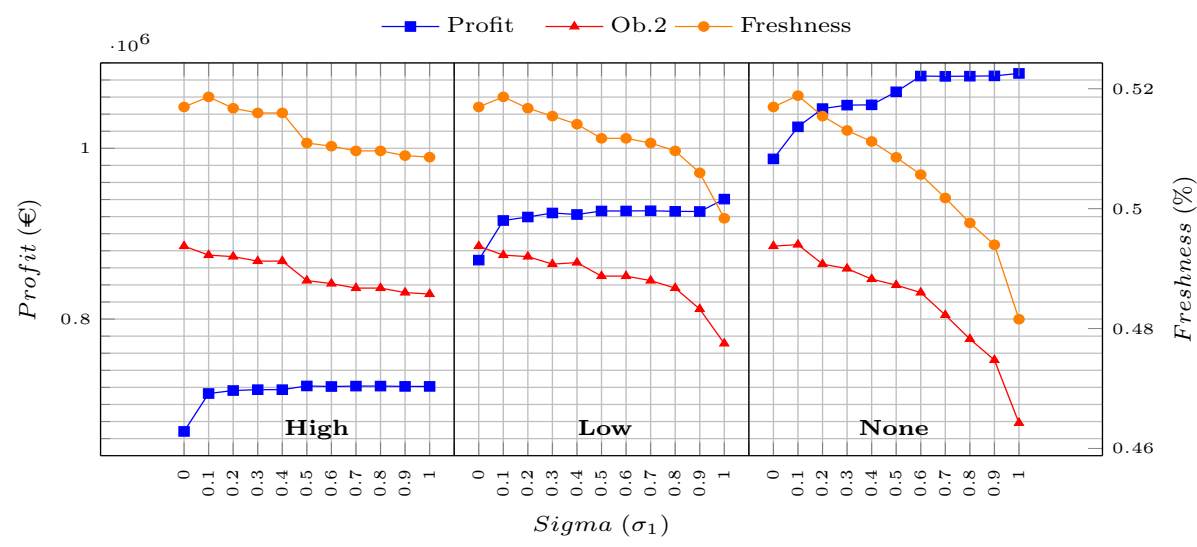

(a) Short SL / High-Low-None price variation.

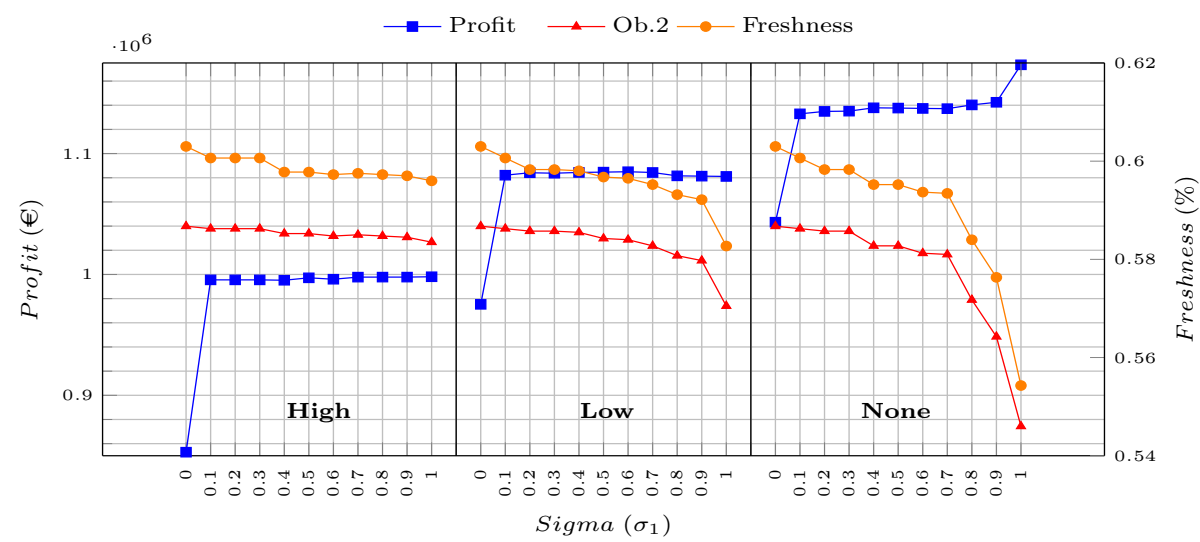

(b) Normal SL / High-Low-None price variation.

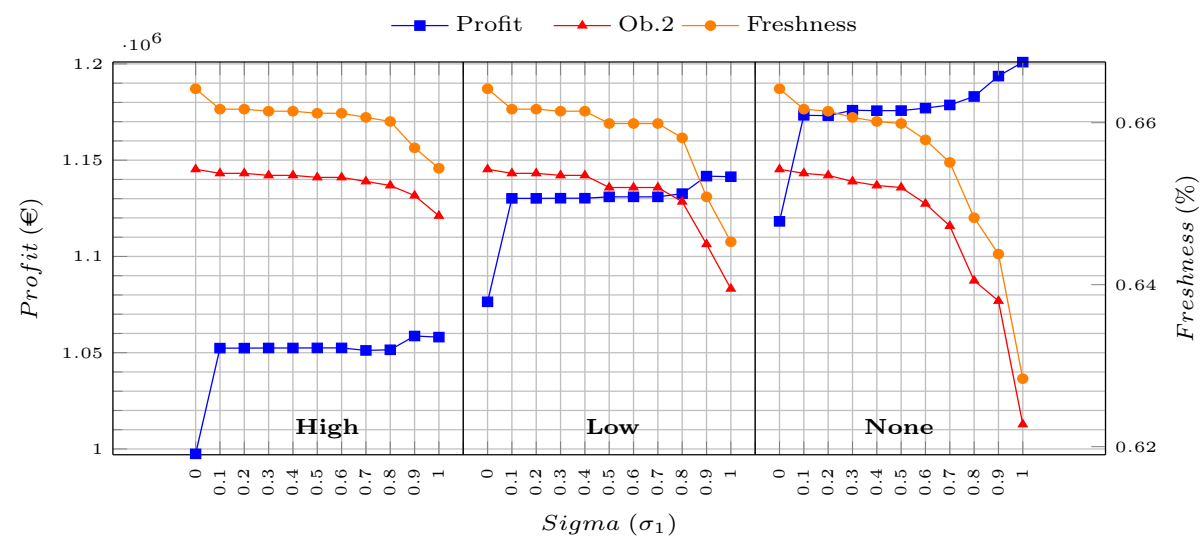

(c) Long SL / High-Low-None price variation.

Figure 4: Experimental results 
if the selling price rises for fresher products, the model is intended to reserve orders with fresher products because higher incomes and greater average freshness are simultaneously obtained. This fact leads to more aligned behaviour between both model objectives, although it is still conflicting. Conversely for "none" variation in prices, freshness decreases much more quickly with increasing profits. This occurs because the income made from reserving an order line will always be the same regardless of its freshness. As a result, the model attempts to serve the order lines with older products to reduce the waste costs of products that reach their minimum RSL.

\subsubsection{Impact of price variation on the objectives}

Fig. 4 shows that increasing price variation has an inverse impact on profits; i.e., if wide variations are considered among the price values for each range, there is a high risk of reducing profitability. Therefore, by assuming that the total quantity ordered by customers is independent of price, applying high discounts to sell the oldest product always results in loss of profits. In contrast, mean freshness remains more constant when the variations between prices within each range are wide. The value obtained for mean freshness also remains practically the same for all three price variation scenarios, specially when the weight provided to Obj.1 $\sigma_{1}$ belongs to the $[0.1,0.5]$ interval. So it is very important to profoundly analyse not only the value of the discount made from one range to the next, but to also define the limits in the RSL for these ranges.

\subsubsection{Impact of SL on the objectives}

From the results, Fig. 4 indicates that for the same price variation case, the longer the SL, the higher the profits. This fact is consistent with defining a pricing policy based on the product's SL because it allows to take advantage during the greatest freshness period of the product when more profits are obtained. Thus all the efforts that the management can make to extend the product's SL as much as possible will raise the probability of making higher profits. Besides, mean freshness variation is significantly lower for longer SL's and when price depends on freshness.

\subsubsection{Computational efficiency}

Finally, Table 1 shows the model statistics, while Table 2 provides its computational efficiency when optimally solved $(\mathrm{GAP}=0.001 \%)$. As seen in Table 1 solution matrix size directly depends on the input data configuration; number of products, planning horizon and quantity of orders (which is why data can change during different executions). The presented data are the average per execution when considering all the sigma scenarios. Since the solution matrix for each execution differs, the number of iterations and solution times also differ in Table 2 for each SL and price variation case. For the problem under study, the solution time 
in Table 2 is in the order of a very few seconds, and model optimisation is feasible to support the OPP. Even when these experiments have been conducted by using realistic data of a FSC with a closely real configuration size, the computational time can considerably increase for problems of this type with larger instances as in [16]. For these cases, depending on the model solution time compared with the time that customers are willing to wait, the development of alternative resolution methods can be assessed; heuristics, meta-heuristics or parallel computing, figure among some of the options.

Table 1: Model statistics per execution

\begin{tabular}{|c|c|c|c|c|c|c|c|}
\hline Execution & $\begin{array}{c}\text { Computed } \\
\text { continuous } \\
\text { variables }\end{array}$ & $\begin{array}{c}\text { Computed } \\
\text { integer } \\
\text { variables }\end{array}$ & $\begin{array}{c}\text { Binary } \\
\text { decision } \\
\text { variables }\end{array}$ & Constraints & $\begin{array}{l}\text { Full } \\
\text { matrix }\end{array}$ & Nonzeros & $\%$ GAP \\
\hline s1 & 8,457 & 174 & 151,856 & 15,044 & $1,787,724$ & $1,475,420$ & 0.001 \\
\hline $\mathrm{s} 2$ & 8,454 & 168 & 146,682 & 15,008 & $1,727,247$ & $1,425,314$ & 0.001 \\
\hline s3 & 8,456 & 172 & 150,140 & 15,032 & $1,767,584$ & $1,458,718$ & 0.001 \\
\hline $\mathrm{s} 4$ & 8,447 & 154 & 134,579 & 14,924 & $1,586,015$ & $1,308,400$ & 0.001 \\
\hline Average & 8,454 & 167 & 145,814 & 15,002 & $1,717,143$ & $1,416,963$ & 0.001 \\
\hline
\end{tabular}

Table 2: Computational efficiency per execution (average of all the sigma scenarios)

\begin{tabular}{|lc|ccc|}
\hline Shelf life & $\begin{array}{c}\text { Price } \\
\text { variation }\end{array}$ & $\begin{array}{c}\text { Paring time } \\
(\mathrm{sec})\end{array}$ & Iterations & $\begin{array}{c}\text { Solution } \\
\text { time }(\mathrm{sec})\end{array}$ \\
\hline Long & High & 15.8 & 312.3 & 6.3 \\
& Low & 21.3 & 325.8 & 6.3 \\
& None & 12.5 & 384.2 & 4.6 \\
\hline Normal & High & 15.0 & 341.7 & 4.6 \\
& Low & 18.2 & 357.8 & 5.4 \\
& None & 13.3 & 446.6 & 5.0 \\
\hline Short & High & 13.7 & 281.8 & 5.5 \\
& Low & 12.2 & 275.2 & 5.2 \\
& None & 17.4 & 306.2 & 5.6 \\
\hline
\end{tabular}

\subsubsection{Managerial insights}

The model's generic structure allows it to be applied to a wide variety of products with inherent heterogeneity in subtypes and a limited SL that cause their deterioration over time until they become waste. Two quality dimensions can be considered: 1) the initial classification of products into subtypes that can be based on attributes related to quality and 2) the quality deterioration due to the decreasing in their freshness. The model also captures the relationship between freshness and the products' value through a price policy based on the freshness of delivered products.

The OPP model can support managers in decisions about the acceptance/rejection of customer order proposals. If enough ATP per subtype exists to promise all the 
orders, the model provides the decision maker with an optimal ATP assignation to each one, their freshness and the price charged to each order line. On the contrary, if the quantities ordered by customers exceed the ATP (shortage situation), the model decides on the most profitable orders or order lines (partial fulfillment) to be served, and those that should not be served. The model reports the unmet orders/order lines, for which managers can either find an alternative supply or renegotiate conditions with customers. In the event of supply shortage, it makes sense to distinguish between more important customers/orders. Assigning a different priority to customers/orders can be implemented into the model by charging higher penalty costs of not serving an order line $\mathbf{n}_{i b}^{o}$ or by not completely serving an order $\mathbf{x}^{o}$ to the orders that belong to more important customers.

The consideration of two objectives during the OPP offers the decision maker a valuable tool to trade-off explicitly total incomes and costs against product freshness, which is closely related to customer satisfaction. The experimental design confirms the conflicting behaviour of the two objectives, which becomes more pronounced when variation of prices with freshness narrows. Therefore, for this situation it becomes crucial to optimize both objectives simultaneously. Indeed, one interesting finding of this study is that conferring a balance weight to both objectives greatly improves the mean freshness at the expense of a slight drop in profits. The results also confirm the advantages that the decision-maker can benefit from, by analysing the trade-off between these two different objectives.

By way of example, let's assume that the decision maker should face the pessimistic scenario of a short SL and narrow price variation. Let's assume that the decision maker can decide to study the three following sigma scenarios: $\left(\sigma_{1}, \sigma_{2}\right)=$ $\{(1,0),(0.5,0.5),(0,1)\}$. The first three columns of Table 3 show the values of each term by integrating the different objectives for each combination of sigma values. The last two columns show the variation percentage between sigma cases $(0.5,0.5)$ and $(0,1)$ and sigma case $(1,0)$, which represents the most widely OPP objective reported in the literature. By this analysis, the decision maker can observe how the balanced scenario reports a decrease of $-1.48 \%$ in profits at the expense of an increase of $2.68 \%$ in the average freshness per line. It is also possible to get information about the behaviour of each cost.

Furthermore, the resulting value of the different decision variables will allow managers to perform a profound analysis. This is shown by means of Table 4 which reports the information on the total orders served, the orders lines served, reserved or failed for each sigma combination, and service levels. Table 4 also reports the percentage of the total amount of orders (88 orders) and order lines (334 order lines) achieved by the solution.

The results in Table 4 show that, for this case, the model indeed tends to serve fewer order lines and full orders as the weight assigned to the freshness objective increases. When comparing the balance scenario (0.5-0.5) with the prioritisation of maximising profits (1-0), we can see that the worsened total income is not marked 
Table 3: Solution comparison

\begin{tabular}{|c|c|c|c|c|c|c|}
\hline & \multicolumn{3}{|c|}{ Sigma case $\left(\sigma_{1}, \sigma_{2}\right)$} & \multicolumn{2}{|c|}{$\%$ Var. vs Sigma $(1-0)$} \\
\hline & & $(1-0)$ & $(0.5-0.5)$ & $(0-1)$ & $(0.5-0.5)$ & $(0-1)$ \\
\hline \multirow[t]{3}{*}{ Incomes } & Served orders' income $(€)$ & $1,313,440$ & $1,297,031$ & $1,258,357$ & $-1.25 \%$ & $-4.19 \%$ \\
\hline & Reserved orders' income $(€)$ & 85,904 & 101,257 & 113,406 & $17.87 \%$ & $32.02 \%$ \\
\hline & Total income $(€)$ & $1,399,344$ & $1,398,288$ & $1,371,763$ & $-0.08 \%$ & $-1.97 \%$ \\
\hline \multirow[t]{7}{*}{ Costs } & Inventory holding cost $(€)$ & 97,090 & 97,374 & 104,391 & $0.29 \%$ & $7.52 \%$ \\
\hline & Transporting cost $(€)$ & 184,320 & 183,089 & 178,405 & $-0.67 \%$ & $-3.21 \%$ \\
\hline & Not accepting order line cost $(€)$ & 39,040 & 41,759 & 57,636 & $6.97 \%$ & $47.63 \%$ \\
\hline & Partial order penalization $(€)$ & 56,998 & 65,894 & 72,684 & $15.61 \%$ & $27.52 \%$ \\
\hline & Garbage cost $(€)$ & 14,128 & 14,128 & 14,128 & $0.00 \%$ & $0.00 \%$ \\
\hline & Expiring cost $(€)$ & 67,280 & 69,461 & 75,466 & $3.24 \%$ & $12.17 \%$ \\
\hline & Total cost $(€)$ & 458,855 & 471,703 & 502,710 & $2.80 \%$ & $9.56 \%$ \\
\hline \multirow[t]{2}{*}{ Objectives } & Total profits $(€)$ & 940,490 & 926,585 & 869,053 & $-1.48 \%$ & $-7.60 \%$ \\
\hline & Average freshness (\% RSL) & 0.498 & 0.512 & 0.517 & $2.68 \%$ & $3.73 \%$ \\
\hline
\end{tabular}

Table 4: Comparison of service levels

\begin{tabular}{|l|c|c|c|c|c|c|}
\cline { 2 - 7 } \multicolumn{1}{c|}{} & \multicolumn{7}{c|}{ Sigma case $\left(\sigma_{1}, \sigma_{2}\right)$} \\
\cline { 2 - 7 } \multicolumn{1}{c|}{} & $(1-0)$ & $\%$ & $(0.5-0.5)$ & $\%$ & $(0-1)$ & $\%$ \\
\hline Orders served & 77 & $87.5 \%$ & 76 & $86.4 \%$ & 74 & $84.1 \%$ \\
\hline Order lines served & 288 & $86.2 \%$ & 284 & $85.0 \%$ & 282 & $84.4 \%$ \\
\hline Order lines reserved & 32 & $9.6 \%$ & 35 & $10.5 \%$ & 37 & $11.1 \%$ \\
\hline Order lines failed & 14 & $4.2 \%$ & 15 & $4.5 \%$ & 15 & $4.5 \%$ \\
\hline
\end{tabular}

$(-0.08 \%$, Table 3), even though fewer orders are served, but at higher prices. Therefore, decision makers can observe that the drop in total profits is explained mainly by two points (Table 3): 1) the penalty costs of not accepting order lines and the partial orders reserved increase by $6.97 \%$ and $15.6 \%$, respectively; 2) an element of particular importance for our modelling approach, which is that the expiring cost considerably increases by $3.24 \%$ (more than twice the reduction in profits as percentage).

The comparison made between the scenario in which freshness is given full priority $(0-1)$ and the other extreme scenario of maximising only profits (1-0) follows a similar behaviour to the former case. However for this last case (Table 3), the variation percentage values become higher (especially in costs), with a relatively smooth increase in freshness compared to the balanced case $(3.73 \%$ vs $2.68 \%)$, but with a more marked drop in profits $(-7.6 \%$ vs $-1.48 \%)$. The results reported in Table 3 and Table 4 show that the balanced scenario has an advantage over the other two if the decision maker aims to truly increase the freshness of the delivered product without considerably sacrificing profits. The above results show that when items are perishable, the order in which they are consumed or, equivalently, the way in which the ATP is assigned to orders, becomes an important factor to consider, especially with a rolling horizon perspective. One of the most widely used strategies are the well-known First-In-First-Out (FIFO) and Last-In-First-Out (LIFO) ones. Recently, new strategies have been defined [36] e.g., First-Expiration-First-Out (FEFO) and Last-Expiration-First-Out (LEFO), which better interpret the need 
for perishable products. Managers can use the OPP model as a suitable tool to handle these two last strategies through the weights assigned to each objective: the heavier the weight assigned to the second objective, the closer the ATP assignation policy comes to the LEFO strategy. This behaviour can be observed in Table 3 the heavier the weight of maximising freshness, the higher the expiring costs. This behaviour becomes even more pronounced with the non-price variation case.

Previous paragraphs show the usefulness of the model at the operational level. However, it can be used as a powerful decision tool at a more strategic level by guiding decisions about: the definition of strategic pricing policies to adjust the profitability goals of FSC; the time to harvest and its impact on SL and, consequently, on profitability and freshness; the prioritisation of customers according to the penalty costs assigned to their orders; the improvement of collaborative relationships with customers by anticipating orders that cannot be served in order to renegotiated them.

\section{Conclusions and future research lines}

In this research, a mixed integer linear programming model is proposed to support the OPP in FSC affected by the so-called LHP. The originality of the model lies in it considering the subtype to be a requirement in customer orders, which forces us to estimate the ATP per subtype. Another of its contributions consists in modelling the product's SL over time (freshness) and a pricing policy based on it. The model includes two conflicting objectives that represent decision makers' common goals in such supply chains; total profit and the product freshness of reserved order lines.

The numerical experiments contemplate different scenarios as regards the weight assigned to the objectives, SL length and price variation among the RSL ranges. The results validate the proposed model and its good performance for simultaneously managing homogeneity of customer requirements, the dynamic performance of product freshness, and its impact on the price charged to customers and the expired product.

The obtained results present some interesting findings for managers. As shown, the narrow the variation in price among ranges, the more marked the conflict between both objectives. Besides, considering only one of the objectives certainly worsens the results obtained in the other objective. Therefore, a balanced weight seems to perform properly. By assuming the total volume ordered by customers to be independent of price, applying high discounts in prices from one RSL range to another always lowers profits. The experiments reveal the importance of extending products' SL as much as possible to improve both objectives, and to adjust the price value within certain ranges that are not too wide to find a good combination 
that fulfils orders with the freshest product and without neglecting performance in the profits made.

Applied Mathematical Modelling 49 (2017) 255-278

\begin{tabular}{ccc}
\hline & Contents lists available at ScienceDirect \\
\hline ELSEVIER & Applied Mathematical Modelling \\
\hline
\end{tabular}

Mathematical modelling of the order-promising process for fruit supply chains considering the perishability and subtypes of products

H. Grillo ${ }^{\mathrm{a}, *}$, M.M.E. Alemany ${ }^{\mathrm{a}}$, A. Ortiz ${ }^{\mathrm{a}}$, V.S. Fuertes-Miquel ${ }^{\mathrm{b}}$

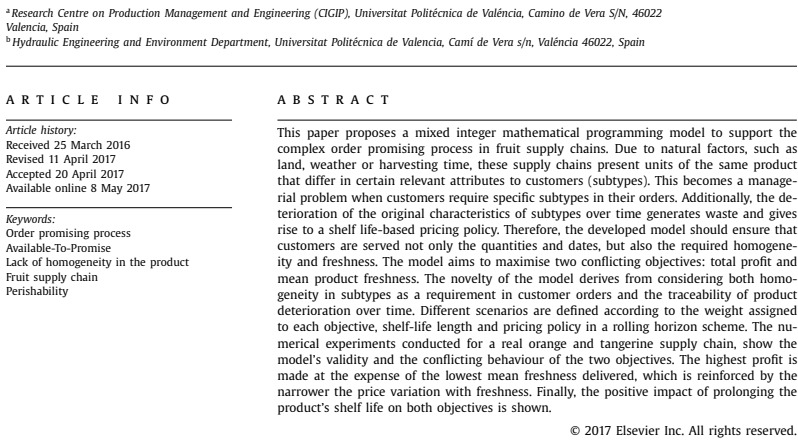

1. Introduction

Some researchers maintain that the order promising process (OPP) ${ }^{1}$ is a highly critical task that clearly impacts the customer service level [1]. Others consider it to be one of the most important processes within an organisation to increase customer satisfaction [2]. During the OPP, the role of the Available-To-Promise (ATP) function is to provide a response to customer order requests based on resource availability. Two different execution modes of assigning ATP to orders are usually - Corresponding author.

E-mail addresses: hangries@upynet.upves, hrilloe@grnailcom, grillo7@gmail.com 〈H. Grillo)

In advance, all the acronyms included in the text are summarised in Table A.1 of Appendix A.

hettp://dx.doi.org/10.1016/j.apm.2017.04.037

0307-904X/10 2017 Flsevier Inc. All rights reserved.

Figure 5: Publication data.

The computational results reveal the model's efficiency for the case under study. Since this is a multiobjective model, and as model size can exponentially grow with uncertainty modelling, increasing orders, products and the considered time periods, and alternative solution techniques, e.g., metaheuristics, can be explored. Furthermore, other more sophisticated multiobjective techniques, e.g., the epsilonconstrained method [42] that allows us to find optimal pareto solutions, can be used to assist decision makers in selecting their most preferred solution in an interactive context. As the division of MPS according to criteria of the subtypes', and 
their perishable nature in these FSC are uncertain, future research lines should be conducted to deal with this uncertainty. Finally, in order to facilitate all the analyses presented in the paper, designing a Model-Driven Decision Support System is recommended by taking this OPP model as the core. This Decision Support System will allow to cope with the real necessity of industries in an easy and user-friendly interface.

\section{Publication data}

Figure 5 shows the first page of the article published in the Applied Mathematical Modelling journal journal (ISSN: 0307-904X).

\section{Acknowledgements}

This research has been partly supported by the Ministry of Science, Technology and Telecommunications, of the government of Costa Rica (MICITT), from the Spanish "Science, Technology and Telecommunications" through the programme of innovation and human capital for competitiveness (PINN) (contract number PED-019-2015-1), and by the Spanish Ministry of Economy and Competitiveness Project 'Methods and models for operations planning and order management in supply chains characterised by uncertainty in production due to the lack of product uniformity' (PLANGES-FHP)(Ref. DPI2011-23597).

\section{Appendix A Acronyms}

Table A.1 summarises all the acronys used along the paper.

Table A.1: Acronyms

\begin{tabular}{|l|l|}
\hline Acronym & \multicolumn{1}{|c|}{ Meaning } \\
\hline ATP & Available-To-Promise \\
FEFO & First-Expiration-First-Out \\
FIFO & First-In-First-Out \\
FSC & Fruit Supply Chain \\
LEFO & Last-Expiration-First-Out \\
LHP & Lack of Homogeneity in the Product \\
LIFO & Last-In-First-Out \\
LSL & Lost Shelf Life \\
MPL & Mathematical Programming Language \\
MPS & Master Production Schedule \\
OF & Objective Function \\
OPP & Order Promising Process \\
RSL & Remaining Shelf Life \\
SC & Supply Chain \\
SL & Shelf Life \\
\hline
\end{tabular}




\section{Appendix B Description of the input data for the OPP Model}

The input data used to test the model came from a Spanish oranges and tangerines FSC. This company provided us with data about production, incoming orders, customers, costs, times and all the required parameters. This information was used as a basis to generate a complete data set for the model that is grouped in the following cathegories: products, FSC configuration, customer orders, supply and the OPP process itself.

Two products $(i)$ are contemplated (oranges and tangerines) with subtypes $(b)$ defined according to the quality level, the caliber and the packaging type (Table B.1). Four quality levels are defined: the first and second levels are used to fulfil incoming orders, the third level is the product sent to the derivatives, and the fourth level is considered waste. About 8-10\% of the incoming production lots harvested from the field are identified as non-usable for fulfilling orders, which includes products directly wasted in the classification activities and the products used for derivatives. Nine possible calibres are considered: the first four correspond to oranges, the following four for tangerines, while the last one (9) is a general calibre defined for derivatives. The SL is also shown in Table B.1 for three diffent cases: short, normal and long. The normal case coincided with that provided by the FSC under study. The short and long cases were obtained by cutting and increasing the SL of the normal case by 2 days, respectively.

Table B.1: Products, subtypes and shelf-life values

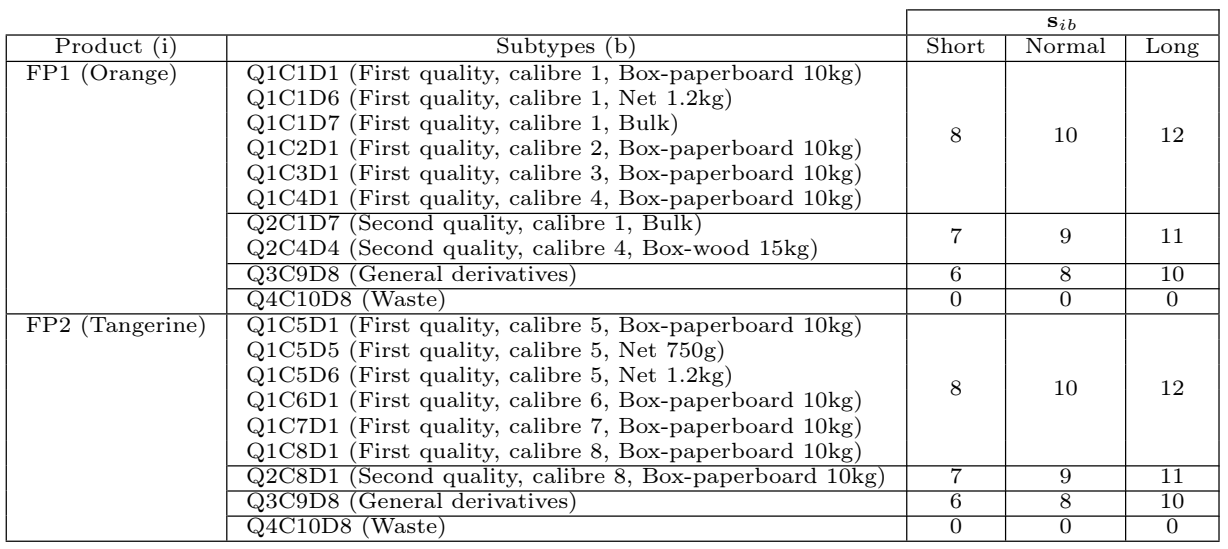

Table B.2 shows the inventory holding cost for each subtype. Table B.3 Table B.6 show the model's parameters: $\boldsymbol{\omega}_{i b}^{p}, \boldsymbol{\nu}_{i}, \boldsymbol{\phi}_{i b}^{r}$ and $\boldsymbol{\vartheta}_{i}$. With $\boldsymbol{\phi}_{i b}^{r}$, four price ranges $(r)$ are considered according to the FSC's pricing policy. Table B.6 shows the 
price ranges definition based on the RSL for each of them. We assumed the same percentages for all subtypes $b$ and products $i$. Three different scenarios for price range variation (Table B.7) were considered: None, Low and High. For the "None" case, the price (R1) remained constant for all the freshness ranges. For the "Low" case, a smooth reduction of $10 \%$ as regards the price for the freshest range (R1) was considered each time; i.e., $\mathrm{R} 2=0.9^{*} \mathrm{R} 1, \mathrm{R} 3=0.8^{*} \mathrm{R} 1, \mathrm{R} 4=0.7^{*} \mathrm{R} 1$. For the "High" case, the variation was established following the rule $\mathrm{R} 2=0.7^{*} \mathrm{R} 1, \mathrm{R} 3=$ $0.5^{*} \mathrm{R} 1$, and finally $\mathrm{R} 4=0.3^{*} \mathrm{R} 1$.

Table B.2: Inventory holding cost

\begin{tabular}{|c|c|c|c|c|c|c|c|}
\hline$(p)$ & $(i)$ & $(b)$ & $\mathbf{h}_{i b}^{p(*)}$ & $(p)$ & $(i)$ & $(b)$ & $\mathbf{h}_{i b}^{p(*)}$ \\
\hline \multirow[t]{15}{*}{$\mathrm{P} 1$} & FP1 & Q1C1D1 & 0.018 & P2 & FP1 & Q1C1D1 & 0.0270 \\
\hline & & Q1C1D6 & 0.018 & & & Q1C1D6 & 0.0270 \\
\hline & & Q1C1D7 & 0.017 & & & Q1C1D7 & 0.0255 \\
\hline & & $\mathrm{Q} 1 \mathrm{C} 2 \mathrm{D} 1$ & 0.017 & & & Q1C2D1 & 0.0255 \\
\hline & & Q1C3D1 & 0.016 & & & Q1C3D1 & 0.0240 \\
\hline & & Q1C4D1 & 0.015 & & & Q1C4D1 & 0.0225 \\
\hline & & Q2C1D7 & 0.014 & & & Q2C1D7 & 0.0210 \\
\hline & & Q2C4D4 & 0.014 & & & Q2C4D4 & 0.0210 \\
\hline & FP2 & Q1C5D5 & 0.018 & & FP2 & Q1C5D5 & 0.0270 \\
\hline & & Q1C5D1 & 0.018 & & & Q1C5D1 & 0.0270 \\
\hline & & Q1C5D6 & 0.019 & & & Q1C5D6 & 0.0285 \\
\hline & & Q1C6D1 & 0.017 & & & Q1C6D1 & 0.0255 \\
\hline & & Q1C7D1 & 0.016 & & & Q1C7D1 & 0.0240 \\
\hline & & Q1C8D1 & 0.015 & & & Q1C8D1 & 0.0225 \\
\hline & & Q2C8D1 & 0.012 & & & Q2C8D1 & 0.0180 \\
\hline
\end{tabular}

As regards the FSC configuration, the existence of two packing plants is assumed from which orders are transported to customers incurring in a transportation time and cost. Transport data are presented in Table B.8.

Each customer usually places four orders a week. The due date $\left(\mathbf{d}^{o}\right)$ of each order usually occurs 4-5 days after the arrival date. Customer orders are integrated by several order lines that randomly vary between 1 and 10 . The due date of each order is defined randomly in the planning horizon of each execution.. The sum of the subtypes requested in all the lines in the same order is usually around 30 pallets, which represents an average real value for the FSC under study. The configuration of these 30 pallets, in terms of the requested subtypes, is based on samples of real orders. Following this procedure, eighty-eight orders were generated and distributed (arrival and due dates) throughout the planning horizon and during each execution (Table B.9.

The initial supply quantities to be promised derived from the $\operatorname{MPS}\left(\mathbf{m}_{i}^{p h t}\right)$ can be consulted in Table B.10. Harvesting time $(h)$ can take negative values because it is assumed that the initial stock is harvested before the first planning horizon period (see Subsection 4.3, Eq. (30), for updating index $h$, which can lead to 
Table B.3: Expired product cost

\begin{tabular}{|c|c|c|c|c|c|c|c|}
\hline$(p)$ & $(i)$ & (b) & $\boldsymbol{\omega}_{i b}^{p}(€ / k g)$ & $(p)$ & (i) & (b) & $\boldsymbol{\omega}_{i b}^{p}(€ / k g)$ \\
\hline \multirow[t]{19}{*}{$\mathrm{P} 1$} & FP1 & Q1C1D1 & 0.322 & $\mathrm{P} 2$ & FP1 & Q1C1D1 & 0.290 \\
\hline & & Q1C1D6 & 0.322 & & & Q1C1D6 & 0.290 \\
\hline & & Q1C1D7 & 0.322 & & & Q1C1D7 & 0.290 \\
\hline & & Q1C2D1 & 0.322 & & & Q1C2D1 & 0.290 \\
\hline & & Q1C3D1 & 0.322 & & & Q1C3D1 & 0.290 \\
\hline & & Q1C4D1 & 0.322 & & & Q1C4D1 & 0.290 \\
\hline & & Q2C1D7 & 0.322 & & & Q2C1D7 & 0.290 \\
\hline & & Q2C4D4 & 0.322 & & & Q2C4D4 & 0.290 \\
\hline & & Q3C9D8 & 0.322 & & & Q3C9D8 & 0.290 \\
\hline & & Q4C9D9 & 0.322 & & & Q4C9D9 & 0.290 \\
\hline & FP2 & Q1C5D1 & 0.327 & & FP2 & Q1C5D1 & 0.294 \\
\hline & & Q1C5D5 & 0.327 & & & Q1C5D5 & 0.294 \\
\hline & & Q1C5D6 & 0.327 & & & Q1C5D6 & 0.294 \\
\hline & & Q1C6D1 & 0.327 & & & Q1C6D1 & 0.294 \\
\hline & & Q1C7D1 & 0.327 & & & Q1C7D1 & 0.294 \\
\hline & & Q1C8D1 & 0.327 & & & Q1C8D1 & 0.294 \\
\hline & & Q2C8D1 & 0.327 & & & Q2C8D1 & 0.294 \\
\hline & & Q3C9D8 & 0.327 & & & Q3C9D8 & 0.294 \\
\hline & & Q4C9D9 & 0.327 & & & Q4C9D9 & 0.294 \\
\hline
\end{tabular}

Table B.4: Selling price to derivatives

\begin{tabular}{|cc|}
\hline$(i)$ & $\boldsymbol{\nu}_{i}(€ / k g)$ \\
\hline FP1 & 0.114 \\
FP2 & 0.114 \\
\hline
\end{tabular}

Table B.5: Cost of rubbish

\begin{tabular}{|cc|}
\hline$(i)$ & $\boldsymbol{\vartheta}_{i}(€ / k g)$ \\
\hline FP1 & 0.217 \\
FP2 & 0.220 \\
\hline
\end{tabular}

Table B.6: Minimum percentage of RSL

\begin{tabular}{|cc|}
\hline$(r)$ & $\phi_{i b}^{r}(\%)$ \\
\hline R1 & $60 \%$ \\
R2 & $40 \%$ \\
R3 & $20 \%$ \\
R4 & $10 \%$ \\
\hline
\end{tabular}


Table B.7: Price variation scenarios

\begin{tabular}{|c|c|c|c|c|c|c|c|c|c|c|c|}
\hline \multirow{2}{*}{$(r)$} & \multirow{2}{*}{ (i) } & \multirow{2}{*}{ (b) } & \multicolumn{3}{|c|}{$\varphi_{i b}^{r}$} & \multirow{2}{*}{$(r)$} & \multirow{2}{*}{ (i) } & \multirow{2}{*}{ (b) } & \multicolumn{3}{|c|}{$\varphi_{i b}^{r}$} \\
\hline & & & None & Low & High & & & & None & Low & High \\
\hline \multirow[t]{15}{*}{$\mathrm{R} 1$} & \multirow[t]{8}{*}{ FP1 } & Q1C1D1 & 1.19 & 1.19 & 1.19 & \multirow[t]{15}{*}{ R3 } & \multirow[t]{8}{*}{ FP1 } & Q1C1D1 & 1.19 & 0.952 & 0.595 \\
\hline & & Q1C1D6 & 1.17 & 1.17 & 1.17 & & & Q1C1D6 & 1.17 & 0.936 & 0.585 \\
\hline & & Q1C1D7 & 1.15 & 1.15 & 1.15 & & & Q1C1D7 & 1.15 & 0.92 & 0.575 \\
\hline & & Q1C2D1 & 1.13 & 1.13 & 1.13 & & & $\mathrm{Q} 1 \mathrm{C} 2 \mathrm{D} 1$ & 1.13 & 0.904 & 0.565 \\
\hline & & Q1C3D1 & 1.07 & 1.07 & 1.07 & & & Q1C3D1 & 1.07 & 0.856 & 0.535 \\
\hline & & Q1C4D1 & 1.01 & 1.01 & 1.01 & & & Q1C4D1 & 1.01 & 0.808 & 0.505 \\
\hline & & $\mathrm{Q} 2 \mathrm{C} 1 \mathrm{D} 7$ & 0.92 & 0.92 & 0.92 & & & $\mathrm{Q} 2 \mathrm{C} 1 \mathrm{D} 7$ & 0.92 & 0.736 & 0.46 \\
\hline & & Q2C4D4 & 0.95 & 0.95 & 0.95 & & & $\mathrm{Q} 2 \mathrm{C} 4 \mathrm{D} 4$ & 0.95 & 0.76 & 0.475 \\
\hline & \multirow[t]{7}{*}{ FP2 } & Q1C5D5 & 1.21 & 1.21 & 1.21 & & \multirow[t]{7}{*}{ FP2 } & Q1C5D5 & 1.21 & 0.968 & 0.605 \\
\hline & & Q1C5D1 & 1.18 & 1.18 & 1.18 & & & Q1C5D1 & 1.18 & 0.944 & 0.59 \\
\hline & & Q1C5D6 & 1.24 & 1.24 & 1.24 & & & Q1C5D6 & 1.24 & 0.992 & 0.62 \\
\hline & & Q1C6D1 & 1.12 & 1.12 & 1.12 & & & Q1C6D1 & 1.12 & 0.896 & 0.56 \\
\hline & & Q1C7D1 & 1.06 & 1.06 & 1.06 & & & Q1C7D1 & 1.06 & 0.848 & 0.53 \\
\hline & & Q1C8D1 & 1.01 & 1.01 & 1.01 & & & Q1C8D1 & 1.01 & 0.808 & 0.505 \\
\hline & & Q2C8D1 & 0.81 & 0.81 & 0.81 & & & Q2C8D1 & 0.81 & 0.648 & 0.405 \\
\hline \multirow[t]{15}{*}{$\mathrm{R} 2$} & \multirow[t]{8}{*}{ FP1 } & Q1C1D1 & 1.19 & 1.071 & 0.833 & \multirow[t]{15}{*}{$\mathrm{R} 4$} & \multirow[t]{8}{*}{ FP1 } & Q1C1D1 & 1.19 & 0.833 & 0.357 \\
\hline & & Q1C1D6 & 1.17 & 1.053 & 0.819 & & & Q1C1D6 & 1.17 & 0.819 & 0.351 \\
\hline & & Q1C1D7 & 1.15 & 1.035 & 0.805 & & & Q1C1D7 & 1.15 & 0.805 & 0.345 \\
\hline & & $\mathrm{Q} 1 \mathrm{C} 2 \mathrm{D} 1$ & 1.13 & 1.017 & 0.791 & & & Q1C2D1 & 1.13 & 0.791 & 0.339 \\
\hline & & Q1C3D1 & 1.07 & 0.963 & 0.749 & & & Q1C3D1 & 1.07 & 0.749 & 0.321 \\
\hline & & Q1C4D1 & 1.01 & 0.909 & 0.707 & & & Q1C4D1 & 1.01 & 0.707 & 0.303 \\
\hline & & $\mathrm{Q} 2 \mathrm{C} 1 \mathrm{D} 7$ & 0.92 & 0.828 & 0.644 & & & $\mathrm{Q} 2 \mathrm{C} 1 \mathrm{D} 7$ & 0.92 & 0.644 & 0.276 \\
\hline & & Q2C4D4 & 0.95 & 0.855 & 0.665 & & & Q2C4D4 & 0.95 & 0.665 & 0.285 \\
\hline & \multirow[t]{7}{*}{ FP2 } & Q1C5D5 & 1.21 & 1.089 & 0.847 & & \multirow[t]{7}{*}{ FP2 } & Q1C5D5 & 1.21 & 0.847 & 0.363 \\
\hline & & Q1C5D1 & 1.18 & 1.062 & 0.826 & & & Q1C5D1 & 1.18 & 0.826 & 0.354 \\
\hline & & Q1C5D6 & 1.24 & 1.116 & 0.868 & & & Q1C5D6 & 1.24 & 0.868 & 0.372 \\
\hline & & Q1C6D1 & 1.12 & 1.008 & 0.784 & & & Q1C6D1 & 1.12 & 0.784 & 0.336 \\
\hline & & Q1C7D1 & 1.06 & 0.954 & 0.742 & & & Q1C7D1 & 1.06 & 0.742 & 0.318 \\
\hline & & Q1C8D1 & 1.01 & 0.909 & 0.707 & & & Q1C8D1 & 1.01 & 0.707 & 0.303 \\
\hline & & $\mathrm{Q} 2 \mathrm{C} 8 \mathrm{D} 1$ & 0.81 & 0.729 & 0.567 & & & Q2C8D1 & 0.81 & 0.567 & 0.243 \\
\hline
\end{tabular}


Table B.8: Transport data

\begin{tabular}{|c|c|c|c|c|c|c|c|c|c|c|c|c|}
\hline Packing plant & $(o)$ & $\mathbf{t}_{i b}^{o p}$ & $f^{o p}$ & $(o)$ & $\mathbf{t}_{i b}^{o p}$ & $\mathbf{f}^{o p}$ & $(o)$ & $\mathbf{t}_{i b}^{o p}$ & $f^{o p}$ & $(o)$ & $f^{o p}$ & $f^{o p}$ \\
\hline \multirow[t]{22}{*}{$\mathrm{P} 1$} & O1 & 0.1 & 1 & $\mathrm{O} 23$ & 0.1 & 1 & O45 & 0.1 & 1 & O67 & 0.1 & 1 \\
\hline & $\mathrm{O} 2$ & 0.1 & 1 & $\mathrm{O} 24$ & 0.1 & 1 & O46 & 0.1 & 1 & O68 & 0.1 & 1 \\
\hline & O3 & 0.1 & 1 & O25 & 0.1 & 1 & O 47 & 0.1 & 1 & O69 & 0.1 & 1 \\
\hline & O4 & 0.15 & 2 & O26 & 0.15 & 2 & $\mathrm{O} 48$ & 0.15 & 2 & O70 & 0.15 & 2 \\
\hline & O5 & 0.1 & 1 & $\mathrm{O} 27$ & 0.1 & 1 & O49 & 0.1 & 1 & O71 & 0.1 & 1 \\
\hline & O6 & 0.15 & 2 & $\mathrm{O} 28$ & 0.15 & 2 & O50 & 0.15 & 2 & O72 & 0.15 & 2 \\
\hline & O7 & 0.15 & 2 & O29 & 0.15 & 2 & O51 & 0.15 & 2 & O73 & 0.15 & 2 \\
\hline & O8 & 0.15 & 2 & O30 & 0.15 & 2 & O52 & 0.15 & 2 & O74 & 0.15 & 2 \\
\hline & O9 & 0.1 & 1 & O31 & 0.1 & 1 & O53 & 0.1 & 1 & O75 & 0.1 & 1 \\
\hline & O10 & 0.15 & 2 & $\mathrm{O} 32$ & 0.15 & 2 & O54 & 0.15 & 2 & O76 & 0.15 & 2 \\
\hline & O11 & 0.15 & 2 & O33 & 0.15 & 2 & O55 & 0.15 & 2 & O77 & 0.15 & 2 \\
\hline & $\mathrm{O} 12$ & 0.1 & 1 & O34 & 0.1 & 1 & O56 & 0.1 & 1 & O78 & 0.1 & 1 \\
\hline & $\mathrm{O} 13$ & 0.15 & 2 & O35 & 0.15 & 2 & O57 & 0.15 & 2 & O79 & 0.15 & 2 \\
\hline & O14 & 0.15 & 2 & O36 & 0.15 & 2 & O58 & 0.15 & 2 & O 80 & 0.15 & 2 \\
\hline & $\mathrm{O} 15$ & 0.15 & 2 & O37 & 0.15 & 2 & O59 & 0.15 & 2 & O81 & 0.15 & 2 \\
\hline & O16 & 0.15 & 2 & O38 & 0.15 & 2 & O60 & 0.15 & 2 & O 82 & 0.15 & 2 \\
\hline & $\mathrm{O} 17$ & 0.15 & 2 & O39 & 0.15 & 2 & O61 & 0.15 & 2 & O83 & 0.15 & 2 \\
\hline & $\mathrm{O} 18$ & 0.15 & 2 & O40 & 0.15 & 2 & O62 & 0.15 & 2 & O84 & 0.15 & 2 \\
\hline & O19 & 0.15 & 2 & O41 & 0.15 & 2 & O63 & 0.15 & 2 & O85 & 0.15 & 2 \\
\hline & $\mathrm{O} 20$ & 0.15 & 2 & $\mathrm{O} 42$ & 0.15 & 2 & O64 & 0.15 & 2 & O86 & 0.15 & 2 \\
\hline & $\mathrm{O} 21$ & 0.15 & 2 & O43 & 0.15 & 2 & O65 & 0.15 & 2 & O87 & 0.15 & 2 \\
\hline & $\mathrm{O} 22$ & 0.15 & 2 & O44 & 0.15 & 2 & O66 & 0.15 & 2 & O88 & 0.15 & 2 \\
\hline \multirow[t]{22}{*}{$\mathrm{P} 2$} & O1 & 0.195 & 2 & $\mathrm{O} 23$ & 0.195 & 2 & $\mathrm{O} 45$ & 0.195 & 2 & O67 & 0.195 & 2 \\
\hline & $\mathrm{O} 2$ & 0.195 & 2 & $\mathrm{O} 24$ & 0.195 & 2 & O46 & 0.195 & 2 & O68 & 0.195 & 2 \\
\hline & O3 & 0.195 & 2 & $\mathrm{O} 25$ & 0.195 & 2 & O47 & 0.195 & 2 & O69 & 0.195 & 2 \\
\hline & $\mathrm{O} 4$ & 0.13 & 1 & $\mathrm{O} 26$ & 0.13 & 1 & O48 & 0.13 & 1 & O70 & 0.13 & 1 \\
\hline & O5 & 0.195 & 2 & $\mathrm{O} 27$ & 0.195 & 2 & O49 & 0.195 & 2 & O71 & 0.195 & 2 \\
\hline & O6 & 0.13 & 1 & $\mathrm{O} 28$ & 0.13 & 1 & O50 & 0.13 & 1 & O72 & 0.13 & 1 \\
\hline & O7 & 0.13 & 1 & O29 & 0.13 & 1 & O51 & 0.13 & 1 & O73 & 0.13 & 1 \\
\hline & O8 & 0.13 & 1 & O30 & 0.13 & 1 & O52 & 0.13 & 1 & O74 & 0.13 & 1 \\
\hline & O9 & 0.195 & 2 & O31 & 0.195 & 2 & O53 & 0.195 & 2 & O75 & 0.195 & 2 \\
\hline & $\mathrm{O} 10$ & 0.13 & 1 & $\mathrm{O} 32$ & 0.13 & 1 & O54 & 0.13 & 1 & O76 & 0.13 & 1 \\
\hline & O11 & 0.13 & 1 & $\mathrm{O} 33$ & 0.13 & 1 & O55 & 0.13 & 1 & O77 & 0.13 & 1 \\
\hline & $\mathrm{O} 12$ & 0.195 & 2 & O34 & 0.195 & 2 & O56 & 0.195 & 2 & O78 & 0.195 & 2 \\
\hline & O13 & 0.13 & 1 & O35 & 0.13 & 1 & O57 & 0.13 & 1 & O79 & 0.13 & 1 \\
\hline & $\mathrm{O} 14$ & 0.13 & 1 & O36 & 0.13 & 1 & O58 & 0.13 & 1 & O80 & 0.13 & 1 \\
\hline & $\mathrm{O} 15$ & 0.13 & 1 & O37 & 0.13 & 1 & O59 & 0.13 & 1 & O 81 & 0.13 & 1 \\
\hline & O16 & 0.13 & 1 & O38 & 0.13 & 1 & O60 & 0.13 & 1 & O 82 & 0.13 & 1 \\
\hline & $\mathrm{O} 17$ & 0.13 & 1 & O39 & 0.13 & 1 & O61 & 0.13 & 1 & O 83 & 0.13 & 1 \\
\hline & O18 & 0.13 & 1 & O40 & 0.13 & 1 & $\mathrm{O} 62$ & 0.13 & 1 & O84 & 0.13 & 1 \\
\hline & O19 & 0.13 & 1 & O41 & 0.13 & 1 & O63 & 0.13 & 1 & O85 & 0.13 & 1 \\
\hline & O20 & 0.13 & 1 & $\mathrm{O} 42$ & 0.13 & 1 & O64 & 0.13 & 1 & O86 & 0.13 & 1 \\
\hline & O21 & 0.13 & 1 & O43 & 0.13 & 1 & O65 & 0.13 & 1 & O 87 & 0.13 & 1 \\
\hline & $\mathrm{O} 22$ & 0.13 & 1 & O44 & 0.13 & 1 & O66 & 0.13 & 1 & O88 & 0.13 & 1 \\
\hline
\end{tabular}

$\left(^{*}\right) \mathbf{t}_{i b}^{o p}$ is expressed in $\left(\frac{€}{\text { unit }}\right)$ and $\mathbf{f}^{o p}$ is expressed in days 
Table B.9: Orders

\begin{tabular}{|c|c|c|c|c|c|c|c|c|c|c|c|c|c|c|c|}
\hline$(s)$ & (o) & $\mathbf{d}^{\circ}$ & $\boldsymbol{\eta}^{\circ}$ & $(s)$ & $(o)$ & $\mathbf{d}^{\circ}$ & $\boldsymbol{\eta}^{\circ}$ & $(s)$ & $(o)$ & $\mathbf{d}^{\circ}$ & $\boldsymbol{\eta}^{\circ}$ & $(s)$ & $(o)$ & $\mathbf{d}^{\circ}$ & $\boldsymbol{\eta}^{\circ}$ \\
\hline \multirow[t]{22}{*}{ s1 } & O1 & 3 & 9 & $\mathrm{~s} 2$ & O23 & 2 & 9 & s3 & O45 & 2 & 9 & s4 & O67 & 2 & 7 \\
\hline & $\mathrm{O} 2$ & 2 & 2 & & O24 & 2 & 2 & & O46 & 2 & 2 & & O68 & 3 & 2 \\
\hline & O3 & 3 & 4 & & O25 & 2 & 1 & & $\mathrm{O} 47$ & 2 & 4 & & O69 & 3 & 1 \\
\hline & $\mathrm{O} 4$ & 4 & 1 & & O26 & 5 & 1 & & $\mathrm{O} 48$ & 3 & 1 & & O70 & 3 & 1 \\
\hline & O5 & 2 & 1 & & O 27 & 3 & 4 & & O49 & 4 & 1 & & O71 & 2 & 4 \\
\hline & O6 & 4 & 7 & & O28 & 3 & 1 & & O50 & 5 & 7 & & O72 & 4 & 1 \\
\hline & O7 & 5 & 3 & & O29 & 5 & 1 & & O51 & 5 & 3 & & O73 & 6 & 1 \\
\hline & O8 & 5 & 1 & & O30 & 5 & 6 & & O52 & 5 & 1 & & O74 & 2 & 5 \\
\hline & O9 & 2 & 1 & & O31 & 2 & 3 & & $\mathrm{O} 53$ & 3 & 1 & & O75 & 4 & 3 \\
\hline & O10 & 6 & 7 & & O32 & 5 & 6 & & O54 & 4 & 7 & & O76 & 4 & 5 \\
\hline & O11 & 6 & 6 & & O33 & 6 & 4 & & O55 & 6 & 6 & & O77 & 6 & 4 \\
\hline & $\mathrm{O} 12$ & 3 & 4 & & O34 & 2 & 5 & & O56 & 2 & 4 & & O78 & 2 & 5 \\
\hline & O13 & 5 & 6 & & O35 & 6 & 7 & & O57 & 6 & 6 & & O79 & 6 & 7 \\
\hline & O14 & 4 & 4 & & O36 & 3 & 5 & & O58 & 3 & 4 & & O80 & 3 & 5 \\
\hline & O15 & 6 & 1 & & O37 & 6 & 4 & & O59 & 6 & 1 & & O81 & 6 & 4 \\
\hline & O16 & 5 & 5 & & O38 & 3 & 1 & & O60 & 4 & 5 & & O82 & 4 & 1 \\
\hline & O17 & 4 & 3 & & O39 & 3 & 2 & & O61 & 5 & 3 & & O83 & 4 & 2 \\
\hline & O18 & 6 & 2 & & O40 & 6 & 10 & & O62 & 6 & 2 & & O84 & 6 & 8 \\
\hline & O19 & 6 & 5 & & O41 & 6 & 3 & & O63 & 6 & 5 & & O85 & 6 & 3 \\
\hline & $\mathrm{O} 20$ & 6 & 1 & & $\mathrm{O} 42$ & 6 & 4 & & O64 & 6 & 1 & & O86 & 6 & 3 \\
\hline & $\mathrm{O} 21$ & 6 & 10 & & O43 & 6 & 1 & & O65 & 6 & 9 & & O87 & 6 & 1 \\
\hline & $\mathrm{O} 22$ & 6 & 4 & & O44 & 6 & 4 & & O66 & 6 & 4 & & O88 & 6 & 4 \\
\hline
\end{tabular}

negative values). The MPS per product and time period at each packing plant was calculated according to the sum of the subtypes requested in the order lines with the same due date during each period. The total sum was set as $\mathbf{m}_{i}^{p h t} 2-3$ periods randomly before the due date in order to confer the model the possibility of taking a wide open window of time in transportation once the product is packed. To the total quantities of the MPS, an aleatory percentage of $8 \%-10 \%$ was added, which included the product directly wasted because of its quality conditions, the product intended for derivatives and a small distortion factor between $0 \%$ and $3 \%$ randomly. Beta parameters $\boldsymbol{\beta}_{i b}^{p t}$ were calculated for each subtype of a product during each period by the sum of the requested quantities of all the order lines of the same subtype, divided by the total requested quantity of the product, to ensure that $\sum_{b} \boldsymbol{\beta}_{i b}^{p t}=1$. The way described to define the MPS implicitly considers the supply that accurately adjusts to real demand in terms of not only quantities and dates, but also of homogeneity. The initial stock $\left(\mathbf{k}_{i b}^{p h}\right)$ is presented in Table B.11 It was obtained as an estimation of the amounts required to fulfil the orders of the first and second period during the first execution.

The global horizon length includes 17 periods subdivided into four OPP executions with a planning horizon of six periods each. The orders are promised twice a week, which is why the model was executed in the batch mode, by considering a 3-day batching interval. Then the orders whose arrival date fall within this interval are promised during each execution; e.g., orders accumulate from Monday to Wednesday according to their respective arrival date. Then the model is executed at the end of Wednesdays, and all the orders are inputted into the model. After- 
Table B.10: Master production schedule

\begin{tabular}{|c|c|c|c|c|c|}
\hline$(s)$ & $(p)$ & $(h)$ & $(t)$ & $(i)$ & $\mathbf{m}_{i}^{p h t}$ \\
\hline \multirow[t]{12}{*}{ s1 } & P1 & -1 & 1 & FP1 & 40037 \\
\hline & & -1 & 1 & FP2 & 30430 \\
\hline & & 1 & 2 & $\mathrm{FP} 1$ & 63226 \\
\hline & & 1 & 2 & FP2 & 27965 \\
\hline & & 2 & 3 & FP2 & 81445 \\
\hline & & 4 & 6 & FP2 & 88521 \\
\hline & P2 & 2 & 3 & FP1 & 156656 \\
\hline & & 2 & 4 & FP1 & 58912 \\
\hline & & 3 & 4 & FP2 & 68250 \\
\hline & & 3 & 5 & FP1 & 66427 \\
\hline & & 3 & 5 & FP2 & 97386 \\
\hline & & 5 & 6 & FP1 & 62560 \\
\hline \multirow[t]{10}{*}{$\mathrm{s} 2$} & P1 & 1 & 3 & FP2 & 88521 \\
\hline & & 3 & 5 & FP2 & 78880 \\
\hline & $\mathrm{P} 2$ & -1 & 1 & FP1 & 58912 \\
\hline & & -1 & 1 & FP2 & 68250 \\
\hline & & 1 & 2 & FP1 & 66427 \\
\hline & & -1 & 2 & FP2 & 97386 \\
\hline & & 1 & 3 & FP1 & 62560 \\
\hline & & 3 & 5 & FP1 & 91730 \\
\hline & & 5 & 6 & FP1 & 105275 \\
\hline & & 4 & 6 & FP2 & 48523 \\
\hline \multirow[t]{10}{*}{ s3 } & P1 & 1 & 2 & FP2 & 78880 \\
\hline & & 3 & 5 & FP1 & 82519 \\
\hline & & 5 & 6 & FP1 & 41121 \\
\hline & & 4 & 6 & FP2 & 42766 \\
\hline & $\mathrm{P} 2$ & -1 & 2 & FP1 & 91730 \\
\hline & & 2 & 3 & FP1 & 105275 \\
\hline & & 1 & 3 & FP2 & 48523 \\
\hline & & 2 & 4 & FP1 & 103669 \\
\hline & & 2 & 4 & FP2 & 75663 \\
\hline & & 4 & 5 & FP2 & 67439 \\
\hline \multirow[t]{8}{*}{ s4 } & P1 & -1 & 2 & FP1 & 82519 \\
\hline & & 2 & 3 & FP1 & 41121 \\
\hline & & 1 & 3 & FP2 & 42766 \\
\hline & & 2 & 4 & FP1 & 40299 \\
\hline & P2 & -1 & 1 & FP1 & 103669 \\
\hline & & -1 & 1 & FP2 & 75663 \\
\hline & & 1 & 2 & FP2 & 67439 \\
\hline & & 3 & 4 & FP2 & 22206 \\
\hline
\end{tabular}

Table B.11: Initial stock

\begin{tabular}{|c|c|c|c|c|}
\hline$(p)$ & (i) & (h) & (b) & $\mathbf{k}_{i b}^{p h}$ \\
\hline \multirow{14}{*}{$\mathrm{P} 1$} & FP1 & -2 & Q1C1D1 & 2500 \\
\hline & & -2 & Q1C1D6 & 8500 \\
\hline & & -2 & Q1C1D7 & 7500 \\
\hline & & -1 & $\mathrm{Q} 1 \mathrm{C} 2 \mathrm{D} 1$ & 9000 \\
\hline & & -2 & Q1C3D1 & 2500 \\
\hline & & -2 & Q1C4D1 & 733 \\
\hline & & -1 & Q2C4D4 & 7000 \\
\hline & FP2 & -2 & Q1C5D1 & 4000 \\
\hline & & -2 & Q1C5D5 & 20000 \\
\hline & & -2 & Q1C5D6 & 4000 \\
\hline & & -2 & Q1C6D1 & 1500 \\
\hline & & -2 & Q1C7D1 & 7000 \\
\hline & & -2 & Q1C8D1 & 7000 \\
\hline & & -2 & $\mathrm{Q} 2 \mathrm{C} 8 \mathrm{D} 1$ & 3000 \\
\hline \multirow[t]{15}{*}{$\mathrm{P} 2$} & FP1 & -3 & Q1C1D1 & 1300 \\
\hline & & -1 & Q1C1D6 & 7500 \\
\hline & & -3 & Q1C1D7 & 902 \\
\hline & & -3 & Q1C2D1 & 1600 \\
\hline & & -3 & Q1C3D1 & 6000 \\
\hline & & -1 & Q1C4D1 & 4000 \\
\hline & & -2 & $\mathrm{Q} 2 \mathrm{C} 4 \mathrm{D} 4$ & 2300 \\
\hline & FP2 & -1 & Q1C5D1 & 5000 \\
\hline & & -1 & Q1C5D5 & 15000 \\
\hline & & -2 & Q1C5D5 & 13000 \\
\hline & & -1 & Q1C7D1 & 3000 \\
\hline & & -1 & Q1C5D6 & 3800 \\
\hline & & -1 & Q1C6D1 & 1500 \\
\hline & & -1 & $\mathrm{Q} 1 \mathrm{C} 8 \mathrm{D} 1$ & 6800 \\
\hline & & -1 & $\mathrm{Q} 2 \mathrm{C} 8 \mathrm{D} 1$ & 2300 \\
\hline
\end{tabular}


wards, incoming orders re-accumulate from Thursday to Saturday, and the model is re-run at the end of Saturdays. The company does not work on Sundays. The cycle starts again every Monday. Therefore the model is executed 4 times during periods 1 (Monday), 4 (Thursday), 8 (Monday) and 11 (Thursday) by simulating real dynamics. The non-accepting cost of each order line $\mathbf{n}_{i b}^{o}$ was obtained as $50 \%$ of the maximum income generated for the order line if served within the first price range. Finally, the penalty cost of serving the order partially $\mathbf{x}^{o}$ was obtained as $40 \%$ of the total income of the order, if it was fully served with all its lines and within the first price range.

\section{Bibliography}

[1] B. Fleischmann and H. Meyr. "Planning hierarchy, modeling and advanced planning systems". In: Handbooks in operations research and management science 11 (2003), pp. 455523. DOI: 10.1016/S0927-0507(03)11009-2

[2] U. Okongwu, M. Lauras, L. Dupont, and V. Humez. "A decision support system for optimising the order fulfilment process". In: Production Planning \&6 Control 23.8 (2011), pp. 581-598. DOI: $10.1080 / 09537287.2011 .566230$

[3] M. O. Ball, C.-Y. Chen, and Z.-Y. Zhao. "Available to Promise". In: Handbook of Quantitative Supply Chain Analysis: Modeling in the E-Business Era. Ed. by D. Simchi-Levi, S. D. Wu, and Z.-J. Shen. Boston, MA: Springer US, 2004, pp. 447-483. DOI: 10.1007/9781-4020-7953-5_11

[4] M. M. E. Alemany, A. Ortiz, A. Boza, and V. S. Fuertes-Miquel. "A model driven decision support system for reallocation of supply to orders under uncertainty in ceramic companies". In: Technological and Economic Development of Economy 21.4 (2015), pp. 596-625. DOI: $10.3846 / 20294913.2015 .1055613$

[5] P. Amorim, H. O. Gunther, and B. Almada-Lobo. "Multi-objective integrated production and distribution planning of perishable products". In: International Journal of Production Economics 138.1 (2012), pp. 89-101. DOI: 10.1016/j.ijpe.2012.03.005.

[6] S. Nahmias. "Perishable inventory theory: A review". In: Operations research 30.4 (1982), pp. 680-708. DOI: $10.1287 /$ opre.30.4.680

[7] O. Ahumada and J. R. Villalobos. "Operational model for planning the harvest and distribution of perishable agricultural products". In: International Journal of Production Economics 133.2 (2011), pp. 677-687. DOI: 10.1016/j.ijpe.2011.05.015

[8] Y. Qin, J. Wang, and C. Wei. "Joint pricing and inventory control for fresh produce and foods with quality and physical quantity deteriorating simultaneously". In: International Journal of Production Economics 152 (2014), pp. 42-48. DOI: 10.1016/j.ijpe.2014.01. 005 .

[9] A. Blanco, G. Masini, N. Petracci, and J. Bandoni. "Operations management of a packaging plant in the fruit industry". In: Journal of Food Engineering 70.3 (2005), pp. 299-307. DOI: $10.1016 / j \cdot j$ foodeng. 2004.05.075

[10] A. Chaudhuri, I. Dukovska-Popovska, C. M. Damgaard, and H.-H. Hvolby. "Supply uncertainty in food processing supply chain: sources and coping strategies". In: IFIP International Conference on Advances in Production Management Systems. Springer, 2014, pp. 183-191. DOI: 10.1007/978-3-662-44733-8_23

[11] M. Yu and A. Nagurney. "Competitive food supply chain networks with application to fresh produce". In: European Journal of Operational Research 224.2 (2013), pp. 273-282. DOI: $10.1016 / \mathrm{j}$. ejor.2012.07.033 
[12] M. Kärkkäinen. "Increasing efficiency in the supply chain for short shelf life goods using RFID tagging". In: International Journal of Retail \& Distribution Management 31.10 (2003), pp. 529-536. DOI: 10.1108/09590550310497058

[13] H. Grillo, M. M. E. Alemany, and A. Ortiz. "A review of mathematical models for supporting the order promising process under Lack of Homogeneity in Product and other sources of uncertainty". In: Computers 83 Industrial Engineering 91 (2016), pp. 239-261. DOI: $10.1016 /$ j.cie.2015.11.013

[14] F. Alarcón, M. M. E. Alemany, F. C. Lario, and R. F. Oltra. "The lack of homogeneity in the product (LHP) in the ceramic tile industry and its impact on the reallocation of inventories". In: Boletin De La Sociedad Espanola De Ceramica Y Vidrio 50.1 (2011), pp. 49-57. DOI: $10.3989 /$ cyv.072011

[15] O. A. Kilic, D. P. van Donk, J. Wijngaard, and S. A. Tarim. "Order acceptance in food processing systems with random raw material requirements". In: Or Spectrum 32.4 (2010), pp. 905-925. DOI: $10.1007 / \mathrm{s} 00291-010-0213-4$

[16] M. M. E. Alemany, F. C. Lario, A. Ortiz, and F. Gomez. "Available-To-Promise modeling for multi-plant manufacturing characterized by lack of homogeneity in the product: An illustration of a ceramic case". In: Applied Mathematical Modelling 37.5 (2013), pp. 33803398. DOI: $10.1016 / \mathrm{j}$.apm.2012.07.022

[17] M. M. E. Alemany, H. Grillo, A. Ortiz, and V. S. Fuertes-Miquel. "A fuzzy model for shortage planning under uncertainty due to lack of homogeneity in planned production lots". In: Applied Mathematical Modelling 39.15 (2015), pp. 4463-4481. DOI: 10.1016/j . apm.2014.12.057

[18] W. E. Soto-Silva, E. Nadal-Roig, M. C. González-Araya, and L. M. Pla-Aragones. "Operational research models applied to the fresh fruit supply chain". In: European Journal of Operational Research 251.2 (2016), pp. 345-355. DOI: 10.1016/j.ejor.2015.08.046

[19] R. Akkerman, P. Farahani, and M. Grunow. "Quality, safety and sustainability in food distribution: a review of quantitative operations management approaches and challenges". In: Or Spectrum 32.4 (2010), pp. 863-904. Dor: 10.1007/s00291-010-0223-2

[20] O. Ahumada and J. R. Villalobos. "Application of planning models in the agri-food supply chain: A review". In: European Journal of Operational Research 196.1 (2009), pp. 1-20. DOI: $10.1016 / \mathrm{j} \cdot$ ejor. 2008.02 .014

[21] M. Bakker, J. Riezebos, and R. H. Teunter. "Review of inventory systems with deterioration since 2001". In: European Journal of Operational Research 221.2 (2012), pp. 275-284. DOI: $10.1016 /$ j.ejor.2012.03.004

[22] R. K. Ahuja, W. Huang, H. E. Romeijn, and D. R. Morales. "A heuristic approach to the multi-period single-sourcing problem with production and inventory capacities and perishability constraints". In: INFORMS journal on Computing 19.1 (2007), pp. 14-26. DOI: $10.1287 /$ ijoc. 1050.0151

[23] S. D. Ekşioğlu and M. Jin. "Cross-facility production and transportation planning problem with perishable inventory". In: International Conference on Computational Science and Its Applications. Springer, 2006, pp. 708-717. DoI: 10.1007/11751595_75.

[24] G. Zhang, W. Habenicht, and W. E. L. Spieß. "Improving the structure of deep frozen and chilled food chain with tabu search procedure". In: Journal of Food Engineering 60.1 (2003), pp. 67-79. DOI: 10.1016/S0260-8774(03)00019-0

[25] A. Rong, R. Akkerman, and M. Grunow. "An optimization approach for managing fresh food quality throughout the supply chain". In: International Journal of Production Economics. 131.1 (2011), pp. 421-429. DOI: 10.1016/j.ijpe.2009.11.026

[26] A. Nagurney, A. H. Masoumi, and M. Yu. "Supply chain network operations management of a blood banking system with cost and risk minimization". In: Computational Management Science 9.2 (2012), pp. 205-231. DOI: 10.1007/s10287-011-0133-z. 
[27] A. Nagurney and A. H. Masoumi. "Supply chain network design of a sustainable blood banking system". In: Sustainable supply chains. Springer, 2012, pp. 49-72. DoI: 10.1007/ 978-1-4419-6105-1_5

[28] P. Amorim, C. H. Antunes, and B. Almada-Lobo. "Multi-objective lot-sizing and scheduling dealing with perishability issues". In: Industrial \& Engineering Chemistry Research 50.6 (2011), pp. 3371-3381. DOI: 10.1021/ie101645h

[29] P. Farahani, M. Grunow, and H. O. Guenther. "Integrated production and distribution planning for perishable food products". In: Flexible Services and Manufacturing Journal 24.1 (2012), pp. 28-51. DOI: $10.1007 /$ s10696-011-9125-0

[30] Z. Firoozi, N. Ismail, S. Ariafar, S. H. Tang, M. Ariffin, and A. Memariani. "Distribution network design for fixed lifetime perishable products: A model and solution approach". In: Journal of Applied Mathematics (2013), p. 13. DOI: 10.1155/2013/891409

[31] P. Amorim, E. Curcio, B. Almada-Lobo, A. P. Barbosa-Póvoa, and I. E. Grossmann. "Supplier selection in the processed food industry under uncertainty". In: European Journal of Operational Research 252.3 (2016), pp. 801-814. Dor: 10.1016/j.ejor.2016.02.005

[32] W. A. Rijpkema, E. M. T. Hendrix, R. Rossi, and J. van der Vorst. "Application of stochastic programming to reduce uncertainty in quality-based supply planning of slaughterhouses". In: Annals of Operations Research 239.2 (2016), pp. 613-624. Dor: 10.1007/ s10479-013-1460-y

[33] S. K. Goyal and B. C. Giri. "Recent trends in modeling of deteriorating inventory". In: European Journal of operational research 134.1 (2001), pp. 1-16. DOI: 10.1016/S03772217(00) 00248-4

[34] Y.-C. Tsao and G.-J. Sheen. "Dynamic pricing, promotion and replenishment policies for a deteriorating item under permissible delay in payments". In: Computers \& Operations Research. Part Special Issue: Topics in Real-time Supply Chain Management 35.11 (2008), pp. 3562-3580. DOI: $10.1016 / \mathrm{j}$.cor.2007.01.024

[35] M. Rahdar and A. S. Nookabadi. "Coordination mechanism for a deteriorating item in a two-level supply chain system". In: Applied Mathematical Modelling 38.11 (2014), pp. 2884 2900. DOI: $10.1016 / \mathrm{j} . \mathrm{apm} .2013 .11 .019$

[36] M. Önal, H. E. Romeijn, A. Sapra, and W. Van den Heuvel. "The economic lot-sizing problem with perishable items and consumption order preference". In: European Journal of Operational Research 244.3 (2015), pp. 881-891. Dor: 10.1016/j.ejor.2015.02.021

[37] S. S. Ali, J. Madaan, F. T. Chan, and S. Kannan. "Inventory management of perishable products: a time decay linked logistic approach". In: International Journal of Production Research 51.13 (2013), pp. 3864-3879. DOI: 10.1080/00207543.2012.752587

[38] L. C. Coelho and G. Laporte. "Optimal joint replenishment, delivery and inventory management policies for perishable products". In: Computers \& O Operations Research 47 (2014), pp. 42-52. DOI: $10.1016 / \mathrm{j}$.cor.2014.01.013

[39] Q. L. Duan and T. W. Liao. "A new age-based replenishment policy for supply chain inventory optimization of highly perishable products". In: International Journal of Production Economics 145.2 (2013), pp. 658-671. DOI: 10.1016/j.ijpe.2013.05.020

[40] R. Haijema. "A new class of stock-level dependent ordering policies for perishables with a short maximum shelf life". In: International Journal of Production Economics 143.2 (2013), pp. 434-439. DOI: 10.1016/j.ijpe.2011.05.021

[41] B. Kristjansson and D. Lee. "The MPL modeling system". In: Modeling languages in mathematical optimization. Springer, 2004, pp. 239-266.

[42] G. Mavrotas. "Effective implementation of the e-constraint method in multi-objective mathematical programming problems". In: Applied mathematics and computation 213.2 (2009), pp. 455-465. DOI: $10.1016 /$ j.amc.2009.03.037 


\title{
Chapter VII
}

\section{Compositions of possibilistic variables and state functions: application to an order promising model for perishables}

\begin{abstract}
In this paper we propose the concepts of composition of possibilistic variables and state functions. While in conventional compositional data analysis, the interdependent components of a deterministic vector must add up to a specific quantity, we consider such components as possibilistic variables. The concept of state function is intended to describe the state of a dynamic variable over the time. If a state function is use to model decay in time, it is called ageing function. We present a practical implementation of our concepts through the development of a model for a supply chain planning problem, specifically the order promising process for perishables. We use the composition of possibilistic variables to model the existence of different nonhomogeneous products in a lot (sublots with lack of homogeneity in the product), and the ageing function to establish a shelf life-based pricing policy. To maintain a reasonable complexity and computational efficiency, we propose the procedure to obtain an equivalent interval representation based on $\alpha$-cuts, allowing to include both tools by means of linear mathematical programming. Practical experiments were conducted based on data of a Spanish supply chain dedicated to pack and distribute oranges and tangerines. The results validated the functionality of both, the compositions of possibilistic variables and ageing func-
\end{abstract}


tions, showing also a very good performance in terms of the interpretation of a real problem with a good computational performance.

Keywords: Composition of Possibilistic Variables, State Function, Ageing Function, Order Promising Process, Perishability, Lack of Homogeneity in The Product, Uncertainty.

\section{Introduction}

There are many situations in mathematical modelling when is necessary to consider interdependent data, i.e., where the variables or the restrictions are not free to behave themselves without having a direct impact on each other. One example of such interdependence is the well-known case where the components should add up to the total amount of a variable, representing for example a raw material or a finished product. Cases of this situation are the distribution of the components in the chemical 11 or food 2] industries, or the consistency of the components of determined material in the metallurgic industry [3] that generate different grades of it. If we analyse this situation in the industry of perishables, it is common to have different "versions" of the same product in the same lot (for instance, different size, different weight, colour, etc.) but all of the subgroups must add up to the total quantity of the lot.

In the area of mathematical modelling of supply chain planning problems 4,5$]$, one can find several situations where determined quantities of products and/or raw materials must be subdivided according to their components. We find the case of the order promising process (OPP), which refers to a set of business activities triggered to provide a response to customer order requests 6 . The OPP bases its functionality on the concept of Available-to-Promise (ATP). The ATP represents the uncommitted availability of product computed by subtracting the already committed orders from the quantities in stock and planned supply defined in the Master Production Schedule (MPS) [7]. Based on the ATP quantities, the OPP answers to each order with an acceptance/rejection decision. There are certain Supply Chains belonging to sectors such as ceramic tile, furniture and agriculture in which products present different characteristics among its units that, in some cases, can vary over time. Furthermore, such characteristics are important and perceptible to the final customers and therefore, the OPP can take these aspects in to account when committing their orders. These sectors are affected by the so-called Lack of Homogeneity in the product (LHP) (for more details on LHP, see Grillo et al. [6], Alemany et al. [8, [9], and Grillo et al. [10]). This is, in fact, the case of fresh fruit and vegetables that are additionally perishable perishables

Under these circumstances, the computation of the ATP must consider the subdivision of the MPS into homogeneous sub-lots that will not be accurately known until the moment the product will be harvested and classified. For this type of supply chain, the lack of homogeneity in the product refers to the existence of 
different units of the same product (subtype) that differ in characteristics such as colour, weight, size or variety. The subdivision of the MPS lots into different subtypes (in order to compute the ATP as a consequence of LHP) is the first issue addressed in this paper to exemplify a situation when there is interdependent data with several elements that must add up to a determined total quantity.

The second issue in the modelling of ATP for perishables, is that it involves another source of complexity, namely the product's lifetime [6]. In this case, the ATP is not just affected by the conventional schema of the LHP in terms of the subdivision in subtypes, but in the way that the shelf life can be considered as another cause of LHP. Since most of the time, customers request certain levels of freshness, it could itself be used to define a subtype. Literature shows that, no models have been developed for these type of problems, specifically in supply chain of perishables [6].

The distribution of a total quantity into several components is known as compositional data and has been extensively studied since Aitchison 11. For reviews on the topic, we refer to Aitchison and J. Egozcue [12, Pawlowsky-Glahn and Buccianti [13], and Pawlowsky-Glahn and Egozcue [14. These research show that compositional data has mainly focused on the deterministic case, i.e., not considering uncertainty in the elements of the composition. However, there exist several situations in the real world where the composition is not precisely defined and the distribution of the elements is varying in a certain range. As a consequence, the total quantity to which they must add up to is also uncertain. An example of such a situation is the computation of ATP per subtype as mentioned before.

There has been recent interest in the study of uncertainty in the elements of a composition from a probabilistic point of view, under the name of joint mixability. A detailed description of joint mixability can be found in the work of Puccetti and Wang [15] and Wang and Wang [16] and the references therein. However, the main disadvantage of the probabilistic approach is that it normally uses long sets of historical data in order to identify suitable probability distributions. If there is not enough representative data available in order to characterize the uncertainty, then the probabilistic approach is not suggested as is highlighted by authors like Peidro et al. 17 and Dubois et al. 18.

Grillo et al. [6] makes an extensive literature review where it is highlighted the need of modelling ATP per subtype in the deterministic case (also called "crisp scene"), but it is also specially remarked that the case when there is uncertainty in the subdivision per subtype has not been studied for perishables.

In order to analyse the uncertainty in the compositional data from a new point of view, we introduce the possibility theory [19 as a suitable tool to model it. We introduce the special case when the elements of a composition are considered to be possibilistic variables. Up to the authors' knowledge the latter case has not been studied. In this work we will present the composition of possibilistic variables in a general way, so that it can be applied in a wide range of situations. We 
will exemplify its practical usefulness through the modelling of ATP under LHP conditions.

As we mentioned in previous paragraphs, the supply chain of perishables has another challenging feature: the subtypes will change some of its characteristics based on the ageing process 20, 21]. In order to face this issue, we introduce the state function, which is a continuous function whose domain is a determined window of time, and the co-domain represents a characteristic of the product (in our example), which we will call state, such as quality or value (price). The state function represents the state of a variable at each time. When the state function is used to model the product's decay, it is called ageing function. Considering that the shelf life of a perishable is usually uncertain (there is just a vague idea of it), the ending time in the domain is represented with a possibilistic variable. Hence, the state itself is computed through a possibilistic variable.

The main contributions of this paper are twofold: to introduce the concepts of composition of possibilistic variables and state/ageing function, and to apply the new concepts in a practical example of OPP under LHP for perishables. We model the quantity of homogeneous product through a composition of possibilistic variables and we propose to link the product's price with an ageing function.

For both, compositions and state functions, we propose general procedures based on $\alpha$-cuts in order to simplify the computations for linear mathematical modelling, a common tool used in applications due to its reasonable complexity and computational efficiency in the solution process.

Numerical experiments have been executed by applying the developed tools to a real case of a Spanish supply chain of the fruit sector, specifically the packing and distribution of oranges an tangerines. We have used a data set based on real information of orders given by the supply chain. The results obtained validated the correct model's functionality with a very good computational performance. We also presented some managerial insights in order to exemplify the usefulness that a tool like this has for decision makers.

The rest of the paper is organized as follows, Section 2 introduces and explains the concepts of composition of possibilistic variables. In Section 3 we describe the state function, meanwhile in Section 4 we describe how to apply both tools in the OPP process for perishables. In Section 5 the numerical experiments are presented. Finally Section 6 presents the main conclusions of this work. 


\section{Modelling compositions with possibilistic variables}

A wide variety of situations in mathematical modelling needs to take into account variables that are interdependent, for example, when certain values need to add up to another given value. Let us consider the data in Table 1 , where the expected composition of a lot of oranges of $100 \mathrm{~kg}$ coming from a field is described according to the subdivision of the product in its possible quality levels, $1^{\text {st }}, 2^{\text {nd }}, 3^{\text {rd }}$ and $4^{\text {th }}$.

Table 1: Composition of a lot of oranges

\begin{tabular}{|c|c|c|c|c|c|}
\hline Quality & $1^{\text {st }}$ & $2^{\text {nd }}$ & $3^{\text {rd }}$ & $4^{\text {th }}$ & Total \\
\hline$(\mathrm{kg})$ & 65 & 20 & 10 & 5 & 100 \\
\hline$(\%)$ & $65 \%$ & $20 \%$ & $10 \%$ & $5 \%$ & $100 \%$ \\
\hline
\end{tabular}

Clearly, the sum of the components should add up to the total quantity of the lot. Let $\mathbf{x}$ be a vector in $\mathbb{R}^{n}$ whose components represent the contribution to the lot of oranges (sublots). If $c$ represents the total quantity of the lot, then we have $\sum_{i=1}^{n} x_{i}=c$.

With the information in Table 1 is easy to see that $x_{1}=65, x_{2}=20, x_{3}=10$, $x_{4}=5$, and $c=100$, hence, the vector $\mathbf{x}$ can be considered as a composition of $c$. The concept of compositional data was originally introduced by Aitchison 11 and it has been oriented to exact data without considering imprecision. Now, let us consider the case where the values of Table 1 are not known precisely until the moment the analysis of its composition is made. Before that moment, there is just a vague idea regarding the values of the composition, for example about $65 \mathrm{~kg}$ of the $1^{\text {st }}$ quality type, about $20 \mathrm{~kg}$ of the $2^{\text {nd }}$ quality type, about $10 \mathrm{~kg}$ of the $3^{\text {rd }}$ quality type and about $5 \mathrm{~kg}$ of waste. All of them highlighted "about", since the exact quantities are not known, but they still have the restriction of adding up to the total quantity of $100 \mathrm{~kg}$. Even more complex, the case when they do not have the condition of adding up to $100 \mathrm{~kg}$ and there is also just a vague idea that the lot will be about $100 \mathrm{~kg}$ with the also vague composition mentioned. This would mean that both things involve imprecision, the values of the composition's components, and the total quantity they must add up to. In the following, we introduce the concepts to model imprecision in compositions, based on possibility distributions.

\subsection{Basic concepts}

Definition 1. Let $n \in \mathbb{N}$ be such that $n>1$. An n-part composition of $c \in \mathbb{R}^{+}$is a vector $\mathbf{x} \in\left(\mathbb{R}^{+}\right)^{n}$ such that $\sum_{i=1}^{n} x_{i}=x$.

\section{Definition 2.}

(i) A possibilistic variable $X$ on a universe $U$ is described by a possibility distribution $\pi_{X}$, i.e. a mapping $\pi_{X}: U \rightarrow[0,1]$ such that $\left(\exists u^{*} \in U\right)\left(\pi_{X}\left(u^{*}\right)=\right.$ 1). 
(ii) A possibilistic vector $\left(X_{1}, \ldots, X_{n}\right)$ on a product universe $U_{1} \times \ldots U_{n}$ consists of $n$ possibilistic variables $X_{i}$ on $U_{i}$ and is described by a joint possibility distribution $\pi_{X_{1}, \ldots, X_{n}}$, i.e. a mapping $\pi_{X_{1}, \ldots, X_{n}}: U_{1} \times \ldots U_{n} \rightarrow[0,1]$ such that $\left(\exists\left(u_{1}^{*}, \ldots, u_{n}^{*}\right) \in U_{1} \times \ldots U_{n}\right)\left(\pi_{X_{1}, \ldots, X_{n}}\left(u_{1}^{*}, \ldots, u_{n}^{*}\right)=1\right)$. The marginal possibility distributions of the variables $X_{i}$ are given by

$\pi_{X_{i}}(u)=\sup \left\{\pi_{X_{1}, \ldots, X_{n}}\left(u_{1}, \ldots, u_{n}\right) \mid\left(u_{1}, \ldots, u_{n}\right) \in U_{1} \times \ldots \times U_{n} \wedge u_{i}=u\right\}$.

Note that $\pi_{X_{i}}\left(u_{i}^{*}\right)=1$.

(iii) The components of a possibilistic vector are called non-interactive if the joint possibility distribution can be written as

$$
\pi_{X_{1}, \ldots, X_{n}}\left(u_{1}, \ldots, u_{n}\right)=\min \left(\pi_{X_{1}}\left(u_{1}\right), \ldots, \pi_{X_{n}}\left(u_{n}\right)\right)
$$

Note that in any case, it holds that

$$
\pi_{X_{1}, \ldots, X_{n}}\left(u_{1}, \ldots, u_{n}\right) \leqslant \min \left(\pi_{X_{1}}\left(u_{1}\right), \ldots, \pi_{X_{n}}\left(u_{n}\right)\right) .
$$

Possibilistic variables can be used to model epistemic uncertainty, the simplest case being that of interval uncertainty. In particular, if a possibilistic variable $X$ on $\mathbb{R}$ is used to model the knowledge that $X$ takes values in an interval $[a, b]$, then its possibility distribution is given by

$$
\pi_{X}(u)= \begin{cases}1 & , \text { if } u \in[a, b] \\ 0 & , \text { if } u \notin[a, b]\end{cases}
$$

Note that $\pi_{X}$ is nothing else but the characteristic mapping of the set $[a, b]$.

More refined and very popular possibility distributions are the so-called triangular fuzzy Interval (TFI), allowing to incorporate a possibility gradient (left, central or right), that we denote as $X=(a, b, c)$ (see Figure 1). Note that, for the case of a normal TFI $\pi_{X}(b)=1$. The following example gives a basic overview of the application of triangular possibility distributions to the components of the lot in Table 1

Example 1. If the composition's components described in Table 1 are considered fuzzy intervals, we have $X_{1} \approx 65, X_{2} \approx 20, X_{3} \approx 10$ and $X_{4} \approx 5$.

For each fuzzy interval we consider $X_{i}=\left(0.75 b_{i}, b_{i}, 1.25 b_{i}\right)$, where $b_{i}$ represents the central value. In this case, $b_{1}=65, b_{2}=20, b_{3}=10$ and $b_{4}=5$. Hence, the first TFI is $X_{1}=(48.75,65,81.25)$, the second one is $X_{2}=(15,20,25)$, and so on. In this way, the values $(60,23,9.5,6)$ are a specific tuple for the composition and by computing their respective possibility distribution, we obtain 


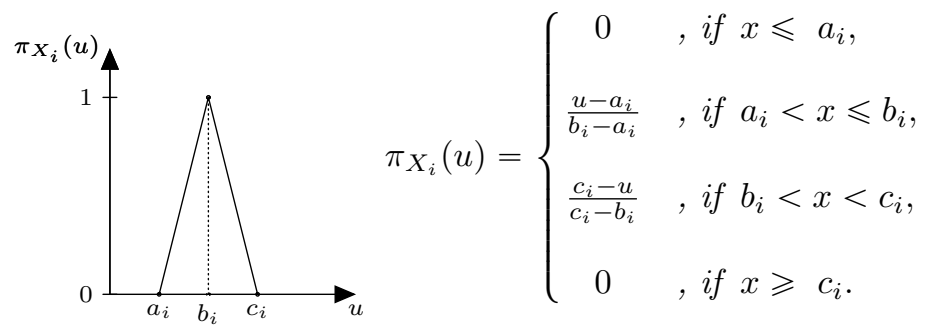

Figure 1: Triangular fuzzy interval

$\pi_{X_{i}}(u)=(0.69,0.40,0.80,0.20)$ which can be interpreted as the possibility degree that each value in the tuple belongs to its respective fuzzy interval.

Computing with possibilistic variables is facilitated by Zadeh's extension principle [22]. Consider a function $f: U_{1} \times \ldots \times U_{n} \rightarrow V$ and a possibilistic vector $\left(X_{1}, \ldots, X_{n}\right)$ on $U_{1} \times \ldots \times U_{n}$, then $Y=f\left(U_{1}, \ldots, U_{n}\right)$ is the possibilistic variable on $V$ with possibility distribution $\pi_{Y}$ defined by

$$
\pi_{Y}(v)=\sup \left\{\pi_{X_{1}, \ldots, X_{n}}\left(u_{1}, \ldots, u_{n}\right) \mid f\left(u_{1}, \ldots, u_{n}\right)=v\right\} .
$$

Consider a possibilistic vector $\left(X_{1}, \ldots, X_{n}\right)$ on $\mathbb{R}^{n}$, then its sum $\sum_{i=1}^{n} X_{i}$ is the possibilistic variable $Y$ with possibility distribution

$$
\pi_{Y}(v)=\sup \left\{\pi_{X_{1}, \ldots, X_{n}}\left(u_{1}, \ldots, u_{n}\right) \mid \sum_{i=1}^{n} u_{i}=v\right\}
$$

When treating the possibilistic variables as non-interactive, i.e. considering only their marginal possibility distributions, then the corresponding sum will be denoted by $Z=\bigoplus_{i=1}^{n} X_{i}$, with possibility distribution

$$
\pi_{Z}(v)=\sup \left\{\min \left(\pi_{X_{1}}\left(u_{1}\right), \ldots, \pi_{X_{n}}\left(u_{n}\right)\right) \mid \sum_{i=1}^{n} u_{i}=v\right\} .
$$

\subsection{Compositions}

Definition 3. Let $n \in \mathbb{N}$ be such that $n>1$. A possibilistic vector $\left(X_{1}, \ldots, X_{n}\right)$ on $\left(\mathbb{R}^{+}\right)^{n}$ is called an $n$-part composition of a possibilistic variable $C$ on $\mathbb{R}^{+}$if $\sum_{i=1}^{n} X_{i}=C$.

In the following discussion, we will develop a practical procedure to construct such $n$-part compositions. We start from the following situation. Suppose we have 
an imprecise description of the quantities $X_{i}, i=1, \ldots, n$, of certain products expressed in terms of possibility distributions $\pi_{X_{i}}$ and an imprecise description of their grand total $C$ expressed in terms of a possibility distribution $\pi_{C}$. An important assumption is

$$
C \subseteq \bigoplus_{i=1}^{n} X_{i}
$$

stating that $C$ is included in the sum of the quantities $X_{i}, i=1, \ldots, n$, when treated as being non-interactive. This can be seen as a kind of coherence condition, expressing that $C$ is indeed realizable.

The aim now is to define a joint possibility distribution $\pi_{X_{1}, \ldots, X_{n}}^{*}$ of the possibilistic vector $\left(X_{1}, X_{2}, \ldots, X_{n}\right)$ satisfying the following conditions:

(i) it holds that $\sum_{i=1}^{n} X_{i}=C$ (using $\pi_{X_{1}, \ldots, X_{n}}^{*}$ ), i.e. the possibilistic vector $\left(X_{1}, \ldots, X_{n}\right)$ is an $n$-part composition of $C$;

(ii) $\pi_{X_{1}, \ldots, X_{n}}^{*}$ is the least specific (i.e. the largest) joint possibility distribution realizing (i).

Theorem 1. The joint possibility distribution of the possibilistic vector $\left(X_{1}, \ldots, X_{n}\right)$ defined by

$$
\pi_{X_{1}, \ldots, X_{n}}^{*}\left(u_{1}, \ldots, u_{n}\right)=\min \left(\pi_{C}\left(\sum_{i=1}^{n} u_{i}\right), \min _{i=1}^{n} \pi_{X_{i}}\left(u_{i}\right)\right)
$$

is the largest distribution such that $\sum_{i=1}^{n} X_{i}=C$.

Proof. Note that the assumption $C \subseteq \bigoplus_{i=1}^{n} X_{i}$ implies that

$$
\pi_{C}(v) \leqslant \sup \left\{\min \left(\pi_{X_{1}}\left(u_{1}\right), \ldots, \pi_{X_{n}}\left(u_{n}\right)\right) \mid \sum_{i=1}^{n} u_{i}=v\right\} .
$$


Let $Y=\sum_{i=1}^{n} X_{i}$, then

$$
\begin{aligned}
\pi_{Y}(v) & =\sup \left\{\min \left(\pi_{C}\left(\sum_{i=1}^{n} u_{i}\right), \min \left(\pi_{X_{1}}\left(u_{1}\right), \ldots, \pi_{X_{n}}\left(u_{n}\right)\right)\right) \mid \sum_{i=1}^{n} u_{i}=v\right\} \\
& =\sup \left\{\min \left(\pi_{C}(v), \min \left(\pi_{X_{1}}\left(u_{1}\right), \ldots, \pi_{X_{n}}\left(u_{n}\right)\right)\right) \mid \sum_{i=1}^{n} u_{i}=v\right\} \\
& =\min \left(\pi_{C}(v), \sup \left\{\min \left(\pi_{X_{1}}\left(u_{1}\right), \ldots, \pi_{X_{n}}\left(u_{n}\right)\right) \mid \sum_{i=1}^{n} u_{i}=v\right\}\right) \\
& =\pi_{C}(v) .
\end{aligned}
$$

Moreover, consider another possibility distribution $\pi_{X_{1}, \ldots, X_{n}}^{\#}$ such that

$$
\pi_{X_{1}, \ldots, X_{n}}^{\#}\left(u_{1}, \ldots, u_{n}\right)>\pi_{X_{1}, \ldots, X_{n}}^{*}\left(u_{1}, \ldots, u_{n}\right)
$$

in some point $\left(u_{1}, \ldots, u_{n}\right)$, while still $\sum_{i=1}^{n} X_{i}=C\left(\operatorname{using} \pi_{X_{1}, \ldots, X_{n}}^{\#}\right)$. Since $\min \left(\pi_{X_{1}}, \ldots, \pi_{X_{n}}\right)$

is an upper bound to the joint possibility distribution, it must hold that $\pi_{X_{1}, \ldots, X_{n}}^{\#}\left(u_{1}, \ldots, u_{n}\right)>$ $\pi_{C}\left(\sum_{i=1}^{n} u_{i}\right)$. However, this implies that for $v=\sum_{i=1}^{n} u_{i}$, it holds that $\pi_{Y}^{\#}(v)>$ $\pi_{C}(v)$, a contradiction.

Remark 1. Obviously, it holds that the marginal distribution $\pi_{X_{i}}^{*}$ of $X_{i}$ obtained from $\pi_{X_{1}, \ldots, X_{n}}^{*}$ satisfies $\pi_{X_{i}}^{*} \leqslant \pi_{X_{i}}$.

Example 2. Let $n=2$.

(i) Consider $X_{1}$ and $X_{2}$ with triangular distribution $\pi_{X_{1}}=\pi_{X_{2}}=\langle 0,5,10\rangle$. Clearly, $X_{1} \oplus X_{2}$ has as possibility distribution the triangular distribution $\langle 0,10,20\rangle$. Suppose that the grand total $C$ is described by the triangular distribution $\pi_{C}=\langle 8,10,12\rangle$. Consider the possibility distribution

$$
\pi_{X_{1}, X_{2}}^{*}\left(u_{1}, u_{2}\right)=\min \left(\pi_{C}\left(u_{1}+u_{2}\right), \min \left(\pi_{X_{1}}\left(u_{1}\right), \pi_{X_{2}}\left(u_{2}\right)\right)\right),
$$

then the marginal distributions of $X_{1}$ and $X_{2}$ are given by $\pi_{X_{1}}^{*}=\pi_{X_{1}}$ and $\pi_{X_{2}}^{*}=\pi_{X_{2}}$. This joint possibility distribution is shown in Figure 2 .

(ii) Consider $X_{1}$ and $X_{2}$ with triangular distribution $\pi_{X_{1}}=\pi_{X_{2}}=\langle 0,8,10\rangle$. Clearly, $X_{1} \oplus X_{2}$ has as possibility distribution the triangular distribution $\langle 0,16,20\rangle$. Suppose that the grand total $C$ is described by the triangular distribution $\pi_{C}=\langle 14,16,18\rangle$. Consider the possibility distribution

$$
\pi_{X_{1}, X_{2}}^{*}\left(u_{1}, u_{2}\right)=\min \left(\pi_{C}\left(u_{1}+u_{2}\right), \min \left(\pi_{X_{1}}\left(u_{1}\right), \pi_{X_{2}}\left(u_{2}\right)\right)\right),
$$




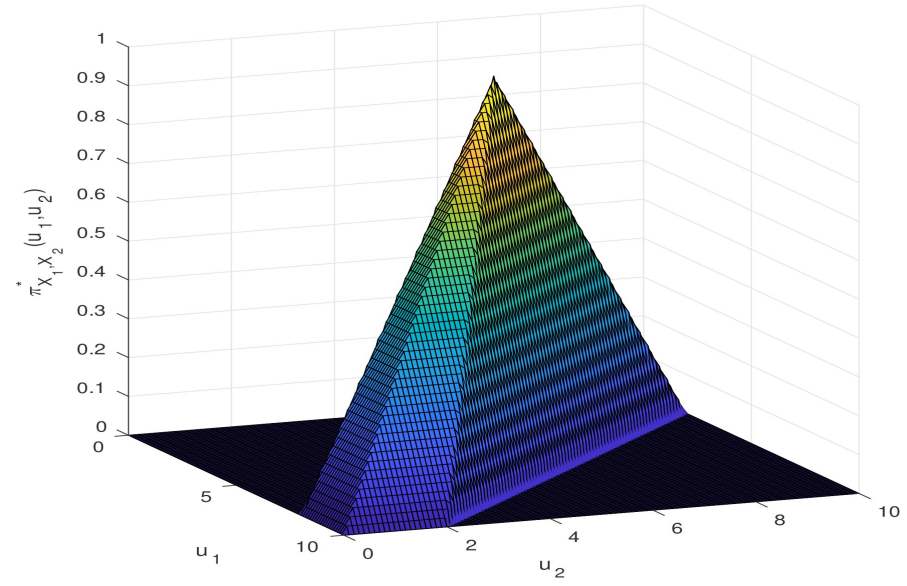

Figure 2: Joint possibility distribution: case $\pi_{X_{1}}=\pi_{X_{2}}=\langle 0,5,10\rangle$.

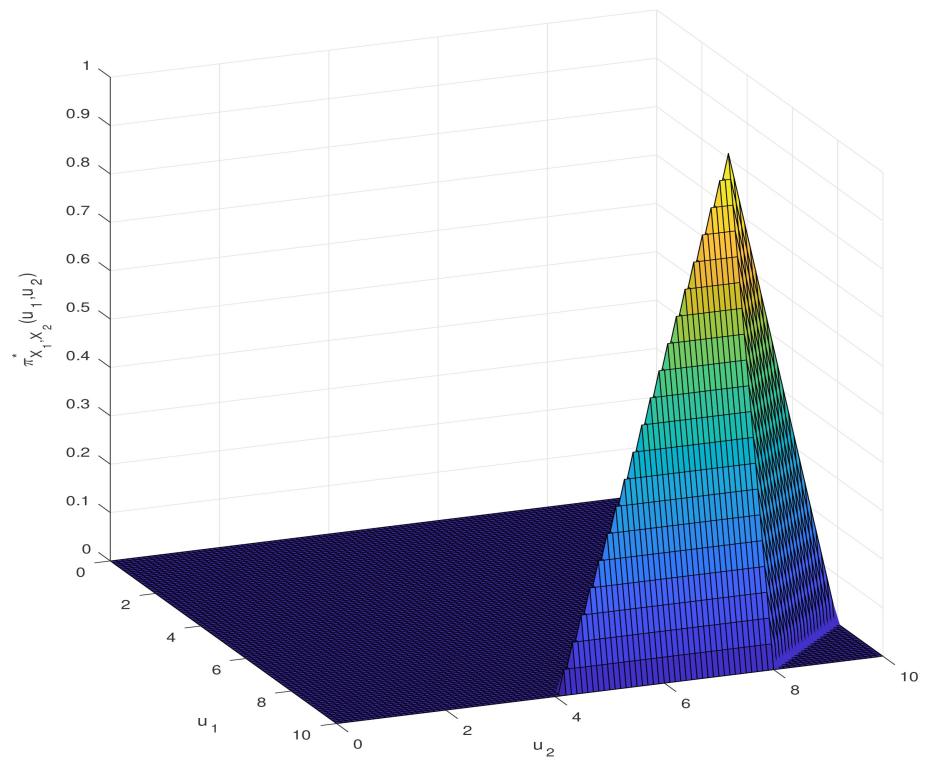

Figure 3: Joint possibility distribution: case $\pi_{X_{1}}=\pi_{X_{2}}=\langle 0,8,10\rangle$. 
then the marginal distributions of $X_{1}$ and $X_{2}$ are given by $\pi_{X_{1}}^{*}=\pi_{X_{2}}^{*}=$ $\langle 4,8,10\rangle$. This joint possibility distribution is shown in Figure 3 .

\subsection{Using compositions in practice}

Suppose we have an imprecise description of the quantities $X_{i}, i=1, \ldots, n$, of certain products expressed in terms of possibility distributions $\pi_{X_{i}}$ and an imprecise description of their grand total $C$ expressed in terms of a possibility distribution $\pi_{C}$ such that $C \subseteq \bigoplus_{i=1}^{n} X_{i}$. We construct the joint possibility distribution $\pi_{X_{1}, \ldots, X_{n}}^{*}$ as explained in the previous section:

$$
\pi_{X_{1}, \ldots, X_{n}}^{*}\left(u_{1}, \ldots, u_{n}\right)=\min \left(\pi_{C}\left(\sum_{i=1}^{n} u_{i}\right), \min _{i=1}^{n} \pi_{X_{i}}\left(u_{i}\right)\right)
$$

In the context of optimization, one usually adopts an $\alpha$-cut approach. For a given $\alpha \in] 0,1]$, this amounts to choosing values $u_{i}$ of $X_{i}$ such that $\pi_{X_{1}, \ldots, X_{n}}^{*}\left(u_{1}, \ldots, u_{n}\right) \geqslant$ $\alpha$ and $\pi_{C}(z) \geqslant \alpha$ with $z=\sum_{i=1}^{n} u_{i}$, in view of the composition constraint. It is immediate that $\pi_{X_{1}, \ldots, X_{n}}^{*}\left(u_{1}, \ldots, u_{n}\right) \geqslant \alpha$ if and only $\pi_{C}(z) \geqslant \alpha$ and $\pi_{X_{i}}\left(u_{i}\right) \geqslant \alpha$, $i=1, \ldots, n$.

Hence, we obtain the following extremely simple procedure. For a given $\alpha \in] 0,1]$, select $u_{i}, i=1, \ldots, n$, such that $\pi_{X_{i}}\left(u_{i}\right) \geqslant \alpha$ (i.e., select $u_{i}$ from the $\alpha$-cut of the original possibility distribution of $X_{i}$ ). Compute the sum $z=\sum_{i=1}^{n} u_{i}$; if $\pi_{C}(z)<\alpha$, then reject the vector of values $\left(u_{1}, \ldots, u_{n}\right)$, otherwise proceed. There is no need to compute the joint possibility distribution $\pi_{X_{1}, \ldots, X_{n}}^{*}$ explicitly.

\section{Modelling State functions}

Let us consider the lot of oranges as described in Example 1. In this case, each composition's component represents a sub-lot of oranges depending on the quality conditions. In the previous section, we explained how to model such composition using possibilistic variables. Now, what happens if the quality conditions are not static and could change with time, as it is normal for perishable products? Or even more, what happens if another characteristic like orange's price is linked with the ageing process?. We now aim to analyse how a situation like this can be modelled. 


\subsection{State functions}

The state of a product with a finite life span $\left[t_{i}, t_{e}\right]$ is modelled by a state function $h:\left[t_{i}, t_{e}\right] \rightarrow \mathbb{R}$ representing the state $h(t)$ of the product at time $t$. State functions can, for instance, be used to model the decaying quality of a perishable product over time; such state functions will be called ageing functions. An ageing function then is a decreasing function $h:\left[t_{i}, t_{e}\right] \rightarrow\left[s_{i}, s_{e}\right]$ with $h\left(t_{i}\right)=s_{i}$ and $h\left(t_{e}\right)=s_{e}$.

In particular, for a perishable product, the ending time $t_{e}$ is usually not precisely known and one has only a vague idea about it. Similarly as before, such an imprecise ending time will be modelled as a possibilistic variable $T_{e}$ with possibility distribution $\pi_{T_{e}}$ satisfying $\pi_{T_{e}}\left(t_{e}\right)=1$. We suppose that the (closure of the) support of $T_{e}$ (i.e. the closure of the set where $\pi_{T_{e}}$ is not zero) is the interval $\left[\ell_{e}, u_{e}\right]$, with a length that is relatively small compared to that of the life span $\left[t_{i}, t_{e}\right]$. The latter assumption implies that if the real ending time would be a value $t^{*}$ in $\left[\ell_{e}, u_{e}\right]$, then the given ageing function could be adapted by linear rescaling to obtain an ageing function $h^{\left(t^{*}\right)}$ for a life span $\left[t_{i}, t^{*}\right]$. For any $t \in\left[t_{i}, t^{*}\right]$, it then holds that

$$
h^{\left(t^{*}\right)}(t)=h\left(t_{i}+\frac{t-t_{i}}{t^{*}-t_{i}}\left(t_{e}-t_{i}\right)\right) .
$$

Obviously, it holds that $h^{\left(t^{*}\right)}\left(t_{i}\right)=s_{i}$ and $h^{\left(t^{*}\right)}\left(t^{*}\right)=s_{e}$.

In case the ending time $t_{e}$ is described by a possibilistic variable $T_{e}$, it is obvious that the state time $t$ is not known precisely either and is described by a possibilistic variable $S_{t}$ with possibility distribution $\pi_{S_{t}}$ on $\left[t_{i}, u_{e}\right]$ defined by

$$
\pi_{S_{t}}(s)=\sup \left\{\pi_{T_{e}}\left(t^{*}\right) \mid h^{\left(t^{*}\right)}(t)=s\right\}
$$

In case no $t^{*}$ exists such that $h^{\left(t^{*}\right)}(t)=s$, then it obviously holds that $\pi_{S_{t}}(s)=0$. The underlying principle is again Zadeh's extension principle, this time not used to extend a function allowing for fuzzy inputs, by to extend a function allowing for a fuzzy parameter (the ending time). In words, the above formula states that the degree of possibility of $s$ being the state at time $t$ is determined by the most possible ending time $t^{*}$ for which it holds that the state at time $t$, according to the ageing function corresponding to $t^{*}$, equals $s$.

In case the ageing function is strictly decreasing, there exists at most one $t^{*}$ and the above formula reduces to $\pi_{S_{t}}(s)=\pi_{T_{e}}\left(t^{*}\right)$ if $h^{\left(t^{*}\right)}(t)=s$, and $\pi_{S_{t}}(s)=0$ if no such $t^{*}$ exists. In case the ageing function is constant on some subinterval, then this uniqueness is not guaranteed.

Example 3. Let us illustrate the above procedure on a simple example. Let the ageing function be linearly decreasing and $\pi_{T_{e}}$ be a TFI with parameters $\left(l_{e}, t_{e}, u_{e}\right)$. Then $\pi_{S_{t}}$ is a TFI as well with parameters $\left(a_{t}, b_{t}, c_{t}\right)$ given by $a_{t}=h^{\left(\ell_{e}\right)}(t), b_{t}=$ 
$h^{\left(t_{e}\right)}(t)=h(t)$ and $c=h^{\left(u_{e}\right)}(t)$. Obviously, the $\alpha$-cuts of $\pi_{S_{t}}$ can be found easily. Figure 4 graphically illustrates this procedure.

Example 4. As a second example, we consider an ageing function that remains constant on part of its domain, and illustrate the impact of an imprecise ending time. Consider the piecewise linear ageing function $h:[0,10] \rightarrow[0,2]$ with $h(0)=$ $2, h(2)=1, h(8)=1$ and $h(10)=0$.

Let $\pi_{T_{e}}$ be the TFI with parameters $(8,10,12)$. We given some examples of $S_{t}$ for different values of $t$ :

(i) the state at $t=1.6$ is the TFI with parameters $(1,1.2,1.33)$;

(ii) the state at $t=2$ is the TFI with parameters $(1,1,1.17)$;

(iii) the state at any time $t \in[2.4,6.4]$ is the crisp value 1 (TFI with parameters $(1,1,1))$;

(iv) the state at time $t=10$ is the TFI with parameters $(0,0,0.83)$.

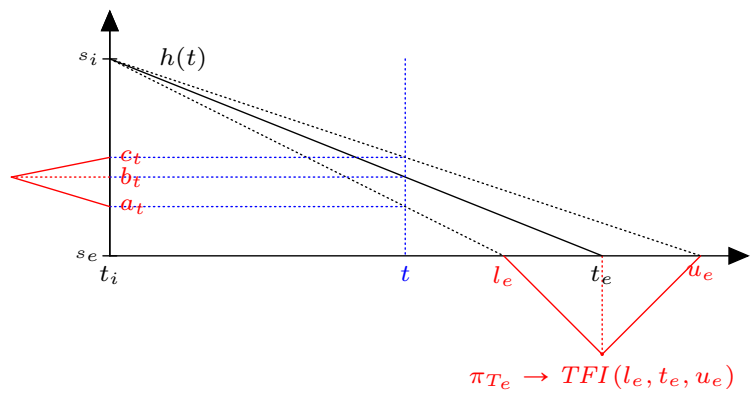

Figure 4: Example of linear ageing function.

\section{Application to the order promising process for perishables}

In this Section the application of the previous concepts to the OPP modelling for perishables, such as fresh fruit and vegetables, is presented. It consists in deciding upon the acceptance/rejection of the customer order proposals and the assignation of the ATP per subtype while maximizing profits.

The following assumptions are made as regards the orders:

(1) Each order is composed by one or several lines. Each line specifies the subtype and the quantity requested of it.

(2) The order's due date is assumed to be the same for all its lines. 
(3) Customers require homogeneous units of the same subtype. It is not possible to fulfil one same line with different subtypes. It is also not possible to accumulate ATP of the same subtype but with different harvesting times in order to fulfil higher future incoming orders (for traceability reasons as regards shelf life consumption).

(4) Customers need to be served on time. Any delay is allowed.

(5) The orders are promised in batching mode [23], i.e., they are accumulated for a given window of time known as batching interval. The orders are promised at the beginning of each batching interval with the expected quantities of ATP.

The following assumptions are made as regards supply:

(1) Units of the same subtype present the same characteristics. Different subtypes of the same product can differ in attributes such as quality, color, size and weight, among others.

(2) The total MPS per product and time period is itself uncertain in supply chains of perishables due to multiple uncontrollable factors, such as weather, temperature, humidity, etc, that impact in the maturation process.

(3) Planned lots in the MPS are assumed to be composed by different sublots of homogeneous subtypes as an effect of the LHP.

(4) The exact amount of each subtype in the MPS is also uncertain until production and classification activities have been performed. Previously, it is only possible to have an estimation.

(5) The ATP per subtype is calculated based on the previous division of the MPS in homogeneous sublots of the same subtype, and subtracting the orders already committed.

(6) The product is perishable. It deteriorates over time and becomes waste when expiring.

(7) For perishables, the product's shelf life can be used as another homogeneity criteria, because customers normally require minimum levels of freshness (which is not necessarily the same of quality).

(8) Since deterioration depends not only on the harvesting time but also on additional factors, the maximum product's shelf life involves uncertainty. If another product's attribute is linked with ageing process, e.g., the selling price, it will also inherit such uncertainty.

From the characteristics mentioned before, in the following Subsection 4.1 we will explain how to model homogeneous ATP through the concepts of compositions with possibilistic variables and a ageing-dependent pricing policy for products with ageing functions. The model is an adapted implementation, of previous deterministic versions of mixed integer linear programming models developed in 
the field of OPP for fruit supply chains by Grillo et al. [10] and Grillo et al. [23], under uncertainty conditions.

\subsection{Notations}

The notation follows the convention: i) indices are represented as single italic letters; ii) sets are represented with single italic capital letters with the indices they refer to; iii) input data (given parameters and parameters computed from other inputs) are represented as single boldface letters with their respective indices; iv) the model's decision variables are represented as single boldface, non-italic capital letters; and finally, v) the computed variables (calculated from the model's decision variables through equations) are represented as single-capital letters.

\section{Indices}

$i$ Products, $i \in\{1, \cdots, I\}$.

$h$ Harvesting time, $h \in\{-S L, \cdots, T-1\}$.

$s \quad$ Subtypes, $s \in\{1, \cdots, S\}$.

$t$ Time buckets, $t \in\{0, \cdots, T\}$.

$o \quad$ Customer order proposals, $o \in\{1, \cdots, O\}$.

\section{Sets}

$O_{i s} \quad$ Set of subtypes $s$ of product $i$ requested in the customer order proposal $o$ in the current model's execution.

$I_{s} \quad$ Set of subtypes $s$ in which each product $i$ can be classified.

\section{Input data}

$\mathbf{d}^{o} \quad$ Due date of the order proposal $o$.

$\mathbf{c}_{i s}^{h t} \quad$ Total committed quantity from previous execution of subtype $s$ of product $i$, in period $t$, and harvested in $h$.

$\mathbf{f}_{i s}^{o} \quad$ Fending unitary cost if $\mathbf{r}_{i s}^{o}$ is rejected.

$\mathbf{h}_{i s} \quad$ Holding unitary cost of subtype $s$ of product $i$ per time period.

$\mathbf{k}_{i s}^{h} \quad$ Initial stock of subtype $s$ of product $i$ harvested in $h$, available at the beginning of each execution.

$\mathbf{n}^{o} \quad$ Total number of lines in each order $o$.

$\mathbf{r}_{i s}^{o} \quad$ Requested quantity of the subtype $s$ of product $i$, in order $o$.

$\rho^{o} \quad$ Unitary transport cost of order $o$.

$\mathbf{t}^{o} \quad$ Transporting time to the delivery place of order $o$.

$\mathbf{w}_{i s} \quad$ Waste unitary cost per unit of the subtype $s$ of product $i$.

$\tau \quad$ Length of the batching interval in time periods. 


\section{Computed intervals}

$\mathrm{A}_{i s}^{h t} \quad$ The homogeneous Available-To-Promise of subtype $s$ of product $i$, harvested in $h$ and available in $t$, after classification activities and taking into account the committed quantities once the model has been executed.

$\mathrm{G}_{i s}^{h t} \quad$ Quantity of $\mathrm{A}_{i s}^{h t}$ becoming waste (garbage) due to expiration.

\section{Possibilistic variables}

$\mathbf{E}_{i s}^{o} \quad$ Possibilistic variable representing the price (earning) assigned to the subtype $s$ of product $i$ in order $o$, considering its harvesting time and the due date $\mathbf{d}^{o}$ when is asked to be delivered. It is computed from an ageing function whose maximum time (representing the product's shelf life) is described by a possibilistic variable.

$\mathbf{L}_{i s} \quad$ Possibilistic variable representing Maximum lifetime (shelf-life) for subtype $s$ of product $i$.

$\mathbf{M}_{i s}^{h t} \quad$ Possibilistic variable representing the MPS per subtype $s$ of product $i$, harvested in period $h$ and available in $t$.

$\mathbf{P}_{i}^{h t} \quad$ Possibilistic variable representing the MPS of product $i$, harvested in period $h$ and available $t$.

\section{Decision variables}

$\mathbf{Y}_{i s}^{\text {oht }} \quad$ Binary variable with a value of 1 if the requested quantity of subtype $s$ of product $i$ in order $o$ is completely served by the corresponding $\mathrm{A}_{i s}^{h t}$ and value of 0 otherwise.

$\mathbf{U}^{o} \quad$ Binary variable with a value of 1 if all subtypes $s$ in order $o$ are finally fulfilled and consequently the order is promised.

\subsection{Mathematical modelling}

Objective function: Profits generated as the difference between the incomes of the promised orders and the total cost of inventory holding, rejecting orders, wasted product due to expiration and transport cost. Eq. (1) computes the objective. 


$$
\begin{aligned}
& \text { SI: } \quad \sum_{(o, i, s) \in O_{i s}} \mathbf{r}_{i s}^{o} \mathbf{E}_{i s}^{o} \quad \rightarrow \text { Selling income. } \\
& \text { HCO: } \quad \sum_{(o, i, s) \in O_{i s}} \mathbf{h}_{i s} \mathbf{r}_{i s}^{o}\left(\mathbf{d}^{o}-\mathbf{t}^{o}-\sum_{h, t} t \mathbf{Y}_{i s}^{o h t}\right) \rightarrow \text { Holding cost of committed orders. } \\
& \text { HCA: } \sum_{(i, s) \in I_{s}} \sum_{h, t \leqslant \tau}(\boldsymbol{\tau}-t) \mathbf{h}_{i s} A_{i s}^{h t} \quad \rightarrow \text { Holding cost of the remaining ATP. } \\
& R C: \quad \sum_{(o, i, s) \in O_{i s}} \sum_{h, t} \mathbf{f}_{i s}^{o}\left(1-\mathbf{Y}_{i s}^{\text {oht }}\right) \quad \rightarrow \text { Rejected order's cost. } \\
& W C: \quad \sum_{(i, s) \in I_{s}} \sum_{h, t} \mathbf{w}_{i s} \mathrm{G}_{i s}^{h t} \quad \rightarrow \text { Wasting cost due to expiration. } \\
& \text { TC: } \quad \sum_{(o, i, s) \in O_{i s}} \sum_{h, t} \boldsymbol{\rho}^{o} \mathbf{r}_{i s}^{o} \mathbf{Y}_{i s}^{\text {oht }} \quad \rightarrow \text { Transporting cost. } \\
& \text { Maximize Profits: } Z=S I-H C O-H C A-R C-W C-T C \text {. }
\end{aligned}
$$

Crisp constraints: The constraint in Eq. (2) guarantees that an order will be served only if all its lines are served. On the other hand, the order will not be served and any of its order lines will be reserved.

$$
\sum_{(i, s) \in I_{s}} \sum_{h, t} \mathbf{Y}_{i s}^{o h t}=\mathbf{n}^{o} \mathbf{U}^{o} \quad \forall o \in O_{i s} .
$$

The constraint in Eq. (3) guarantees that each subtype requested in each order line can only be fulfilled with ATP harvested in the same $h$ and reserved in one only $t$. It is not possible to accumulate subtypes to fulfil order lines.

$$
\sum_{h, t} \mathbf{Y}_{i s}^{o h t} \leqslant 1 \quad \forall(o, i, s) \in O_{i s} .
$$

The constraint in Eq. (4) states that not tardiness is allowed for any promised order. The reservation time must take place before the order's due date less the required transporting time.

$$
\sum_{h, t} t \mathbf{Y}_{i s}^{o h t} \leqslant \mathbf{d}^{o}-\mathbf{t}^{o} \quad \forall(o, i, s) \in O_{i s}
$$

Possibilistic constraints: The constraint in Eq. (5) represents the balance between the total MPS and the production schedule per subtype. This constraint is modelled through a composition of possibilistic variables.

$$
\mathbf{P}_{i}^{h t}=\sum_{s \in I_{s}} \mathbf{M}_{i s}^{h t} \quad \forall i \in I_{s}, h, t .
$$

The constraint in Eq. 6 establishes that the $\mathrm{A}_{i s}^{h t}$ can not be negative. This ensures that promised quantities cannot be higher than the existing MPS.

$$
\mathrm{A}_{i s}^{h t} \geqslant 0 \quad \forall(i, s) \in I_{s}, h, t
$$


Where: The Available To Promise $\mathrm{A}_{i s}^{h t}$ is calculated in Eq. (7). By definition 8, the ATP is obtained as the difference between the MPS in each period of time, less the quantities already promised in previous executions and the quantities promised during the current execution.

$$
A_{i s}^{h t}=\left\{\begin{array}{l}
\mathbf{k}_{i s}^{h}-\mathbf{c}_{i s}^{h t}-\sum_{o \in O_{i s}} r_{i s}^{o} \mathbf{Y}_{i s}^{o h t}, \forall(i, s) \in I_{s}, h, t=0, \\
\mathbf{M}_{i s}^{h t}-\mathbf{c}_{i s}^{h t}-\sum_{o \in O_{i s}} r_{i s}^{o} \mathbf{Y}_{i s}^{o h t}, \forall(i, s) \in I_{s}, h, t>0 .
\end{array}\right.
$$

Furthermore, Eq. (8) calculates the part of the ATP becoming waste in each period, because of ageing effect. It is important to remark that the latter quantity depends on the condition of $t-h$ to be higher than the maximum shelf life, which would imply the expiring.

$$
G_{i s}^{h t}=\left\{\begin{array}{cl}
A_{i s}^{h t}, & \text { if } t-h>\mathbf{L}_{i s}, \quad \forall(i, s) \in I_{s}, h, t, \\
0, \text { otherwise. } &
\end{array}\right.
$$

\subsection{Equivalent MILP model}

In this Subsection we describe the required computations on possibilistic variables and computed intervals of the model, in order to represent it with an equivalent MILP model. We consider all the possibilistic variables as TFI; for example $\mathbf{P}_{i}^{h t}=$ $\left(p_{i}^{1 h t}, p_{i}^{2 h t} p_{i}^{3 h t}\right)$. A possible value in such TFI is represented as a single italic letter with the respective indices, i.e., $p_{i}^{h t}$ is a possible value of $\mathbf{P}_{i}^{h t}$; this same logic applies for all the computed intervals also.

\subsubsection{Computations on the price for the objective function}

We use a piecewise linear ageing function $f(t)$ describing the price state in the time. It is based on the information of the pricing policy given in Grillo et al. [23] where deterministic price ranges were applied. The maximum time value of such ageing function is described by $\mathrm{L}_{i s}=\left(l_{i s}^{1}, l_{i s}^{2}, l_{i s}^{3}\right)$. It considers 4 ranges of price, as showed in Figure 5, with a linear decreasing transition time between consecutive ranges. This function applies for each subtype $s$ of product $i$. The number of constant intervals of the function and the parameters of $\mathrm{L}_{i s}$ should be given, according to the normal behaviour of the product and the decision maker's need.

The price's state over time, is then represented by $\mathbf{E}_{i s}^{o}=\left(e_{i s}^{1 o}, e_{i s}^{2 o}, e_{i s}^{3 o}\right)$ where $e_{i s}^{1 o}=f^{\left(l_{i s}^{1}\right)}(t), e_{i s}^{2 o}=f^{\left(l_{i s}^{2}\right)}(t)$ and $e_{i s}^{3 o}=f^{\left(l_{i s}^{3}\right)}(t)$. 


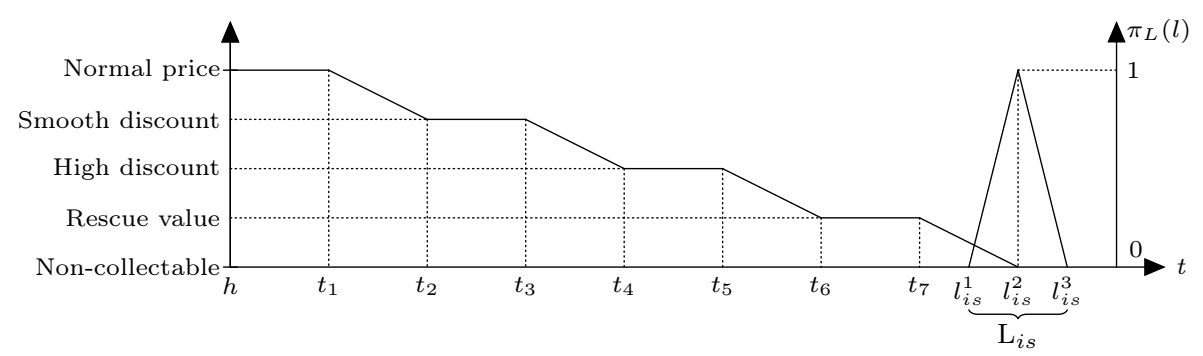

Figure 5: Price-ageing function

Now we can easily compute a conventional interval for the product's price by applying an $\alpha$-cut on $\mathbf{E}_{i s}^{o}$. We obtain $\left(\mathbf{E}_{i s}^{o}\right)_{\alpha}=\left[e_{i s}^{o(\text { a) }}, e_{i s}^{o(b)}\right]$, where:

$$
e_{i s}^{o(\mathrm{a})}=e_{i s}^{1 o}+\alpha\left(e_{i s}^{2 o}-e_{i s}^{1 o}\right), e_{i s}^{o(\mathrm{~b})}=e_{i s}^{3 o}-\alpha\left(e_{i s}^{3 o}-e_{i s}^{2 o}\right) .
$$

Note that in order to compute the price of each subtype requested in $\mathbf{r}_{i s}^{o}$, if it is promised to be delivered in its due date $\mathbf{d}^{o}$, then it is required to evaluate $e_{i s}^{o \text { (a) }}$ and $e_{i s}^{o(\mathrm{~b})}$ in $t=\mathbf{d}^{o} \sum_{h, t} \mathbf{Y}_{i s}^{o h t}$.

Now the model's objective function becomes a matter of limits, lower and upper profit as if each subtype in each order earns the minimum and maximum values of the interval of shelf life-based price respectively.

$$
\begin{array}{lll}
S I(L o w): & \sum_{(o, i, s) \in O_{i s}} \mathbf{r}_{i s}^{o} e_{i s}^{o(a)} & \rightarrow \text { Lower bound of selling income. } \\
\text { SI }(U p): & \sum_{(o, i, s) \in O_{i s}} \mathbf{r}_{i s}^{o} e_{i s}^{o(b)} & \rightarrow \text { Upper bound of selling income. } \\
H C O: & \sum_{(o, i, s) \in O_{i s}} \mathbf{h}_{i s} \mathbf{r}_{i s}^{o}\left(\mathbf{d}^{o}-\mathbf{t}^{o}-\sum_{h, t} t \mathbf{Y}_{i s}^{o h t}\right) & \rightarrow \text { Holding cost of committed orders. } \\
H C A: & \sum_{(i, s) \in I_{s}} \sum_{h, t \leqslant \tau}(\boldsymbol{\tau}-t) \mathbf{h}_{i s} a_{i s}^{h t} & \rightarrow \text { Holding cost of the remaining ATP. } \\
R C: & \sum_{(o, i, s) \in O_{i s}} \sum_{h, t} \mathbf{f}_{i s}^{o}\left(1-\mathbf{Y}_{i s}^{o h t}\right) & \rightarrow \text { Rejected order's cost. } \\
W C: & \sum_{(i, s) \in I_{s}} \sum_{h, t} \mathbf{w}_{i s} g_{i s}^{h t} & \rightarrow \text { Wasting cost due to expiration. } \\
T C: & \sum_{(o, i, s) \in O_{i s}} \sum_{h, t} \boldsymbol{\rho}^{o} \mathbf{r}_{i s}^{o} \mathbf{Y}_{i s}^{\text {oht }} & \rightarrow \text { Transporting cost. }
\end{array}
$$

Lower profit:

$$
Z_{a}=S I(L o w)-H C O-H C A-R C-W C-T C .
$$

Upper profit:

$$
Z_{b}=S I(U p)-H C O-H C A-R C-W C-T C .
$$

Note that $H C A$ and $W C$ now depend on possible values of their possibilistic variables respectively. The optimization strategy will rely on the decision maker's needs, for example, maximize the lower profit, maximize the upper profit or maximize the average of both (balanced). 


\subsubsection{Computations on the possibilistic constraints}

We start by describing the computations on the constraint in Eq. (5) modelled as a composition of possibilistic variables. We follow now the $\alpha$-cut approach explained in Subsection 2.3. Since we have already used and $\alpha$-cut for the computations in the product's price, in this part we use $\gamma$-cut to differentiate them. We must include the following equations according to the procedure

$$
\begin{gathered}
p_{i}^{h t}=\sum_{s \in I_{s}} m_{i s}^{h t} \quad \forall i \in I_{s}, h, t . \\
m_{i s}^{h t} \geqslant m_{i s}^{1 h t}+\gamma\left(m_{i s}^{2 h t}-m_{i s}^{1 h t}\right) \quad \forall(i, s) \in I_{s}, h, t . \\
m_{i s}^{h t} \leqslant m_{i s}^{3 h t}-\gamma\left(m_{i s}^{3 h t}-m_{i s}^{2 h t}\right) \quad \forall(i, s) \in I_{s}, h, t . \\
p_{i}^{h t} \geqslant p_{i}^{1 h t}+\gamma\left(p_{i}^{2 h t}-p_{i}^{1 h t}\right) \quad \forall i, h, t . \\
p_{i}^{h t} \leqslant p_{i}^{3 h t}-\gamma\left(p_{i}^{3 h t}-p_{i s}^{2 h t}\right) \quad \forall i, h, t .
\end{gathered}
$$

And the remaining constraints will now turn now into

$$
a_{i s}^{h t} \geqslant 0 \quad \forall(i, s) \in I_{s}, h, t .
$$

Where:

$$
a_{i s}^{h t}=\left\{\begin{array}{l}
\mathbf{k}_{i s}^{h}-\mathbf{c}_{i s}^{h t}-\sum_{o \in O_{i s}} r_{i s}^{o} \mathbf{Y}_{i s}^{o h t}, \forall(i, s) \in I_{s}, h, t=0, \\
m_{i s}^{h t}-\mathbf{c}_{i s}^{h t}-\sum_{o \in O_{i s}} r_{i s}^{o} \mathbf{Y}_{i s}^{o h t}, \forall(i, s) \in I_{s}, h, t>0 .
\end{array}\right.
$$

and

$$
g_{i s}^{h t}=\left\{\begin{array}{cl}
a_{i s}^{h t}, & \text { if } t-h>l_{i s}^{3}, \quad \forall(i, s) \in I_{s}, h, t \\
0, & \text { otherwise. }
\end{array}\right.
$$

The crisp constraints remain the same.

\subsubsection{Equivalent MILP model}

In summary the MILP equivalent model will be

\section{Maximize:}

(1) Eq. 9 for profit's lower bound maximization,

(2) Eq. 10 for profit's upper bound maximization,

(3) $\frac{Z_{a}+Z_{b}}{2}$ for a balanced optimization strategy. 


\section{Subject to:}

- Eq. 2 to Eq. (4)

- Eq. 11] to Eq. 16 .

\section{Considering:}

- Eq. 17) and Eq. 18

\subsubsection{Implementing dynamic batching mode}

In order to implement the model in a batching mode, it is required to perform an actualization of input data between consecutive executions. Specifically parameters $\mathbf{k}_{i s}^{h}$ and $\mathbf{c}_{i s}^{h t}$ should be updated according to the procedure explained in Grillo et al. 23]. The main difference in this case, is that we consider the orders are served at the beginning of each period. Then, it is expected that any quantity of the initial stock is previously committed because it is the remaining product after serving orders. Considering $e$ as the current execution in the batching mode, the actualization is computed in the following Eqs. (19) and 20

$$
\begin{array}{cc}
\mathbf{c}(e+1)_{i s}^{h t}=\mathbf{c}(e)_{i s}^{h t}+\sum_{o \in O_{i s}} \mathbf{r}_{i s}^{o} \mathbf{Y}_{i s}^{o h t}, & \forall(i, s) \in I_{s}, h, t>\boldsymbol{\tau} . \\
\mathbf{k}(e+1)_{i s}^{h}=\sum_{t \leqslant \boldsymbol{\tau}}\left(a_{i s}^{h t}-g_{i s}^{h t}\right), & \forall(i, s) \in I_{s}, h .
\end{array}
$$

Finally, once the parameters $\mathbf{c}(e+1)_{i s}^{h t}$ and $\mathbf{k}(e+1)_{i s}^{h}$ have been computed, it is required to execute for both of them an actualization of the indices $t$ and $h$. This is because, from one execution to the next one, the product aged $\tau$ periods. This is achieved with the following Eq. 21

$$
\operatorname{ind}(e+1)=\operatorname{ind}(e)-\tau, \quad \forall i n d=h \vee \operatorname{ind}=t .
$$

Note that for the case of parameter $\mathbf{c}(e+1)_{i s}^{h t}$ with its indices $h$ and $t$ updated, it should coincide with enough supply in the possibilistic variables $\mathbf{P}_{i}^{h t}$ and $\mathbf{M}_{i s}^{h t}$ in execution $e+1$; otherwise the model would go infeasible.

\section{Experimental design: application to an orange an tangerine supply chain}

In this section we will validate the model with the application to a real case of a Spanish supply chain of the fruit sector, specifically the packing and distribution of orange and tangerine. The implementation was carried out using the CMPL mathematical programming language 24 to code the model, and an algorithm of execution to implement the batching mode and different instances of evaluation 
developed in Java. CMPL supports different commercial and non commercial optimizers available in the market. In our case, the Gurobi 7.2 solver was used. Experiments were executed by an Intel (R) Core (TM) i7-4510 CPU $2.60 \mathrm{GHz}$ processor, with 8GB RAM under a Ubuntu 14.04 - Linux operative system.

\subsection{Input data overview}

In order to test the model, we have based our data set in that presented in Grillo et al. 23]. It comes from a Spanish supply chain dedicated to pack and distribute oranges and tangerines. The scenario includes one packing plant with two products (oranges and tangerines) that can be subdivided in 8 and 7 subtypes each one respectively. Transporting costs and times are considered as well as inventory holding cost and wasting cost due to product's decay. The orders from customers have between one to ten lines. As in Grillo et al. [23, a total of eighty-eight incoming orders are considered. The orders are promised twice a week by considering a 3-day batching interval and a 6-day horizon length. The global horizon for the experiments includes seventeen periods subdivided into four executions. The complete data set for the model can be consulted in Appendix A.

\subsection{Definition of evaluation instances}

Here we define the cases that will be evaluated in the numerical experiments. We focus in the elements that need to be given by the decision maker beforehand the execution.

Optimization strategy: Given the three possibilities mentioned in Subsection 4.3.3. for simplicity, we use the profit's average maximization as the objective function (which is one of the commonest strategies followed in this type of optimization).

The $\alpha$-cut and $\gamma$-cut: As we have previously described in Subsections 4.3.1 and 4.3 .2 , the $\alpha$-cut and $\gamma$-cut are applied in order to find equivalent crisp intervals in the computations of the possibilistic price and the possibilistic composition modelling the master plans. Both parameters must be in the interval $[0,1]$. We will discretise both parameters starting in 0.2 with steps of 0.2 until 1 . Thus we will evaluate the points $\{0.2,0.4,0.6,0.8,1.0\}$. We will use such values because they are representative in order to explore the trend of the model as both parameters increase their values. In the case under study, the $\alpha$-cut regulates the uncertainty degree in the product's shelf life; the closer $\alpha$ is to 1 , the less uncertainty in the extension of the shelf life, and as a consequence, the price of the product resembles more to the one determined by piecewise linear ageing function used in our case. Meanwhile, the $\gamma$-cut has the same role, but in the total MPS and the MPS per subtype.

In summary, we will execute the model 5 times per each case of the $\alpha$-cut and 5 times per each case of the $\gamma$. Since the model will be executed in batching mode, 
a full run is composed by 4 executions given the bathing window considered and the planning horizon. This brings a total amount of $5 * 5 * 4=100$ executions.

\subsection{Results}

\subsubsection{Committed orders and generated profits}

In terms of practical application, the decision maker's main interest of our model is the resulting values of the binary variables $\mathbf{Y}_{i s}^{\text {oht }}$ and $\mathbf{U}^{o}$ (as well as the profit generated by them) since they answer to the questions of what orders to accept, and what ATP to use in order to fulfil them. The model' solution returns the values of $\mathbf{Y}_{i s}^{\text {oht }}$ and $\mathbf{U}^{o}$ considering that the supply remains within the intervals established by the $\gamma$-cut in the TFI describing the possibilistic variables $\mathbf{P}_{i}^{h t}$ and $\mathbf{M}_{i s}^{h t}$. Additionally, the limits of profit in the objective function should be seen as the lower and upper possible values that can be earned if such configuration of the variables $\mathbf{Y}_{i s}^{\text {oht }}$ and $\mathbf{U}^{o}$ were executed in reality. This is, the selling incomes achieved if the set of accepted orders are paid based on the lower and upper price respectively resulting from the $\alpha$-cut in $\mathbf{E}_{i s}^{o}$. Note that the parameters of the TFI used to describe $\mathbf{E}_{i s}^{o}$ depend on the product's maximum shelf life, i.e., the TFI describing $\mathbf{L}_{i s}$. This is the key point of our shelf-life based pricing policy.

As regards the expected behaviour of the results in relation to the parameters $\alpha$ and $\gamma$, we can say that the lower and upper limits of profit should get closer in the way that both parameters increase their value. This is because both the master plan and the shelf life get closer to the central values of their respective TFI. The greater the value of $\gamma$, the smaller the crisp interval for the MPS. Regarding to the shelf life, since the product's price is linked with its ageing process, the greater $\alpha$, the smaller difference between bounds of the product's price in the same expected delivery date. The results of profit obtained are showed graphically in Figure 6 .

It can be observed how the expected trend is properly achieved. In cases when the same value of alpha is maintained, the limits of profit get farther in the way that gamma is near to 1 . This behaviour is expected considering that, for one same alpha, the lower and upper product's price remains the same while the supply varies within the intervals defined by the $\gamma$-cut. Hence, if more or less supply are available according to gamma's variation, consequently more or less orders are accepted (see orange curve in Figure 6). Those orders will be paid within the same upper and lower price if alpha stays constant. Otherwise they will be paid with a smaller upper price and with a bigger lower price if alpha gets near to 1 . This is why, in the way that alpha gets near to one, the lower and upper limits of profit, curves blue and red in Figure 6, get closer independently of the gamma value.

It is important to remark that, when gamma is near to 0 , the supply has a very opened range of variation, then the model has considerably more solution space to find better combinations. This fact can also be confirmed in Figure 6 in the way that gamma increases, both lower and upper limits of profit, and the total 


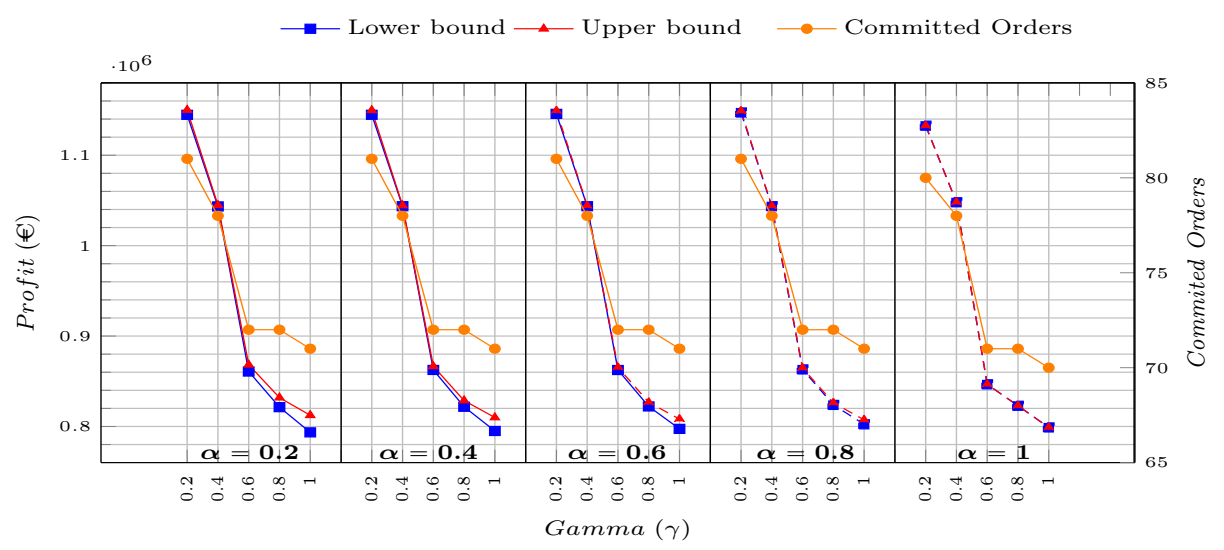

Figure 6: Experimental results

quantity of committed orders lower. As we mentioned before, this is because the possible values of supply, $m_{i s}^{h t}$ and $p_{i}^{h t}$, have less possible combinations, and they get closer to the the crisp values $m_{i s}^{2 h t}$ and $p_{i}^{2 h t}$ respectively. The negative part of gamma near to 0 is that such opened solution space imply a huge level of uncertainty. Then, there is a proportional risk level in the final solution, i.e., the resulting accepted orders cannot be finally served when the real quantities of supply are available due to shortages. If the orders finally served with real supply are considerably different of those accepted with planned supply, the real profit could go out of the interval established by the respective lower and upper planned bounds. Take a special look in the Figure 6 for the gamma values 0.2 and 0.4 . The orders accepted and the profits achieved are considerably higher than the rest of the cases tested. This is because of the already explained opened solutions space in the possibilistic composition applied. See how variations in the supply limits can critically affect the possibility to accept or reject an order. But in term of practical implementations, such solutions will involve high uncertainty and the orders could not be finally served. Instead, for combinations of gamma near to 1 , it is expected that the planned supply has less uncertainty involved and will be near to the real quantities. Then, the accepted orders have considerably more probability to be finally served. The decision of what case is better or not will be briefly described in the next Subsection 5.3.2.

These results validate the proper functionality of the model. The composition of possibilistic variables applied to model the LHP's effect has worked in a very good way in terms of the interpretation of the situation versus the complexity in the modelling approach achieved. For its part, the state functions and ageing functions 
have proven a correct functionality and a very good performance in therms of the usefulness they have when linking related variables to the product's ageing process.

\subsubsection{Managerial insights}

From the managerial point of view, it is required to analyse the detail of the objective function in order to evaluate the suitability of the different instances of $\alpha$ and $\gamma$ tested. Table 2 shows the different results of the profit's components.

Table 2: Objective function components

\begin{tabular}{|c|c|c|c|c|c|c|c|c|}
\hline$\alpha$ & $\gamma$ & SI(Low) & SI(Up) & HCO & HCA & RC & WC & TC \\
\hline 0.2 & 0.2 & $1,444,992$ & $1,439,689$ & 21,771 & 21,155 & 56,553 & 19,787 & 175,700 \\
& 0.4 & $1,370,322$ & $1,368,980$ & 24,003 & 23,647 & 88,269 & 22,584 & 167,087 \\
& 0.6 & $1,235,201$ & $1,227,720$ & 28,632 & 28,362 & 132,532 & 23,672 & 153,747 \\
& 0.8 & $1,209,038$ & $1,198,515$ & 30,226 & 29,248 & 146,114 & 22,928 & 148,652 \\
& 1 & $1,191,265$ & $1,172,360$ & 31,577 & 29,933 & 151,126 & 19,795 & 146,453 \\
\hline 0.4 & 0.2 & $1,444,686$ & $1,439,725$ & 21,771 & 21,155 & 56,553 & 19,787 & 175,700 \\
& 0.4 & $1,370,051$ & $1,369,189$ & 24,003 & 23,647 & 88,269 & 22,584 & 167,087 \\
& 0.6 & $1,233,460$ & $1,229,472$ & 28,810 & 28,184 & 132,532 & 23,672 & 153,747 \\
& 0.8 & $1,205,819$ & $1,198,973$ & 30,273 & 29,201 & 146,114 & 22,928 & 148,652 \\
& 1 & $1,189,421$ & $1,174,529$ & 31,383 & 30,061 & 151,348 & 20,274 & 146,453 \\
\hline 0.6 & 0.2 & $1,444,187$ & $1,440,738$ & 21,808 & 21,118 & 56,553 & 19,787 & 175,700 \\
& 0.4 & $1,369,729$ & $1,369,189$ & 24,003 & 23,647 & 88,269 & 22,584 & 167,087 \\
& 0.6 & $1,232,774$ & $1,229,871$ & 28,691 & 28,303 & 132,532 & 24,151 & 153,747 \\
& 0.8 & $1,204,386$ & $1,199,804$ & 30,194 & 29,280 & 146,114 & 23,408 & 148,652 \\
& 1 & $1,187,666$ & $1,176,863$ & 31,383 & 30,061 & 151,348 & 20,274 & 146,453 \\
\hline 0.8 & 0.2 & $1,443,730$ & $1,442,174$ & 21,835 & 20,999 & 56,553 & 19,787 & 175,700 \\
& 0.4 & $1,369,505$ & $1,369,189$ & 24,003 & 23,647 & 88,269 & 22,584 & 167,087 \\
& 0.6 & $1,232,024$ & $1,230,515$ & 28,731 & 28,263 & 132,532 & 24,151 & 153,747 \\
& 0.8 & $1,203,795$ & $1,201,493$ & 30,194 & 29,280 & 146,114 & 23,408 & 148,652 \\
& 1 & $1,186,864$ & $1,181,896$ & 31,372 & 30,072 & 151,348 & 20,274 & 146,453 \\
\hline 1 & 0.2 & $1,430,974$ & $1,430,974$ & 22,718 & 20,002 & 63,891 & 17,641 & 174,014 \\
& 0.4 & $1,367,529$ & $1,367,529$ & 24,543 & 22,292 & 88,269 & 17,350 & 167,087 \\
& 0.6 & $1,215,756$ & $1,215,756$ & 30,161 & 27,915 & 140,546 & 19,408 & 151,108 \\
& 0.8 & $1,199,473$ & $1,199,473$ & 31,094 & 28,707 & 150,070 & 19,372 & 147,333 \\
& 1 & $1,180,333$ & $1,180,333$ & 32,199 & 30,354 & 156,221 & 17,198 & 145,427 \\
\hline
\end{tabular}

For supply chain planning problems, in this type of optimization based on possibility distributions and $\alpha$-cuts, it appears as a common practice to discard values of alpha less than 0.5 because it is considered a very high level of uncertainty 8]. Then, in order to analyse the data of Table 2, let consider the values of alpha and gamma more than 0.5 (0.6 and 0.8 in the evaluated cases) compared to the case when alpha and gamma have a value of 1 (this would be the deterministic behaviour). The Table 3 shows the resulting variation percentages of such comparison.

Table 3: Variation percentage (\%) vs deterministic case

\begin{tabular}{|l|c|c|c|c|c|c|c|c|c|c|}
\hline$\alpha$ & $\gamma$ & SI(Low) & SI(Up) & HCO & HCA & RC & WC & TC & $Z_{a}$ & $Z_{b}$ \\
\hline 0.6 & 0.6 & 4.20 & 4.44 & -10.89 & -6.76 & -15.16 & 40.44 & 5.72 & 7.95 & 8.31 \\
& 0.8 & 1.65 & 2.04 & -6.23 & -3.54 & -6.47 & 36.11 & 2.22 & 2.91 & 3.48 \\
\hline 0.8 & 0.6 & 4.25 & 4.38 & -10.77 & -6.89 & -15.16 & 40.44 & 5.72 & 8.03 & 8.22 \\
& 0.8 & 1.79 & 1.99 & -6.23 & -3.54 & -6.47 & 36.11 & 2.22 & 3.12 & 3.41 \\
\hline
\end{tabular}


From the pricing policy side, it is clear that better results are achieved when $\alpha=0.8$ for both, the selling incomes and cost performance. One can think that better results should be achieved for $\alpha=0.6$ because this means more variability in the products' shelf life. This is not necessarily true because of the conflicting situation with wasting costs at expenses of selling more fresh product, and the interaction with the uncertainty in the supply. Hence, for this specific case, with this data set in the evaluated instances, it would be a better option to consider $\alpha=0.8$ given the results in profit for both cases of gamma.

As regards the uncertainty in supply, based on the configuration of the data set for the possibilistic variable $\mathbf{M}_{i s}^{h t}$, a $\gamma=0.6$ would imply a range of variation from 0 to 0.9 truck (one truck includes around 30 pallets, $750 \mathrm{Kg}$ ) of product at most, depending on the subtype. Meanwhile, a $\gamma=0.8$ would imply a range from 0 to 0.4 truck. Based on this, both cases are relatively reasonable, and it will depend on the decision makers the option to choose. If they are able to risk more, $\gamma=0.6$ would be the option with the aim to earn about $5 \%$ more than if they consider $\gamma=0.8$. Otherwise if they prefer to handle a less risky solution, with less profit (about 3\% more than the deterministic case), but with a relatively small risk, $\gamma=0.8$ would be the option. There are other approaches used to evaluate the suitability of the $\alpha$-cuts, for example in Alemany et al. 8 where an interactive procedure is applied computing a fuzzy decision vector based on decision maker's requirements, or in Grillo et al. 25] where another interactive procedure based on fuzzy TOPSIS is applied. These type of analysis are out of the scope of this work, but readers are refereed to them in order to see practical examples.

\subsubsection{Computational efficiency}

Finally, the Table 4 shows the computational efficiency data of the model executions. It can be seen how the model has a very good performance in terms of resolution time with the solutions matrix's size considered in this case.

Table 4: Computational efficiency

\begin{tabular}{|c|c|c|c|c|c|c|}
\hline Execution & Constraints & $\begin{array}{c}\text { Binary } \\
\text { variables }\end{array}$ & $\begin{array}{c}\text { Continuous } \\
\text { variables }\end{array}$ & Non-zeros & $\begin{array}{c}\text { Aver. sol. } \\
\text { time (s) }\end{array}$ & $\%$ Gap \\
\hline$e_{1}$ & 12,194 & 13,246 & 7,438 & 130,718 & 2.08 & 0.001 \\
$e_{2}$ & 12,188 & 12,790 & 7,438 & 126,923 & 2.09 & 0.001 \\
$e_{3}$ & 12,192 & 13,094 & 7,438 & 129,453 & 2.09 & 0.001 \\
$e_{4}$ & 12,174 & 11,726 & 7,438 & 118,106 & 1.96 & 0.001 \\
\hline
\end{tabular}




\section{Conclusions}

Compositions of possibilistic variables are based on the concept of compositional data where different elements of a vector should add up to a specific resulting quantity. We considered not only the case when the elements are possibilistic variables, but also the case when the resulting quantity is another possibilistic variable. This type of compositions can be applied to a wide open variety of situations when the conventional compositional data is not recommended due to the existence of epistemic uncertainty in the composition's components. The $\alpha$-cut approach is applied in order to simplify the application of compositions into linear mathematical programming, obtaining more computational efficient models.

Furthermore, we introduced the concepts of state functions, which describe the "state" of a variable over the time. If a state function is used to model product's decay, it is called ageing function. This type of functions are defined from an initial time until an uncertain ending time represented by a possibilistic variable. Ageing functions allow to link related shelf life-based variables, for example price, and describe them also as possibilistic variables. This modelling approach has the advantage of being an easy and good performing option to be applied in several types of situations when dealing with perishables.

In order to exemplify the application of compositions with possibilistic variables and ageing functions into linear mathematical modelling, we have developed a model of a supply chain planning problem, specifically the order promising process, where both concepts can be applied simultaneously. The compositions are used to represent the effect of the so called Lack of Homogeneity in Product, LHP, in the master production schedule when the handled product is perishable and as a consequence it must be classified in subtypes. The total master production schedule and its corresponding quantities per subtype are represented as a composition of possibilistic variables. Moreover, since the product is perishable, some of its characteristics can change with time. We use an ageing function to link product's price. Hence, this application includes both concepts, the compositions of possibilistic variables to model the master plan schedule from which the orders must be promised, and the ageing functions to model product's price at delivery time.

Practical experiments have been executed by applying the model to a real case of a Spanish supply chain of the fruit sector, specifically the packing and distribution of oranges an tangerines. We have used a data set based on real information given by the supply chain, and we have executed different instances in a batching ordering mode in rolling horizon. The results obtained validated the correct model's functionality with a very good computational performance. We also presented some managerial insights in order to exemplify the usefulness that a tool like this has for decision makers.

Compositions of possibilistic variables and state functions can be applied in other type of problems, not just supply chain, but other areas like technology, mathemat- 
ics and other problems in the engineering field. Regarding to the order-promising processes, we recommend to apply them in an extended model, considering additional features like different manufacturing strategies, renegotiation processes for the rejected orders, advance and delays, etc. We also recommend the application of these tools for problems of more operative level for perishables, where the changes of state can occur in very short periods of time, for example, operations of transformation of a row material, freezing or holding of finished products, transportation under controlled conditions, etc. Another interesting case would be the application in the handling of by-products.

\section{Acknowledgement}

This research has been supported by the Ministry of Science, Technology and Telecommunications, government of Costa Rica (MICITT), through the program of innovation and human capital for competitiveness (PINN) (Contract number PED-019-2015-1). We would also thank Msc. José de Jesús Arias García for useful discussions during the development of this work.

\section{Appendix A Input data}

We have based our data set in that presented in Grillo et al. 23] with the required modifications in order to implement the compositions of possibilistic variables and the state functions. The global horizon length includes 17 periods (in order

Table A.1: Products, subtypes and shelf-life values

\begin{tabular}{|c|c|c|c|c|}
\hline \multirow{2}{*}{ Product (i) } & \multirow[b]{2}{*}{ Subtypes (s) } & \multicolumn{3}{|c|}{$\mathbf{L}_{i s}$ (days) } \\
\hline & & $l_{i s}^{1}$ & $l_{i s}^{2}$ & $l_{i s}^{3}$ \\
\hline \multirow[t]{2}{*}{$i_{1}$ (Orange) } & $\begin{array}{l}s_{1} \text { (First quality, calibre 1, Box-paperboard 10kg) } \\
s_{2} \text { (First quality, calibre 1, Net 1.2kg) } \\
s_{3} \text { (First quality, calibre 1, Bulk) } \\
s_{4} \text { (First quality, calibre 2, Box-paperboard 10kg) } \\
s_{5} \text { (First quality, calibre 3, Box-paperboard 10kg) } \\
s_{6} \text { (First quality, calibre 4, Box-paperboard 10kg) }\end{array}$ & 8 & 10 & 12 \\
\hline & $\begin{array}{l}s_{7} \text { (Second quality, calibre } 1, \text { Bulk) } \\
\left.s_{8} \text { (Second quality, calibre } 4, \text { Box-wood } 15 \mathrm{~kg}\right)\end{array}$ & 7 & 9 & 11 \\
\hline \multirow[t]{2}{*}{$i_{2}$ (Tangerine) } & $\begin{array}{l}s_{9} \text { (First quality, calibre 5, Box-paperboard 10kg) } \\
\left.s_{10} \text { (First quality, calibre } 5, \text { Net } 750 \mathrm{~g}\right) \\
s_{11} \text { (First quality, calibre } 5, \text { Net } 1.2 \mathrm{~kg} \text { ) } \\
s_{12} \text { (First quality, calibre 6, Box-paperboard } 10 \mathrm{~kg} \text { ) } \\
s_{13} \text { (First quality, calibre } 7, \text { Box-paperboard } 10 \mathrm{~kg} \text { ) } \\
s_{14} \text { (First quality, calibre } 8, \text { Box-paperboard } 10 \mathrm{~kg} \text { ) }\end{array}$ & 8 & 10 & 12 \\
\hline & $s_{15}$ (Second quality, calibre 8, Box-paperboard 10kg) & 7 & 9 & 11 \\
\hline
\end{tabular}

to consider two weeks of incoming orders at least), subdivided into four OPP executions with a planning horizon of six periods each. The orders are promised 
Table A.2: Price data

\begin{tabular}{|l|l|c|c|c|c|}
\hline$i$ & $s$ & Normal price & Smooth discount & High discount & Rescue value \\
\hline$i_{1}$ & $s_{1}$ & 1.19 & 0.833 & 0.595 & 0.357 \\
& $s_{2}$ & 1.17 & 0.819 & 0.585 & 0.351 \\
& $s_{3}$ & 1.15 & 0.805 & 0.575 & 0.345 \\
& $s_{4}$ & 1.13 & 0.791 & 0.565 & 0.339 \\
& $s_{5}$ & 1.07 & 0.749 & 0.535 & 0.321 \\
& $s_{6}$ & 1.01 & 0.707 & 0.505 & 0.303 \\
& $s_{7}$ & 0.92 & 0.644 & 0.46 & 0.276 \\
& $s_{8}$ & 0.95 & 0.665 & 0.475 & 0.285 \\
\hline$i_{2}$ & $s_{9}$ & 1.21 & 0.847 & 0.605 & 0.363 \\
& $s_{10}$ & 1.18 & 0.826 & 0.59 & 0.354 \\
& $s_{11}$ & 1.24 & 0.868 & 0.62 & 0.372 \\
& $s_{12}$ & 1.12 & 0.784 & 0.56 & 0.336 \\
& $s_{13}$ & 1.06 & 0.742 & 0.53 & 0.318 \\
& $s_{14}$ & 1.01 & 0.707 & 0.505 & 0.303 \\
& $s_{15}$ & 0.81 & 0.567 & 0.405 & 0.243 \\
\hline
\end{tabular}

$\left.{ }^{*}\right)$ Data in $€$

Table A.3: Inventory holding and waste costs

\begin{tabular}{|c|c|c|c|}
\hline$i$ & $s$ & $\mathbf{h}_{i s}\left(\frac{€}{k g \cdot d a y}\right)$ & $\mathbf{w}_{i s}\left(\frac{€}{k g}\right)$ \\
\hline$i_{1}$ & $s_{1}$ & 0.018 & 0.3221 \\
& $s_{2}$ & 0.018 & 0.322 \\
& $s_{3}$ & 0.017 & 0.322 \\
& $s_{4}$ & 0.017 & 0.322 \\
& $s_{5}$ & 0.016 & 0.322 \\
& $s_{6}$ & 0.015 & 0.322 \\
& $s_{7}$ & 0.014 & 0.322 \\
& $s_{8}$ & 0.014 & 0.322 \\
\hline$i_{2}$ & $s_{9}$ & 0.018 & 0.327 \\
& $s_{10}$ & 0.018 & 0.327 \\
& $s_{11}$ & 0.019 & 0.327 \\
& $s_{12}$ & 0.017 & 0.327 \\
& $s_{13}$ & 0.016 & 0.327 \\
& $s_{14}$ & 0.015 & 0.327 \\
& $s_{15}$ & 0.012 & 0.327 \\
\hline \multicolumn{3}{|c}{}
\end{tabular}


Table A.4: Order's data

\begin{tabular}{|c|c|c|c|c|c|c|c|c|c|c|c|}
\hline Exec. & $O$ & $d^{\circ}$ & $\mathbf{n}^{\circ}$ & $\mathbf{t}^{\circ}$ & $\rho^{\circ}$ & Exec. & $O$ & $\mathrm{~d}^{\circ}$ & $\mathbf{n}^{\circ}$ & $\mathbf{t}^{O}$ & $\rho^{\circ}$ \\
\hline \multirow{22}{*}{$e_{1}$} & $o_{1}$ & 3 & 9 & 1 & 0.10 & \multirow[t]{22}{*}{$e_{3}$} & $O_{45}$ & 3 & 9 & 1 & 0.10 \\
\hline & $o_{2}$ & 4 & 2 & 2 & 0.10 & & $o_{46}$ & 2 & 2 & 1 & 0.10 \\
\hline & $o_{3}$ & 3 & 4 & 1 & 0.10 & & $O_{47}$ & 4 & 4 & 1 & 0.10 \\
\hline & $o_{4}$ & 4 & 1 & 2 & 0.15 & & $O_{48}$ & 3 & 1 & 1 & 0.15 \\
\hline & $o_{5}$ & 3 & 1 & 1 & 0.10 & & $o_{49}$ & 4 & 1 & 1 & 0.10 \\
\hline & $o_{6}$ & 4 & 7 & 2 & 0.15 & & $O_{50}$ & 5 & 7 & 2 & 0.15 \\
\hline & $o_{7}$ & 5 & 3 & 2 & 0.15 & & $o_{51}$ & 5 & 3 & 2 & 0.15 \\
\hline & $o_{8}$ & 5 & 1 & 2 & 0.15 & & $o_{52}$ & 5 & 1 & 2 & 0.15 \\
\hline & $o_{9}$ & 2 & 1 & 1 & 0.10 & & $o_{53}$ & 3 & 1 & 1 & 0.10 \\
\hline & $o_{10}$ & 6 & 7 & 2 & 0.15 & & $o_{54}$ & 4 & 7 & 2 & 0.15 \\
\hline & $o_{11}$ & 6 & 6 & 2 & 0.15 & & $o_{55}$ & 6 & 6 & 2 & 0.15 \\
\hline & $o_{12}$ & 3 & 4 & 1 & 0.10 & & $O_{56}$ & 2 & 4 & 1 & 0.1 \\
\hline & $o_{13}$ & 5 & 6 & 1 & 0.15 & & $O_{57}$ & 6 & 6 & 1 & 0.15 \\
\hline & $o_{14}$ & 4 & 4 & 2 & 0.15 & & $o_{58}$ & 3 & 4 & 1 & 0.15 \\
\hline & $o_{15}$ & 6 & 1 & 2 & 0.15 & & $o_{59}$ & 6 & 1 & 2 & 0.15 \\
\hline & $o_{16}$ & 5 & 5 & 2 & 0.15 & & $o_{60}$ & 4 & 5 & 2 & 0.15 \\
\hline & $o_{17}$ & 4 & 3 & 2 & 0.15 & & $o_{61}$ & 5 & 3 & 2 & 0.15 \\
\hline & $o_{18}$ & 6 & 2 & 2 & 0.15 & & $o_{62}$ & 6 & 2 & 2 & 0.15 \\
\hline & $o_{19}$ & 6 & 5 & 2 & 0.15 & & $o_{63}$ & 6 & 5 & 2 & 0.15 \\
\hline & $o_{20}$ & 6 & 1 & 2 & 0.15 & & $o_{64}$ & 6 & 1 & 2 & 0.15 \\
\hline & $o_{21}$ & 6 & 10 & 1 & 0.15 & & $o_{65}$ & 6 & 9 & 1 & 0.15 \\
\hline & $o_{22}$ & 6 & 4 & 2 & 0.15 & & $o_{66}$ & 6 & 4 & 2 & 0.15 \\
\hline \multirow[t]{22}{*}{$e_{2}$} & $O_{23}$ & 4 & 9 & 1 & $\overline{0.10}$ & \multirow[t]{22}{*}{$e_{4}$} & $o_{67}$ & 5 & 7 & 1 & 0.1 \\
\hline & $o_{24}$ & 2 & 2 & 1 & 0.10 & & $o_{68}$ & 3 & 2 & 1 & 0.10 \\
\hline & $o_{25}$ & 2 & 1 & 1 & 0.10 & & $o_{69}$ & 3 & 1 & 1 & 0.10 \\
\hline & $o_{26}$ & 5 & 1 & 2 & 0.15 & & $o_{70}$ & 5 & 1 & 2 & 0.15 \\
\hline & $o_{27}$ & 3 & 4 & 1 & 0.10 & & $o_{71}$ & 2 & 4 & 1 & 0.10 \\
\hline & $o_{28}$ & 3 & 1 & 1 & 0.15 & & $O_{72}$ & 4 & 1 & 2 & 0.15 \\
\hline & $o_{29}$ & 5 & 1 & 2 & 0.15 & & $o_{73}$ & 6 & 1 & 2 & 0.15 \\
\hline & $o_{30}$ & 5 & 6 & 2 & 0.15 & & $o_{74}$ & 5 & 5 & 2 & 0.15 \\
\hline & $o_{31}$ & 2 & 3 & 1 & 0.10 & & $o_{75}$ & 4 & 3 & 1 & 0.10 \\
\hline & $o_{32}$ & 5 & 6 & 2 & 0.15 & & $o_{76}$ & 4 & 5 & 2 & 0.15 \\
\hline & $o_{33}$ & 6 & 4 & 2 & 0.15 & & $o_{77}$ & 6 & 4 & 2 & 0.15 \\
\hline & $o_{34}$ & 2 & 5 & 1 & 0.10 & & $o_{78}$ & 2 & 5 & 1 & 0.10 \\
\hline & $o_{35}$ & 6 & 7 & 2 & 0.15 & & $o_{79}$ & 6 & 7 & 2 & 0.15 \\
\hline & $o_{36}$ & 4 & 5 & 1 & 0.15 & & $o_{80}$ & 3 & 5 & 1 & 0.15 \\
\hline & $o_{37}$ & 6 & 4 & 2 & 0.15 & & $o_{81}$ & 6 & 4 & 2 & 0.15 \\
\hline & $o_{38}$ & 3 & 1 & 1 & 0.15 & & $o_{82}$ & 4 & 1 & 2 & 0.15 \\
\hline & $o_{39}$ & 3 & 2 & 1 & 0.15 & & $o_{83}$ & 4 & 2 & 1 & 0.15 \\
\hline & $o_{40}$ & 6 & 10 & 1 & 0.15 & & $o_{84}$ & 6 & 8 & 1 & 0.15 \\
\hline & $o_{41}$ & 6 & 3 & 2 & 0.15 & & $O_{85}$ & 6 & 3 & 2 & 0.15 \\
\hline & $o_{42}$ & 6 & 4 & 2 & 0.15 & & $o_{86}$ & 6 & 3 & 2 & 0.15 \\
\hline & $o_{43}$ & 6 & 1 & 2 & 0.15 & & $o_{87}$ & 6 & 1 & 2 & 0.15 \\
\hline & $O_{44}$ & 6 & 4 & 2 & 0.15 & & $o_{88}$ & 6 & 4 & 2 & 0.15 \\
\hline
\end{tabular}

$\left(^{*}\right) \boldsymbol{\rho}^{o}$ is expressed in $\left(\frac{€}{\text { unit.day }}\right), \mathbf{d}^{o}$ and $\mathbf{f}^{o}$ are expressed in days 
Table A.5: Master production schedule

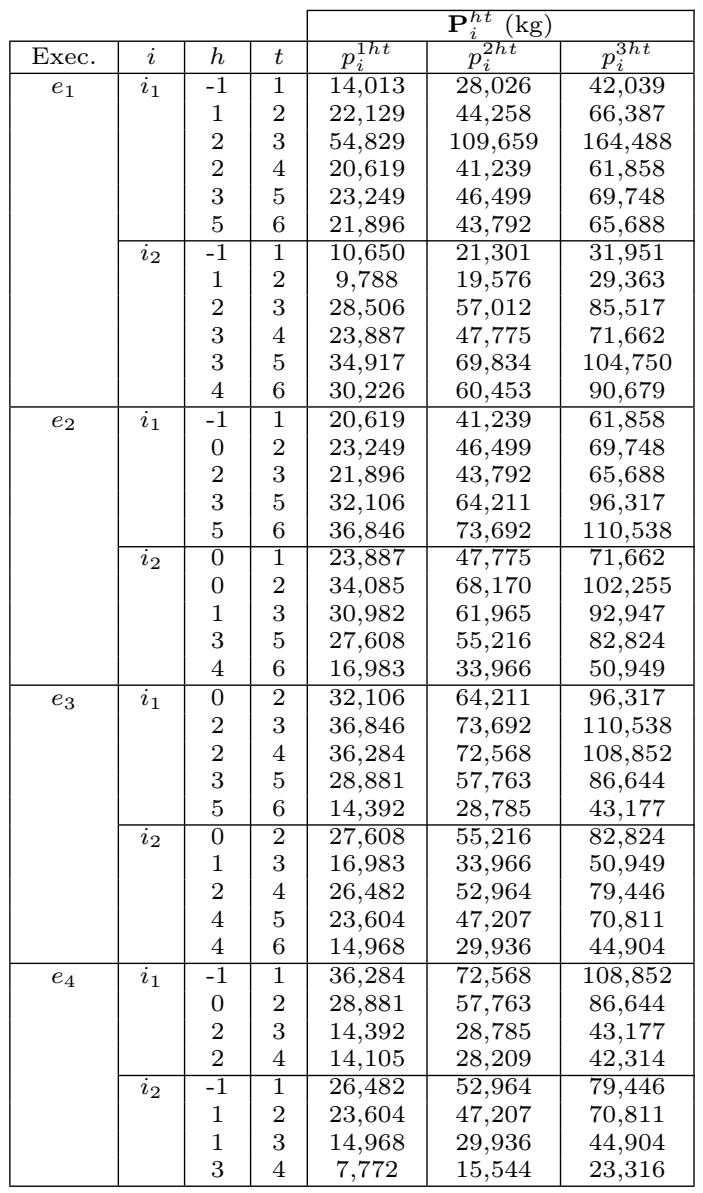

Table A.6: Initial stock

\begin{tabular}{|c|c|c|c|}
\hline$i$ & $s$ & $h$ & $\mathbf{k}_{i s}^{h}(\mathrm{~kg})$ \\
\hline$i_{1}$ & $s_{1}$ & -3 & 1300 \\
& $s_{1}$ & -2 & 2500 \\
& $s_{2}$ & -2 & 8500 \\
& $s_{2}$ & -1 & 7500 \\
& $s_{3}$ & -3 & 902 \\
& $s_{3}$ & -2 & 7500 \\
& $s_{4}$ & -3 & 1600 \\
& $s_{4}$ & -1 & 9000 \\
& $s_{5}$ & -3 & 6000 \\
& $s_{5}$ & -2 & 2500 \\
& $s_{6}$ & -2 & 733 \\
& $s_{6}$ & -1 & 4000 \\
& $s_{8}$ & -2 & 2300 \\
& $s_{8}$ & -1 & 7000 \\
\hline$i_{2}$ & $s_{9}$ & -2 & 4000 \\
& $s_{9}$ & -1 & 5000 \\
& $s_{10}$ & -2 & 33000 \\
& $s_{10}$ & -1 & 15000 \\
& $s_{11}$ & -2 & 4000 \\
& $s_{11}$ & -1 & 3800 \\
& $s_{12}$ & -2 & 1500 \\
& $s_{12}$ & -1 & 1500 \\
& $s_{13}$ & -2 & 7000 \\
& $s_{13}$ & -1 & 3000 \\
& $s_{14}$ & -2 & 7000 \\
& $s_{14}$ & -1 & 6800 \\
& $s_{15}$ & -2 & 3000 \\
& $s_{15}$ & -1 & 2300 \\
\hline \multirow{6}{1}{} & & &
\end{tabular}


twice a week, considering a 3-day batching interval. The executions occur in periods 1, 4, 8 and 11 simulating real dynamics. Two products $(i)$ are contemplated (oranges and tangerines) with subtypes $(s)$ defined according to the quality level, the calibre and the packaging type. The Table A.1 shows the products with their respective subtypes and the parameters of the possibilistic variable $\mathbf{L}_{i s}$. Table A.2 shows the price data required to build the piecewise linear ageing function of each subtype as presented in figure 5 . As regards the different time points presented such figure, where there are changes in the price value, the following procedure is considered (depending on the harvesting time $h$ of the ATP reserved for the orders of each subtype):

$$
\begin{aligned}
& \text { - } t_{1}=h+l_{i s}^{2} * 0.40 \\
& \text { - } t_{2}=h+l_{i s}^{2} * 0.45 \\
& \text { - } t_{3}=h+l_{i s}^{2} * 0.60 \\
& \text { - } t_{4}=h+l_{i s}^{2} * 0.65 \\
& \text { - } t_{5}=h+l_{i s}^{2} * 0.80 \\
& \text { - } t_{6}=h+l_{i s}^{2} * 0.85 \\
& \text { - } t_{7}=h+l_{i s}^{2} * 0.90
\end{aligned}
$$

The Table A.3 shows the inventory holding and wasting costs for each subtype. The fending unitary cost $\mathbf{f}_{i s}^{o}$ was obtained as $50 \%$ of the maximum income generated for the order line if it was served within the maximum possible price.

As regards the configuration of the incoming orders, we also follow the description given in Grillo et al. 23. Each customer usually places four orders per week. The due date $\left(\mathbf{d}^{o}\right)$ of each order usually occurs 4-5 days after the arrival date. Customer orders are integrated by several order lines randomly varying between 1 and 10. Authors presented a total of 88 orders following the rule that the sum of the subtypes requested in all the lines in the same order usually completes around 30 pallets (realistic quantity which is the equivalent to one truck). They used such rule based on samples of real orders. Since in this case we have considered the existence of just one packing plant, and the authors originally considered two plants, we have made corrections in the transporting time and due date of the orders, maintaining the general rules they presented. The Table A.4 shows the configuration of each order with the due date, number of order lines, transporting time and transporting cost.

Concerning to the supply data required to implement the compositions of possibilistic variables, it was necessary to make some additional considerations. First, in Grillo et al. 23 they considered the possibility to reserve lines even when the entire order could not be served. They also considered a percentage of about $8 \%$ to $10 \%$ of the incoming production lots as non-usable for fulfilling orders. That product was intended to the production of by-products or directly wasted. It is 
also required to consider that it is worth to use compositions of posibilistic variables in presence of epistemic uncertainty, i.e., when there is just a vague idea of the real value. This means a considerable high level of uncertainty that in our case should be reflected in the parameters of the possibilistic variables $\mathbf{P}_{i}^{h t}$ and $\mathbf{M}_{i s}^{h t}$. Due to all the previous reasons, in order to define our supply data, we have taken the master production schedule presented in Grillo et al. 23] and we have cut the quantities in $30 \%$. The resulting quantities will be the central value of the triangular fuzzy set representing $\mathbf{P}_{i}^{h t}$. In order to define the limits of such triangular fuzzy set, we consider a variation of $\pm 50 \%$ from the central value, with the aim to reflect a very high level of uncertainty. The resulting input are showed in Table A.5. The harvesting time $(h)$ can take negative values because it is assumed that the product can be harvested before the first period in the planning horizon.

The parameters of the possibilistic variable $\mathbf{M}_{i s}^{h t}$ are obtained based on the values of $\mathbf{P}_{i}^{h t}$ given in Table A.5 and considering the proportional subdivision used originally in Grillo et al. 23. According to them, the proportional subdivision was obtained based on the sum of the subtypes requested in the order lines with the same due date during each period. The total sum was set as master production schedule 2-3 periods randomly before the due date in order to confer the model the possibility of taking a wide open window of time in transportation once the product is packed.

Finally, the initial stock $\mathbf{k}_{i s}^{h}$ is presented in Table A.6 and it coincides with that given in Grillo et al. 23. If readers are interested in reproducing the numerical experiments, they can easily follow the description given here. Otherwise they can ask to us by e-mail for the exact data we have used.

\section{Bibliography}

[1] A. Nureize and J. Watada. "A fuzzy regression approach to a hierarchical evaluation model for oil palm fruit grading". In: Fuzzy Optimization and Decision Making 9.1 (2010), pp. 105-122. DOI: $10.1007 / \mathrm{s} 10700-010-9072-3$

[2] O. A. Kilic, R. Akkerman, D. P. van Donk, and M. Grunow. "Intermediate product selection and blending in the food processing industry". In: International Journal of Production Research 51.1 (2013), pp. 26-42. DOI: 10.1080/00207543.2011.640955

[3] S. A. Slotnick. "Optimal and heuristic lead-time quotation for an integrated steel mill with a minimum batch size". In: European Journal of Operational Research 210.3 (2011), pp. 527-536. DOI: $10.1016 /$ j.ejor.2010.09.031

[4] J. Mula, D. Peidro, M. Díaz-Madroñero, and E. Vicens. "Mathematical programming models for supply chain production and transport planning". In: European Journal of Operational Research 204.3 (2010), pp. 377-390. DoI: 10.1016/j.ejor.2009.09.008

[5] D. Peidro, J. Mula, R. Poler, and J.-L. Verdegay. "Fuzzy optimization for supply chain planning under supply, demand and process uncertainties". In: Fuzzy Sets and Systems 160.18 (2009), pp. 2640-2657. DOI: 10.1016/j.fss.2009.02.021

[6] H. Grillo, M. M. E. Alemany, and A. Ortiz. "A review of mathematical models for supporting the order promising process under Lack of Homogeneity in Product and other sources of uncertainty". In: Computers 8 Industrial Engineering 91 (2016), pp. 239-261. DOI: $10.1016 / \mathrm{j}$.cie.2015.11.013 
[7] M. O. Ball, C.-Y. Chen, and Z.-Y. Zhao. "Available to Promise". In: Handbook of Quantitative Supply Chain Analysis: Modeling in the E-Business Era. Ed. by D. Simchi-Levi, S. D. Wu, and Z.-J. Shen. Boston, MA: Springer US, 2004, pp. 447-483. DOI: 10.1007/9781-4020-7953-5_11

[8] M. M. E. Alemany, H. Grillo, A. Ortiz, and V. S. Fuertes-Miquel. "A fuzzy model for shortage planning under uncertainty due to lack of homogeneity in planned production lots". In: Applied Mathematical Modelling 39.15 (2015), pp. 4463-4481. DOI: 10.1016/j. apm.2014.12.057

[9] M. M. E. Alemany, F. C. Lario, A. Ortiz, and F. Gomez. "Available-To-Promise modeling for multi-plant manufacturing characterized by lack of homogeneity in the product: An illustration of a ceramic case". In: Applied Mathematical Modelling 37.5 (2013), pp. 33803398. DOI: $10.1016 / \mathrm{j} . \mathrm{apm} .2012 .07 .022$

[10] H. Grillo, M. M. E. Alemany, and A. Ortiz. "Modelling Pricing Policy Based on Shelf-Life of Non Homogeneous Available-To-Promise in Fruit Supply Chains". In: Working Conference on Virtual Enterprises. Springer, 2016, pp. 608-617. DOI: 10.1007/978-3-319-45390-3_52

[11] J. Aitchison. "The Statistical Analysis of Compositional Data". In: Journal of the Royal Statistical Society. Series B (Methodological) 44.2 (1982), pp. 139-177. Dor:0035-9246/ $82 / 44139 \$ 2.00$

[12] J. Aitchison and J. J. Egozcue. "Compositional Data Analysis: Where Are We and Where Should We Be Heading?" In: Mathematical Geology 37.7 (2005), pp. 829-850. Dor: 10 . 1007/s11004-005-7383-7

[13] V. Pawlowsky-Glahn and A. Buccianti. Compositional data analysis: theory and applications. John Wiley \& Sons, 2011. ISBN: 0-470-71135-3.

[14] V. Pawlowsky-Glahn and J. J. Egozcue. "Spatial analysis of compositional data: a historical review". In: Journal of Geochemical Exploration 164 (2016), pp. 28-32. DOI: 10.1016/j. gexplo.2015.12.010

[15] G. Puccetti and R. Wang. "Detecting complete and joint mixability". In: Journal of Computational and Applied Mathematics 280 (2015), pp. 174-187. DoI: 10.1016/j.cam.2014. 11.050

[16] B. Wang and R. Wang. "Joint mixability". In: Mathematics of Operations Research 41.3 (2016), pp. 808-826. DOI: 10.1287/moor.2015.0755

[17] D. Peidro, J. Mula, and R. Poler. "Fuzzy linear programming for supply chain planning under uncertainty". In: International Journal of Information Technology \& Decision Making 09.03 (2010), pp. 373-392. DOI: 10.1142/S0219622010003865

[18] D. Dubois, H. Fargier, and P. Fortemps. "Fuzzy scheduling: Modelling flexible constraints vs. coping with incomplete knowledge". In: Fuzzy Sets in Scheduling and Planning 147.2 (2003), pp. 231-252. DOI: 10.1016/S0377-2217(02)00558-1

[19] D. Dubois and H. Prade. Possibility theory: an approach to computerized processing of uncertainty. Springer Science \& Business Media, 2012.

[20] R. Haijema. "A new class of stock-level dependent ordering policies for perishables with a short maximum shelf life". In: International Journal of Production Economics 143.2 (2013), pp. 434-439. DOI: 10.1016/j.ijpe.2011.05.021

[21] M. L. Entrup, H. O. Gunther, P. Van Beek, M. Grunow, and T. Seiler. "Mixed-integer linear programming approaches to shelf-life-integrated planning and scheduling in yoghurt production". In: International Journal of Production Research 43.23 (2005), pp. 50715100. DOI: $10.1080 / 00207540500161068$

[22] L. Zadeh. "Fuzzy sets as a basis for a theory of possibility". In: Fuzzy Sets and Systems 1.1 (1978), pp. 3-28. DOI: 10.1016/0165-0114(78)90029-5 
[23] H. Grillo, M. Alemany, A. Ortiz, and V. Fuertes-Miquel. "Mathematical modelling of the order-promising process for fruit supply chains considering the perishability and subtypes of products". In: Applied Mathematical Modelling 49 (2017), pp. 255-278. ISSN: 0307-904X. DOI: $10.1016 / \mathrm{j} . \mathrm{apm} .2017 .04 .037$

[24] M. Steglich and T. Schleiff. "CMPL: Coliop Mathematical Programming Language". In: Technische Hochschule Wildau (2010). DOI: 10.15771/978-3-00-031701-9.

[25] H. Grillo, M. M. E. Alemany, A. Ortiz, and J. Mula. "A Fuzzy Order Promising Model With Non-Uniform Finished Goods". In: International Journal of Fuzzy Systems (2017), pp. 1-22. DOI: $10.1007 / \mathrm{s} 40815-017-0317-\mathrm{y}$ 



\section{Chapter VIII}

\section{Conclusions and future research lines}

In this chapter, the main conclusions of the dissertation and the future research lines identified along its development are presented. Although the dissertation is composed by a compendium of articles that have their own section of conclusions, an integrated overview of the novelties, findings and key points of the research in each chapter is provided in the Section 1. Furthermore, in Section 2, the future research lines are presented, based on specific topics that were raised as possible steps further, after the finalization of each chapter.

\section{Contributions of the dissertation: general overview}

In this section, the contributions of each chapter of the dissertation are presented firstly based on the LHP characteristics addressed by each of them and secondly by the novelties and contributions introduced during their modelling. Finally, some remarks on LHP inherent uncertainty are highlighted.

\subsection{Inherent LHP characteristics addressed}

Along this dissertation, research has been done in the area of mathematical modelling of the order promising process (OPP) and shortage planning (SP) under the effect of the Lack of homogeneity in the Product (LHP) and its inherent uncertainty.

The main issue with the LHP relies on the fact that units of the same product, component or raw material in a lot (or between lots) are not homogeneous, generating different homogeneous sublots of different subtypes. The LHP becomes 
a managerial problem when customers require homogeneity, because companies should classify lots in subtypes in accordance with the homogeneity attributes relevant to other companies downstream the supply chain or the final costumers. Furthermore, in certain cases the value of the attributes used to classify lots in subtypes can vary over the time. The uncertainty inherent to the LHP is originated by the lack of knowledge of the final characteristics of the lots before they are produced and classified. Beforehand, it is only possible to have a rough idea of their value. LHP generates different types of uncertainty along several stages of the supply chain that have been classified in the following classes: number of subtypes, quantity of each subtype, state and value of each subtype.

An improper management of the LHP's uncertainty can cause a number of different problems including:

- To promise orders that cannot be finally served in the committed terms. Not serving orders due to errors in the estimation of the total supply and its division in subtypes.

- Unusable remains of subtypes that cannot be mixed to serve complete orders due to the homogeneity requirement in the orders.

- Loss of profits in case the subtype state (i.e. freshness) and its value (i.e price) are not properly considered during the order management (OPP and SP) and the increase in waste (subtype with no value).

- Even anticipating the LHP characteristics by considering its inherent uncertainty, discrepancies between the planned and real situation can occur originating a shortage situation. As a result, some already promised orders can not be finally fulfilled due to the lack of real enough availability of the respective subtype, being necessary to provide a solution to minimize the negative impact for both, the customer and the supply chain.

Although the great number of sectors affected by LHP and its negative impact on the supply chain's global performance, very scarce research exists on OPP and SP in this context. Therefore, this dissertation contributed to this research field by managing the uncertainty inherent to the LHP in the OPP and SP.

Table 1 shows the chapters according to the inherent LHP characteristics they covered (see Figure 2 of Chapter I): subtype definition (S.T.), subtype quantity (S.Q.), subtype value (S.V.) and subtype state (S.S.), for the three main stages of the supply chain; supply, process and demand. Table 1 shows the LHP characteristics modelled by each chapter for the OPP, SP and in general, in deterministic and uncertainty contexts. In case a chapter does not appear in a specific stage of the supply chain, it means that no contribution has been made for this stage.

The main contribution of Chapter II consisted in characterising the LHP, its inherent sources of uncertainty and its impact on the OPP and SP by means a conceptual framework. Based on this framework, a detailed literature review was made, providing the existing gaps intended to be covered in the subsequent chapters by 
means of mathematical tools. The literature review showed a poor consideration of all the LHP characteristics in OPP and SP for both, deterministic and uncertainty contexts. This situation is more accentuated in uncertainty contexts because just a few works have include some characteristic related to the LHP but any of them dealing with the concept of LHP itself or its specific problematic.

Table 1: Contributions of the dissertation as regards the LHP characteristics addressed.

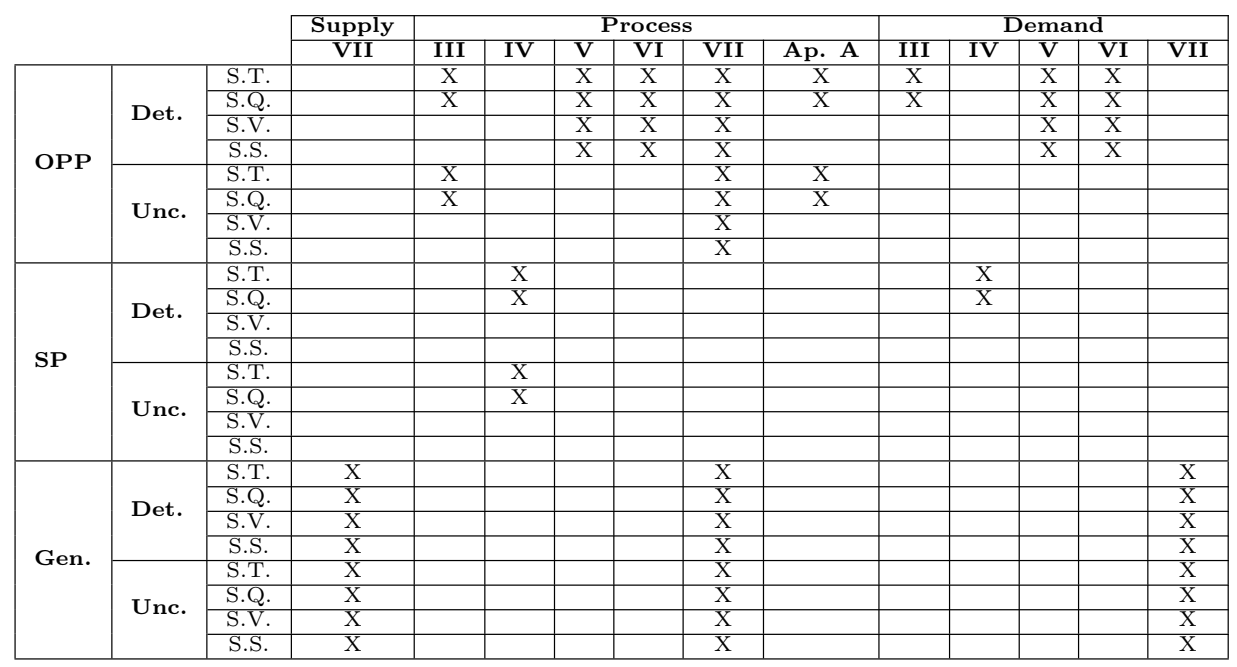

Since the uncertainty modelling approach in this work is based on the deterministic version of the models, Table 1 also presents the detail of the LHP characteristic modelled in deterministic conditions. It can be seen how the dissertation achieves the objective of covering all the main inherent LHP characteristics for both deterministic and uncertainty environments for the OPP, along several chapters (III, V, VII, VII and Appendix A) for the three stages of the supply chain. It is important to remark that all the models developed under uncertainty conditions based on the application of fuzzy sets, implicitly included the deterministic scenario because in the solution process, they are represented as equivalent alpha-parametric models whose intervals depend on the alpha-cut considered; hence the cases with $\alpha=1$ present the same behaviour as in deterministic case. The SP model developed in Chapter IV also considers the "S.T." and "S.Q." under both, deterministic and uncertainty environments in the process and demand stages of the supply chain. Since the work developed in Chapters III and IV is an extension from a previous deterministic work to the uncertainty context in the ceramic tile sector for OPP and SP respectively, and since the original work did not consider variation ranges of price or the state of the subtype, Chapters III and IV also did not consider such variation. Instead, all the work developed afterwards (Chapters V, VI and VII) 
considered the whole scope of the LHP characteristics including the subtype state and the value for both, deterministic and uncertainty environments.

As it can be seen in Table 1, the work of Chapters III-VI has focused on the LHP effect, mainly in the process and demand stages, and more on the OPP than SP. Finally, due to the generic approach adopted in Chapter VII, its contributions cover the four LHP characteristics (S.T., S.Q., S.V., and S.S.) for all the three supply chain stages (supply, process, demand) under both deterministic and uncertainty context for any decision process in LHP environments. For this reason, Table 1 shows a "Generic" category of problem where Chapter VII stands in both the deterministic and uncertainty scenarios for all the three stages of the supply chain. Chapter VII also appears in the OPP category for process stage of the supply chain, because its practical application derives in an OPP model.

\subsection{Mathematical modelling contributions}

In this section, we remark the mathematical modelling contributions developed in each chapter. A summary of such contributions is showed in Table 2

In order to model the subdivision of the ATP in subtypes (S.T. and S.Q), it was introduced the concept of homogeneity coefficients (called betas), that represent the homogeneous fraction of each lot in the master plan. For one same lot, all the betas must add up to 1 . This is equivalent to force that the sum of the homogeneous sublots should be equal to its corresponding lot. From the deterministic point of view it is easy to interpret the beta coefficients, but when considering them as fuzzy sets, as in some chapters in this dissertation, additional constraints must be incorporated in order to ensure the model validity. The modelling of the interdependency among technological fuzzy coefficients constitutes a novel contribution from chapters III and IV, and validated in real applications for the ceramic tile industry.

Other LHP characteristics have been modelled deterministically in Chapters V and VI based on the supply chain of perishables. The subtype definition (S.T.) and subtype quantity (S.Q.) were implemented for the fist time in the fresh produce sector, through the implementation of deterministic betas. The state of subtype (S.S.) was modelled through the computation of the product's Remaining Shelf Life (RSL) at the delivery time. Based on the RSL, the value of the subtype (S.V.) was computed through a step function whose segments represent the price in function of its ranges of RSL. This approach allowed to define as many price values as subtypes but it did not consider changes from one subtype to another.

In an effort to formalize the previous tools in general concepts able to be applied in both deterministic and uncertainty contexts, Chapter VII includes the following original approaches:

i) The compositions of possibilistic variables were introduced as an extension of the original concept of compositional data. In this case, the components 
of the composition are considered as possibilistic variables which can be conventional intervals or fuzzy intervals. These new compositions allows the substitution of the previous approach via deterministic beta coefficients, for a possibilistic variable representing the subtype's amount of product. Even more, it is considered the case when the total quantity of the lot is also uncertain. The concepts of this type of compositions are introduced in a general framework that allows its application into a wide open number of modelling situations. The case of fruit supply chain was used in order to exemplify the application of such compositions in the OPP affected by the LHP and its inherent uncertainty.

ii) In regard to the state and value of the subtype, the concept of fuzzy state functions was introduced. Fuzzy state functions are time-dependent functions allowing to model any variable (state)'s change with the time. Its main characteristic is that the ending time is considered uncertain and it is proposed to model it as a possibilistic variable. If an state function is used to model product's decay, it is called ageing function. Clearly, the ageing function is decreasing in an interval of time, representing the uncertain product's shelf life. The ageing function allows to link any characteristic of the product (that takes the state role) with its shelf life consumption. We propose to link the price of the product (S.V.), with the ageing process (S.S.). In this way the product's price is also obtained as a possibilistic variable. State functions could also be applied to model other situations with the same conceptual structure in other areas.

Table 2 shows the contribution to the mathematical modelling made in each chapter dealing with uncertainty. Chapters III, IV and the Appendix A contributed by including the fuzzy interdependent coefficients; while Chapter III contributed in the solution process that is an adapted TOPSIS based methodology in order to rank the different instances of alpha-cuts tested. Finally, Chapter VII made the generalization of compositions of possibilistic variables and state functions as new concepts that are also applied in the OPP.

Table 2: Characteristics of the modelling approach

\begin{tabular}{|c|c|c|c|c|c|c|c|c|c|}
\hline \multirow[b]{3}{*}{ Chapter } & \multicolumn{3}{|c|}{ Deterministic } & \multicolumn{3}{|c|}{ Uncertainty } & \multirow{2}{*}{\multicolumn{3}{|c|}{ Contributions to the fuzzy set / possibility theory }} \\
\hline & S.T. / S.Q. & S.S & S.V. & & 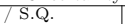 & S.S./S.V. & & & \\
\hline & Betas & LSL & $\begin{array}{l}\text { Price } \\
\text { ranges }\end{array}$ & Betas & $\begin{array}{c}\text { Compositions } \\
\text { of } \\
\text { possibilistic } \\
\text { variables }\end{array}$ & $\begin{array}{c}\text { State } \\
\text { functions }\end{array}$ & $\begin{array}{l}\text { Mathematical } \\
\text { modelling }\end{array}$ & $\begin{array}{l}\text { Resolution } \\
\text { process }\end{array}$ & $\begin{array}{c}\text { New } \\
\text { concepts }\end{array}$ \\
\hline III & & & & $\mathrm{X}$ & & & $\mathrm{X}$ & $\mathrm{X}$ & \\
\hline IV & & & & $\mathrm{X}$ & & & $\mathrm{X}$ & & \\
\hline $\mathrm{V}$ & $\mathrm{X}$ & $\mathrm{X}$ & $\mathrm{X}$ & & & & & & \\
\hline VI & $\mathrm{X}$ & $\mathrm{X}$ & $\mathrm{X}$ & & & & & & \\
\hline VII & & & & & $\mathrm{X}$ & $\mathrm{X}$ & $\mathrm{X}$ & & $\mathrm{X}$ \\
\hline Ap. A & & & & $\mathrm{X}$ & & & $\mathrm{X}$ & & \\
\hline
\end{tabular}

As previously mentioned, when serving orders in the demand stage, as additional LHP features in the mathematical modelling of the OPP (see Table 3): if the 
Table 3: Characteristics of the modelling approach

\begin{tabular}{|c|c|c|}
\hline Chapter & Customer specify the subtype? & Pricing policy? \\
\hline III & No & No \\
IV & No & No \\
V & Yes & Yes \\
VI & Yes & Yes \\
VII & Yes & Yes \\
\hline
\end{tabular}

customer specifies or not the subtype and if a pricing policy exists that links the subtype state and its value.

In regard to the specification of the subtype by customers in their orders, there are two possibilities:

1. Customers only require homogeneity in the units of the same product and they do not specify the subtype. This is the case when customers make the request of one product expecting homogeneity on it and the supply chain chooses the subtype to fulfil the order. This situation corresponds to the type of supply chains like the ceramic tile sector. The customers require a quantity of a ceramic tile, and the supply chain selects the tone and gage (subtype) of that tile. It is ensured that the order will be served with only one subtype regardless which of them. This type of situation was developed in Chapters III and VI.

2. Customers not only require homogeneity in the units of the same product, but also specify the subtype required. In this situation, the supply chain must respond with the specific product and subtype requested. This case matches different types of supply chains, but in this dissertation it is only considered the case of perishables. In this sector, the subtypes (commonly related to quality, size, or weight for example) are normally specified by the customers in their orders. Chapters V, VI and VII deal with this scenario.

In regard to the subtype state and its value, there are also two possibilities:

1. The subtype value does not depend on the subtype state (there is not any pricing policy). In this case the value can be differentiated among different subtypes, but it remains invariant within time. This case was studied in Chapters III and IV.

2. The subtype value is dependent on the subtype state (a pricing policy is required). In this case the subtype value is dynamic, and is linked with the state of the product through the time. The pricing policy can be established deterministically as it was done in Chapters V and VI, based on ranges of RSL, or under uncertainty conditions as was is done in Chapter VII through ageing functions. 
The shelf life of the product must be considered also as an inherent source of uncertainty associated to the LHP. The subtype is affected by the ageing process, and the freshness is also a factor of LHP that could be specified by the customer.

\subsection{Final remarks on LHP inherent uncertainty}

In terms of the mathematical modelling of the OPP and SP, under the effect of the LHP and its inherent uncertainty, the additional level of complexity of the subdivision of the ATP in subtypes can be done for both deterministic and uncertainty scenarios. If it is done under uncertainty conditions, different options can be considered. Simulation, system dynamics and stochastic modelling are options used in the literature. These tools are well-known and all of them require a proper data analysis in order to identify the probability distributions describing the uncertain parameters or variables. In this dissertation, it is considered the special case when there is not much information available regarding to the uncertain value. In regard to the LHP, the uncertainty relies on the subdivision of the lots in their respective subtypes, and it is proposed to apply the fuzzy set theory and possibility theory in order to model uncertainty. The previous tools have been successfully applied when modelling epistemic uncertainty and when due to the lack of information, the stochastic approach is not suggested.

Since the mathematical modelling of supply chain planning problems normally implies big instances of experimentation, it is recommended to apply the tools of linear programming, due its computational efficiency and the variety of existing tools for the solution process.

Procedures were conducted in order to obtain equivalent alpha-parametric interval representations of the fuzzy sets used to model the beta interdependent coefficients (Chapters III and IV), compositions of possibilistic variables and state functions (Chapter VII). Hence, it was possible to implement solution processes based on linear programming.

The handling of fuzzy sets through the representation principle based on alphacuts implies the use of ranking methods in order to evaluate different instances of alpha. Since the latter involves considerable levels of ambiguity, procedures that include the requirements of the decision maker were applied. In general terms, the results of the experiments conducted show that the uncertainty approach overcomes the deterministic one when real scenarios are projected. Besides, in term of profitability, the uncertainty approach can achieve higher profits, considering that there always exists a risk level. This risk is associated with the amplitude of the intervals used to model the uncertain variables and the alpha-cut applied (in case of). It also represents the real feasibility of the final solution if it were executed in the real process or the risk of having real shortages.

The product's perishability makes that a subtype cannot be stored indefinitely because it can expire. The latter produces a very conflictive situation with the optimization of this type of supply chains. If the freshness of the product is not 
considered as an objective, the orders will normally be fulfilled the old product in order to avoid the expiring costs. If only the maximisation of profits is considered, given the shelf life-based pricing policy, the orders will normally be served with the freshest product, but increasing the risk of having a considerable expiring cost. The mathematical tools developed in Chapters V, VI and VII show a very good performance in order to simultaneously consider both objectives for deterministic and uncertainty environments.

Since this dissertation has a limited scope, it has been identified multiple points that could be seen as further work. In the next section 2 , the future research lines are presented.

\section{Future research lines}

As a conclusion of this dissertation, three different sets of future research lines are identified: those related with LHP inherent characteristics, other with OPP and $\mathrm{SP}$ and finally, the modelling approach and the resolution tools.

\section{$2.1 \quad$ Inherent LHP characteristics}

From the point of view of the inherent LHP characteristics already addressed in the literature plus the contribution of this dissertation (see Table 1), it can be remarked the need of considering the LHP effect more deeply in the SP (shortage planning) for the three stages of the supply chain, and along all its main characteristics (S.T., S.Q., S.V. and S.S.). This can be achieved, by first extending our work in the fruit sector. It could be done in deterministic conditions by extending the modelling approach presented in Chapter VI; and in uncertainty conditions by applying compositions of possibilistic variables and state functions as it was presented in the Chapter VI.

It is advisable to go up-stream in the supply and to consider the original causes of the LHP, i.e., raw material transformation processes for supply chains of non perishable products, and farming and harvesting for perishables.

It would be interesting to analyse the cases that could have a mixture in the specification of the subtype from customer, i.e., they can specify the subtypes for some products and not for others in the same order. Other interesting scenario to study would be the case when some subtypes could be accumulated if and only if the incoming product belongs to the exact same subtype.

Another challenge is the modelling of the situation where the dynamism in the state of the subtype implies a modification in the subtype itself. This dissertation has only dealt with the case when the subtype is defined and the product is classified and packed (for perishables), but the already packed products belong to the same subtype until they are sold or wasted. The only uncertain parameter that changes with the ageing process is the freshness and the price linked to it. But, if a 
subtype is defined by the quality for example, a new approach can consider that the quality itself can change with the ageing process. The new approach should consider the dynamism in both, the variation of a related parameter like a price, but possible changes in the subtype itself (i.e., product going from first quality to second quality, etc.).

\subsection{Other OPP characteristics}

According to the existing literature, the majority of the papers consider the Make to Order manufacturing strategy. Although the OPP is severely affected by the manufacturing strategy (Customer Order Decoupling Point, CODP), it assumes this aspect as already given. Therefore, it would be interesting to investigate not only the effect of LHP modelling, but also the impact of CODP location on reducing LHP uncertainty.

Another important question is the need for more explicit consideration of allocation rules designed to achieve more efficient assignation of the subtypes considering their state. The development of Decision Support Systems (DSS) considering these features in the OPP and SP plus the LHP and its inherent uncertainty is needed. This development can also consider other additional availability levels such as Capable to promise (CTP), Deliver-To-Promise (DTP) or Profitable-ToPromise (PTP).

Future research lines can also include another type of uncertain variables like cost factors, customer type and the arrival orders' trend, among others.

\subsection{Mathematical modelling and resolutions tools}

Compositions of possibilistic variables and state functions can be applied in other type of problems and areas like technology, applied mathematics and other problems in the engineering field. It is also recommended the application of such compositions and state functions in problems at a more operative level for perishables, where the changes of state can occur in very short periods of time. For example, operations of transformation of a raw material, freezing or holding of finished products, transportation under controlled conditions, etc. Another interesting case would be the application of them in the handling of by-products.

It would be interesting to apply other methods like stochastic modelling or simulation in order to model the LHP inherent uncertainty and to stablish a comparison of these results with the ones presented in this dissertation.

There is also a requirement for the execution of experiments for bigger instances, i.e., bigger sets of order proposals, more products, more extended planning horizon, bigger instances in the configuration of supply chain (more suppliers and priority of them, source fields, more production/packing plants, intermediate distribution nodes, etc). This could lead to a very difficult situation in terms of the solution process, given the capacity of the available solvers for mixed integer linear pro- 
gramming. In this sense, the exploration of alternative solution techniques can be a very interesting future step. As examples of such techniques, heuristics and meta heuristics, parallel computation, artificial intelligence or hybrid approaches can be mentioned.

Given the observed need to include several objectives in the optimization and their common conflicting behaviour, multi objective optimization approaches are required. This could also lead to the exploration of alternative solution methods such as the ones highlighted in the previous paragraph. Multi-objective optimization with meta heuristics is an on-going research area.

For all the points exposed above, this dissertation can be considered as a starting point of a very wide potential research area, especially in the sector of perishables where all the LHP characteristics appear. 


\title{
Appendix A
}

\section{Mathematical modelling of uncertainty in non-homogeneous lots.}

\begin{abstract}
There are manufacturing contexts where units of the same finished good (FG) in lots are non-homogeneous. Sometimes, this lack of homogeneity in the product (LHP) originates several qualities of a FG in the same lot, meanwhile other times units of the same FG with different attributes (subtypes) appear. The result is that each lot of a FG is composed by homogeneous sublots of different subtypes. Due to the LHP inherent sources of uncertainty, the finally size of each homogeneous sublot will be only known when produced and classified. This aspect becomes a problem when customers should be served with homogeneous units of the same FG. In this paper, the definition of customer classes and a set of fuzzy constraints are proposed to model the uncertainty in non-homogeneous lots. The incorporation of these constraints will improve the customer service level and the company performance by the properly sizing of non-homogeneous lots.
\end{abstract}

Keywords: Uncertainty; Fuzzy; Lack of Homogeneity in the Product; Customer Classes; Mixed Integer Linear Programming. 


\section{Introduction}

The lack of homogeneity in the product (LHP) is defined as the lack of uniformity required by the customer in the products. LHP causes the non-homogeneity of FGs as regards certain attributes that are relevant to customers $\sqrt{1}$. LHP becomes a problem when customers order several units of the same FG and require homogeneity among them. In order to comply with the homogeneity specifications, LHP companies include some classification stages for sorting units of the same FGs into homogeneous subsets (subtypes). The classification criteria of an FG into subtypes depend on each sector. Indeed, the LHP in lots appears in very different sectors in several ways. For instance, the LHP origin in Fruit Supply Chains is mainly due to the non-uniformity of the raw materials (the fruit obtained directly from the nature). Because customers require homogeneity among the units of the same FG in their orders, there are several classification (sorting and grading) activities located in different points along the productive process with the aim of eliminate waste and classify fruits into several qualities based on different attributes. The main attributes for sorting and grading fresh fruit are size, weight, ripeness, damage, color, shape and firmness.

These LHP characteristics complicate the system management in different ways. 1) The customer homogeneity requirement introduces new constraints to be accomplished, complicating the identification not only the optimal solution but also a feasible one. 2) After each classification stage, the quantity of each subtype in the production lots will be only known after production has finished and FGs have been classified. Therefore, companies with LHP will face a new kind of uncertainty: the uncertainty in the homogeneous quantities of each subtype that will be available in the planned production lots. In this paper, the modeling of the LHP uncertainty in lots by means Fuzzy Sets is proposed. As it is described in section 4. when modeling this type of LHP uncertainty, it is necessary to apply the Fuzzy Theory to dependent technological coefficients. Up to our knowledge, the uncertainty modeling by fuzzy sets has been limited to independent fuzzy coefficients. Therefore, this aspect constitutes one of the main contributions of this paper.

\section{Background literature}

Uncertainty refers to "the unpredictability of environmental or organisational variables that have an impact on corporate performance. A variety of uncertainty factors affect distinct organizations in different ways. In fact, supply chains (SCs) with lack of homogeneity in the product (LHP) have unique characteristics with inherent sources of uncertainty that have a great impact on customer service level. Most SC planning research [2] models SC uncertainties with probability distributions, which are usually predicted from historical data. However, probability distributions deriving from past evidence are not always available or reliable 3. Therefore whenever statistical data are unreliable, or are not even available, 
stochastic models may not be the best choice. The Fuzzy Set Theory and the Possibility Theory may be simpler, less data-demanding alternatives than the Probability Theory to deal with SC uncertainties [4]. The Fuzzy Set Theory provides a means for representing uncertainties and is a marvelous tool for modeling the kind of uncertainty associated with vagueness, with imprecision, and/or with lack of information on a particular element of the problem at hand. For LHP contexts, the unpredictable characteristics of the raw materials and/or the existence of uncontrollable productive factors, make the knowledge of the homogeneous quantities of each subtype available in future planned lots imprecise. Furthermore, sometimes it is not feasible or very costly to measure them reliably being correct the use of fuzzy sets.

\section{Modelling Context}

The objective of this research is to address the modelling of LHP uncertainty in production lots for planning purposes. Some assumptions are made when modelling this situation. As regards the productive/supply stage, it is assumed the existence of parallel resources that are able to process/supply several FGs. Units of the same FG with different attributes (subtypes) appear in each lot. Therefore, each FG lot is assumed to be composed by several homogeneous sublots of different subtypes.

As regards the demand stage, it is worth stressing that LHP becomes a managerial problem because of the customers' homogeneity requirements. Therefore, LHP introduces a new customized aspect in the order proposals: the homogeneity type required among the ordered products. The customer may require uniformity between components of a product (pearls on a necklace) or between units of the same product (ceramic tiles) or between different products in the order (chairs and a dining table). In this paper it is assumed that customer requires homogeneity among units of the same FG without specifying the subtype, i.e. the only LHP constraint is that all the units of each FG in the order will be homogeneous, not being relevant from which subtype the order is completed.

On the other hand, the way of modelling the customer demand primarily depends on the model purpose. For planning purposes, the demand is usually expressed as forecasts of product families or FGs. But, when modelling the LHP in production lots at the planning level, the homogeneity requirement in the demand should be incorporated in some manner with the aim of better sizing the lots on each productive resource. Note that the order size becomes a very relevant LHP factor because the larger the orders size, the more difficult will be to meet the uniformity requirement among all their units. For these reason, in this paper a novel way of modelling the customer demand is introduced at the planning level: by means of the forecasted number of customer order classes. Each customer order class is characterized to request a similar order quantity (size) of a FG. 


\begin{tabular}{|c|c|c|}
\hline \multicolumn{3}{c}{$M P_{i l t}=3000 \mathrm{~m}^{2}$} \\
\hline$M P B_{i l t}^{1}=2100 \mathrm{~m}^{2}$ & $M P B_{i l t}^{3}=600 \mathrm{~m}^{2}$ & $M P B_{i l t}^{3}=300 \mathrm{~m}^{2}$ \\
\hline$B_{i l t}^{1}=0.7$ & $B_{\text {ilt }}^{2}=0.2$ & $B_{\text {ilt }}^{3}=0.1$
\end{tabular}

Figure 1: Splitting of a non-homogenous lot into homogeneous sublots.

\section{LHP modelling in production lots}

In this section, a general way of modelling the above LHP characteristics for planning purposes is shown. It is worth stressing that this formulation does not represent a model itself, but it can be embedded and adapted in a particular planning model. Let us assume the existence of parallel resources $(l)$ that are able to supply/process some FG $(i)$, being the $I l(i)$ the set of FG $i$ that can be processed on each productive resource $l$. Suppose that each production lot $M P_{i l t}$ of FG $i$ on productive resource $l$ in a time period $t$ is composed by different homogeneous sublots $M P B_{i l t}^{\beta}$ of specific subtype $\beta$.

Assume $B_{i l t}^{\beta}$ to be the fraction of each lot of a FG $i$ processed on a production line $l$ that can be considered as a homogeneous sublot of subtype $\beta$ in time period $t$. An example of this situation is shown in Figure 1 where it is assumed a lot of 3000 $\mathrm{m}^{2}\left(M P_{i l t}\right)$ with three subtypes $\beta=1,2,3$. The values of $B_{i l t}^{\beta}$ for this lot are considered to be: $0.7,0.2$ and 0.1 . These fractions originate three homogeneous sublots $\left(M P B_{i l t}^{\beta}\right)$ of $2100 \mathrm{~m}^{2}, 600 \mathrm{~m}^{2}$ and $300 \mathrm{~m}^{2}$, respectively.

At this point, some characteristics related to the $B_{i l t}^{\beta}$ parameters should be stressed. As it can be observed, the subindices of $B_{i l t}^{\beta}$ allow that different percentages of homogenous sublots can exist for each FG depending on the resource and time period. On the other hand, the sum of $B_{i l t}^{\beta}$ must be equal to 1 , because the union of all homogeneous sublots must match the overall lot. That is, there is a dependency among the beta parameters that can be expressed in the form of Eq.(1). Finally, it should be highlighted that the value of each $B_{i l t}^{\beta}$ is not deterministic because its value is dependent on the raw material characteristics and/or the uncontrollable productive factors.

$$
\sum_{\beta} B_{i l t}^{\beta}=1 \quad \forall l, i \in I l(l), t .
$$




\subsection{Deterministic LHP modelling in production lots}

In this section, the set of constraints that can be taking into account to model the LHP in production lots are described. Eq. 22 defines the size of each homogeneous sublot $\left(M P B_{i l t}^{\beta}\right.$ based on the quantity to be finally supplied/produced $\left(M P_{i l t}\right.$ of each FG $i$ on each resource $l$ and time period $t$ and its corresponding homogeneous fraction $\left(B_{i l t}^{\beta}\right.$. For production planning contexts, the $M P_{i l t}$ represents the main decision variable and $M P B_{i l t}^{\beta}$ is a derived variable from the first one and the $B_{i l t}^{\beta}$ coefficient.

$$
M P B_{i l t}^{\beta}=B_{i l t}^{\beta} * M P_{i l t} \quad \forall \beta, l, i \in I l(l), t .
$$

Taking into account the homogeneous sublots at the planning level follows the objective of better sizing the lots on each resource in each time period with the aim of accomplishing with customers' homogeneity constraints. Therefore, the lot size $\left(M P_{i l t}\right.$ should be defined in such a way that the derived $M P B_{i l t}^{\beta}$ can fulfil an integer number of a combination of customer orders of class $\mathrm{k}\left(N K L B_{i l k t}^{\beta}\right.$ (see Eq. (3)). The parameter $o r d q_{i k}$ in Eq. (3) represents the average order size of FG $i$ of customer order class $k$.

$$
M P B_{i l t}^{\beta}=\sum_{k} N K L B_{i l k t}^{\beta} * \operatorname{ordq}_{i k} \quad \forall \beta, l, i \in I l(l), t .
$$

Finally, the way of formulating the customer demand $\left(d_{i k t}\right)$ at the planning level, Eq. (4), should be consistent with Eq. (4), being necessary to forecast the number of orders $\left(n k_{i k t}\right)$ of customer class $k$ requesting FG $i$ in period $t$.

$$
d_{i k t}=n k_{i k t} * o r d q_{i k} \quad \forall i, k, t
$$

\subsection{Modelling the LHP uncertainty in production lots}

As previously mentioned, the coefficients $B_{i l t}^{\beta}$ in Eq. 22 are not deterministic parameters because the size of the homogenous sublots in relation to the overall lot size in the production plan depends on uncontrollable productive factors and/or raw material characteristics. Therefore, they are considered as fuzzy numbers $\left(\tilde{B}_{i l t}^{\beta}\right)$ when the fuzziness is represented by the tilde " " meaning that they can change in a near region of an initial value. For example, let's assume that some $B_{i l t}^{\beta}$ is deterministic with a value of 0.4 ; in this case, tilde means that $\tilde{B}_{i l t}^{\beta}$ is about 0.4. When $\tilde{B}_{i l t}^{\beta}$ is considered a fuzzy number, the Eq. 2 is expressed as the fuzzy Eq.(5).

$$
M P B_{i l t}^{\beta}=\tilde{B}_{i l t}^{\beta} * M P_{i l t} \quad \forall \beta, l, i \in I l(l), t .
$$

There is a body of literature on models including fuzzy coefficients, and a wellknown one is the Possibility Theory. Peidro et al. [4] describe how the expected 
$\mathrm{EV}$ value of a fuzzy number $\tilde{z}$ can be expressed as a half point within its expected interval just as the following Eq. [6] shows, where $E_{1}^{z}$ and $E_{2}^{z}$ are the lower and upper values of the expected interval:

$$
E V(\tilde{z})=\frac{E_{1}^{z}+E_{2}^{z}}{2}
$$

Fuzzy constraints require the membership functions, even when uncertainty is included in their technological coefficients. There are several options of membership functions to describe a fuzzy number $z_{i}$. Pedrycz [5] mention the common use of basic fuzzy triangular and trapezoidal membership functions. This author shows them as basic functions used to represent fuzzy numbers in linear models.

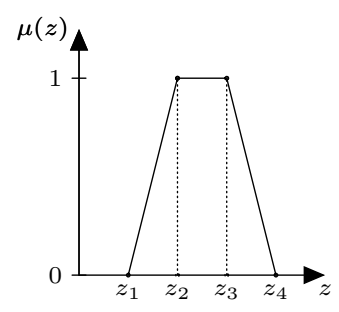

Figure 2: Trapezoidal fuzzy number $\tilde{z}$

If the fuzzy number $\tilde{z}$ presents a trapezoidal membership function as in Figure 2. its expected interval can be calculated as expressed in Eq.(7), where $z_{1}$ and $z_{4}$, represent the lower and upper limits of the interval, respectively, and $z_{2}$ and $z_{3}$ represent its intermediate numbers. In trapezoidal membership function terms (see Fig. 2), alpha $(\alpha)$ represents the degree to which the curve progresses toward limits $z_{2}$ and $z_{3}$.

$$
E I(\tilde{z})=\left[E_{1}^{z}, E_{2}^{z}\right]=\left[\frac{z_{1}+z_{2}}{2}+\frac{z_{3}+z_{4}}{2}\right] .
$$

If the perspective of Peidro et al. [4], is applied to the fuzzy number beta in Eq.(5), it is possible to convert the original LHP Fuzzy Eq. (5) into an auxiliary crisp alpha-parametric equations Eq. (8) and Eq. (9) by considering the fuzzy coefficients $\tilde{B}_{i l t}^{\beta}=\left(B 1_{i l t}^{\beta}, B 2_{i l t}^{\beta}, B 3_{i l t}^{\beta}, B 4_{i l t}^{\beta}\right) . \alpha$ represents the degree of feasibility of the solution obtained.

$$
M P B_{i l t}^{\beta} \leqslant\left[\frac{\alpha}{2}\left(\frac{B 1_{i l t}^{\beta}+B 2_{i l t}^{\beta}}{2}\right)+\left(1-\frac{\alpha}{2}\right)\left(\frac{B 3_{i l t}^{\alpha}+B 4_{i l t}^{\alpha}}{2}\right)\right] * M P_{i l t} \quad \forall \beta, l, i \in I L(l), t, \alpha \in[0,1] .
$$

$$
M P B_{i l t}^{\beta} \geqslant\left[\frac{\alpha}{2}\left(\frac{B 3_{i l t}^{\beta}+B 4_{i l t}^{\beta}}{2}\right)+\left(1-\frac{\alpha}{2}\right)\left(\frac{B 1_{i l t}^{\alpha}+B 1_{i l t}^{\alpha}}{2}\right)\right] * M P_{i l t} \quad \forall \beta, l, i \in I L(l), t, \alpha \in[0,1] .
$$


A new aspect when modeling LHP uncertainty in the beta coefficients consists in ensuring that they all sum just one. Because they represent the fraction of a homogeneous sublot in the master plan, the sum of the homogeneous sublots integrating a lot will equal the corresponding lot in the master plan. The most evident way is to model this aspect by adding one constraint forcing the sum of the betas to be equal to one. However, when the beta coefficients are considered fuzzy, they are represented by membership functions and do not, therefore, take a unique value. After several proofs, a decision was made to model this aspect by means of Eq.(10), which was obtained by summing Eq. (5) and by taking into account that $\sum_{\beta} \tilde{B}_{i l t}^{\beta}=1$. Eq. 10 ensures that the beta coefficients are adjusted within their membership function to sum up to one and that the quantity assigned to the different customer orders classes does not exceed the overall quantity of lots in the master plan.

$$
M P_{i l t}=\sum_{\beta} M P B_{i l t}^{\beta} \quad \forall l, i \in I l(l), t .
$$

All the literature consulted about Fuzzy Set Theory assumes the independence of the fuzzy technological coefficients. As mentioned earlier, in LHP productive contexts, each planned lot is divided into homogeneous sublots of different subtypes. To model this aspect, technological coefficients representing the fraction of a lot that will be considered homogeneous are defined. However, these fractions are not independent because they should always sum up to one; i.e. the sum of all the homogeneous sublots will be equal to the original planned lot. We have no knowledge of any research that has dealt with fuzzy interdependent coefficients; therefore their modeling represents one of the main contributions of this paper.

Finally, the equivalent auxiliary crisp equations that model LHP uncertainty in production lots are the following: Eq.(3), Eq.(4), Eq.(8), Eq. (9) and Eq. 10 .

\section{Conclusions}

The above constraints have been included into a particular planning model whose objective function was to maximize profits. Three LHP scenarios have been defined all assuming the existence of three sublots (Figure 3) that differ in the relative size of ech sublot. For each LHP scenario, the equivalent crisp model of the fuzzy model has been solved from $\alpha=0$ to $\alpha=1$ with increments of 0.1 (Figure 3). Two relevant conclusions can be deduced from these experiments: 1) the fuzzy approach always provides better results than the deterministic one and 2) the more balanced the homogeneous sublots, the more horizontal the $\alpha$-curve is. The decision-maker should choose one value of $\alpha$ in order to obtain a specific solution. Because the $\alpha$-parameter represents the different degrees of feasibility, if the decision-maker sets a high degree of satisfaction of the constraints (with $\alpha$ close to 1 ), the feasible solution set becomes smaller, consequently the optimal objective value worsens. So, the decision-maker has to find a balanced solution between two objectives in 
conflict: to improve the objective function value and to improve the degree of satisfaction of the constraints. From the figure 2 it can be deduced that the more balanced the homogeneous sublots a higher improvement of the objective function is achieved with minor risk, i.e. with a high degree of feasibility ( $\alpha$ closer to one).
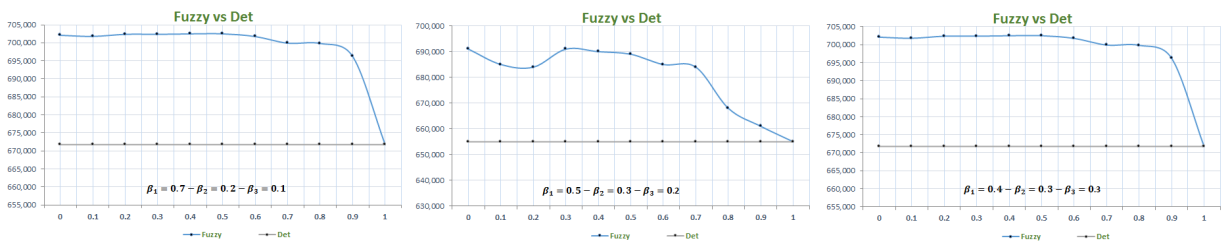

Figure 3: Representation of the profit versus the $\alpha$-value for the three LHP scenarios

As future research lines, a method should be applied to choose the most satisfactory $\alpha$-value. Finally, though it seems that the fuzzy approach outperforms the deterministic one, the real profit and customer service level of the two approaches should be compared once planned lots be finally produced and classified and the real size of each homogeneous sublot were known.

\section{Publication data}

Figure 4 shows the first page of the article published in the " $8^{\text {th }}$ International Conference on Industrial Engineering and Industrial Management" , "XX International Conference on Industrial Engineering and Operations Management" and "International IIE Conference 2014" that took place in Malaga, Spain.

\section{Bibliography}

[1] M. M. E. Alemany, F. C. Lario, A. Ortiz, and F. Gomez. "Available-To-Promise modeling for multi-plant manufacturing characterized by lack of homogeneity in the product: An illustration of a ceramic case". In: Applied Mathematical Modelling 37.5 (2013), pp. 33803398. DOI: $10.1016 / \mathrm{j} . \mathrm{apm} .2012 .07 .022$

[2] A. Gupta and C. D. Maranas. "Managing demand uncertainty in supply chain planning". In: 2nd Pan American Workshop in Process Systems Engineering 27.8-9 (2003), pp. 1219 1227. DOI: 10.1016/S0098-1354(03)00048-6

[3] J. Mula, D. Peidro, and R. Poler. "The effectiveness of a fuzzy mathematical programming approach for supply chain production planning with fuzzy demand". In: International Journal of Production Economics 128.1 (2010), pp. 136-143. DOI: 10.1016/j.ijpe.2010.06. 007.

[4] D. Peidro, J. Mula, M. Jiménez, and M. del Mar Botella. "A fuzzy linear programming based approach for tactical supply chain planning in an uncertainty environment". In: European Journal of Operational Research 205.1 (2010), pp. 65-80. DOI: 10.1016/j.ejor. 2009.11.031

[5] W. Pedrycz. "Why triangular membership functions?" In: Fuzzy Sets and Systems 64.1 (1994), pp. 21-30. DOI: 10.1016/0165-0114(94)90003-5 


\title{
043 Mathematical modelling of uncertainty in non-homogeneous lots
}

\author{
Alemany MME, Grillo H, Mundi I, Poler R \\ María del Mar Eva Alemany Díaz ( $\bowtie$ e-mail: mareva@omp.upv.es) \\ Centro de Investigación de Gestión e Ingeniería de Producción. Dpto de Organización de \\ Empresas. Universidad Politécnica de Valencia. Camino de Vera S/N, 46022, Valencia. \\ Hanzel Grillo Espinoza ( e-mail: hangries@upvnet.upv.es) \\ Centro de Investigación de Gestión e Ingeniería de Producción. Universidad Politécnica de \\ Valencia. Camino de Vera S/N, 46022, Valencia. \\ Isabel Mundi ( e-mail: mamunsan@doctor.upv.es) \\ Doctoral School.Universidad Politécnica de Valencia. Camino de Vera S/N, 46022, Valencia. \\ Raúl Poler ( $₫$ e-mail: rpoler@cigip.upv.es) \\ Centro de Investigación de Gestión e Ingeniería de Producción. Dpto de Organización de \\ Empresas. Universidad Politécnica de Valencia. Camino de Vera S/N, 46022, Valencia.
}

Abstract: There are manufacturing contexts where units of the same finished good (FG) in lots are non-homogeneous. Sometimes, this lack of homogeneity in the product (LHP) originates several qualities of a FG in the same lot, meanwhile other times units of the same FG with different attributes (subtypes) appear. The result is that each lot of a FGis composed by homogeneous sublots of different subtypes. Due to the LHP inherent sources of uncertainty, the finally size of each homogeneous sublot will be only known when produced and classified. This aspect becomes a problem when customers should be served with homogeneous units of the same FG. In this paper, the definition of customer classes and a set of fuzzy constraints are proposed to model the uncertainty in non-homogeneous lots. The incorporation of these constraints will improve the customer service level and the company performance by the properly sizing of non-homogeneous lots.

Keywords: Uncertainty; Fuzzy; Lack of Homogeneity in the Product; Customer Classes; Mixed Integer Linear Programming.

\section{Introduction}

The lack of homogeneity in the product (LHP) is defined as the lack of uniformity required by the customer in the products.LHP causes the non-homogeneity of FGs as regards certain attributes that are relevant to customers (Alemany et al.,

Figure 4: Publication data. 



\section{Appendix B}

\section{Journal authorizations}

In this Appendix we provide the authorizations from the journals where we published each chapter, in order to include them to this dissertation. 
This Agreement between Hanzel Grillo ("You") and Elsevier ("Elsevier") consists of your license details and the terms and conditions provided by Elsevier and Copyright Clearance Center.

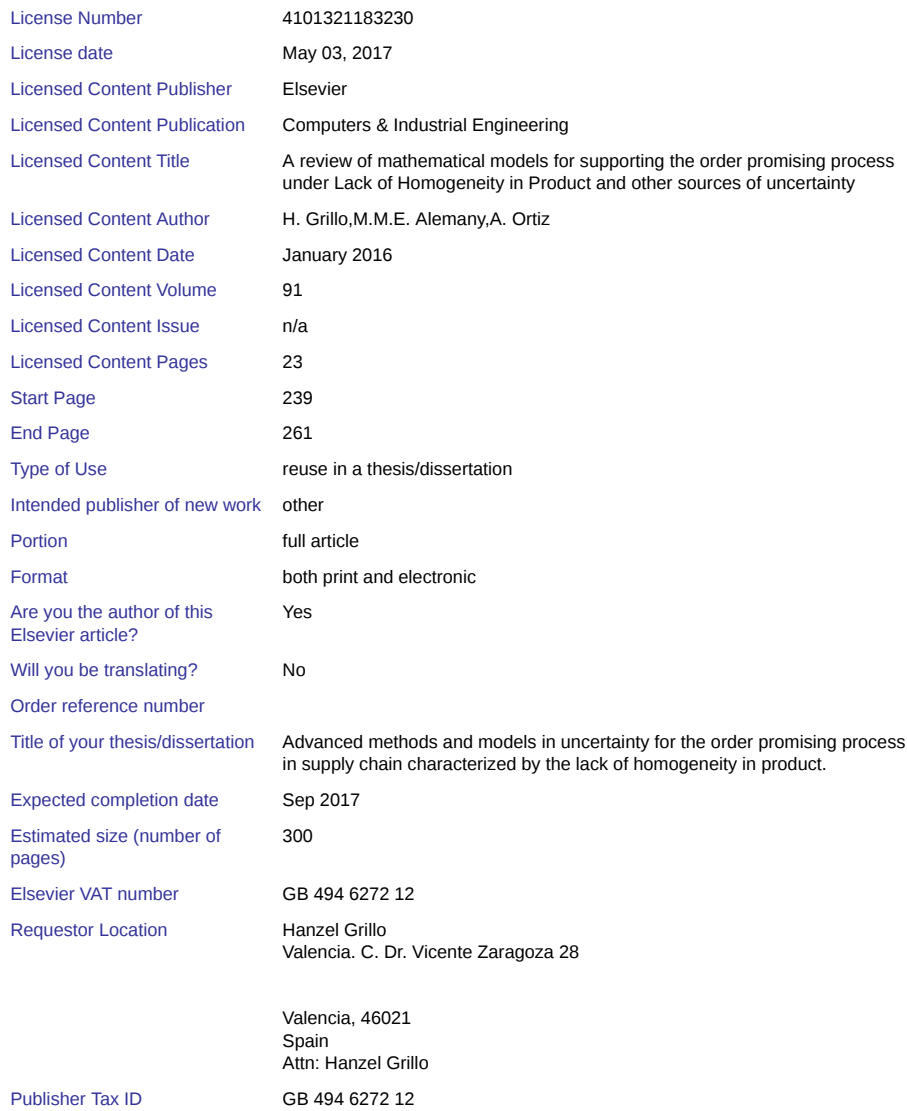

Figure 1: Authorization from Computers \& Industrial Engineering for Chapter II. 
This Agreement between Hanzel Grillo ("You") and Springer ("Springer") consists of your license details and the terms and conditions provided by Springer and Copyright Clearance Center.

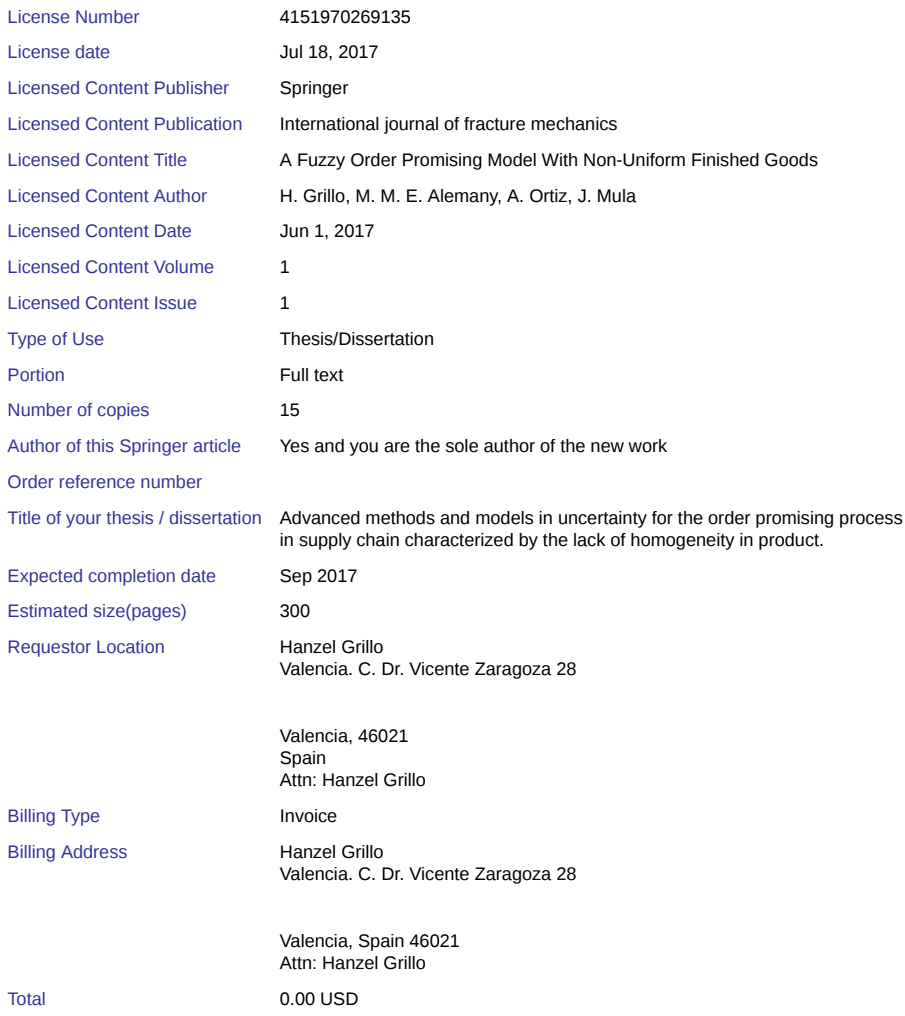

Terms and Conditions

Introduction

Figure 2: Authorization from International Journal of Fuzzy Systems for Chapter III. 
This Agreement between Hanzel Grillo ("You") and Elsevier ("Elsevier") consists of your license details and the terms and conditions provided by Elsevier and Copyright Clearance Center.

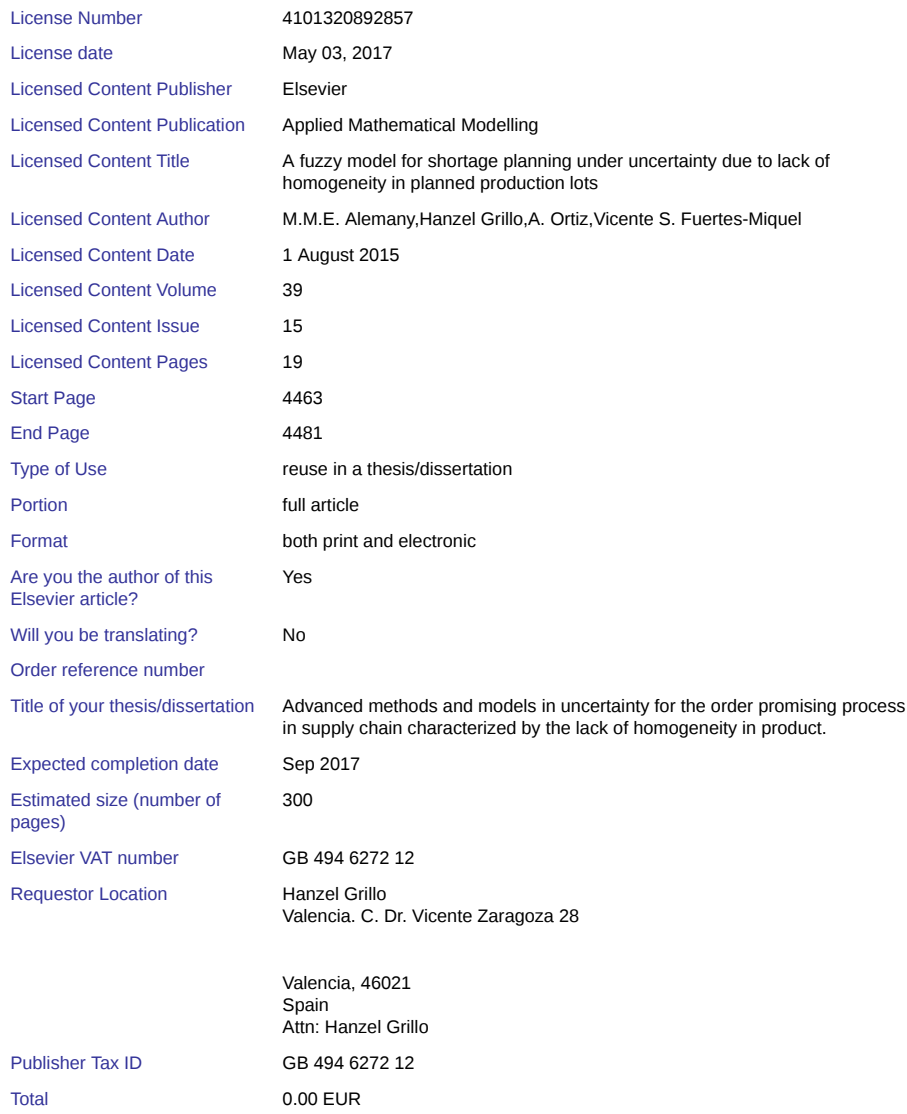

Figure 3: Authorization from Applied Mathematical Modelling for Chapter IV. 
This Agreement between Hanzel Grillo ("You") and Springer ("Springer") consists of your license details and the terms and conditions provided by Springer and Copyright Clearance Center.

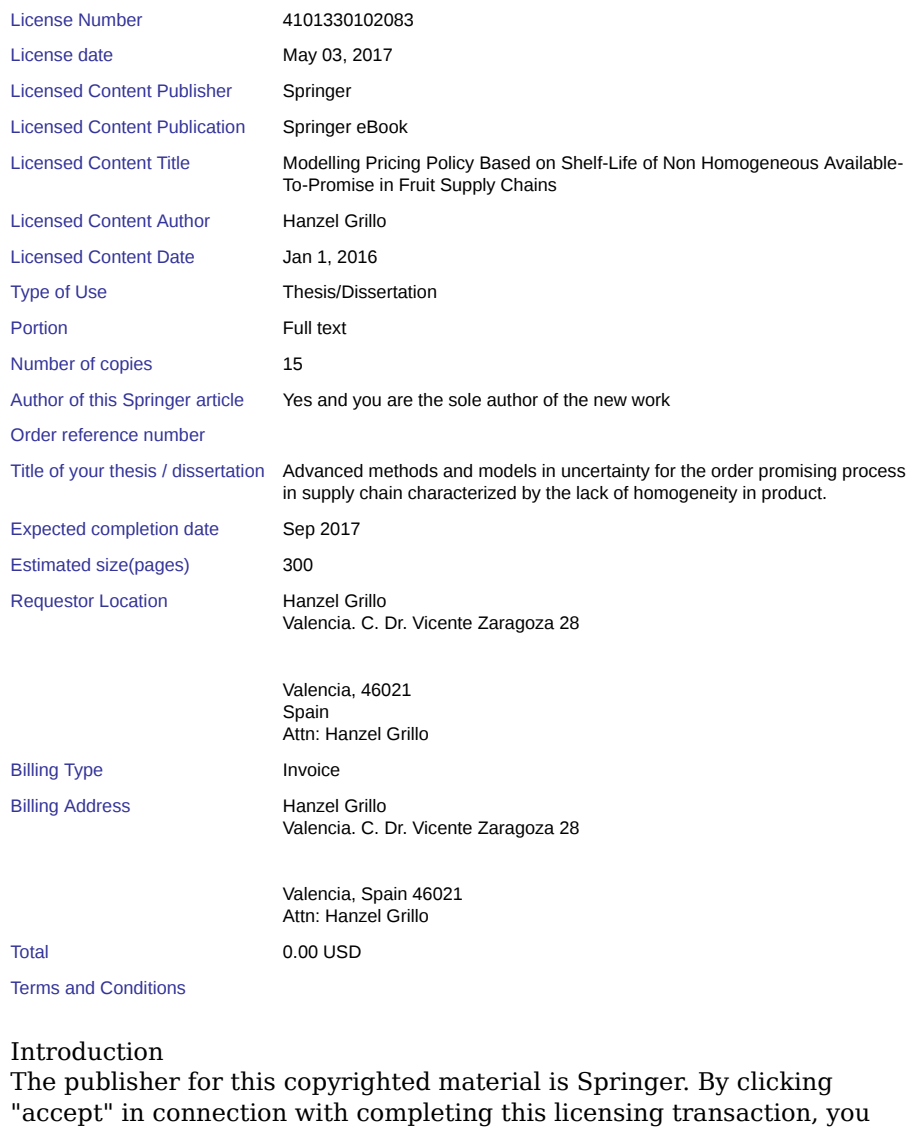

Terms and Conditions

Introduction

The publisher for this copyrighted material is Springer. By clicking "accept" in connection with completing this licensing transaction, you

Figure 4: Authorization from Springer for Chapter V. 
This Agreement between Hanzel Grillo ("You") and Elsevier ("Elsevier") consists of your license details and the terms and conditions provided by Elsevier and Copyright Clearance Center.

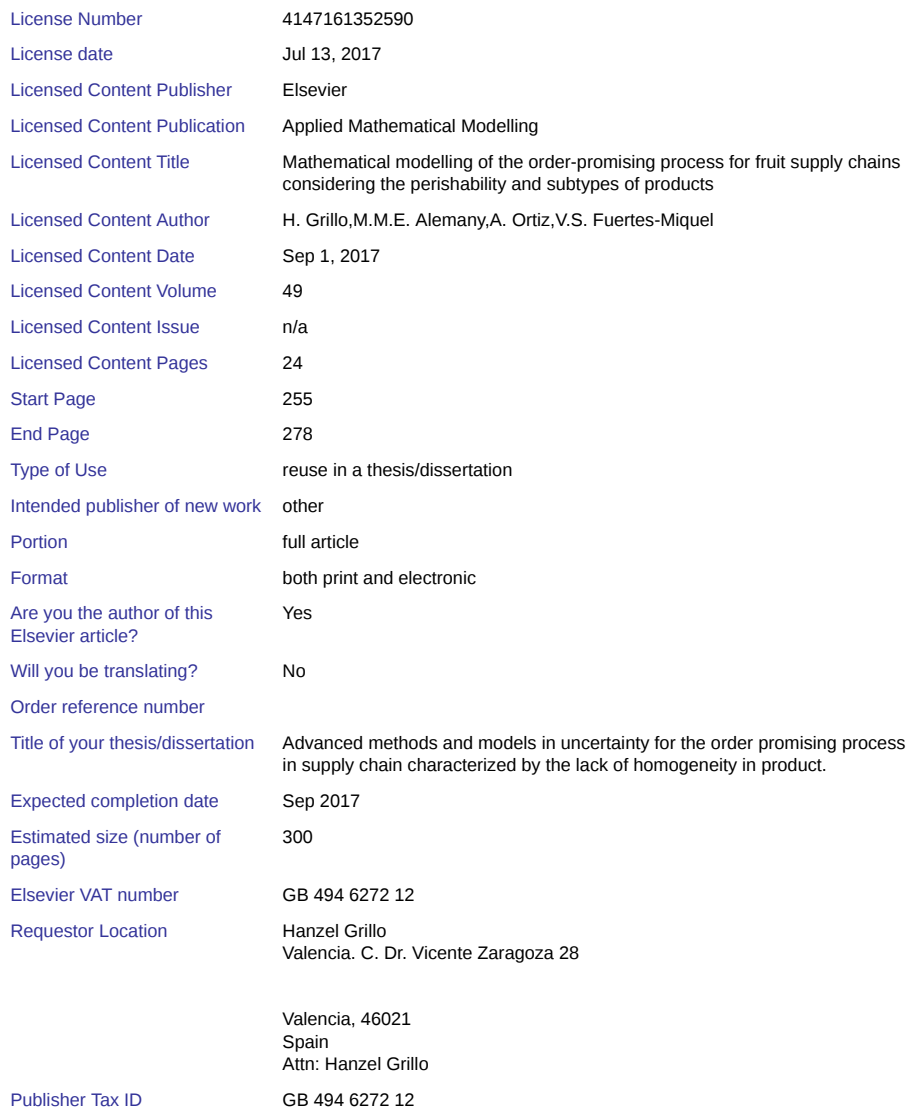

Figure 5: Authorization from Applied Mathematical Modelling for Chapter VI. 